

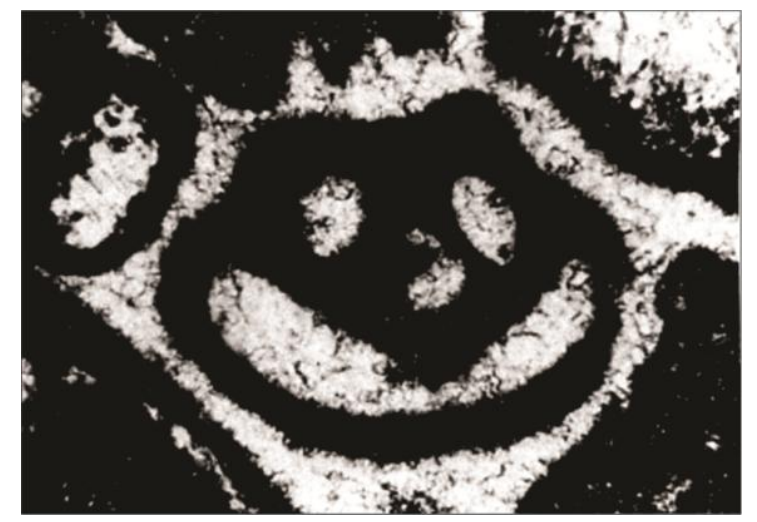

"Rocks do not suffer deformation; they enjoy it"

Rob Knipe, $1982^{* *}$

\section{CARACTERIZACIÓN ESTRUCTURAL DE ANTICLINALES \\ EN EL EXTREMO SUR DE LA CORDILLERA ORIENTAL, PROVINCIA DE SALTA, ARGENTINA}

Lic. Mariano Hernández

Tesis Doctoral 2015

Facultad de Ciencias Naturales y Museo

Universidad Nacional de La Plata 


\section{AGRADECIMIENTOS}

A Paula, simplemente por todo.

A mi familia, por el aliento y apoyo incondicional, desde el principio de este proyecto, desde el principio de todo lo que hecho hasta hoy, y seguramente de lo que haré en el futuro (¡Aunque no sepan exactamente lo que hago!).

A mis directores, Juan Franzese y Gustavo Vergani, por sus enseñanzas, consejos, guía, amistad, apoyo ¡Muchísimas gracias!

A los jurados, Dres. Carlos A. Cingolani, Eduardo A. Rossello y Jose A. Salfity, por sus comentarios y sugerencias que permitieron mejorar sustancialmente este manuscrito.

A todos los integrantes del Centro de Investigaciones Geológicas, con quienes compartí los 5 años de mi beca, a los que se fueron y a los que se incorporaron últimamente. Sin importar el tiempo compartido, de todos aprendí algo, y todos me ayudaron, aun sin saberlo. ¡Muchas gracias a todos!

A Rita, Mercedes y Amelia, tres pilares del Instituto.

A todas las personas que me acompañaron al campo, Leo Sierra, Martin Irigoyen, Abril Cereceda, Pablo Salgado, Adrian Larroca, Rodrigo Feo, Manuel Isla y Dardo Lozano. ¡Para algo sirvió tanta caminata!

A Leandro D'Elia, Andres Bilmes y Martin Muravchik, por invitarme a sus campañas. ¡Aprendí muchísimo con ustedes!

A la Administración de Parques Nacionales, Delegación Regional Noroeste, por su amabilidad y colaboración en este proyecto. A los excelentes guardaparques del Parque Nacional Los Cardones, Rosaura Garro, Roberto Canelo, Marcos Bulacio, Mario Zuretti, y a los que no conocí también. Gracias a su profesionalismo y vocación, mi trabajo fue mucho más fácil. Muchas gracias a todos. ¡Gracias Rosaura por tu amistad! 
A mis compañeros y amigos de la cátedra de Geología Estructural, pasados y presentes. No puedo decir lo mucho que aprendí con todos ustedes, y como me ayudaron especialmente durante este último año. ¡Que año difícil!

A la gente de Pluspetrol, por su colaboración (en muchos aspectos) durante todo el transcurso de mi trabajo, por las experiencias de campo, y en la oficina también.

A mis amigos de la vida, de la facultad, del dojo, conocidos, no tan conocidos, todos me formaron, sin dudas.

A la Facultad de Ciencias Naturales y Museo, a la Universidad Nacional de La Plata y al CONICET. 


\section{INDICE}

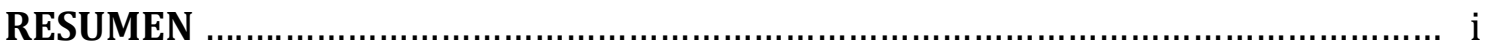

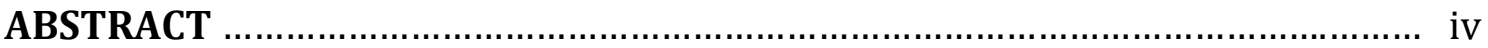

CAPITULO 1 - INTRODUCCIÓN

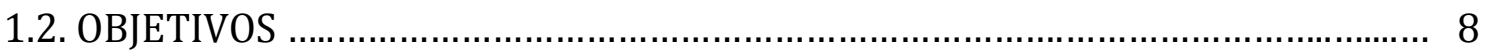

CAPITULO 2 - UBICACIÓN Y MARCO GEOLÓGICO ….................................... 10

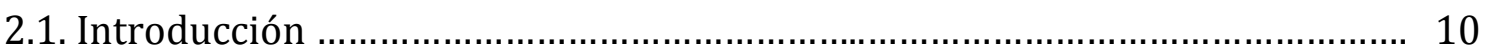

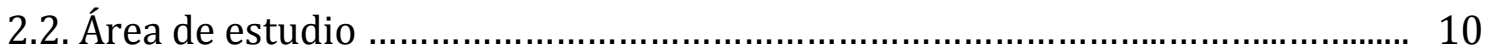

2.3. Cordillera Oriental .................................................................................. 11

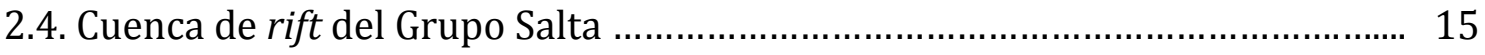

2.5. Estratigrafía del área de estudio (Subcuenca de Alemanía) .......................... 16

2.5.1. Basamento ….................................................................................................... 16

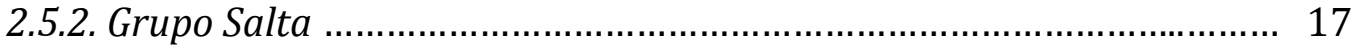

2.5.2.1. Subgrupo Pirgua ......................................................... 17

2.5.2.2. Subgrupo Balbuena ....................................................... 19

2.5.2.3. Subgrupo Santa Bárbara ................................................. 21

2.5.3. Grupo Payogastilla ..................................................................... 22

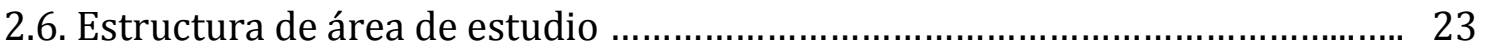

CAPITULO 3 - METODOLOGÍA DE TRABAJO _................................................. 27 
3.1.1. Mapeo geológico ….................................................................................. 27

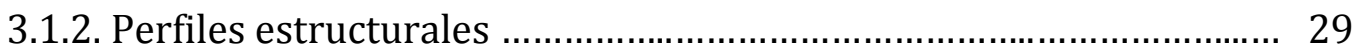

3.1.3. Perfiles estratigráficos ...................................................................... 29

3.1.4. Caracterización de pliegues ........................................................ 31

3.1.5. Caracterización de fallas ............................................................................ 31

3.1.6. Caracterización de fracturas menores ............................................. 32

3.1.7. Recolección de muestras de roca orientadas .................................. 33

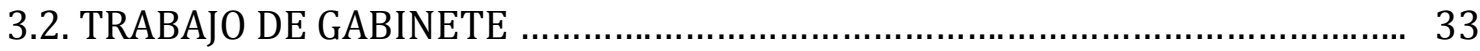

3.2.1. Recopilación bibliográfica ................................................................... 33

3.2.2. Organización y centralización de la información cartográfica y satelital 33

3.2.3. Confección de mapa geológico ................................................................ 35

3.2.4. Análisis de datos estructurales ................................................... 35

3.2.5. Análisis de scan lines .................................................................. 36

3.2.6. Perfiles estructurales .............................................................. 37

3.2.7. Análisis microscópico ................................................................. 38

CAPITULO 4 - GEOLOGÍA ESTRUCTURAL DEL ÁREA DE ESTUDIO ................ 40

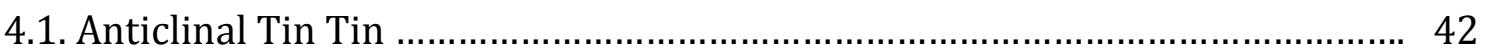

4.1.1. Características mesoestructurales …................................................................ 45

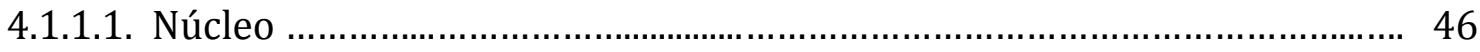

A) Basamento del núcleo del anticlinal Tin Tin ........................................ 46 
Pliegues en el basamento del núcleo del anticlinal Tin Tin

Fallas en el basamento del núcleo del anticlinal Tin Tin

Diaclasas y venas en el basamento del núcleo del anticlinal Tin Tin .. 50

B) Falla NW-SE sinestral en el basamento del anticlinal Tin Tin 52

4.1.1.2. Vertiente occidental

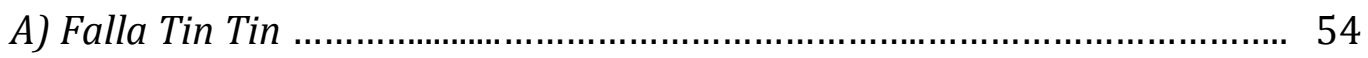

B) Afloramientos aislados de la cobertura sedimentaria ........................... 57

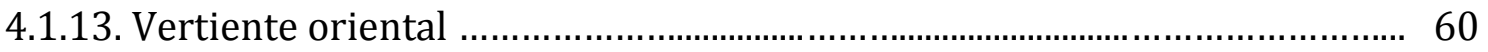

A) Flanco dorsal del anticlinal Tin Tin ................................................... 60

Pliegues en el flanco dorsal del anticlinal Tin Tin ............................... 61

Fallas en el flanco dorsal del anticlinal Tin Tin .................................. 66

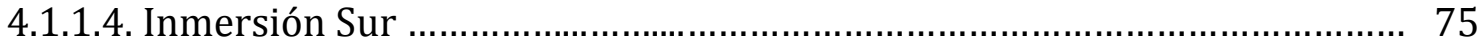

Pliegues en el sector de inmersión sur del anticlinal Tin Tin ............ 76

Fallas en el sector de inmersión sur del anticlinal Tin Tin ................ 80

4.1.2. Observaciones estructurales en un bloque de basamento en las cercanías del

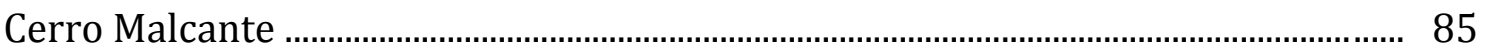

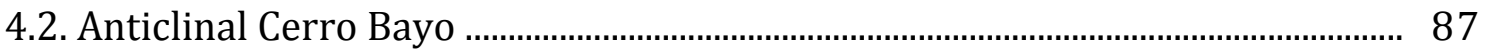

4.2.1. Características mesoestructurales ................................................................... 90

4.2.1.1. Flanco frontal del anticlinal Cerro Bayo ....................................................... 91

4.2.1.2. Extremo de inmersión Sur del anticlinal Cerro Bayo .................................... 98

CAPITULO 5 - FRACTURAS A ESCALA DE AFLORAMIENTO …....................... 101

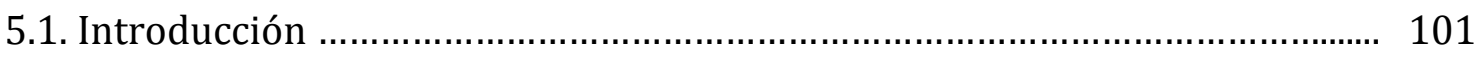


5.2. Las fracturas del Anticlinal Tin Tin

5.2.1. Estación de medición $1 T T$

5.2.2. Estación de medición $2 T T$ 105

5.2.3. Estación de medición 3TT 106

5.2.4. Estación de medición $4 T T$ 110

5.2.5. Estación de medición 5TT 112

5.2.6. Estación de medición 6TT 114

5.2.7. Estación de medición 7TT 117

5.2.8. Estación de medición 8TT 120

5.2.9. Estación de medición 9TT 122

5.2.10. Estación de medición 10TT 124

5.2.11. Estación de medición 11TT 128

5.2.12. Estación de medición $12 T T$ 129

5.2.13. Estación de medición 13TT 133

5.2.14. Estación de medición 14TT 137

5.2.15. Estación de medición 15TT 143

5.2.16. Estación de medición 16TT 145

5.2.17. Estación de medición 17TT 148

5.2.18. Estación de medición 18TT 151

5.3. Las fracturas del Anticlinal Cerro Bayo 153

5.3.1. Estación de medición $1 C B$ 155

5.3.2. Estación de medición $2 C B$ 157

5.3.3. Estación de medición $3 C B$ 
6.1. Características estructurales del Anticlinal Tin Tin

Estructuras paralelas al rumbo del anticlinal Tin Tin (o al rumbo de la secuencia sedimentaria local) 179 Estructuras oblicuas y subpendiculares al rumbo del anticlinal Tin Tin .... 183

6.1.3. Fracturas de escala de afloramiento en el anticlinal Tin Tin 184

Fracturas perpendiculares al eje de pliegue del anticlinal Tin Tin 186

Fracturas paralelas al eje de pliegue del anticlinal Tin Tin 187 Fracturas oblicuas al eje de pliegue del anticlinal Tin Tin 190 
Scan lines: Frecuencia de las fracturas en diferentes posiciones estructurales .

6.2. Anticlinal Cerro Bayo: Diferencias estructurales con el anticlinal Tin Tin ... 192

6.2.1. Fallas y pliegues en el anticlinal Cerro Bayo ..................................................... 192

6.2.2. Fracturas de escala de afloramiento en el anticlinal Cerro Bayo ................. 194

6.3. Evolución estructural del anticlinal Tin Tin: Acortamiento en una zona de

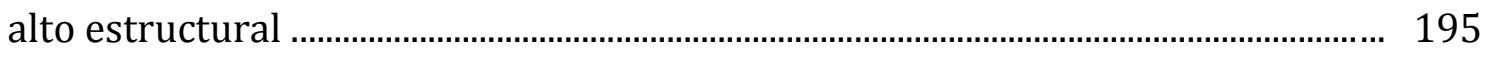

6.4. Estilos de inversión tectónica en el extremo Sur de la Cordillera Oriental ... 205 6.5. Fracturación de la Formación Yacoraite como reservorio de hidrocarburos . 207

\section{ANEXO}




\section{RESUMEN}

El estudio de las características mesoestructurales presentes en anticlinales $\mathrm{y}$ sinclinales que conforman grandes sistemas fallados y plegados, permite entender los procesos de deformación que tuvieron lugar durante la evolución de la estructura en particular, y a una escala mayor, clarificar la historia cinemática del sistema fallado y plegado, siendo esta información sumamente importante ya que éstas estructuras sirven como análogos de reservorios de hidrocarburos en subsuelo.

En este trabajo se presenta un estudio estructural de detalle sobre el anticlinal Tin Tin, un pliegue con núcleo de basamento ubicado en los Valles Calchaquíes del Noroeste argentino, en el extremo Sur de la provincia geológica Cordillera Oriental. Esta zona se caracteriza geológicamente por la presencia de pliegues y extensos bloques de basamento. Estos son el resultado de la inversión tectónica regional y exponen en sus flancos la estratigrafía parcial o completa de la cuenca de rift cretácica-paleógena del Grupo Salta y la cuenca de antepaís del Grupo Payogastilla.

El estudio estructural del anticlinal Tin Tin se realizó sobre el Grupo Salta, con un enfoque particular en la deformación de la Formación Yacoraite (Subgrupo Balbuena), ya que esta unidad es principalmente conocida por conformar importantes yacimientos de hidrocarburos en áreas adyacentes. También se estudió la deformación de esta unidad en otra estructura vecina y con características particularmente diferentes (anticlinal Cerro Bayo), con fines comparativos.

La metodología de trabajo (medición de orientación de estratos y estructuras geológicas, mapeo de unidades) permitió caracterizar las estructuras principales que deforman el núcleo de basamento y los flancos y charnela del anticlinal Tin Tin (cobertura sedimentaria). Estas estructuras son pliegues, fallas inversas y fracturas de mesoescala (diaclasas, venas y fracturas de cizalla). 
Las observaciones y mediciones realizadas sobre las estructuras del basamento permitieron definir pliegues con rumbo E-W, fallas inversas con transporte occidental, paralelas al eje de pliegue, y una fracturación de mesoescala ampliamente distribuida (diaclasas y venas). A partir del análisis de estas estructuras se concluyó que los planos axiales de los pliegues E-W se reactivan y posibilitan el movimiento de bloques menores dentro del basamento, que en ocasiones se propagan como fallas en la cobertura sedimentaria. La fracturación, como debilidad estructural homogéneamente distribuida, permitió la generación de fallas inversas que levantaron los bloques de basamento de la zona, incluyendo el bloque de basamento (núcleo) del anticlinal Tin Tin, mediante la Falla inversa Tin Tin.

Dentro de la cobertura sedimentaria, los pliegues, fallas y fracturas de mesoescala presentan orientaciones específicas con respecto al rumbo NNE-SSW del eje de pliegue del anticlinal Tin Tin, ya que formaron parte del crecimiento del anticlinal. Del análisis de pliegues y fallas, se concluyo que estas estructuras se formaron relativamente antes del levantamiento principal del anticlinal Tin Tin, en respuesta al acortamiento andino.

Del análisis de los sistemas de fracturación se concluyó que los diferentes sets de diaclasas afectan a todas las posiciones estructurales del anticlinal y están relacionadas a su evolución. Las diaclasas se formaron secuencialmente (siguiendo un orden cronológico de formación) y se agrupan en cuatro direcciones principales: Diaclasas subperpendiculares al eje de pliegue del anticlinal (se formaron relativamente primero siguiendo los esfuerzos compresivos andinos); dos grupos de diaclasas oblicuos al eje de pliegue (se formaron posteriormente debido a perturbaciones durante el plegamiento de los flancos y charnela); y diaclasas subparalelas al eje de pliegue (últimas en formarse debido a la curvatura externa de las capas plegadas). Los sistemas de fracturas se formaron en un estadio inicial a intermedio en el crecimiento del anticlinal Tin Tin.

En base al análisis e interpretación de las estructuras en conjunto se propuso un modelo evolutivo para la deformación y crecimiento del anticlinal Tin Tin, dividido en tres estadios: 1) Los esfuerzos compresivos de dirección aproximada E-W actúan sobre capas subhorizontales en el inicio de la contracción 
andina. Se forman diaclasas paralelas a los esfuerzos (subperpendiculares al futuro eje de pliegue) y fracturas de cizalla de bajo ángulo de inclinación. 2) Se produce el inicio del levantamiento del basamento y se forman diaclasas oblicuas al eje de plegamiento. Posteriormente se forman los pliegues y fallas que acortan la cobertura sedimentaria y las diaclasas paralelas al eje de pliegue del anticlinal Tin Tin. Hacia el final del estadio se producen las fallas en el basamento y el levantamiento general del Cerro Tin Tin. 3) Se reactivan fracturas con movimiento de rumbo para acomodar mayor deformación. La evolución estructural del anticlinal ocurre entre el inicio de la deformación andina (Eoceno Medio) y el PlioPleistoceno. Esta evolución estructural implica una combinación de mecanismos de plegamiento, dominados por buckling en un principio y seguido por bending hasta alcanzar su forma actual.

El estudio del anticlinal Tin Tin permite inferir que la deformación general de la zona de estudio comenzó con una estructuración de piel fina (involucrando sólo cobertura sedimentaria) antes del levantamiento principal de los bloques de basamento (deformación de piel gruesa) y que la inversión tectónica en el extremo Sur de la Cordillera Oriental constó de la generación de estructuras nuevas y de la reactivación inversa de antiguas fallas normales pertenecientes al rift cretácico (mayormente en la zona de cuenca), como indican otros autores.

La fracturación estudiada en la Formación Yacoraite se comparó con los sistemas de fracturas en anticlinales dentro de la zona de estudio (anticlinal Cerro Bayo) y en áreas adyacentes dentro de la cuenca del Grupo Salta, algunos conformando yacimientos de hidrocarburos en subsuelo. Las comparaciones indican que existen características similares en la mayoría de los casos. También arroja conclusiones sobre la importancia de trabajo estructural de campo en la interpretación de procesos y génesis de fracturas. 


\begin{abstract}
The study of mesoscale structures within anticlines and synclines belonging to large fold-and-thrust belts, provide useful information about the deformation processes that involve the structural evolution of any particular structure or, at a larger scale, a better understanding of the kinematic history of the entire fold-andthrust-belt. These studies are very important because anticlines serve as analogues of hydrocarbon reservoirs at subsurface.

In this work, a detailed structural study of the Tin Tin anticline, a basementcored fold located at the Valles Calchaquíes of Northwestern Argentine, in the southern end of the Cordillera Oriental is presented. This area is geologically characterized by folds and basement blocks. The structure is covered, partially or completely, by the Cretaceous-Paleogene, rift-related Salta Group and the Cenozoic infill of the Andean foreland basin, the Payogastilla Group.
\end{abstract}

The structural study of Tin Tin anticline was performed on the Salta Group, with special interest on the deformation of the Yacoraite Formation (Balbuena Subgroup), since it is known as a hydrocarbon reservoir at nearby oil and gas fields. This unit was also studied in a neighbour anticline that has different characteristics (Cerro Bayo). Field work (attitude measurements of geological structures and beds, mapping units) allowed the characterization of main structures that deform the basement core, hinge and flanks (sedimentary cover). These structures are folds, faults and outcrop-scale fractures (joints, veins and shear fractures).

Structural analysis of basement allowed to define the presence of E-W trending folds, westward-transported basement thrusts sheets and a welldeveloped outcrop-scale fracturing (joints and veins). From the analysis of these structures it is concluded that fold axial surfaces are reactivated, allowing minor basement block movement that can propagate as faults into the sedimentary cover. Fracturing allow the generation of new thrust faults that uplifted basement block, including the Tin Tin anticline core through the Tin Tin Fault. 
Within the sedimentary cover, folds, faults and outcrop-scale fractures showed different orientations regarding the NNE-SSW trend of the Tin Tin fold axis, since they were part of the anticline growth. From the analysis of folds and faults, it is concluded that these structures were formed before the main anticline uplift, in response to the early Andean shortening.

From the analysis of fracture systems is concluded that different sets of fractures affect both hinge and flank positions and are related to the anticline structural evolution. Fractures formed sequentially and are grouped into four main directions: Fold axis-subperpendicular joints (formed at first, following the Andean compressive stresses); two groups of fold axis-oblique joints (subsequently formed, due to perturbations during folding process); and fold axis-subparallel joints (formed at last, due to outer-arc extension). Fracture system was formed at the beginning to intermediate stage of folding.

Based on an integrated analysis of structural data, a structural model for the Tin Tin anticline, with three deformation stages, is proposed: 1) E-W Andean compressive stresses are superimposed on subhorizontal beds. Joints following the stresses direction (fold axis- subperpendicular) and shear fractures are formed. 2) Basement uplift starts and fold axis-oblique joints form. Subsequently, folds and faults are formed, and the fold axis-subparallel joints are also formed. 3) Fractures are reactivated with strike-slip movement, in order to accommodate more deformation. Its structural evolution is set between the Middle Eocene and PlioPleistocene. This structural arrangement involve a combination of buckling (at the beginning) and bending (at the end), as many natural folds.

The study of Tin Tin anticline allows inferring that general deformation in the study area began with thin-skinned deformation (involving sedimentary cover only) before the main basement block uplifting phase (thick-skinned deformation), and that the tectonic inversion at the Southern end of Cordillera Oriental consist of new fault generation and, as described by other authors, the reverse reactivation of rift-related normal faults (mainly toward the basin centre).

Fracture systems studied in Yacoraite Formation were compared to those in other anticlines, within the same study area (Cerro Bayo anticline) and nearby 
areas with hydrocarbon potential in the Salta basin. The comparison showed similarities in the fracture systems in most of the cases. Also, the importance of structural field work regarding the interpretation of fracturing processes and genesis is addressed. 


\section{CAPÍTULO 1 INTRODUCCIÓN}




\section{CAPITULO 1 - INTRODUCCIÓN}

La conformación actual de la cadena andina, y en particular la de los Andes del Noroeste argentino está ligada a procesos orogénicos que ocurren desde el Mesozoico Superior debido a la subducción de la placa oceánica de Nazca por debajo del borde occidental de la placa Sudamericana (Allmendinger et al., 1983; Jordan et al., 1983; Dewey y Lamb, 1992). Estos procesos, que tuvieron su mayor impacto durante el Cenozoico, engrosaron la corteza y produjeron un acortamiento de decenas de kilómetros mediante la generación de cinturones fallados y plegados y cuencas de antepaís (Allmendinger et al., 1983; Jordan, 1998). La complejidad estructural y la segmentación que presentan los cinturones plegados, y la geología del Noroeste argentino en general, es el resultado de la superposición de los eventos contraccionales andinos con cuencas paleozoicas y mesozoicas desarrolladas sobre basamentos de diferentes edades y deformaciones previas, con la subsecuente inversión y reactivación tectónica de la región, además de características propias de la placa que subduce (Allmendinger et al., 1983; Jordan et al., 1983; Mon y Salfity, 1995; Kley et al., 1999; Ramos, 1999; Hongn et al., 2011; Carrera y Muñoz, 2013; Iaffa et al., 2013). Dentro del marco del complejo tectonismo, se definieron diferentes provincias geológicas con características particulares (Ramos, 1999): Puna, Cordillera Oriental, Sierras Subandinas, Sistema de Santa Bárbara y Sierras Pampeanas (Figura 1.1). Una de las más externas, las Sierras Subandinas, es la que presenta las mejores condiciones para la producción de hidrocarburos al Norte de los $26^{\circ}$ de latitud Sur (Mon y Salfity, 1995). 


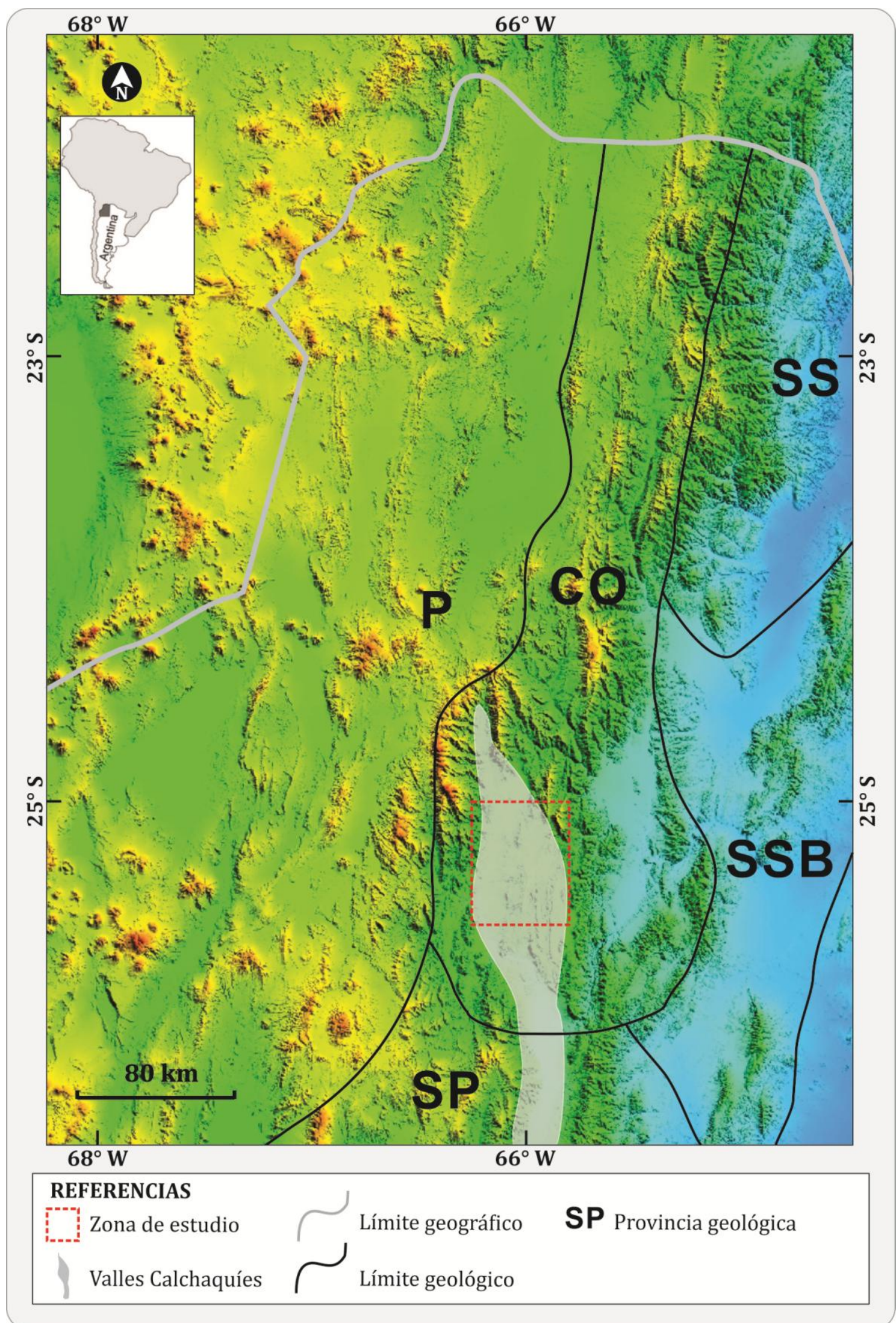

FIGURA 1.1. Provincias geológicas del Noroeste argentino: P - Puna; SP - Sierras Pampeanas; CO Cordillera Oriental; SS - Sierras Subandinas; SSB - Sistema de Santa Bárbara. Ubicación de los Valles Calchaquíes y de la zona de estudio en el extremo Sur de la Cordillera Oriental. 
La Cordillera Oriental es un cinturón fallado y plegado de piel gruesa, adyacente a la Puna (Figura 1.1). Consiste en láminas de basamento precámbrico falladas, con vergencias tanto hacia el Este como hacia el Oeste y orientación NNE (Mon, 1979; Grier et al., 1991; Carrera y Muñoz, 2008, 2013), y muestra marcadas diferencias en su estratigrafía a lo largo de su rumbo. Al Norte de los $25^{\circ}$ de latitud Sur contiene espesas secuencias cambro-ordovicicas y entre los $25^{\circ}$ y $26^{\circ}$ de latitud Sur, rocas continentales cretácico-paleógenas correspondientes a la cuenca de rift del Grupo Salta, y depósitos terciarios sinorogénicos. Estos depósitos terciaros yacen sobre el basamento precámbrico al Sur de los $26^{\circ}$ debido a la ausencia de depósitos paleozoicos y cretácico-paleógenos (Mon y Salfity, 1995). Dentro del relleno del rift se encuentra la Formación Yacoraite del Subgrupo Balbuena (Salfity y Marquillas, 1981; Marquillas et al., 2005), un conjunto de rocas carbonáticas, arenosas y pelíticas que constituye el principal sistema petrolero de la cuenca cretácica del Grupo Salta, ya que por sus características composicionales y mecánicas es roca madre, reservorio y sello de hidrocarburos (Disalvo et al., 2002; Starck, 2011).

El estilo estructural de la parte más austral de la Cordillera Oriental está fuertemente vinculado a los episodios de inversión tectónica del rift cretácico ocurridos a partir del Paleógeno, y a la instauración de una cuenca de antepaís fragmentada por bloques de basamento levantados durante los sucesivos episodios de deformación Andina (Mon, 1979; Grier et al., 1991; Salfity y Marquillas, 1994; Mon y Salfity, 1995; Cristallini et al., 1997; Salfity, 2004; Kley et al., 2005; Carrera et al., 2006; Carrera y Muñoz, 2008; Starck, 2011; del Papa et al., 2013). La contracción y conformación de la faja plegada de piel gruesa para este sector de la Cordillera Oriental generó estructuras menores y sistemas de fracturación de diversas escalas asociados a los anticlinales y sinclinales. Estas estructuras en conjunto (anticlinales con fracturas), que son los potenciales targets exploratorios en la industria de hidrocarburos, pueden ser estudiadas en superficie y comparadas con datos de subsuelo (Antonellini y Mollema, 2000; Hennings et al., 2000; Nelson, 2001) en las áreas productivas adyacentes (Cf. Grosso et al., 2013). 
El estudio de estructuras particulares (fallas, anticlinales y sinclinales) a diferentes escalas es fundamental para comprender el funcionamiento de los cinturones plegados y el marco deformacional donde se encuentran (Casas y Muñoz, 1987; Tavani et al., 2006, 2011; Beaudoin et al., 2012; Turienzo et al., 2012; entre otros). A su vez, estos sistemas adquieren un interés económico muy importante al presentar las condiciones estructurales favorables para la acumulación de hidrocarburos (Cooper, 2007; Lacombe et al., 2007), como es el caso del potencial petrolero del Noroeste argentino (Disalvo, 2002). Las fracturas son las estructuras predominantes en la corteza terrestre, que ocurren en una gran variedad de tipos de roca y ambientes tectónicos. Éstas afectan profundamente la fisiografía de la superficie de la Tierra y controlan la forma de muchos paisajes naturales como líneas de costa, sistemas de drenaje, lagos, montañas, y a su vez, juegan un rol muy importante en el transporte de fluidos (Pollard y Aydin, 1988; Aydin, 2000). Esta característica les confiere a las fracturas un alto impacto desde un punto de vista socio-económico, ya que el arreglo estructural de los sistemas de fracturas y la permeabilidad que aquéllos generan son parámetros clave en depósitos minerales hidrotermales, reservorios de hidrocarburos naturalmente fracturados, reservorios de agua, almacenamiento de sustancias tóxicas, construcciones civiles de ingeniería (Pollard y Aydin, 1988; McCaffrey et al., 1999; Ameen, 2003; entre otros).

El entendimiento de la relación genética entre el plegamiento y la fracturación de mesoescala, como se mencionó previamente, es de importancia fundamental por el control que ejerce sobre la migración y acumulación de fluidos en reservorios de hidrocarburos (Stearns y Friedman, 1972; Nelson, 2001; Tavani et al., 2012). Desde los trabajos pioneros de la década del 60 y 70 (Stearns, 1964; Friedman, 1969; Stearns y Friedman, 1972) muchas investigaciones se han enfocado en la descripción e interpretación de patrones de fracturas relacionadas a anticlinales en superficie (Bellahsen et al., 2006; Cooper et al., 2006; Ismat, 2008; Savage et al., 2010; Tavani et al., 2011a, 2011b; Iñigo et al., 2012; Quintà and Tavani, 2012) y en subsuelo (Hennings et al., 2000; Nelson, 2001; Masaferro et al., 2003; entre otros). De la misma forma, el estudio e interpretación de estructuras de mesoescala en afloramiento, en conjunto con los conocimientos aportados por experimentos sobre la deformación en rocas, han sido una herramienta importante 
para establecer el campo de esfuerzos y el comportamiento mecánico de las rocas y de las estructuras asociadas a escalas locales y regionales (Pollard y Aydin, 1988; Silliphant et al., 2002; Whitaker y Engelder, 2005, 2006). Es así que el estudio de las fracturas y otras estructuras menores pueden permitir la interpretación evolutiva de las estructuras mayores que las contienen dentro del contexto geológico-estructural regional, ligado al cinturón plegado y fallado (Tavani et al., 2006, 2008; Ismat, 2008).

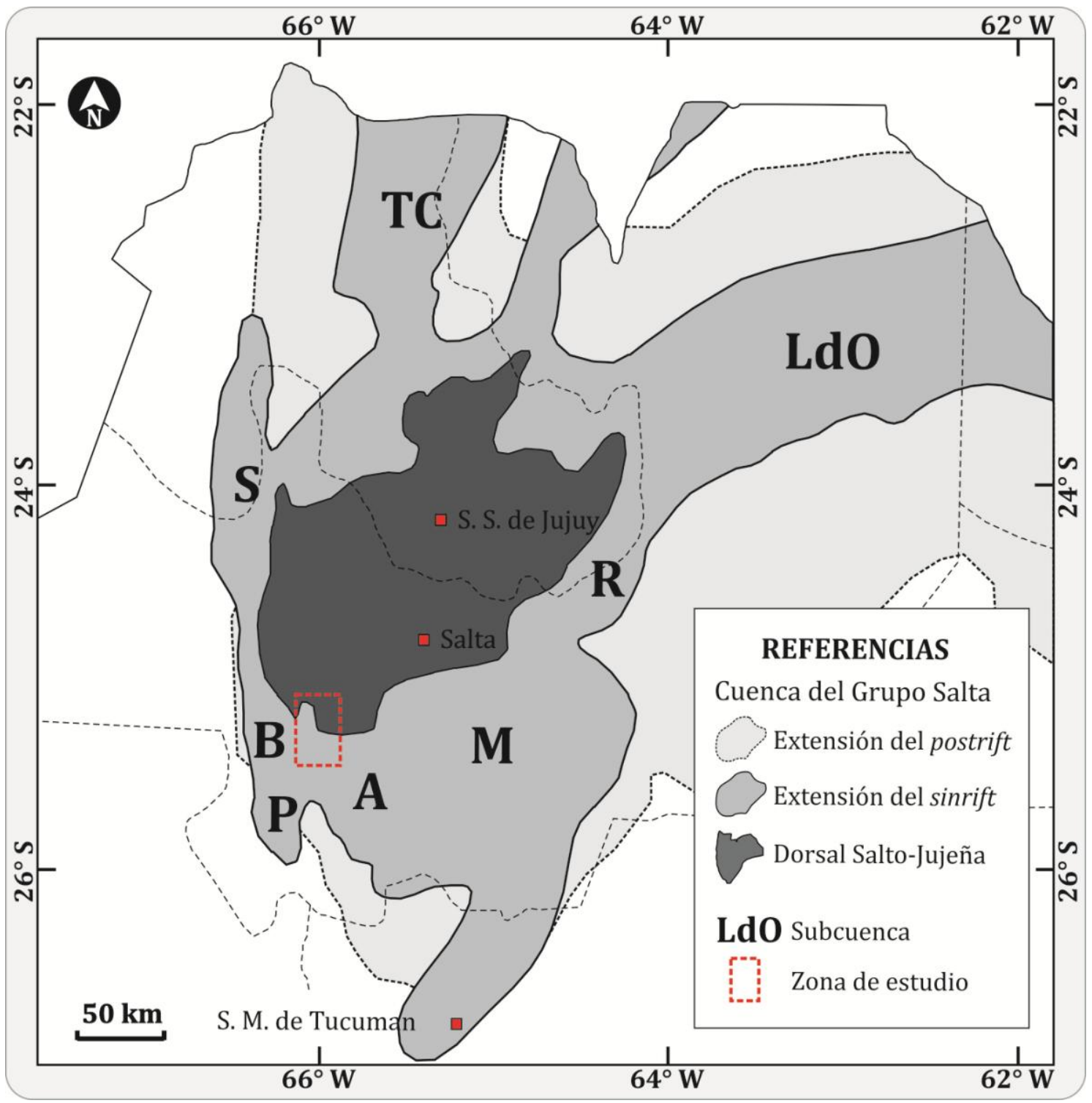

FIGURA 1.2. Mapa de ubicación esquemático de la zona de estudio en el marco de la cuenca del Grupo Salta. Se destaca la extensión de los depósitos de sinrift (Cretácico) y postrift (CretácicoPaleógeno), y la dorsal Salto-Jujeña (Simplificado de Sabino, 2004; Marquillas et al., 2005; Starck, 2011). Subcuencas principales: TC - Tres Cruces; S - Sey; B - Brealito; P - Pucará; A - Alemanía; M Metán; R - El Rey; Ldo - Lomas de Olmedo. 
El extremo Sur de la Cordillera Oriental, donde se emplazó el rift cretácico, provee un marco óptimo para la realización de un estudio estructural de esta índole ya que muestra el desarrollo de estructuras anticlinales accesibles para su estudio en superficie y se encuentra ubicada en las adyacencias de zonas petroleras con yacimientos conocidos y datos disponibles que permitirían realizar una revisión comparativa.

El área de trabajo para la realización de este proyecto se encuentra en la zona de los Valles Calchaquíes (Figura 1.1 y 1.3), provincia de Salta, una depresión tectónica que se sitúa en el sector Suroeste de la Cordillera Oriental, entre los $25^{\circ}$ $00^{\prime}$ y $25^{\circ} 35^{\prime}$ de latitud Sur, y los $65^{\circ} 42^{\prime}$ y $66^{\circ} 10^{\prime}$ de longitud Oeste. Esta zona se encuentra dentro de la subcuenca de Alemanía de la cuenca del Grupo Salta (Figura 1.2). Aquí afloran dos estructuras anticlinales con presencia de la Formación Yacoraite y con buen acceso a sus afloramientos: el anticlinal Tin Tin y el anticlinal Cerro Bayo (Figura 1.3). 


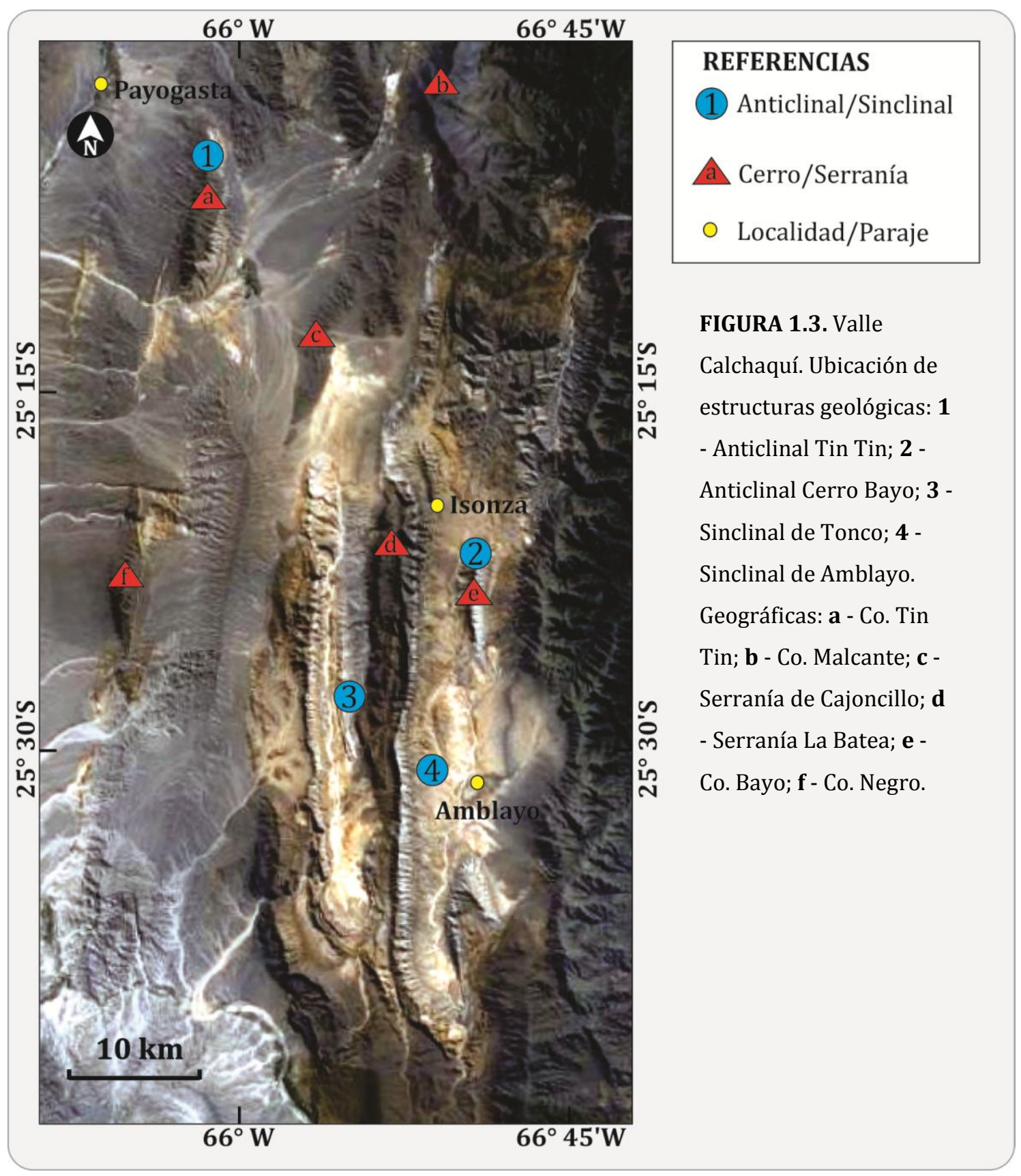




\subsection{OBJETIVOS}

Este plan tiene como objetivo general la realización de un estudio estructural de campo y gabinete con el fin de determinar y modelizar la geometría y los procesos de formación de estructuras frágiles menores, con énfasis en la fracturación, en los sistemas contraccionales cenozoicos del sector Sur de la Cordillera Oriental. Esto implica un análisis a diversas escalas, desde la escala del anticlinal individual hasta el estudio de la estructuración menor en su interior, y su impacto en la roca productiva a nivel de reservorio. De esta forma, se pretende conseguir una comprensión más acabada en los siguientes aspectos (objetivos específicos):

- Análisis de la geometría de las estructuras anticlinales relacionada con la inversión tectónica. Mecanismos y procesos que actuaron en su formación.

- Rol del basamento en la deformación local y regional.

- Análisis de las estructuras menores (pliegues, fallas, fracturas) en diferentes posiciones estructurales dentro del anticlinal.

- Análisis de la fracturación. Génesis de los diferentes tipos de fracturas. Inferencias sobre su comportamiento frente al campo de esfuerzos imperante al momento de su formación. Comparación expeditiva de la frecuencia de fracturación en distintas posiciones estructurales.

- Revisión estructural comparativa con información de superficie y subsuelo de áreas productivas adyacentes. 


\section{CAPÍTULO 2 \\ UBICACIÓN Y MARCO GEOLÓGICO DE LA ZONA DE ESTUDIO}




\section{CAPITULO 2 - UBICACIÓN Y MARCO GEOLÓGICO DE LA ZONA DE ESTUDIO}

\subsection{Introducción}

Los Andes Centrales del Noroeste argentino comprenden cinco provincias geológicas principales: Puna, Cordillera Oriental, Sierras Subandinas, Sistema de Santa Bárbara y Sierras Pampeanas (véase Figura 1.1). La evolución tectónica de cada una de estas provincias resultó del acortamiento provocado por la subducción de la placa de Nazca por debajo de la placa Sudamericana durante la tectónica Andina cenozoica (Jordan et al., 1983).

La provincia geológica Cordillera Oriental es una faja plegada y corrida doble vergente, de piel gruesa, que rodea a la Puna por su flanco oriental (Allmendinger et al., 1983; Mon y Salfity, 1995). En el sector Suroeste de esta provincia, entre los $24^{\circ} 20^{\prime}$ y $27^{\circ} 30^{\prime}$ de latitud Sur, se encuentran los Valles Calchaquíes del Noroeste argentino, un conjunto de valles intermontanos (Santa María, Calchaquí propiamente dicho, Luracatao, Amblayo, Tonco, Pucará, Hualfín, entre otros) que se extienden a lo largo del extremo Suroeste de la Cordillera Oriental en transición con la Puna austral, y hacia el Sur en las Sierras Pampeanas Noroccidentales (Figura 2.1). El límite Norte lo marca un lineamiento continental, el lineamiento de El Toro (Salfity, 2004).

\section{2. Área de estudio}

El área donde se ubican los anticlinales de estudio (véase Figura 1.3) se encuentra dentro del sector medio del Valle Calchaquí, entre los paralelos $25^{\circ} \mathrm{y}$ $25^{\circ} 15^{\prime}$ de latitud Sur, y los meridianos $65^{\circ} 45^{\prime}$ y $66^{\circ} 10^{\prime}$ de longitud Oeste (Suroeste de la provincia de Salta). Este valle es una depresión tectónica elongada en dirección N-S, limitado por fallas inversas con vergencia hacia el eje del valle que ponen rocas de basamento precámbrico por sobre rocas más jóvenes que afloran en la depresión (Mon y Salfity, 1995). Las secuencias de unidades estratigráficas afloran (en general) en los flancos dorsales de los anticlinales y representan la estratigrafía de la zona (Figura 2.2). Las edades de estas sucesiones abarcan desde el Cretácico hasta la actualidad y corresponden a diferentes episodios tectónicos que estructuraron la región. Estos episodios se pueden resumir en dos grandes procesos: un régimen extensional que instauró una cuenca 
de rift cretácico-paleógena en gran parte del Noroeste argentino, y la posterior instauración de un régimen contraccional a partir del Eoceno que generó la actual cuenca de antepaís, cuyos depósitos son bien preservados en la zona del Valle Calchaquí (del Papa et al., 2013b). La figura 2.3 muestra el mapa geológico del área de estudio.

\subsection{Cordillera Oriental.}

La Cordillera Oriental es una faja plegada y corrida de piel gruesa que sigue el borde Este de la Puna (véase Figura 1.1). Esta caracterizada por grandes láminas de corrimientos de orientación general N-S a NNE y vergencia doble, conformadas por el basamento Proterozoico-Cámbrico de la región, la Formación Puncoviscana. Esta unidad presenta intrusiones graníticas de edad similar, y sobre ella se apoyan sedimentitas paleozoicas, mezosoicas y cenozoicas. La escasa presencia o ausencia de volcanismo cenozoico es característica de esta provincia geológica (Ramos, 1999).

La Cordillera Oriental en su conjunto presenta dos sectores con diferente comportamiento estructural, separados por el lineamiento El Toro (Salfity, 2004). El sector Norte presenta una deformación de piel fina con láminas de corrimientos con vergencia oriental. La estratigrafía en este sector son secuencias del Paleozoico inferior, Cretácico-Paleógeno y Cenozoico (Ramos, 1999). El sector Sur se caracteriza por una deformación de piel gruesa con láminas de basamento con vergencia occidental en su mitad Oeste, y vergencia oriental en su mitad Este (Ramos, 1999). Aquí las secuencias cretácico-paleógenas se depositaron directamente sobre el basamento, indicando que el lineamiento El Toro condicionó la depositación de los depósitos paleozoicos que afloran en el sector Norte, y que este sector Sur constituyó un alto estructural para esos tiempos (Salfity y Marquillas, 1994). La doble vergencia de la faja plegada se le atribuye al control del rift cretácico en la reactivación de las antiguas fallas normales (Allmendinger et al., 1983). La zona de estudio se encuentra enmarcada en este sector, donde se ubica la subcuenca de Alemanía, uno de los depocentros más occidentales de la cuenca del Grupo Salta (véase Figura 1.2). 


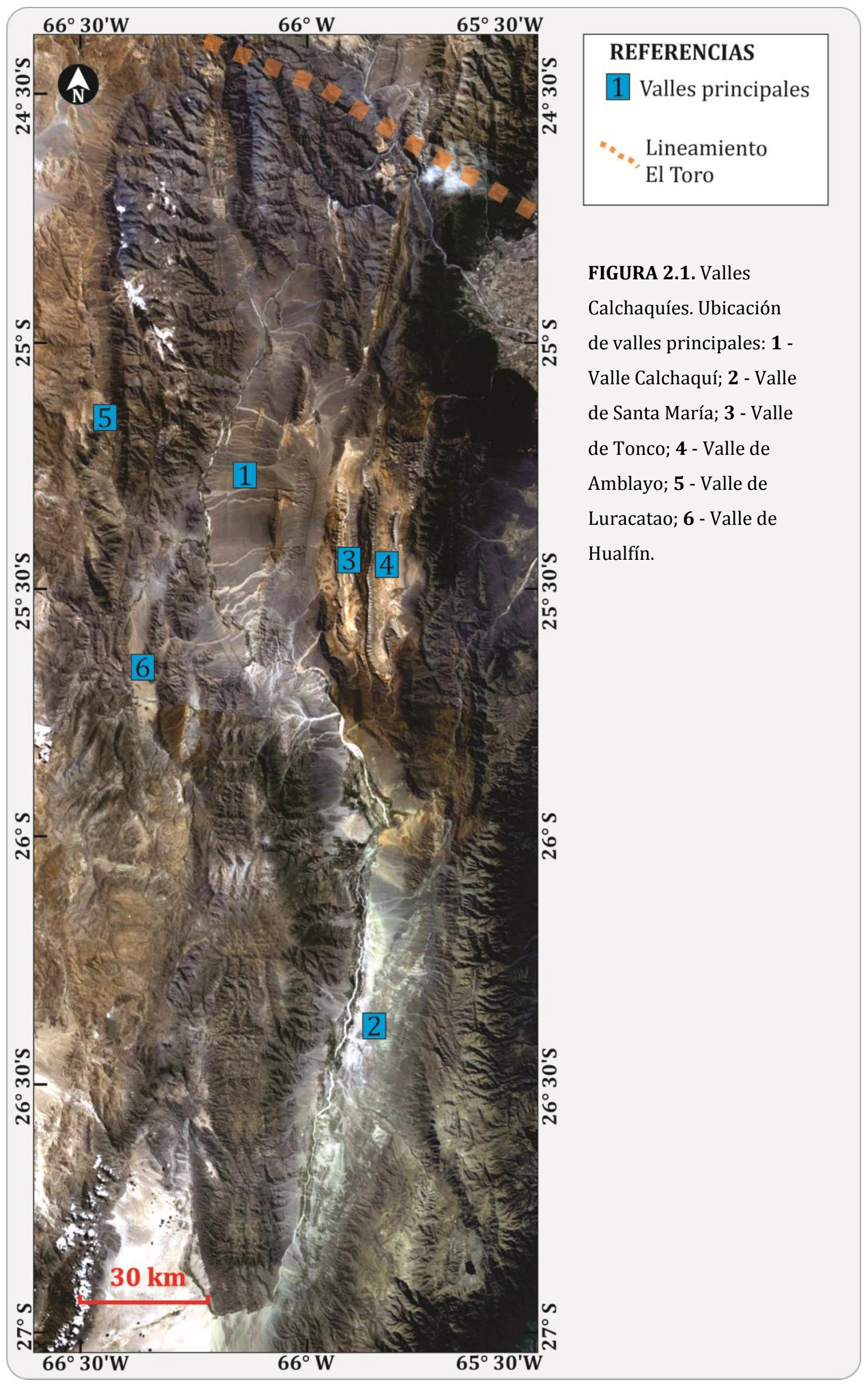




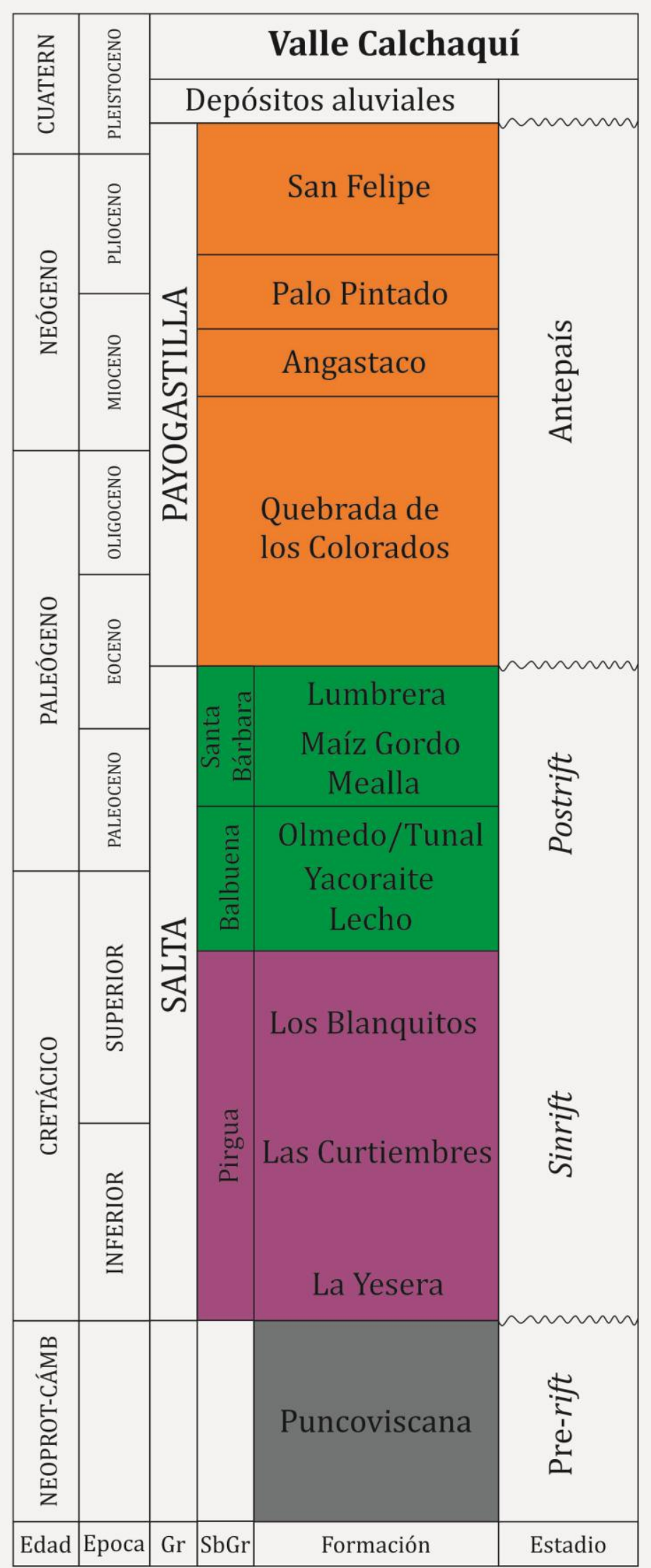

FIGURA 2.2. Estratigrafía del área de estudio en los Valles Calchaquíes. 


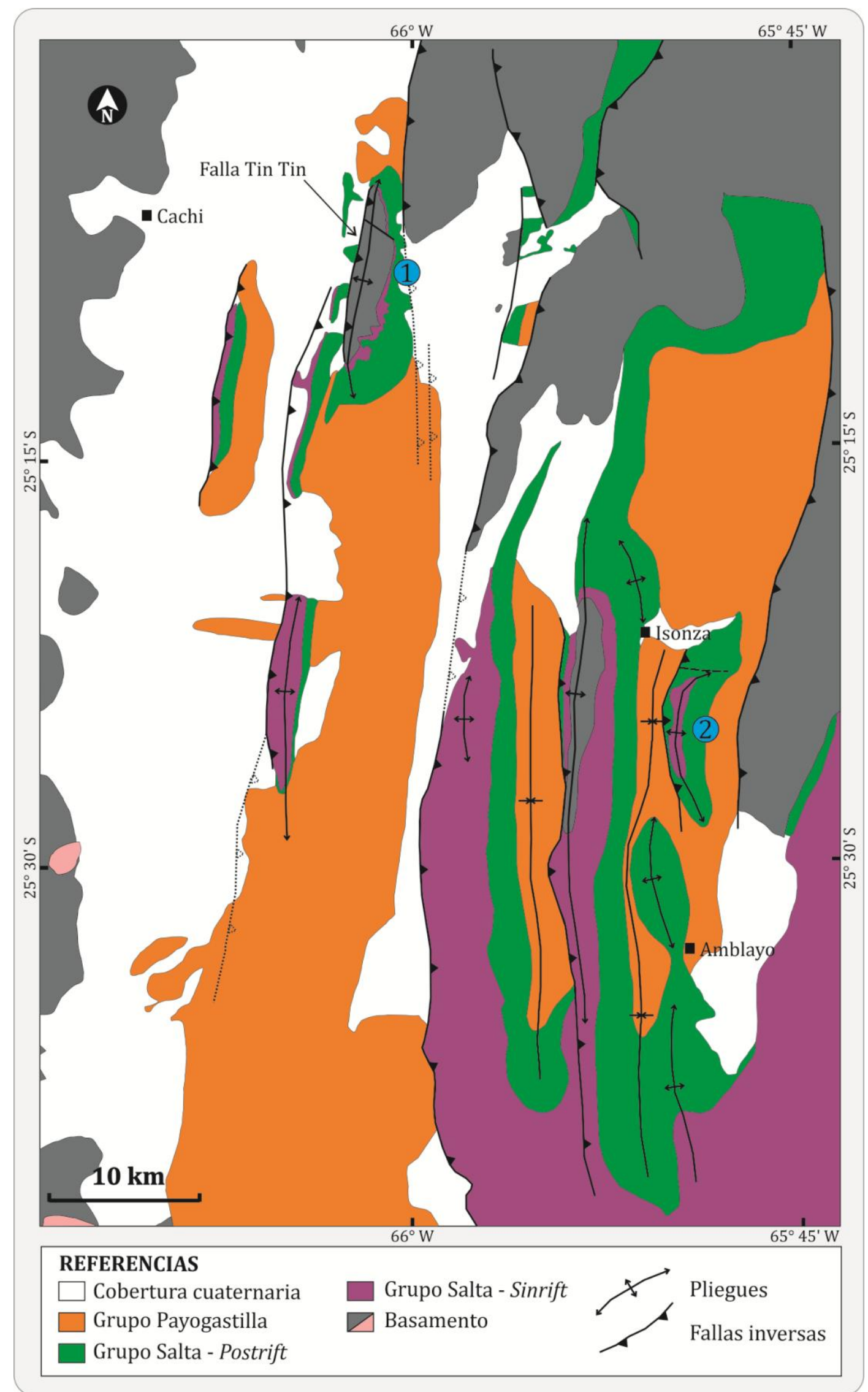

FIGURA 2.3. Mapa geológico del área de estudio (Simplificado de Carrera y Muñoz, 2013; del Papa et al., 2013a). 1) Anticlinal Tin Tin. 2) Anticlinal Cerro Bayo. 


\subsection{Cuenca de rift del Grupo Salta.}

La cuenca cretácico-paleógena del Grupo Salta se desarrolló en los Andes Centrales del Norte argentino (véase Figura 1.2), formando parte de una compleja e intensa historia tectónica que data desde tiempos precámbricos (Salfity y Marquillas, 1994; Mon y Salfity, 1995). Esta cuenca se asocia a un rift intracontinental (Galliski y Viramonte, 1988; Viramonte et al., 1999) y abarca gran parte de las provincias de Salta y Jujuy, con ramales que se extienden hasta el Norte de Tucumán, y en subsuelo, hasta el Oeste de Formosa (Starck, 2011).

El relleno de la cuenca del Grupo Salta se divide en tres subgrupos: Pirgua, asociado genéticamente al estadio de sinrift de subsidencia mecánica por fallas normales, Balbuena y Santa Bárbara, asociados al estadio de postrift de subsidencia termal (Salfity y Marquillas, 1994; Marquillas et al., 2005).

La historia geológica del Grupo Salta comenzó en el Cretácico Inferior probablemente como consecuencia de los movimientos Araucanos, cuando una serie de grábenes se abrieron en el Norte de Argentina, al principio como depocentros aislados y más tarde conectados estructuralmente. La orientación de los mismos siguen tres rumbos estructurales preferenciales: N-S, NE-SW y NW-SE (Salfity y Marquillas, 1994; Mon y Salfity, 1995). Los depocentros aislados se desarrollaron sobre un basamento heterogéneo Precámbrico y Paleozoico y sufrieron una fuerte subsidencia en los primeros estadios de la extensión (Mon y Salfity, 1995). Los más prominentes son Lomas de Olmedo, Tres Cruces, Metán, Alemanía, Sey, El Rey y Brealito (Marquillas et al., 2005), todos estos rodeados externamente por arcos limitantes y a su vez, rodeando en su centro a un alto estructural presente desde los inicios de la cuenca, el alto (o dorsal) Salto - Jujeño (Mon y Salfity, 1995).

La sedimentación de la etapa inicial (sinrift), conjuntamente con periodos de actividad magmática (Galliski y Viramonte, 1988), se restringió a los depocentros (grábenes) mencionados, siendo los limites las fallas extensionales de borde. Los depósitos que rellenaron y nivelaron los depocentros, luego fueron traslapados por los extensos depósitos acumulados durante la subsidencia termal (postrift) de la cuenca, confiriéndoles su característica geometría planar, 
depositados más allá de los limites de las fallas normales, muchas veces sobre el basamento. Durante el Eoceno (Fase Incaica), la sedimentación del Grupo Salta es interrumpida y se instaura un régimen contraccional generalizado debido a cambios en la dinámica de las placas tectónicas, provocando el inicio de la inversión tectónica de la cuenca del Grupo Salta junto con la erosión de algunas unidades cuspidales en varias posiciones de la misma, y el comienzo de una nueva cuenca de antepaís que fue fragmentada por bloques de basamento levantados por fallas inversas (del Papa et al., 2013b).

La inversión tectónica de la cuenca cretácica, que comenzó en el Eoceno Medio (del Papa et al., 2013b), ocurrió en al menos tres pulsos: Durante los movimientos Incaicos en el Eoceno, Quechua en el Mioceno, y Diaguita en el Pleistoceno, siendo estos últimos los más importantes y los que definieron el relieve morfoestructural actual. Durante estos periodos, los depósitos del Grupo Salta e incluso los depósitos sinorogénicos (Grupo Payogastilla) fueron plegados y erosionados (Mon y Salfity, 1995).

\subsection{Estratigrafía del área de estudio (Subcuenca de Alemanía).}

\subsubsection{Basamento}

El basamento del Norte argentino está conformado por un conjunto de cinturones orogénicos en contacto tectónico, con diferentes grados de metamorfismo y estructurados durante la orogenia Panamericana (Mon y Hongn, 1996). El terreno central es el que presenta mayor complejidad estructural y se extiende entre el borde oriental de la Puna, en Norte de las Sierras Pampeanas y la franja occidental de la Cordillera Oriental. Éste está integrado por varios cinturones de grado metamórfico variable que forman un antiforme regional con

eje NNW-SSE y buzamiento hacia el NNW. Particularmente el Cinturón de Choromoro, donde se encuentra el área de estudio, es un cinturón de bajo grado metamórfico que muestra pliegues apretados de charnelas agudas engrosadas y flancos adelgazados, con longitudes de ondas de 8 a 10 metros, vergentes hacia el Este y clivaje de plano axial que acompaña al plegamiento que inclina hacia el Oeste. Los ejes de los pliegues son aproximadamente horizontales con rumbo NNESSW (Mon y Hongn, 1996). 
Un segundo evento de deformación está representado por una superficie de clivaje de rumbo NE-SW e inclinaciones de 30 a $50^{\circ}$ al Noroeste, intersectando los elementos de la primera deformación. Como rasgo póstumo aparecen bandas kink de rumbo E-W con inclinación de bajo ángulo al Norte y espesores de 5 a 20 centímetros (Mon y Hongn, 1996). En términos regionales, el basamento del Noroeste argentino muestra gran diversidad de edades, litologías y estructuras, y es el resultado de la superposición de sucesivos eventos de deformación, metamorfismo y magmatismo (Mon y Hongn, 1996; Hongn y Becchio, 1999; Hongn y Seggiaro, 2001; Hongn et al., 2010a, 2010b; entre otros).

El basamento aflorante en el área de estudio es conocido con el nombre genérico de Formación Puncoviscana de edad proterozoica-cámbrica (Hongn y Seggiaro, 2001), y está constituido por una secuencia alternante de pelitas, grauvacas y areniscas, afectada por metamorfismo de grado bajo. La deformación del basamento en este sector, a diferencia de las descripciones regionales, consta de pliegues con charnelas agudas y longitud de onda pequeña, de rumbo general EW (Ruiz Huidobro, 1955).

\subsubsection{Grupo Salta}

La historia del rift de la cuenca de Grupo Salta está relacionada a la evolución de los Andes Centrales y a la actividad del margen Pacifico sudamericano, donde ocurre su ubicación geográfica. La sedimentación ocurrió desde el Neocomiano hasta el Paleogeno, con depositos que alcanzan más de 5000 metros en espesor (Marquillas et al., 2005).

\subsubsection{Subgrupo Pirgua (Neocomiano tardio-Maastrichtiano temprano).}

Representa el relleno de sinrift de la cuenca (Marquillas et al., 2005) y está compuesto por capas generalmente rojizas (areniscas, conglomerados y limolitas en casi todas las localidades) y rocas volcánicas. La geometría de los depósitos revela un marcado control tectónico con más de $4000 \mathrm{~m}$ de espesor en las cercanías de las fallas normales de rumbo N-S y NE-SW, como ocurre en los depocentros de Pucará y Brealito (Sabino, 2004), al Oeste de la zona de estudio (véase Figura 1.2), presentando geometría de hemigraben. 
En el cerro Tin Tin (Figura 2.3; véase Figura 4.3), el Subgrupo Pirgua está representado por areniscas conglomerádicas y conglomerados, con clastos de metamorfitas, cuarcitas y cuarzo, de tonalidades parduscas, con un espesor de 145 metros (Monaldi, 2001). En este trabajo se midió el espesor del Grupo Pirgua en tres posiciones dentro del cerro. En su sector Suroeste (flanco frontal del anticlinal Tin Tin) se medió un espesor de 150 metros; aproximadamente en el sector medio del cerro se midió un espesor de 45 metros; hacia su sector Norte se midió un espesor de 50 metros. Se destaca la disminución de espesor de este subgrupo, en los afloramientos del cerro Tin Tin, desde el Sur hacia el Norte. En los alrededores del área del cerro Tin Tin, el Subgrupo Pirgua carece de intercalaciones de volcánicas alcalinas, que si son muy abundantes hacia el interior de la subcuenca de Alemanía (véase Figura 1.2).

\section{Formación La Yesera}

Son conglomerados finos de color rojo claro, en estratos medianos a gruesos. Se intercalan areniscas finas y gruesas de tono rojizo, y en la parte basal, lutitas verde-amarillentas y gris-parduscas. Los depósitos corresponden a abanicos aluviales poco seleccionados asociados a las fallas directas principales del rift, y a ríos entrelazados arenosos, con planicies fangosas. Hay presencia de lavas asociadas a los abanicos aluviales, por medio de las fallas directas (Marquillas et al., 2005). Su espesor aproximado en la subcuenca de Brealito (véase Figura 1.2) es de 2300 metros (Sabino, 2004). En el cerro Tin Tin (Figura 2.3; véase Figura 4.3), su base se compone de brechas y conglomerados mal seleccionados, sin estratificación marcada, de aproximadamente unos 2 a 10 metros de espesor.

\section{Formación Las Curtiembres}

Son lutitas y lutitas arenosas de colores pardo rojizo, pardo grisáceo y verde. Se intercalan areniscas arcósicas finas a medianas de color rojo claro. Eventos volcánicos aportaron material piroclástico y lávico (Marquillas et al., 2005). Los depósitos corresponden a lagos someros de agua dulce a salobre (Marquillas et al., 2005). Su espesor parcial en el depocentro de Brealito (véase Figura 1.2) es de 1250 metros (Sabino, 2004). 
Son areniscas arcósicas gruesas, pardo rojizas, con laminación horizontal y entrecruzada. Se intercalan areniscas finas, micáceas y estratos delgados de conglomerado fino compuesto por clastos de granito rosado. El conjunto tiene coloración rojiza y el análisis de sus facies indica ambientes de ríos arenosos (Marquillas et al., 2005). A diferencia de la Formación La Yesera que presenta los máximos espesores en las cercanías de las fallas directas, esta formación presenta sus máximos espesores (hasta 1500 metros) en el centro de las subcuencas (Marquillas et al., 2005). Monaldi (2001) indica que en el depocentro de Brealito (véase Figura 1.2) el espesor medido es de 90 metros con su techo erosionado, aunque Sabino (2004) destaca la ausencia de esta formación en la zona de Brealito.

\subsubsection{Subgrupo Balbuena (Maastrichtiano-Paleoceno temprano).}

Este subgrupo representa el estadio de postrift temprano. La sección típica tiene 400 a 500 metros de espesor. Está formado por areniscas blanquecinas en su parte inferior (Formación Lecho), areniscas y calizas amarillentas (Formación Yacoraite) y pelitas oscuras (Formación Olmedo/Tunal) en su parte superior (Marquillas et al., 2005). En general las facies se desarrollan más o menos paralelamente al borde de cuenca. En los bordes predominan las litologías cuarzofeldespáticas y los espesores reducidos, mientras que hacia el centro de cuenca (o subcuencas) aumenta considerablemente el contenido pelítico y carbonático (Moreno, 1970). En el área de estudio este subgrupo presenta espesores reducidos. Sus características litológicas indican depositación en cercanías de borde de cuenca (Monaldi, 2001; Marquillas et al., 2005), en este caso, el borde Noroccidental de la subcuenca de Alemanía (véase Figura 1.2).

Formación Lecho.

Conformado principalmente por areniscas calcáreas blanquecinas y verdosas, cuarzosas, granodecreciente de base a techo. Intercalan niveles conglomerádicos con clastos de granitos y pegmatitas (Moreno, 1970). Estos depósitos se asocian con ríos entrelazados distales y campos de dunas. En el cerro Tin Tin (Figura 2.3; véase Figura 4.3) presenta un espesor de 35 metros (Monaldi, 2001). 
Formación Yacoraite.

Consiste en calizas arenosas, calizas oolíticas y areniscas calcáreas y cuarzosas, de tonos gris blanquecino y gris amarillento, en estratos finos a medianos. En distintos niveles de la secuencia se intercalan calizas estromatolíticas y niveles de conglomerados finos de cuarzo. Hacia el techo la unidad contiene restos de gasterópodos. Estos depósitos corresponden a un ambiente carbonatico somero, similar a un mar epírico, con facies correspondientes a un ambiente marino litoral somero y de energía variable (Marquillas et al., 2005). Según datos palinológicos e isotópicos, el techo de esta unidad es de edad Daniano, por lo que se ubica al límite K/T dentro de esta formación (Marquillas et al., 2003, 2005, 2007). En el cerro Tin Tin (Figura 2.3; véase Figura 4.3), esta formación está conformada casi totalmente por areniscas calcáreas y cuarzosas, compactas, bien estratificadas, de color amarillento, con finas intercalaciones de bancos estromatolíticos (Pucalithus) y calizas oolíticas, y por delgados bancos de lutitas grises y verdosas, con abundantes y diminutas hojuelas de mica en los planos de estratificación. En alternancia se encuentran además calizas bien estratificadas con ondulas (Moreno, 1970). Según datos publicados, el espesor de la formación Yacoraite en el cerro Tin Tin es de 57 metros en su sector Sureste (Monaldi, 2001). En este trabajo se midió el espesor de esta unidad en diferentes sectores del cerro, con los siguientes resultados: 42 metros de espesor en la charnela del anticlinal (sector de inmersión Sur); 83 metros de espesor, medidos aproximadamente en el sector medio del cerro; 90 metros de espesor, medidos en el sector Norte del cerro (aunque la zona se ve afectada por fallas inversas). Las descripciones litológicas concuerdan con las descripciones de Moreno (1970), con predominio de areniscas cuarzosas y calizas oolíticas. En el Cerro Bayo (Figura 2.3; véase Figura 4.21), las litologías son similares pero se describen más intercalaciones arcillosas y calcáreas (Ruiz Huidobro, 1955). Aquí, el espesor medido sobre el flanco frontal y dorsal del anticlinal en una posición media del cerro, alcanza los 210 metros.

\section{Formación Olmedo/Tunal.}

Esta formación es reconocida principalmente en el subsuelo de la subcuenca Lomas de Olmedo, con un espesor de 150 a 200 metros. Está compuesta de lutitas grises y negras, limolitas con sal y sulfatos, y areniscas finas. Estos 
depósitos corresponden a sistemas de planicies de barro y lagos salinos, en condiciones climáticas temporal y localmente áridas (Marquillas et al., 2005). Según las observaciones realizadas en el Cerro Tin Tin, esta unidad presenta un espesor muy reducido o se encuentra ausente, ya que en general, son depósitos calcáreos o silicoclásticos de la Formación Mealla (Subgrupo Santa Bárbara) los que sobreyacen a la Formación Yacoraite.

\subsubsection{Subgrupo Santa Bárbara (Daniano-Eoceno).}

Este subgrupo representa el estadio de postrift tardío de la cuenca del Grupo Salta. La sucesión sedimentaria es dominada por areniscas finas y limolitas rojizas y lutitas verdosas (Marquillas et al., 2005). Sus afloramientos se distribuyen de manera similar al los del Subgrupo Balbuena (Monaldi, 2001). En el área del cerro Tin Tin (Figura 2.3; véase Figura 4.3), las litologías corresponden a un borde de cuenca. Aquí el Subgrupo Santa Bárbara tiene un espesor de 554 metros (Monaldi, 2001).

\section{Formación Mealla}

Consiste en una sucesión de areniscas rosadas, bien estratificadas, con intercalaciones de conglomerados y areniscas conglomerádicas de color gris blanquecino y pelitas color parduzco. En algunos sectores de la cuenca intercalan niveles estromatolíticos. Estas litologías corresponden a ambientes fluviales de ríos meandrosos con planicies de inundación y paleosuelos, y a lagos cerrados y someros (Marquillas et al., 2005). En el cerro Tin Tin (Figura 2.3; véase Figura 4.3) esta formación tiene un espesor de 157 metros (Monaldi, 2001).

\section{Formación Maíz gordo}

Son conglomerados y areniscas conglomerádicas de colores castaños y pardos. Se intercalan limolitas y areniscas de colores grises y verdosos. Presentan cementaciones carbonáticas. Los ambientes sedimentarios corresponden a ríos entrelazados arenosos, lagos muy someros de baja energía y planicies de barro (Marquillas et al., 2005). Su espesor total es de 320 metros. 
Esta formación está conformada por arcillitas, fangolitas, areniscas y conglomerados de color rojo ladrillo, y para la sección inferior de la formación, los depósitos corresponden a sistemas fluviales arenosos meandrosos con barras, albardones, y planicies aluviales. Las secciones media y superior de esta formación corresponden a depósitos lacustres, con niveles anóxicos y salinos, respectivamente (Marquillas et al., 2005). El espesor de esta unidad es de 77 metros (Monaldi, 2001).

\subsubsection{Grupo Payogastilla}

Con esta denominación Díaz y Malizzia (1983) agruparon a los depósitos distribuidos entre $24^{\circ}$ y $26^{\circ}$ de latitud Sur y $66^{\circ}$ y $66^{\circ} 30^{\prime}$ de longitud Oeste. Está integrado de base a techo por las Formaciones Quebrada de los Colorados, Angastaco, Palo Pintado y San Felipe (Díaz y Malizzia, 1983). Estos depósitos corresponden al relleno de una cuenca de antepaís andina en los Valles Calchaquíes (Grier y Dallmeyer, 1990; DeCelles et al., 2011; Hongn et al., 2011; del Papa et al., 2013; entre otros) y su edad es Eoceno Inferior a Medio - PlioPleistoceno (del Papa et al., 2013b; Hongn et al., 2007).

Formación Quebrada de los Colorados.

Aflora en fajas de rumbo meridional. Se trata de ciclos granodecrecientes constituidos por conglomerado mediano a fino, arenisca gruesa, arenisca fina y limolita arenosa. El color predominante es pardo rojizo en la base y rojo oscuro en el techo. Las estructuras sedimentarias más comunes son: maciza, laminación paralela, estratificación cruzada y estratificación cruzada cuneiforme de gran escala (3 y 25 metros). Estos depósitos se interpretan como sistemas fluviales entrelazados a meandriformes con presencia de niveles eólicos, y corresponden al inicio de la cuenca de antepaís para el sector de los Valles Calchaquíes (González, 2001; Hongn et al., 2007; del Papa et al., 2013). El espesor de esta formación es de aproximadamente 1300 metros (Hongn et al., 2011).

Formación Angastaco. 
Está conformada principalmente por areniscas y conglomerados grises y pardo-rojizos, con presencia de pelitas subordinadas (González, 2001). El ambiente sedimentario corresponde a sistemas fluviales entrelazados, planicies aluviales, y depósitos eólicos hacia su parte superior (del Papa et al., 2013b; Hongn et al., 2011). Según Grier y Dallmeyer (1990, en Hongn y Seggiaro, 2001) el espesor alcanza los 3750 metros.

\section{Formación Palo Pintado.}

Se trata de una espesa sucesión grano y estratodecreciente de conglomerados matriz sostén, areniscas medianas a finas y pelitas verdes, marrones y grises. Estos depósitos se interpretan como sistemas fluviales sinuosos areno-gravoso con desarrollo de lagunas y pantanos (Galli et al., 2011). Grier y Dallmeyer (1990, en Hongn y Seggiaro, 2001) indican un espesor de 1270 metros sobre el borde Oeste del Valle Calchaquí.

\section{Formación San Felipe.}

Está constituida por conglomerados muy gruesos, textura clastosoportada, con rodados imbricados y en menor proporción areniscas y pelitas. Los conglomerados tienen mayor desarrollo en el extremo superior de la unidad. Estos depósitos han sido interpretados como un sistema fluvial entrelazado gravoso profundo (Galli et al., 2011). El espesor indicado por Grier y Dallmeyer (1990, en Hongn y Seggiaro, 2001) supera los 660 metros.

\subsection{Estructura de área de estudio.}

El área de estudio está caracterizada por pliegues anticlinales y sinclinales y bloques de basamento que conforman los límites de los Valles Calchaquíes (Figura 2.3). Todas estas estructuras se relacionan a fallas inversas que exponen en superficie el relleno sedimentario de la cuenca cretácica del Grupo Salta y Payogastilla, y en ocasiones, láminas de basamento también quedan expuestas formando parte de los pliegues en superficie.

Estructuralmente, el valle Calchaquí está limitado bloques de basamento levantados por dos fallas inversas vergentes hacia el eje del valle (Mon y Salfity, 1995). En el interior del valle existen fallas inversas que pliegan la cobertura 
sedimentaria generalmente en su bloque colgante, formando las principales estructuras aflorantes. Las orientaciones principales de las estructuras contraccionales son N-S y NNE-SSW (Figura 2.3), y en menor medida, NW-SE y EW. Las estructuras N-S predominan en el sector medio del Valle Calchaquí, donde se encuentran fallas inversas con vergencia occidental asociadas a pliegues anticlinales y sinclinales (sinclinal de Tonco, sinclinal de Amblayo, cerro Negro; véase Figura 1.3 para ubicación). Las estructuras de orientación NNE-SSW predominan en los sectores asociados con basamento aflorante, como el cerro Tin Tin o el borde Este del Valle Calchaquí (Figura 2.3). En el sector Sur del valle se encuentran fallas de orientación NW-SE y E-W, según mencionan otros autores que han trabajado en la zona (Carrera et al., 2006; Carrera y Muñoz, 2008, 2013). Las diferencias en orientación de estas estructuras resulta en un patrón complejo de interferencia de pliegues a diferentes escalas (Carrera et al., 2006). La interpretación propuesta para la presencia de estas estructuras, y para la configuración estructural general en esta parte de la Cordillera Oriental, es la inversión tectónica positiva de la cuenca del Grupo Salta durante la contracción cenozoica (Grier et al., 1991; Hongn y Seggiaro, 2001; Carrera et al., 2006; Carrera y Muñoz, 2008, 2013; entre otros), donde espesos depósitos del Subgrupo Pirgua son extruidos a través de la reactivación inversa de las fallas directas que controlaron su depositación, como por ejemplo en la zona de Luracatao (Payrola Bosio et al., 2009) o hacia el centro de la subcuenca de Alemanía (Carrera et al., 2006; Carrera y Muñoz, 2008, 2013; véase Figura 1.2). Otros autores han propuesto que heterogeneidades preexistentes en el basamento actuaron como zonas de debilidad e indujeron la generación de nuevas estructuras. Estas heterogeneidades también habrían influenciado local y parcialmente la nucleación de las fallas normales cretácicas (Hongn et al., 2010a, 2007, 2011).

En el área del cerro Tin Tin (Figura 2.3), Carrera et al. (2013) proponen una falla normal de rumbo N-S con alta inclinación al Oeste (Falla Pakaskka) para explicar los potentes depósitos de sinrift ubicados al Suroeste del Cerro Tin Tin. Esta falla normal estaría ubicada en subsuelo y sería cortada y plegada por la Falla Tin Tin durante su crecimiento (véase Figuras 4.1, 4.2a y 4.3). Otros ejemplos similares son descriptos por estos autores para la zona de Sur del valle (Carrera et al., 2006). En este contexto, la Falla Tin Tin no es producto de la reactivación de las 
fallas normales previas, sino que es necesario otro mecanismo que explique su formación, como así también la diferencia en el sentido de inclinación con respecto a la falla normal, cuestión que será desarrollada en capítulos subsiguientes.

La evolución estructural de los Valles Calchaquíes queda evidenciada por la disposición espacial de los depósitos cretácico-paleógenos del Grupo Salta (Salfity y Marquillas, 1994). Las fallas directas pertenecientes a los limites depocentrales del rift presentan grandes espesores de sinrift en sus adyacencias, y los sectores donde los depósitos de sinrift son escasos o nulos y los depósitos de postrift yacen directamente sobre el basamento epimetamórfico marcan los altos estructurales presentes para los tiempos cretácicos (Mon y Salfity, 1995). El estudio de los depósitos de antepaís y sus discordancias internas (del Papa et al., 2013b; Hongn et al., 2008) permitió realizar interpretación acerca de la evolución tectónica del área durante la inversión cenozoica (Carrapa et al., 2012; del Papa et al., 2013; Galli et al., 2014; entre otros).

Se han podido determinar y diferenciar al menos tres episodios importantes de inversión tectónica en el área, comenzando con la fase Incaica en el Eoceno Medio. La estructuración más importante se desarrolló durante el Mioceno, con la fase Quechua, cuando se levantaron la Puna y la Cordillera Oriental. El tercer pulso tectónico importante se produce durante el Plio-Pleistoceno con la reactivación de la fase compresiva Diaguita que definió los principales rasgos actuales que conforman la región de los valles Calchaquíes (Salfity y Marquillas, 1994; Mon y Salfity, 1995; Hongn y Seggiaro, 2001).

Además de la contracción E-W cenozoica generalizada, se han propuesto regímenes transpresivos con los consecuentes movimientos de rumbo horizontales en los bordes del valle Calchaquí (Mon y Salfity, 1995; Riller y Oncken, 2003). Mon et al. (2012) han propuesto periodos de extensión temporal durante el Mioceno para algunos sectores aledaños a la zona de estudio (Valle de Santa María; Figura 2.1), como así también componentes de rumbo importantes durante el Cuaternario para la Puna y sectores aledaños del antepaís (Marrett et al., 1994; Hongn y Seggiaro, 2001). 


\section{CAPÍTULO 3 \\ METODOLOGÍA DE TRABAJO}




\section{CAPITULO 3 - METODOLOGÍA DE TRABAJO}

El presente trabajo de tesis doctoral se basa en un estudio geológico estructural y consiste en el reconocimiento, mapeo, medición y análisis de estructuras geológicas. Este tipo de trabajo conlleva en forma implícita un estudio de carácter estratigráfico en el cual enmarcarlo. Para alcanzar los objetivos propuestos, esta tesis doctoral requirió de trabajo de campo para la recolección de datos estructurales y trabajo de gabinete para el procesamiento y análisis de los datos recolectados, entre otras tareas.

A los fines de organización en la descripción de las actividades desarrolladas, se describirán en primer lugar las tareas de campo y luego las tareas de gabinete, aunque ambas fueron llevadas a cabo en forma simultánea e integrada.

\subsection{TRABAJO DE CAMPO}

Las tareas de campo se desarrollaron entre Junio del 2010 y Noviembre del 2013, con un total de 97 días de campo. En las instancias iniciales del proyecto, las tareas de campo se basaron en el reconocimiento y mapeo de las unidades estratigráficas principales relacionadas a las estructuras geológicas, y en la recolección de datos estructurales iniciales. Posteriormente, a partir de un mayor conocimiento geológico de la zona y de las estructuras, los trabajos se enfocaron en el estudio estructural de detalle en lugares estratégicos (Figura 3.1). Los instrumentos utilizados en el campo fueron una brújula tipo Brunton, GPS, cinta métrica, imágenes satelitales y mapas geológicos, cámara fotográfica.

\subsubsection{Mapeo geológico}

La zona de estudio cuenta con material cartográfico y mapas geológicos publicados por diferentes autores en revistas periódicas. Estos, al presentar objetivos diferentes a los propuestos en este proyecto, no cuentan con el detalle necesario sobre las estructuras anticlinales de estudio, pero aportaron un soporte estratigráfico zonal y regional. Por esto se confeccionó un mapa de detalle del anticlinal Tin Tin, anticlinal Cerro Bayo y zonas aledañas a ambos, ubicando los contactos entre las unidades estratigráficas y mapeando las estructuras geológicas 
en diferentes sectores de las estructuras principales (por ejemplo, flanco y charnela de un anticlinal principal). Los mapas fueron evolucionando a medida que se avanzaba con los trabajos de campo de las sucesivas campañas.

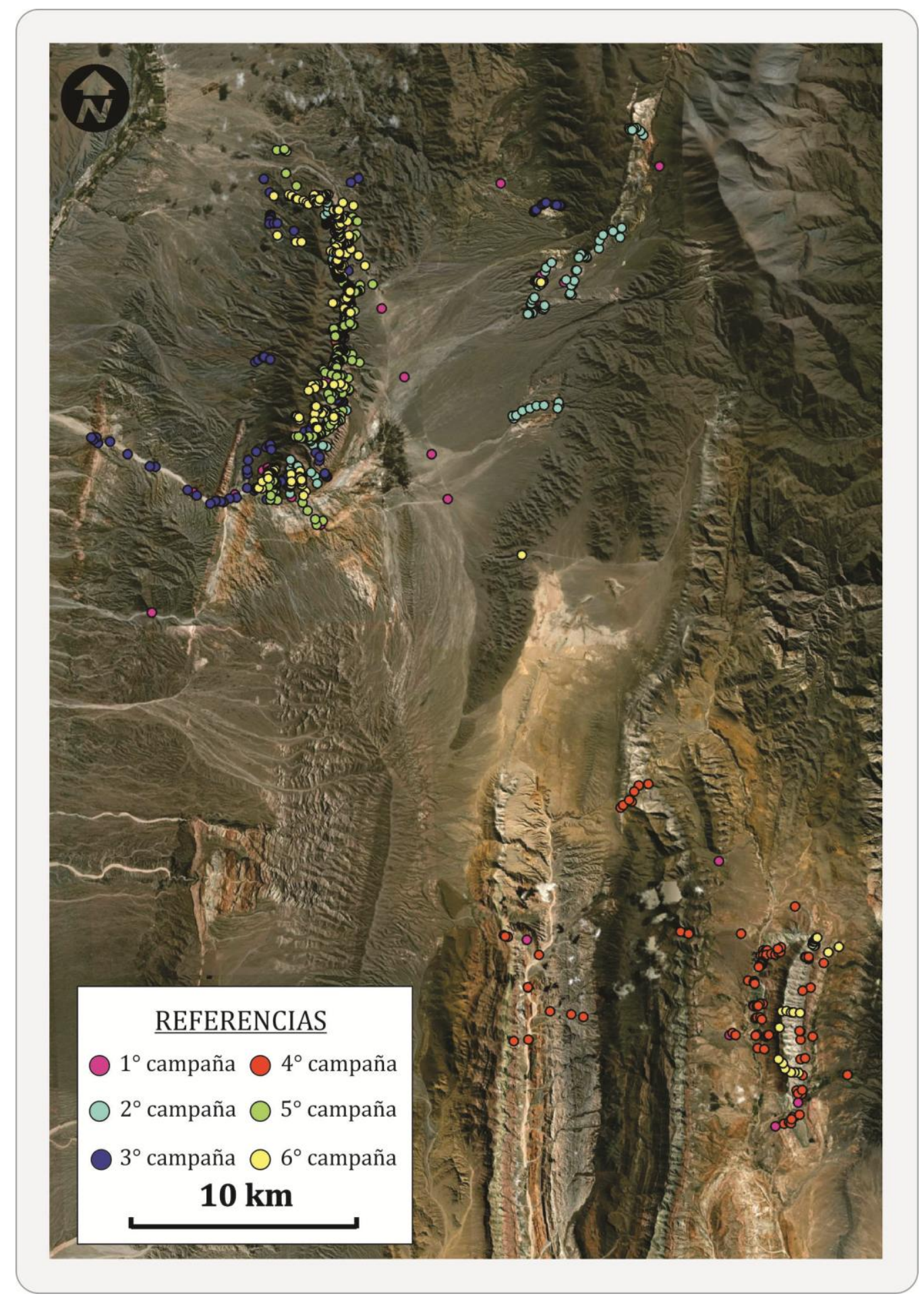

FIGURA 3.1. Puntos GPS de los sitios de observación y medición durante el trabajo de campo. Vista en ArcGIS 9.2 ${ }^{\circledR}$. 
Para el trabajo de campo se llevaron y utilizaron los mapas publicados, para la ubicación y reconocimiento de la estratigrafía, y también imágenes satelitales obtenidas de Google Earth ${ }^{\circledR}$ para zonas donde se requería mayor detalle. Estas imágenes se utilizaron en versión impresa en papel tamaño $\mathrm{A} 4$, y en formato digital como imagen de fondo en GPS Trimble ${ }^{\circledR}$ Juno SB. Se utilizó papel transparente para mapear sobre las imágenes satelitales de Google Earth ${ }^{\circledR}$ (Figura 3.2a). Se midió sistemáticamente la orientación de las capas estratificadas y de las estructuras geológicas (pliegues y fallas) con una brújula tipo Brunton, utilizando la notación Rbz (Rumbo del buzamiento). Las litologías fueron descriptas en muestra de mano con la ayuda de una lupa x10 aumentos. Cada sitio de medición, descripción, observación y/o toma de fotografías, se posicionó geográficamente (latitud, longitud y altitud) con GPS Garmin ${ }^{\circledR}$ eTrex y Trimble ${ }^{\circledR}$ Juno SB.

\subsubsection{Perfiles estructurales}

Con el fin de construir secciones geológicas de escala zonal, se recolectaron datos de orientación de capas estratificadas, mapearon estructuras geológicas y contactos entre unidades (todos los datos ubicados con GPS) a lo largo de transectas de 20-30 kilómetros de longitud y orientación E-W (ver figuras 4.2a-b).

\subsubsection{Perfiles estratigráficos}

Se realizaron perfiles estratigráficos con el objetivo de determinar el espesor de las unidades involucradas en los anticlinales. Para esto se tomaron datos de Rbz, ubicados con GPS, a lo largo de una transecta lo mas perpendicular posible al rumbo de las capas estratificadas, desde el núcleo del anticlinal hacia su parte más externa. Se registraron los contactos entre unidades y se realizaron observaciones litológicas y estructurales pertinentes. Con los datos de orientación de las capas, la ubicación de los contactos, y la topografía (obtenida por la altura de los puntos GPS), se pudo determinar geométricamente el espesor de cada unidad. 


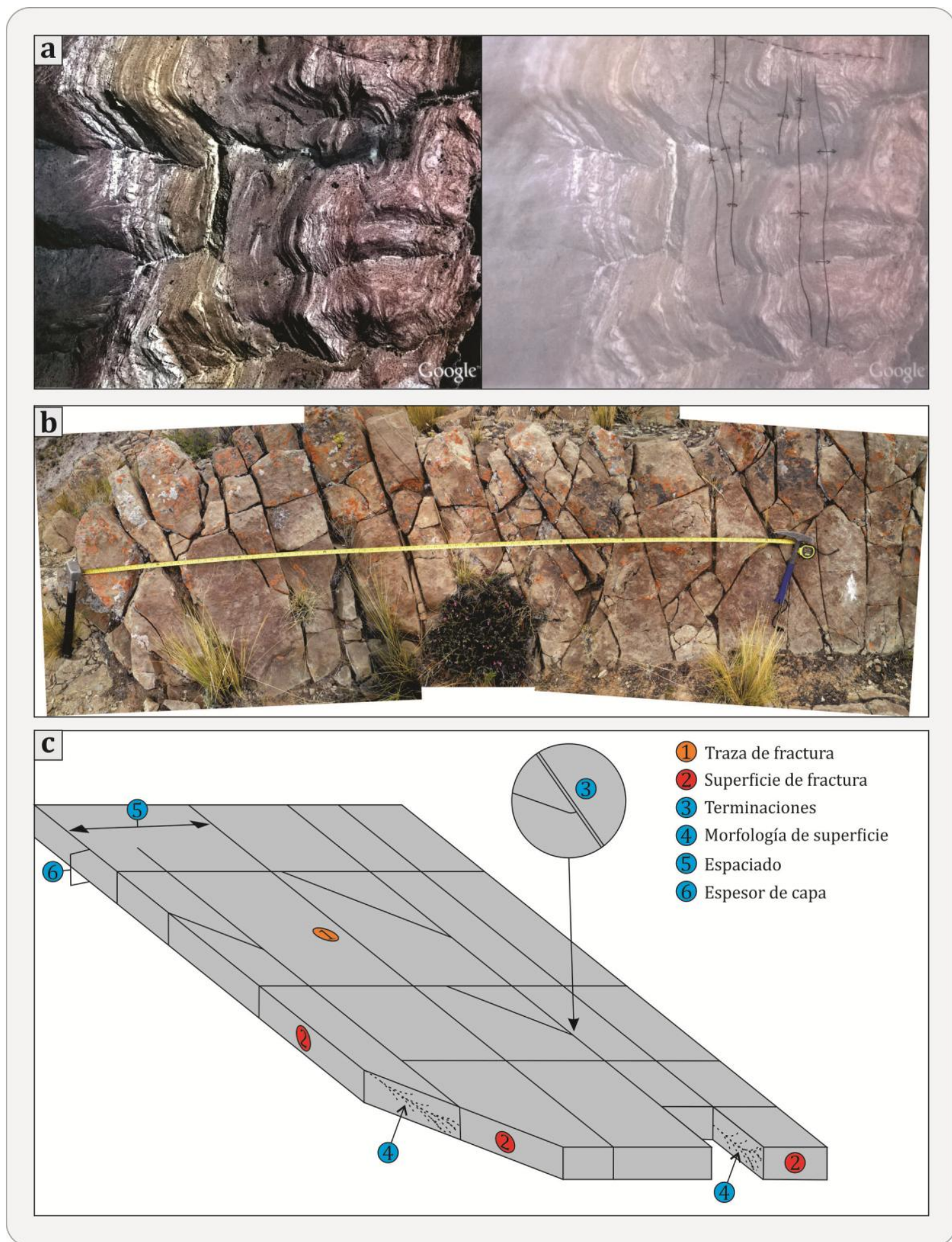

FIGURA 3.2. a) Imagen satelital impresa (izq.) y su utilización en el mapeo de detalle con papel transparente (der.). b) Medición de fracturas en el campo mediante el método de línea transversal (scan line) y el uso de la cinta métrica. c) Esquema sobre la caracterización de fracturas en el campo. 


\subsubsection{Caracterización de pliegues}

La caracterización de campo del anticlinal principal resulta del mapeo de unidades involucradas y de la medición del Rbz de sus capas en diferentes partes de la estructura general (flanco, charnela, cresta). Para caracterizar geométricamente los pliegues dentro del anticlinal principal (pliegues de mesoescala) se midió la orientación (Rbz) de sus flancos. La cantidad de datos a tomar es dependiente de la dispersión de los mismos. Cuanto más parecidos resulten los datos tomados a medida que se realiza la medición, menos datos se toman. En general, no más de 10 datos de Rbz fueron tomados por flanco.

El tamaño del pliegue se determinó mediante el parámetro Longitud de onda, que es la distancia entre dos puntos (o líneas) de inflexión alternados, es decir, que comprenden a un anticlinal y sinclinal completos. Esta medición se realiza con cinta métrica para los pliegues de pequeña magnitud. Para pliegues de decenas a centenas de metros, la medición se realiza directamente desde la imagen satelital (en campo o gabinete), una vez que la estructura ha sido mapeada y delimitada.

Otros parámetros geométricos se obtuvieron en gabinete, mediante el procesado de los datos de campo con programas informáticos adecuados.

\subsubsection{Caracterización de fallas}

Para la caracterización de campo de las fallas, en cualquier escala de trabajo, se midió la orientación del plano de falla $(\mathrm{Rbz})$ y las lineaciones contenidas en el mismo (minerales, estrías), mediante la orientación acimutal de la línea.

La traza de las fallas se mapearon conectando diferentes punto de afloramiento de las mismas (ubicados con GPS), con ayuda de la interpretación de imágenes satelitales.

Para complementar la descripción, se realizaron observaciones sobre la geometría general de las fallas, su relación angular con respecto a la estratificación afectada, y las características de las rocas afectadas por las mismas. 


\subsubsection{Caracterización de fracturas menores (diaclasas, venas, fracturas de cizalla).}

La recolección de datos de fracturas (diaclasas, venas, fracturas de cizalla) se realizó en estaciones de medición, posicionadas con GPS. Estas se clasificaron en estaciones de medición principal, donde se tomaron gran cantidad de datos estructurales, y estaciones de medición auxiliar, donde los datos tomados eran para complementar las estaciones principales. El muestreo de fracturas se realizó a través de tres métodos de muestreo que se describen brevemente a continuación (Marshak y Mitra, 1988):

Método de selección: Se visualiza el afloramiento, se seleccionan los sets de fracturas prominentes y se miden de cuatro a ocho fracturas por set. Es útil cuando el patrón de fracturación es relativamente simple.

Método de cantidad: Se mide la mayor cantidad de fracturas individuales posibles sin considerar su tamaño o si es sistemática o no. La representación de los datos mostrará a los sets principales de forma más obvia.

Método de línea transversal (scan line): El método consiste en trazar una línea en el afloramiento, con una orientación determinada (Figura 3.2b). Se puede realizar tanto en planta (techo del estrato) como en perfil. A lo largo de la línea trazada, se mide la orientación de cada plano de fractura que ésta cruza. Este método permite la cuantificación de las fracturas en parámetros como Espaciado (distancia perpendicular entre dos fracturas del mismo set) y Frecuencia (cantidad de fracturas por unidad de longitud).

El método elegido en cada afloramiento estuvo sujeto a las dimensiones del mismo, y a si representaba una estación de medición principal o auxiliar. En las principales se usó el método de cantidad y/o de scan line, y en las auxiliares el método de selección o de cantidad.

Los planos de fracturas se midieron en Rbz cuando tenían su superficie expuesta, en caso contrario se midió la dirección de su traza. A su vez se recolectaron datos y observaciones acerca del tipo de fractura, morfología de sus superficies, terminación y relaciones de corte (cronología relativa de formación), 
espaciado general (no mediante scan line), longitud de las trazas, tipo de relleno, patrón del sistema de fracturas del afloramiento, espesor y litología de la capa afectada (Figura 3.2c).

\subsubsection{Recolección de muestras de roca orientadas.}

Se recolectaron muestras orientadas de la Formación Yacoraite en las estaciones donde se realizaron scan lines para estudiar la fracturación a microescala en cortes delgados, con el objetivo de determinar cuan penetrativa fue la deformación, y para descripciones litológicas más precisas.

\subsection{TRABAJO DE GABINETE}

Las tareas de gabinete se llevaron a cabo durante todo el proceso de tesis doctoral. Estas consistieron en dos tipos de actividades principales: La recopilación, lectura y análisis bibliográfico y cartográfico, y el análisis, interpretación y representación (textual, cartográfica, gráfica) de los datos obtenidos durante los trabajos de campo. Estas actividades se complementaron en forma permanente, y para ellas se utilizaron programas informáticos con diferentes utilidades (procesadores de texto, de diseño gráfico, programas SIG, programas específicos).

\subsubsection{Recopilación bibliográfica.}

Como punto de partida en la investigación del proyecto, se realizó una recopilación y lectura crítica de la bibliografía referente a la zona de estudio (estratigrafía, estructura y tectónica regional) y a la temática específica de geología estructural (estudio estructural de diaclasas, fallas y pliegues). Esta tarea se desarrollo durante todo el trabajo de tesis doctoral.

\subsubsection{Organización y centralización de la información cartográfica y satelital.}

Con el objetivo de facilitar el manejo y visualización de mapas y cartas geológicas, las mismas fueron digitalizadas con un scanner y cargadas en el programa ArcGIS 9.2 ${ }^{\circledR}$ (Sistema de Información Geográfico), para su posterior georreferenciación espacial y edición a diferentes escalas. De la misma forma se procedió con los mapas publicados por diferentes autores y con las imágenes 
satelitales descargadas desde Google Earth ${ }^{\circledR}$ (Figura 3.3). De esta forma se contó con una base cartográfica-satelital para su análisis e interpretación, que sirvió como herramienta de partida para la posterior confección de mapas de detalle.

La empresa PLUSPETROL S.A. suministró una imagen satelital de alta definición (50 cm de pixel).

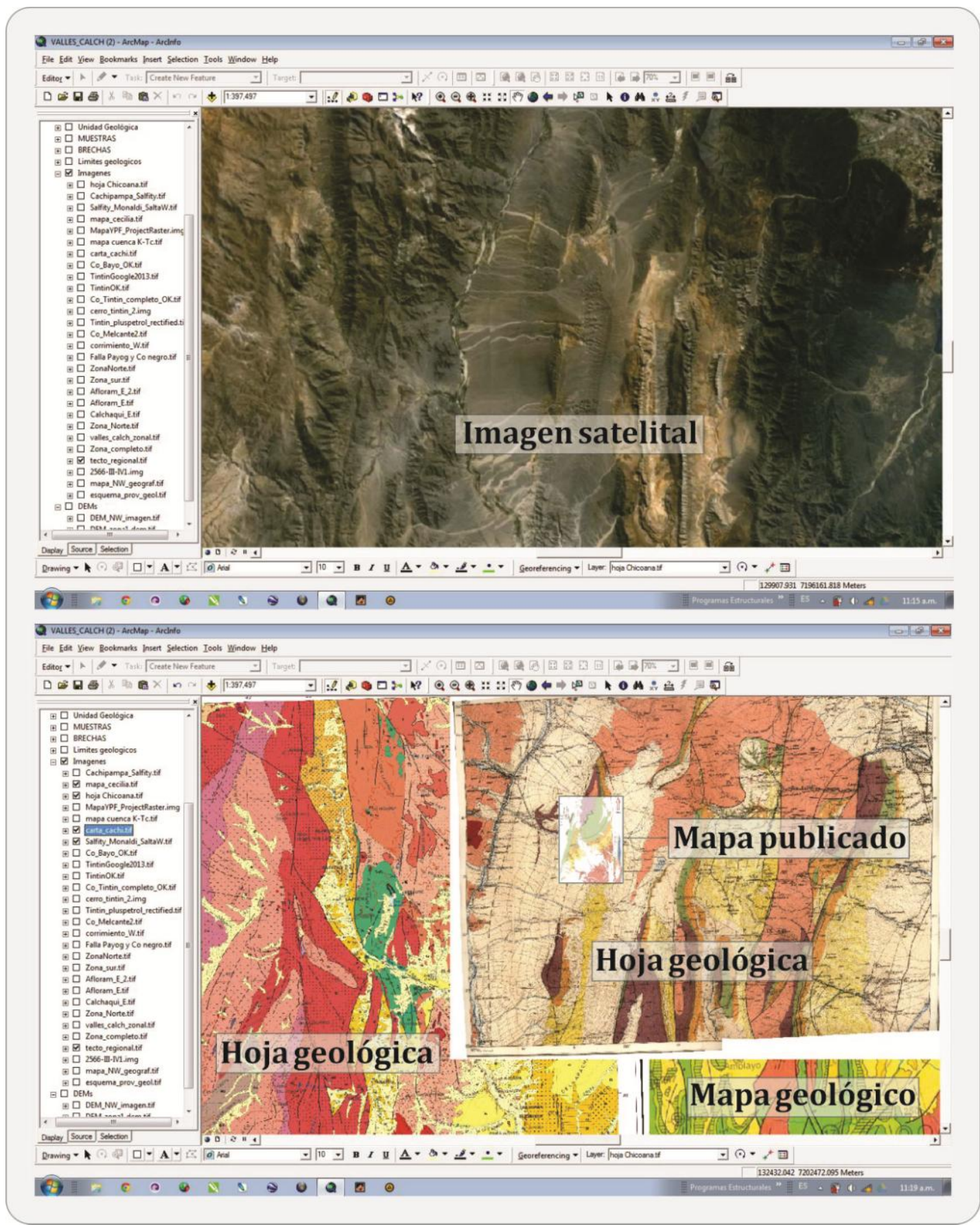

FIGURA 3.3. Recopilación y visualización de en ArcGIS $9.2^{\circledR}$ de imágenes satelitales, hojas y mapas geológicos y mapas publicados. 


\subsubsection{Confección de mapa geológico}

La confección de mapas fue una tarea continua a lo largo del proyecto, avanzando en su precisión en conjunto con las tareas de mapeo de campo. Esto se realizó con el programa ArcGIS 9.2 ${ }^{\circledR}$, integrando los mapas previos (sección 3.2.1) con los datos de GPS y respectivas descripciones de campo. El resultado de este trabajo son diferentes mapas geológicos de diversas escalas.

\subsubsection{Análisis de datos estructurales.}

Los datos estructurales de campo, medidos en Rbz, fueron procesados $\mathrm{y}$ analizados con los programas estereográficos Stereonet $9{ }^{\circledR}$, GEOrient ${ }^{\odot}$ y GEOcalculator ${ }^{\circledR}$.

Análisis de orientación de capas: Los datos de Rbz obtenidos de cualquier tipo de superficie fueron tratados y ploteados en diagramas estereográficos de proyección equiangular sobre el hemisferio inferior.

Análisis geométrico de pliegues: Partiendo de los datos de Rbz de los flancos medidos y mediante técnicas de proyección estereográfica (equiangular, hemisferio inferior), se pudo determinar la orientación de ejes de pliegue y de planos axiales, como así también el valor del ángulo interflanco (Figura $3.4 \mathrm{a})$.

Análisis geométrico de fallas: Se calculó el rake para las superficies de falla que contenían lineaciones (estrías o minerales de calcita) en su plano, con el objetivo de determinar la cinemática de los bloques. El mismo análisis se utilizó para cizalla interestratal (Figura 3.4b). Se utilizó el programa GEOcalculator ${ }^{\circledR}$.

Análisis de fracturas: Los datos de orientación de fracturas recolectados con los métodos de selección y de cantidad, fueron procesados y analizados con los programas estereográficos Stereonet $9^{\circledR}$ y GEOrient ${ }^{\circledR}$. Los datos ingresados fueron rotados a una posición que representa el estrato original horizontal (utilizando el Rbz de la capa medida). De esta forma se puede 
determinar la orientación de los planos de fracturas antes de que el estrato fuera afectado por el plegamiento (Tavani et al., 2011a; Tavani et al., 2011b). Los diagramas resultantes del ploteo de los datos se muestran como diagramas estereográficos de planos de fracturas (equiangular, hemisferio inferior), diagramas de rosas con orientaciones de trazas $\left(10^{\circ} \mathrm{de}\right.$ rango azimutal), y diagramas de contornos (equiareal, hemisferio inferior, intervalo de 5\%) para polos de fracturas recolectadas mediante scan line (Figura 3.4c).

Los datos procesados se exportaron en formato de imagen para su visualización.

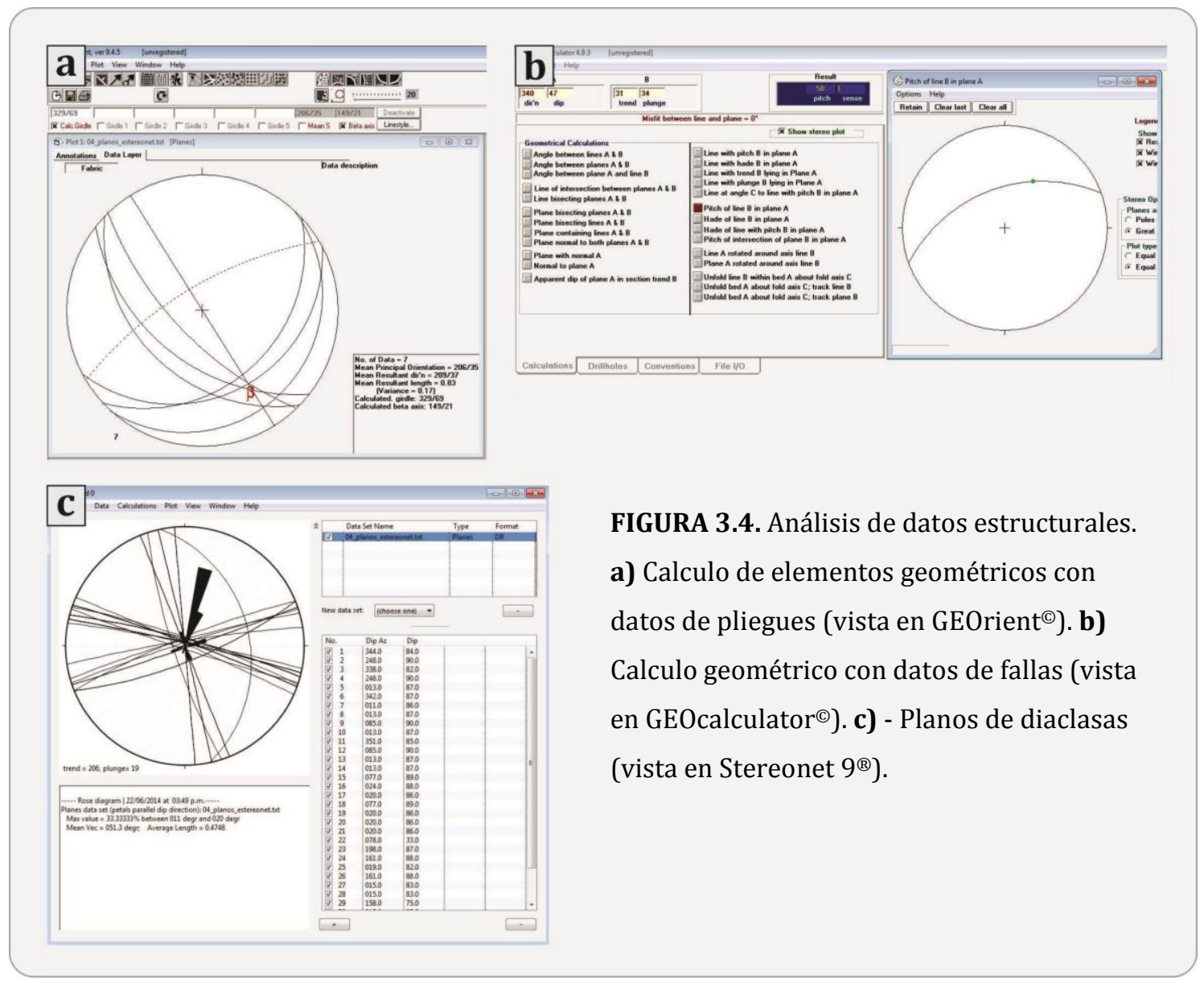

\subsubsection{Análisis de scan lines.}

Las orientaciones de las fracturas atravesadas por el scan line se procesaron y analizaron con los programas estereográficos Stereonet $9^{\circledR}$ y GEOrient ${ }^{\circledR}$. Del procesado resultaron los diagramas estereográficos y diagramas de contornos 
(intervalo de $2 \%$ y con corrección de Terzaghi) de los datos. A partir de estos se discriminaron los principales grupos de fracturas con sus respectivas orientaciones. Para cada set de orientaciones de fracturas se obtuvo el espaciado (entre cada fractura individual y el promedio) y la frecuencia (cantidad de fracturas por unidad de longitud: $\mathrm{F}=\mathrm{n}^{\circ}$ fracturas/longitud el scan line). Para obtener el espaciado y la frecuencia real es necesario que la orientación del scan line sea perpendicular a los sets de fracturas. Dadas las dimensiones longitudinales de los afloramientos, la dirección del scan line solo se pudo realizar en forma paralela al rumbo de la capa. Es por eso que se aplicó una corrección para obtener el espaciado real y el número de fracturas real, a través de la formula:

$$
\mathbf{N}=\mathbf{n} / \operatorname{seno} \phi
$$

Donde $\mathbf{N}$ es el número real de fracturas, $\mathbf{n}$ es el número medido de fracturas y $\phi$ el ángulo entre la dirección del scan line y la dirección del set de fracturas (Figura 3.5).

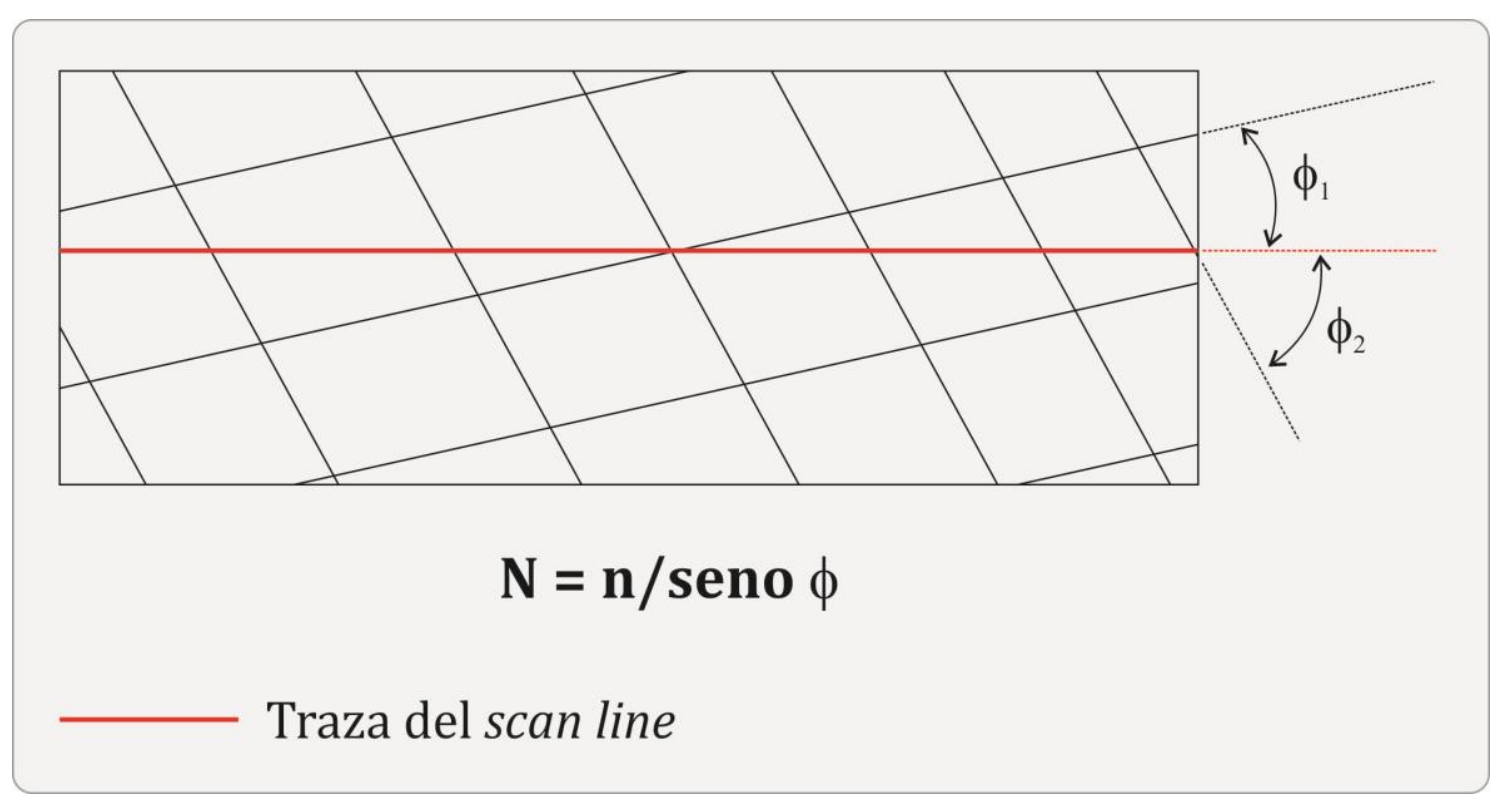

FIGURA 3.5. Corrección aplicada a los datos medidos mediante el método de scan line.

\subsubsection{Perfiles estructurales.}

Los datos recolectados en las transectas de campo (Rbz de capas, contactos entre unidades geológicas y estructuras aflorantes) se usaron para reconstruir perfiles geológicos a diferentes escalas. Estos perfiles verticales muestran las 
relaciones geológico-estructurales entre la geología de superficie y de subsuelo. Los mismos se realizaron con la ayuda del programa $\mathrm{MOVE}^{\circledR}$, suministrado por la empresa Midland Valley Exploration Ltd. (Figura 3.6).

\subsubsection{Análisis microscópico.}

Se obtuvieron cortes delgados a partir de las muestras de roca orientadas recolectadas en el campo, para observar la relación entre la deformación frágil de microescala con la mesoesacla (fracturas de afloramiento).

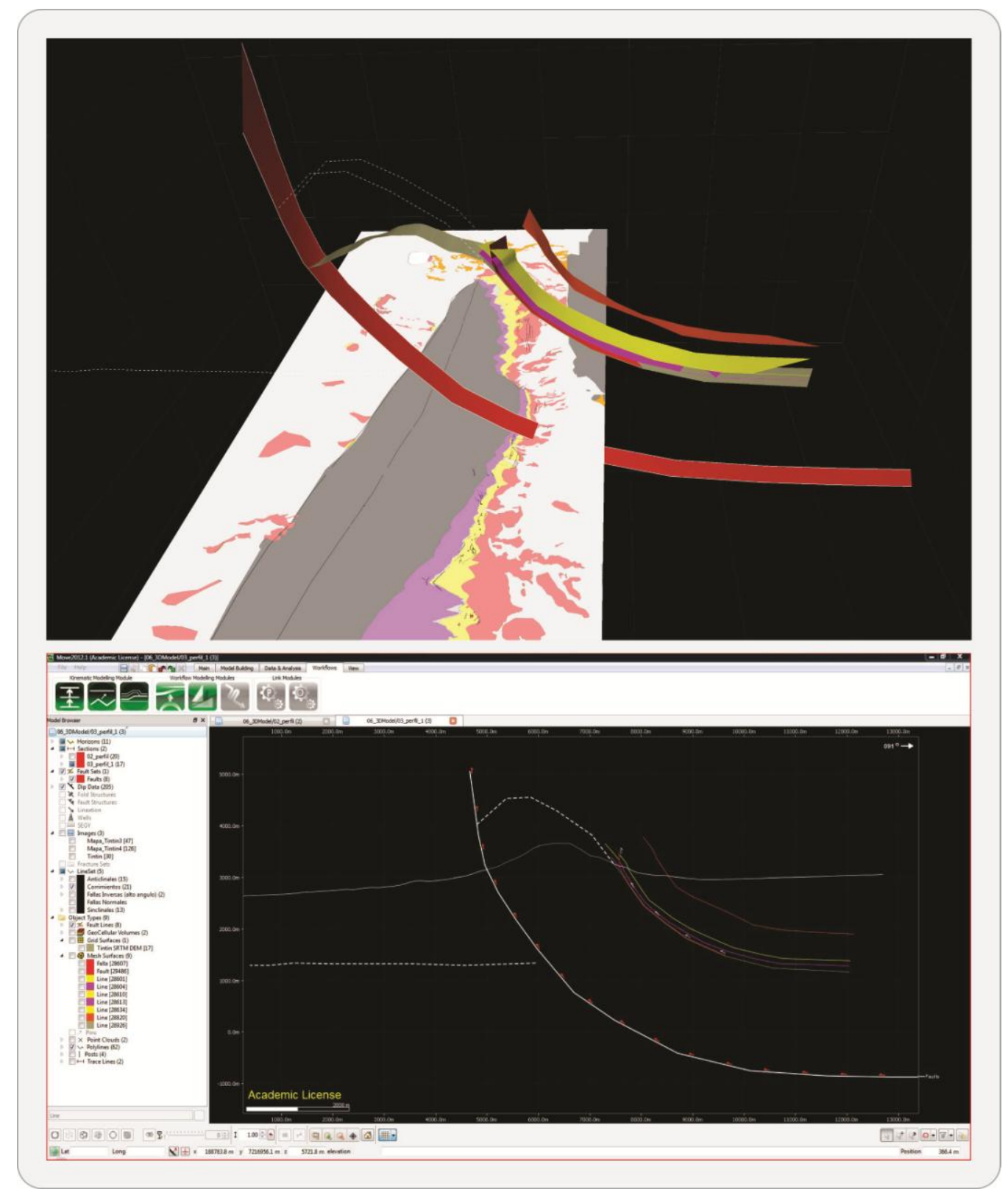

FIGURA 3.6. Reconstrucción de transectas geológicas. Visualización en 2D (abajo) y 3D (arriba). 


\section{CAPÍTULO 4 GEOLOGÍA ESTRUCTURAL DEL ÁREA DE ESTUDIO}




\section{CAPITULO 4 - GEOLOGIA ESTRUCTURAL DEL AREA DE ESTUDIO}

El área de estudio se caracteriza por la presencia pliegues anticlinales y sinclinales y fallas inversas de gran escala que estructuran y deforman la estratigrafía de la región. Al analizar la fisiografía del área en mapas e imágenes satelitales se observa que las orientaciones de estas estructuras son N-S, NNE-SSW y NNW-SSE, y tienen longitudes desde $10 \mathrm{~km}$ hasta más de $40 \mathrm{~km}$, con resaltos topográficos de 300 a 800 metros, conformando los característicos cerros y valles de la zona. El área presenta grandes exposiciones de basamento en su sector Norte, generalmente aflorando en el núcleo de los anticlinales, mientras que en el sector Sur del área predominan los afloramientos del relleno sedimentario por sobre los de basamento. En cada uno de estos sectores se encuentran los cerros estudiados y descriptos en este apartado: el Cerro Tin Tin (anticlinal Tin Tin) en el sector Norte y el Cerro Bayo (anticlinal Cerro Bayo) en el sector Sur (Figura 4.1).

La figura 4.2a muestra un perfil geológico local construido a partir de datos de orientación de capas y contactos entre unidades en superficie, de orientación aproximada E-W a la latitud de $25^{\circ} 07^{\prime} 40^{\prime \prime} \mathrm{S}$, donde se ubica el anticlinal Tin Tin y otras estructuras de la zona (Figura 4.1 - perfil Norte). Se puede observar que en el Cerro Tin Tin y hacia el Oeste afloran los Subgrupos Pirgua, Balbuena y Santa Bárbara del Grupo Salta y los depósitos terciarios, mientras que hacia el Este del cerro, solo afloran los Subgrupos Balbuena y Santa Bárbara, que se depositan directamente sobre el basamento. La figura $4.2 \mathrm{~b}$ es un corte regional E-W, construido con la misma metodología que el perfil anterior, a la latitud del Cerro Bayo ( $\left.25^{\circ} 24^{\prime} 50^{\prime \prime} \mathrm{S}\right)$, donde se puede ver los pliegues anticlinales y sinclinales de la zona. La geometría puntiaguda de los pliegues y la inclinación de las fallas es la solución geométrica del software para una determinada distribución de datos de Rbz (Nótese la geometría redondeada del anticlinal Cerro Bayo que implica un mayor número de datos).

Los anticlinales Tin Tin y Cerro Bayo presentan características estratigráficas y estructurales propias del sector donde se ubican, tanto a escala macro como meso (anticlinal principal y estructuras dentro del mismo, respectivamente). El presente trabajo se enfocará principalmente en el anticlinal 
Tin Tin, considerando al anticlinal Cerro Bayo como objeto de estudio complementario y comparativo.

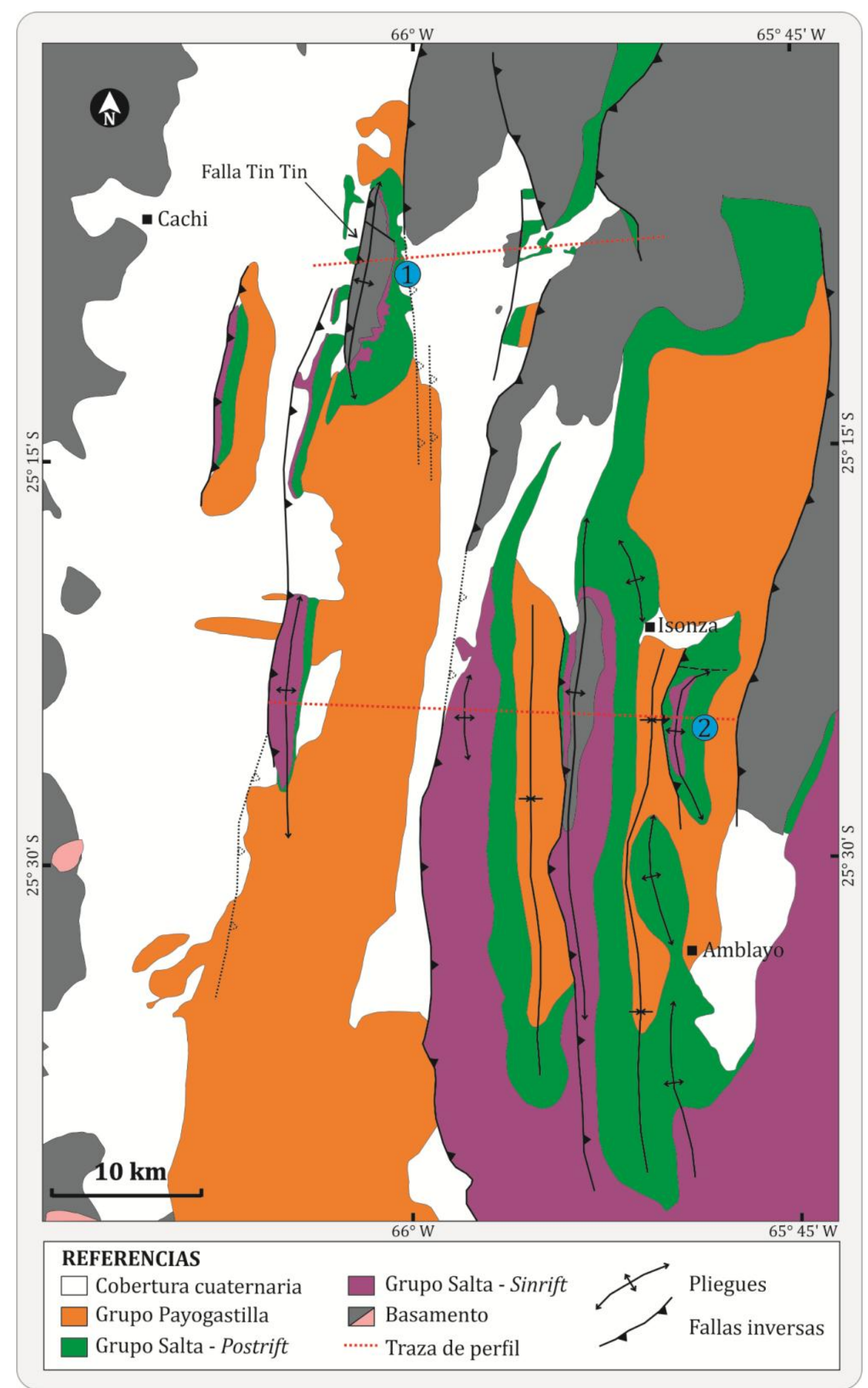

FIGURA 4.1. Mapa geológico del área de estudio (sector central del Valle Calchaquí; simplificado de Carrera y Muñoz, 2013; del Papa et al., 2013a). Se muestran los anticlinales estudiados y la traza de los perfiles geológicos confeccionados. 1) Anticlinal Tin Tin. 2) Anticlinal Cerro Bayo. 

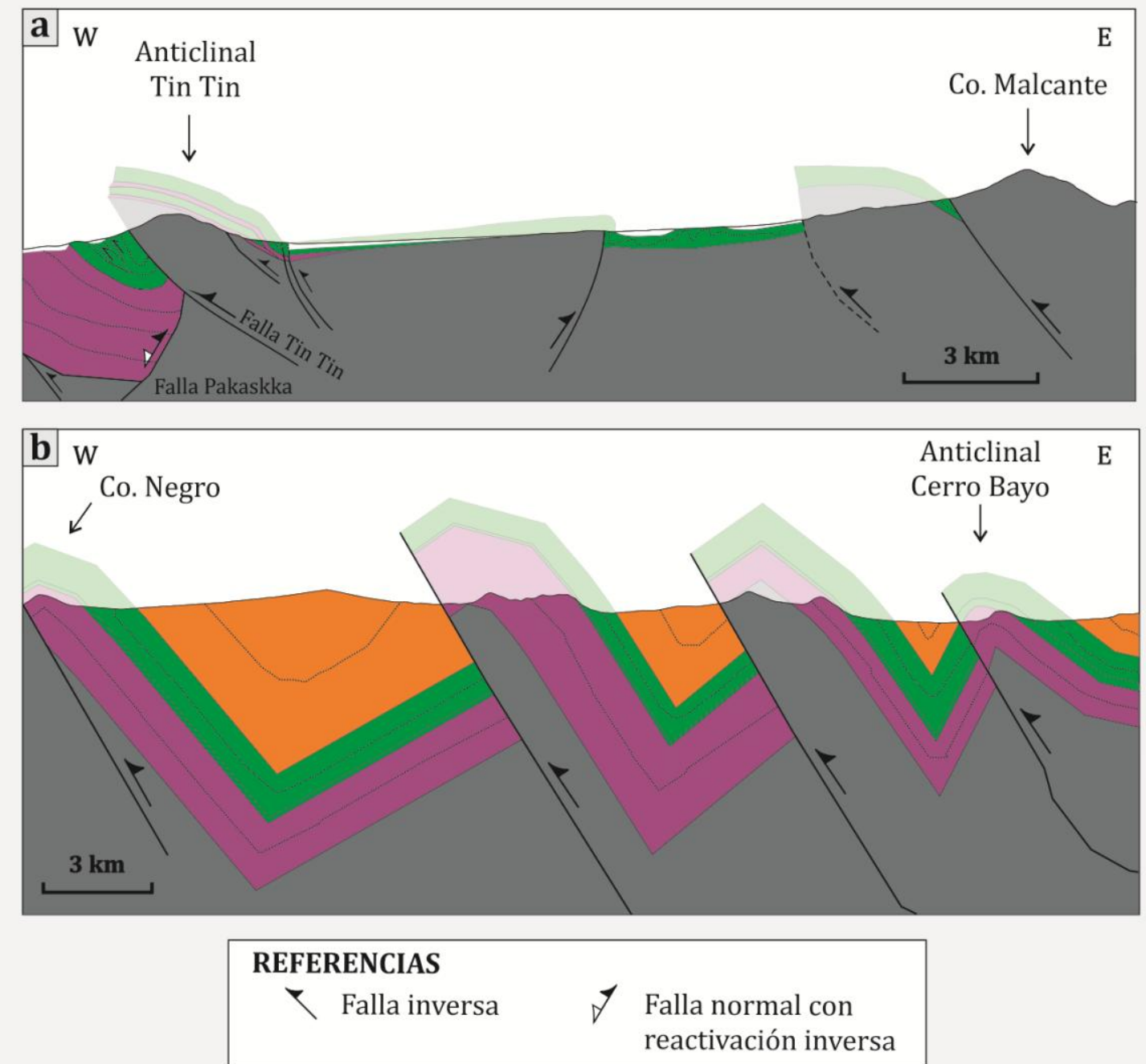

FIGURA 4.2. Perfiles geológicos zonales construidos sobre las transectas mostradas en la figura 4.1. a) Perfil a la latitud del anticlinal Tin Tin (sector al Oeste del anticlinal Tin Tin, tomado de Carrera y Muñoz, 2013). b) Perfil a la latitud del anticlinal Cerro Bayo.

\subsection{Anticlinal Tin Tin}

El Cerro Tin Tin es un bloque de basamento levantado por una falla inversa, la Falla Tin Tin (Figura 4.1 y 4.2a), que lo flanquea por su vertiente occidental. Este bloque levantado, junto con la cobertura sedimentaria plegada suprayacente, conforman el anticlinal Tin Tin, un pliegue de orientación NNE-SSW con $13 \mathrm{~km}$ de longitud en esta dirección, y un ancho en dirección E-W que varía entre 3,5 km en su parte Sur y casi $2 \mathrm{~km}$ en su extremo Norte. El bloque de basamento posee una asimetría hacia el Oeste (Figura 4.2a), confiriéndole al flanco frontal (occidental) del anticlinal una mayor inclinación de las capas sedimentarias que al flanco dorsal 
(oriental). Presenta inmersión en ambos extremos, y en su mitad Norte es atravesado por una falla de dirección NW-SE que en planta lo desplaza sinestralmente. La figura 4.3 muestra un mapa del anticlinal Tin Tin donde se observan esquemáticamente las estructuras visibles a la escala del anticlinal.

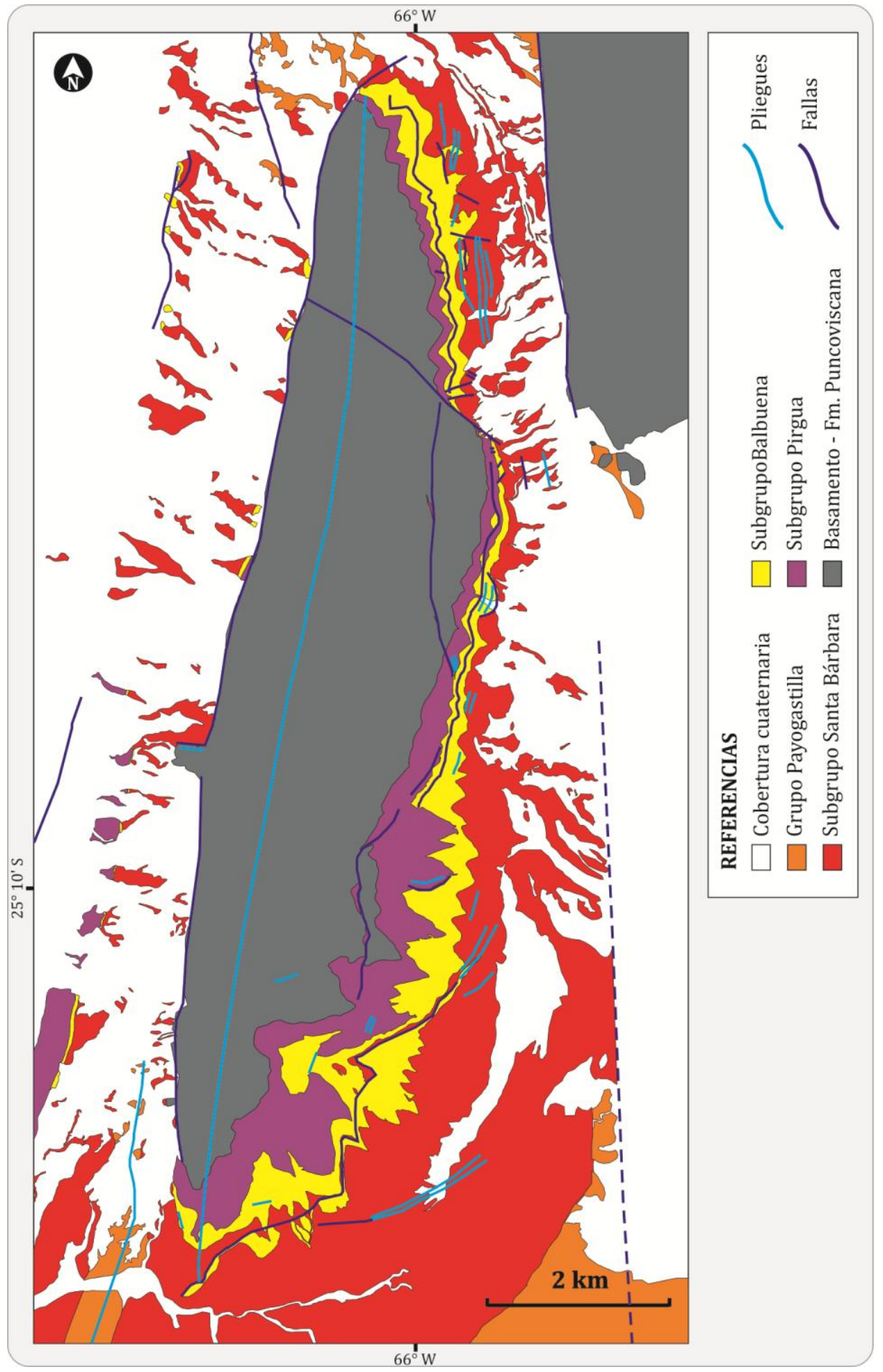

FIGURA 4.3. Mapa geológico de detalle del anticlinal Tin Tin (Nótese el cambio en las referencias estratigráficas). Se muestran esquemáticamente los pliegues y fallas principales que afectan al basamento y a la cobertura sedimentaria. 
Este tipo de plegamiento puede ser clasificado como un pliegue forzado (forced folds, drape folds), siguiendo la definición de (Stearns, 1978) que los define como aquellos pliegues en los cuales su orientación y forma final son dominadas por la forma del miembro forzante inferior. En este caso, el ascenso de un bloque de basamento, hizo que la cobertura sedimentaria se adapte y adquiera su forma y geometría general.

Estratigráficamente, el anticlinal Tin Tin está conformado por un núcleo de metamorfitas de muy bajo grado (Formación Puncoviscana) sobre las cuales se apoyan las secuencias sedimentarias correspondientes a los Grupos Salta (Cretácico-Paleógeno) y Payogastilla (Cenozoico). Esta cobertura sedimentaria aflora principalmente en la vertiente oriental y en el extremo Sur del cerro, preservada casi en su totalidad, mientras que en la vertiente occidental el flanco frontal se encuentra mayormente erosionado y cubierto, dejando afloramientos aislados de las unidades del Grupo Salta. En algunos casos en este flanco se observa una fuerte deformación debida a la actividad de la falla principal (Falla Tin Tin). La charnela del pliegue está expuesta únicamente en el extremo Sur del cerro y presenta una geometría redondeada. En esta posición, donde se produce la inmersión del eje de pliegue, se puede observar la asimetría del plegamiento de clara vergencia occidental, y se puede determinar la orientación del eje y del plano axial ya que cuenta con sus dos flancos. El flanco frontal en este sector Sur inclina desde $35^{\circ}$ hacia el W-SW en capas cercanas a la charnela, hasta capas volcadas en posiciones más alejadas a la misma (Figura 4.4d), mientras que en el flanco dorsal la inclinación de las capas varía desde $6^{\circ}$ hasta $36^{\circ}$ y más, promediando los $30^{\circ}$, con direcciones de inclinación hacia el E, SE y S (Figura 4.4e). Las inclinaciones de las capas sedimentarias a lo largo de todo el flanco dorsal no son uniformes, sino que presentan un gran abanico de valores debido a que se encuentran dominadas por estructuras que deforman el flanco, principalmente en el Grupo Salta (Figura $4.4 \mathrm{a}-\mathrm{b}-\mathrm{c})$.

La orientación del eje de pliegue para este sector de inmersión Sur se determinó a partir de las mediciones de Rbz en las capas sedimentarias de ambos flancos, principalmente en los Subgrupos Balbuena y Santa Bárbara (Figura 4.4de). Estas mediciones arrojan un valor de Rbz de $162^{\circ} / 19^{\circ}$ para el eje del anticlinal 
Tin Tin en su extremo de inmersión Sur (Figura 4.4f). Datos individuales del eje de pliegue medidos en la zona charnelar arrojan valores de Rbz de $199^{\circ} / 26^{\circ}$ y $187^{\circ} / 30^{\circ}$. Puede notarse como el eje de pliegue del anticlinal cambia su orientación desde su dirección general NNE-SSW (inferido por la geometría del pliegue) a una dirección S a SSE en su extremo Sur (Figura 4.3). La superficie axial, determinada a partir de los mismos datos de capas sedimentarias, arrojó un valor promedio de Rbz de $73^{\circ} / 75^{\circ}$ (Figura $4.4 f$ ).

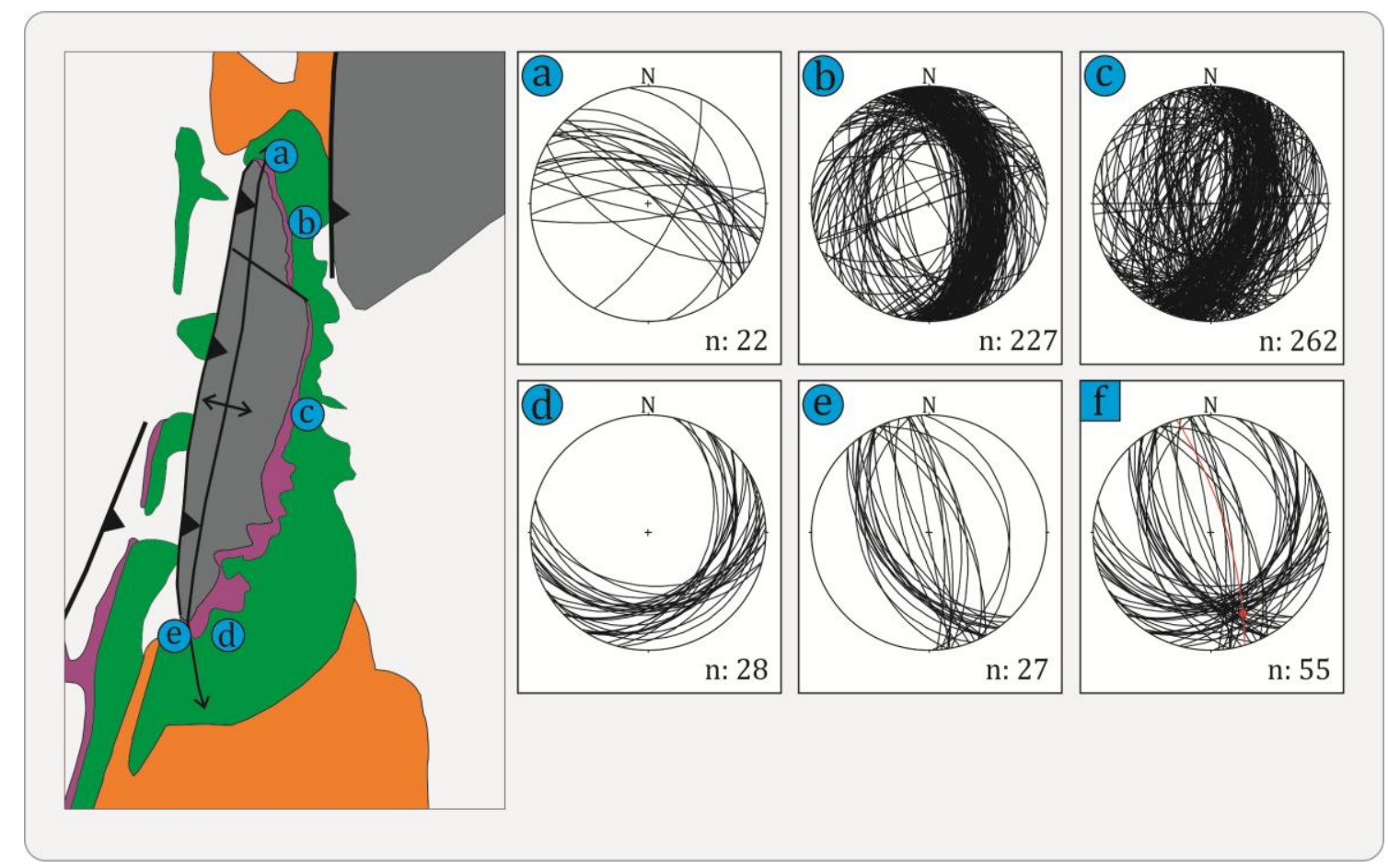

FIGURA 4.4. Diagramas estereográficos de la orientación de las capas a lo lago de los flancos del anticlinal Tin Tin. a) Flanco dorsal en el sector de inmersión Norte. b) Flanco dorsal en el sector Norte del cerro. c) Flanco dorsal en el sector central del cerro. d) Flanco dorsal en el sector de inmersión Sur del anticlinal. e) Flanco frontal en el sector de inmersión Sur del anticlinal. f) Eje de pliegue y plano axial a partir del punto d) y el punto e).

\subsubsection{Características mesoestructurales}

Cambiando la escala de observación a una de mayor detalle, las diferentes partes del anticlinal (núcleo, flanco dorsal y frontal, extremos de inmersión) contienen estructuras propias de deformación que evidencian los procesos que tuvieron lugar durante el crecimiento de la estructura principal. Estas estructuras se describirán por sectores para una mejor organización y comprensión de la 
deformación a lo largo de todo el anticlinal Tin Tin. Las divisiones son las siguientes:

- Núcleo: Se describen las estructuras del basamento aflorante en el Cerro Tin Tin y la falla NW-SE que lo desplaza sinestralmente.

- Vertiente occidental: Se describe la Falla Tin Tin y los afloramientos aislados de la cobertura sedimentaria.

- Vertiente oriental: Se describen las estructuras del flanco dorsal del anticlinal. Este incluye la cubierta sedimentaria de la parte central y Norte del cerro (al Norte y Sur de la falla NW-SE).

- Inmersión Sur: Se describen las estructuras del flanco frontal y flanco dorsal correspondientes al extremo Sur del anticlinal.

\subsubsection{Núcleo}

\section{A) Basamento del núcleo del anticlinal Tin Tin}

El núcleo del anticlinal Tin Tin está conformado por depósitos deformados y levemente metamorfizados de la Formación Puncoviscana. Estos conservan, en general, la estratificación sedimentaria original y por lo tanto, la orientación de sus capas (Rbz) puede ser obtenida. La figura 4.5 muestra los datos de Rbz medidos en el basamento y su ubicación discriminada por cuadrantes en el cerro. En el cuadrante Norte del basamento, los rumbos de las capas son E-W a ENE-WSW y NW-SE. En el cuadrante medio se obtuvieron rumbos E-W a ENE-WSW y NW-SE a N-S. En el cuadrante Sur, los rumbos de las capas son ENE-WSW a NE-SW y NW-SE.

El basamento contiene estructuras de diferentes escalas, desde fracturas pervasivas de centímetros de longitud, muchas veces utilizadas como conductos para fluidos, hasta fallas y pliegues de decenas de metros hasta kilómetros de longitud en sus trazas. 


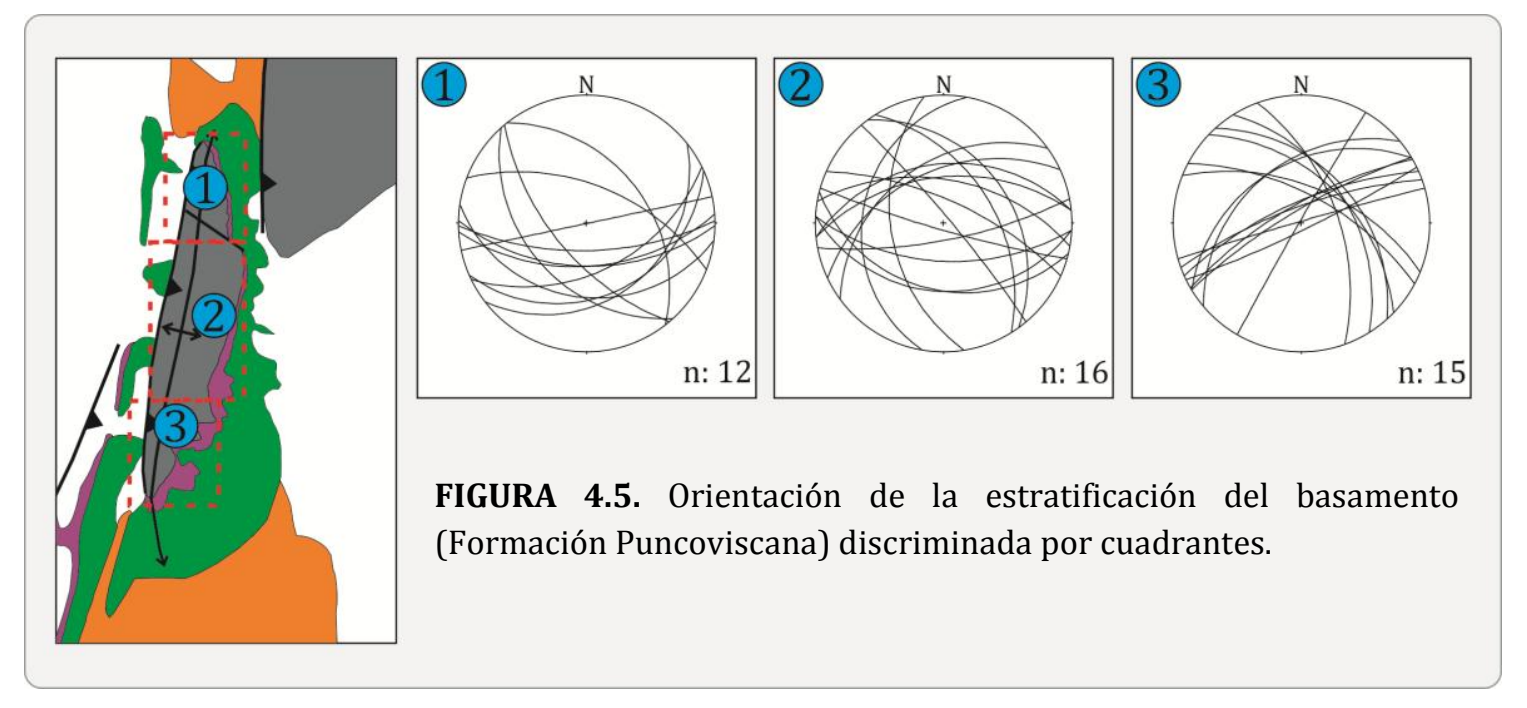

Pliegues en el basamento del núcleo del anticlinal Tin Tin

En el extremo Norte del cerro se midieron dos pliegues contiguos, un anticlinal y un sinclinal. Estos presentan flancos rectos y charnelas agudas, con longitud de onda (incluye ambos pliegues) de 20 metros (Figura 4.6a y d). Presentan ejes de pliegue de orientación E-W, con leve inclinación al Este, y superficies axiales con fuerte inclinación al Sur, clasificados como pliegues cerrados por su ángulo interflanco. En una capa del flanco Sur del sinclinal se midió un estriado con dirección Norte (rake $84^{\circ} \mathrm{W}$ ), indicando que el deslizamiento entre capas es uno de los mecanismos de formación del pliegue. Asociado al pliegue sinclinal hay un dique de material carbonático con clastos angulosos de basamento, de 50 centímetros de espesor y Rbz $179^{\circ} / 66^{\circ}$ (Figura 4.6e). En asociación con el anticlinal se midió una falla inversa de Rbz $175^{\circ} / 64^{\circ}$ de escala métrica, originada en el basamento y afectando a la base del Subgrupo Pirgua.

En el sector Sur del cerro se midió un sinclinal con similares características geométricas pero de escala mayor a los anteriores (150 m es la media longitud de onda). El Rbz de su eje de pliegue es $70^{\circ} / 49^{\circ}$, con un plano axial de $\mathrm{Rbz} 14^{\circ} / 64^{\circ} \mathrm{y}$ ángulo interflanco de $78^{\circ}$ que lo clasifica como un pliegue abierto (Figura 4.6b). 

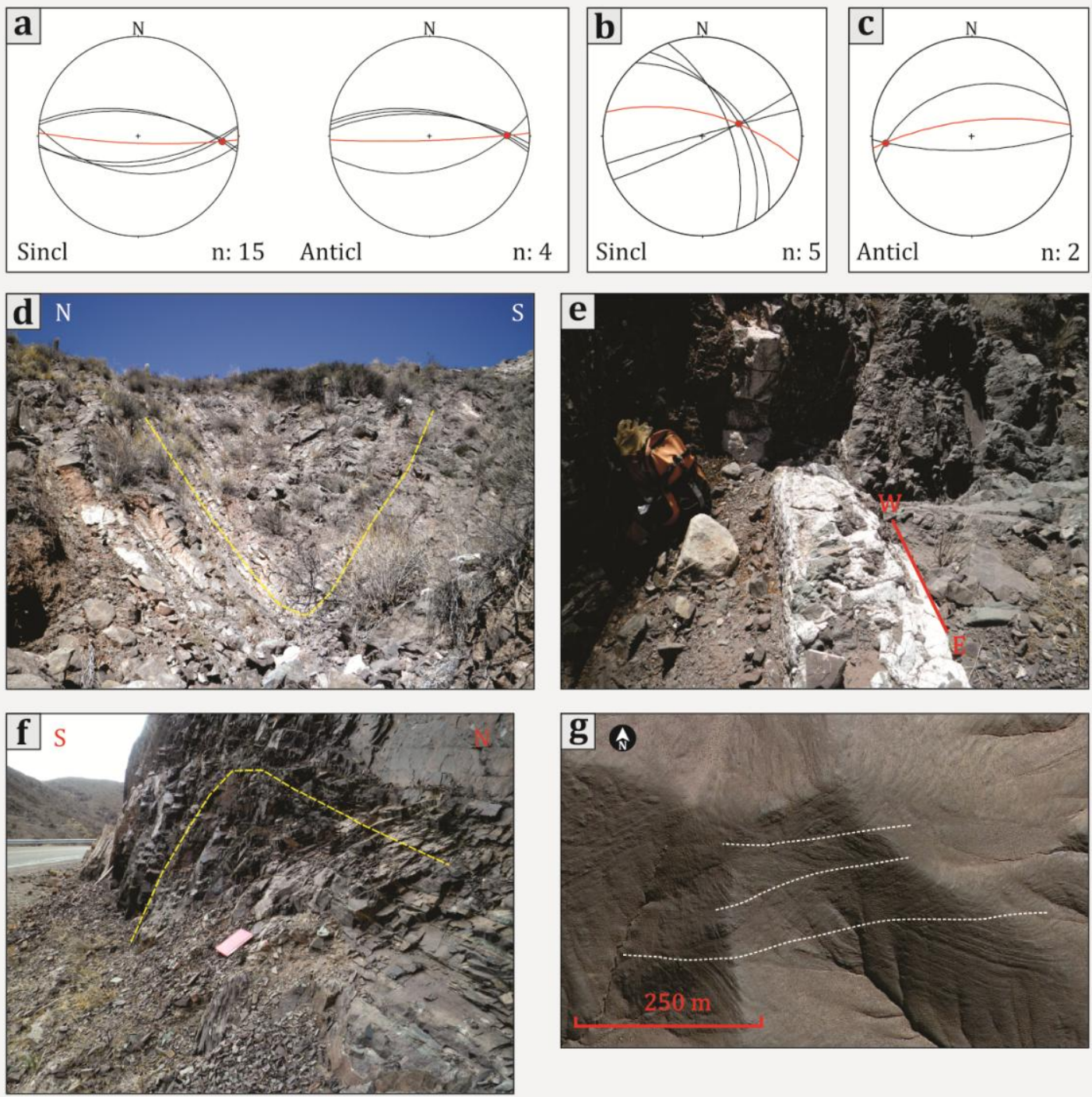

FIGURA 4.6. Pliegues en el basamento del núcleo del anticlinal Tin Tin y en otros sitios del área.

En la serranía de Cajoncillo (véase Figura 1.3), un bloque de basamento al Este del Cerro Tin Tin (Figura 4.6c y f), en el corte de la ruta provincial $\mathrm{n}^{\circ} 33$, se midió un pliegue anticlinal, de metros a decenas de metros de longitud de onda, con orientación y características similares a los del Norte del Cerro Tin Tin. La medición de los flancos arrojó un valor de $\mathrm{Rbz}$ de $266^{\circ} / 8^{\circ}$ para el eje de pliegue, $\mathrm{Rbz} 353^{\circ} / 71^{\circ}$ para su plano axial, con $71^{\circ}$ de ángulo interflanco (pliegue abierto).

Por último, como se puede ver en las imágenes satelitales (Figura 4.6g), muchos afloramientos importantes de basamento en esta región presentan plegamiento. Con diferencias en escala (longitud de onda), se pueden ver 
estructuras con características geométricas similares a los medidos en el Cerro Tin Tin, con superficies axiales y ejes de pliegue con orientación aproximada E-W.

Fallas en el basamento del núcleo del anticlinal Tin Tin

El núcleo de basamento del anticlinal Tin Tin está afectado por fallas inversas de gran escala con transporte hacia el Oeste, que sobrecorren al basamento sobre sí mismo, o en ocasiones, sobre depósitos basales del Subgrupo Pirgua, dejándolos atrapados dentro del basamento (Figuras 4.3 y 4.7a). En el cerro se mapearon dos de estas fallas, una en el sector Sur y otra en el sector central, de mayor magnitud, que aumentan el ancho de afloramiento del núcleo para esta parte del cerro. La orientación de sus trazas es aproximadamente paralela a la del anticlinal y alcanzan alrededor de dos a tres kilómetros de longitud (Figura 4.7a). La falla inversa del sector Sur del cerro es subparalela a las capas de Subgrupo Pirgua que sobrecorre, y presenta una inclinación de entre $25^{\circ}$ y $55^{\circ}$ hacia el ESE (Figura 4.7b). La falla del sector central del cerro presenta (en general) mayor inclinación hacia el E, con zonas de alta inclinación, hasta subvertical (Figura 4.7c). Esta última produce el plegamiento y fallamiento de la cobertura sedimentaria, involucrando al Subgrupo Pirgua principalmente, cuando atraviesa el contacto basamento-relleno. 


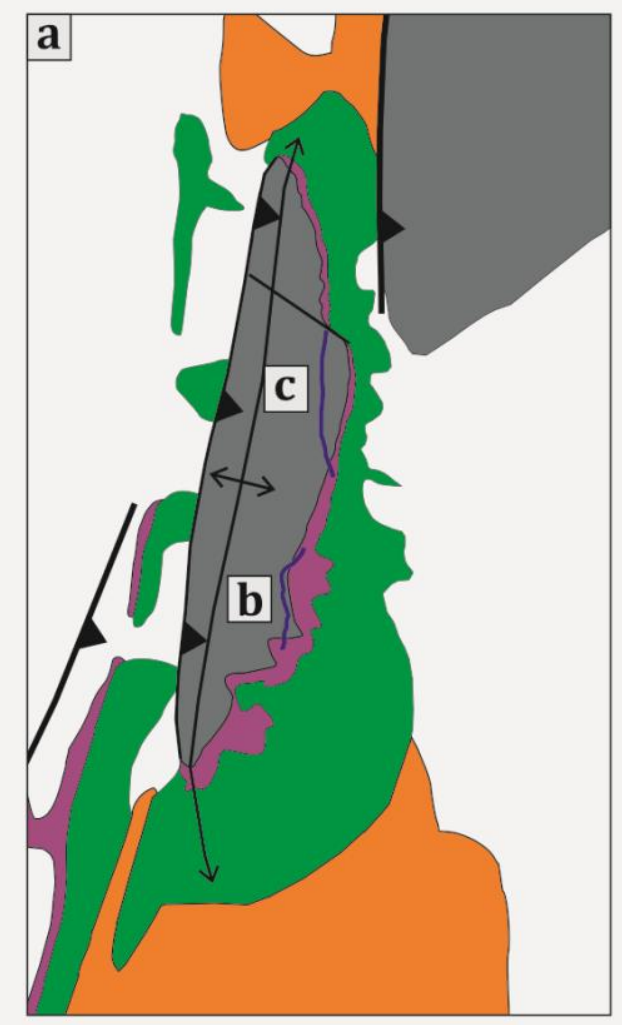

FIGURA 4.7. Fallas inversas dentro del basamento en el núcleo del anticlinal Tin Tin.
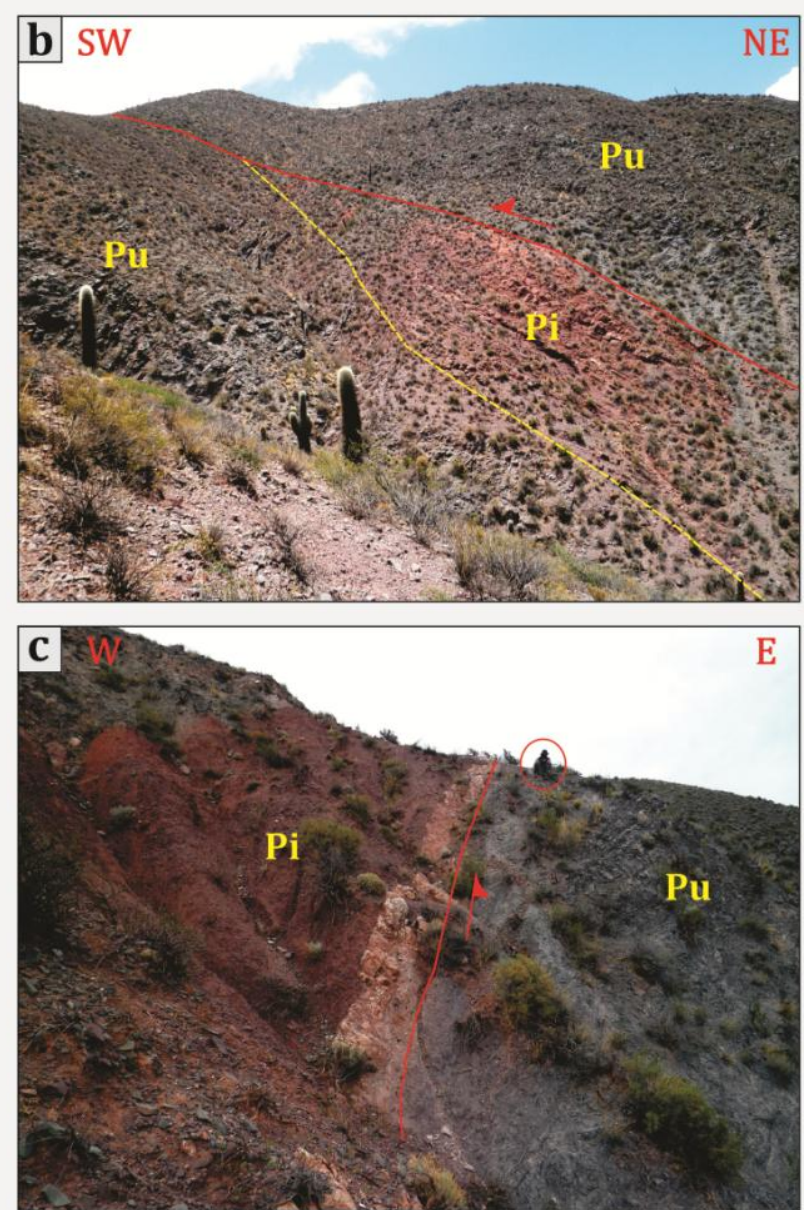

Diaclasas y venas en el basamento del núcleo del anticlinal Tin Tin

En las capas de la Formación Puncoviscana se midieron fracturas de centímetros a metros de escala. La gran mayoría de ellas son diaclasas, reconocidas por la estructura plumosa desarrollada en sus superficies (Figura 4.8b), en muchos casos con estriado (Figura 4.8d). También se pueden observar venas con relleno carbonatico ó cuarzoso (Figura 4.8c). Como muestra la figura 4.8a-e, los Rbz de sus planos se disponen en diversas orientaciones y no puede hablarse de una moda en particular. Fracturas en localidades cercanas comparten las mismas características (Figura 4.8a). 

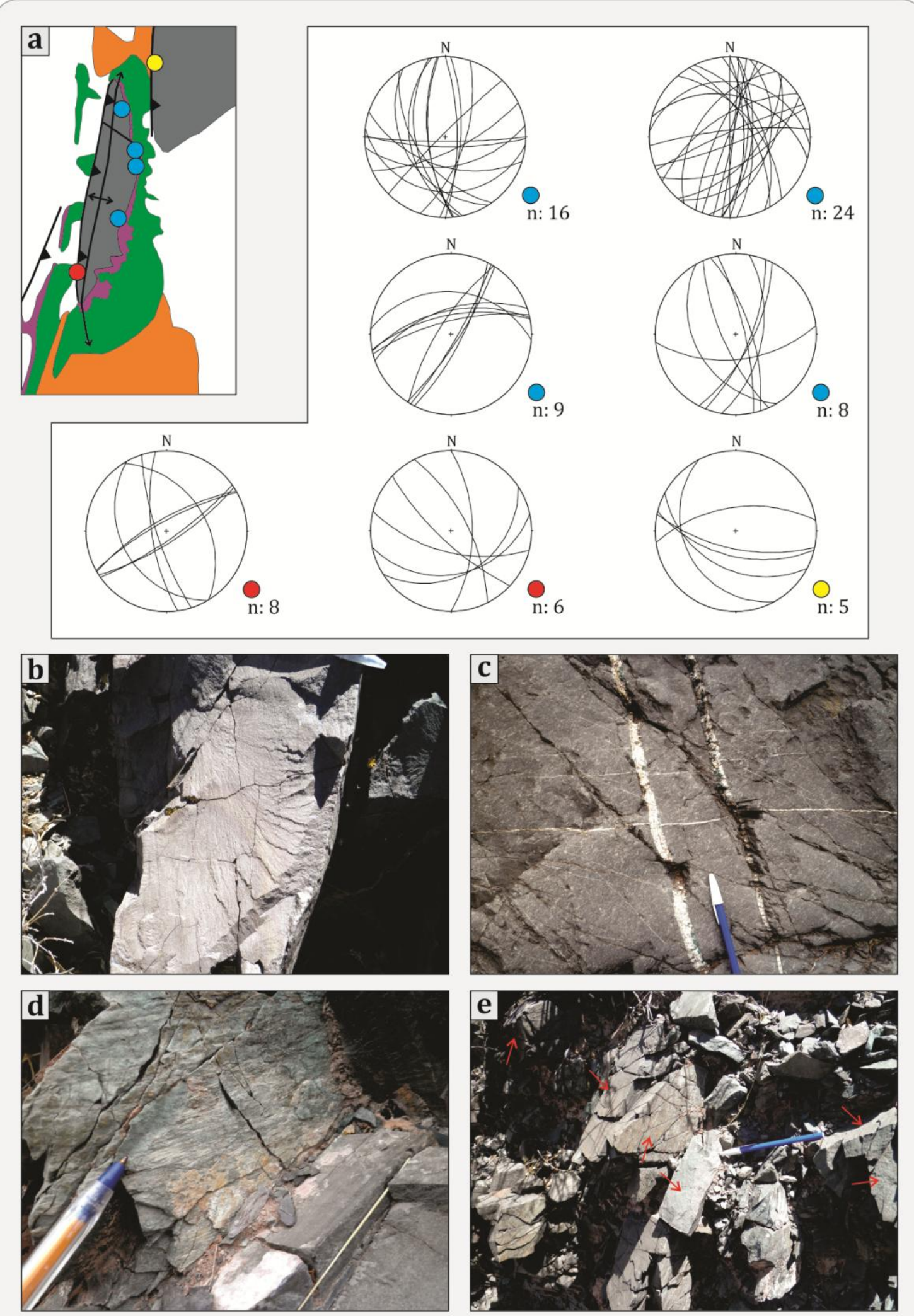

FIGURA 4.8. Diaclasas y venas del basamento en el anticlinal Tin Tin y zona aledaña. 
El anticlinal Tin Tin es cortado en la parte Norte del cerro por una falla de orientación NW-SE (azimut aproximado $\mathrm{N} 130^{\circ}$ ), que en planta muestra desplazamiento sinestral (Figura 4.3 y 4.9a). Al Sur de esta estructura, la orientación del eje del anticlinal es $\mathrm{N}^{\circ} 5^{\circ}$ (NNE-SSW) mientras que al Norte de la misma la orientación cambia a $\mathrm{N} 170^{\circ}$ (NNW-SSE). Una de las fallas inversas que afectan al núcleo, descripta anteriormente, termina contra esta discontinuidad.

A una escala de mayor detalle, dentro de la zona de falla el basamento está altamente brechado y foliado, adquiriendo una coloración violácea-azulada, con planos de foliación con $\mathrm{Rbz} 228^{\circ} / 39^{\circ}$ (orientación NW-SE, figura 4.9b). El ancho de la zona alcanza los 40 metros aproximadamente, y hacia los bordes de la misma la deformación disminuye y se concentra sólo en algunos planos donde se produce la cizalla, separando capas no deformadas (Figura 4.9c). Aquí la estratificación del basamento posee un $\mathrm{Rbz}$ de $154^{\circ} / 48^{\circ}$, comúnmente con estrías en sus techos con direcciones $\mathrm{N} 99^{\circ}$ y $\mathrm{N} 190^{\circ}$ (perpendiculares entre sí). Éstas concuerdan con la cinemática de desplazamiento sinestral de la falla de rumbo NW-SE, con capas moviéndose hacia el Este y hacia el Sur en el bloque Sur de la falla.

En el bloque Norte, la falla corta la secuencia sedimentaria en forma oblicua e invierte las capas adyacentes a la estructura (Figura 4.9a). En estos sectores aledaños a la estructura de primer orden, la secuencia sedimentaria se encuentra afectada por fallas de desplazamiento de rumbo. Dos estructuras importantes se muestran en la figura 4.9a. La falla que se encuentra más al Sur, de rumbo E-W a ENE-WSW, muestra un desplazamiento dextral de entre 10 a 20 metros y una longitud de traza visible en el terreno de 270 metros. Esta falla pone al Subgrupo Santa Bárbara en contacto lateral con el Subgrupo Balbuena, observándose un contraste debido a sus coloraciones características. Se obtuvieron dos datos de orientación de la superficie de falla, con $\mathrm{Rbz}$ de $162^{\circ} / 45$ y $181^{\circ} / 59^{\circ}$, este último con estriado de rake $29^{\circ} \mathrm{W}$ (leve componente normal, con descenso relativo del bloque Sur). Unos 120 metros al Norte de la falla anterior se encuentra la segunda estructura, con rumbo ENE-WSW (Figura 4.9a). Ésta muestra un desplazamiento dextral de aproximadamente 40 metros que se evidencia principalmente en el Subgrupo Balbuena. La longitud de su traza en el terreno alcanza los 280 metros. 
No se pudo determinar la inclinación de la superficie de falla, pero se infiere de características geométricas similares a la primera. También se midió una falla de rumbo sinestral de menor escala a las anteriores descriptas, que en planta desplaza unas capas volcadas por unos 5 metros (Figura 4.9d). El Rbz de la falla es $46^{\circ} / 62^{\circ}$ (NW-SE) y presenta un estriado de rake $82^{\circ} \mathrm{N}$, indicando una componente normal de movimiento con descenso del bloque Norte.

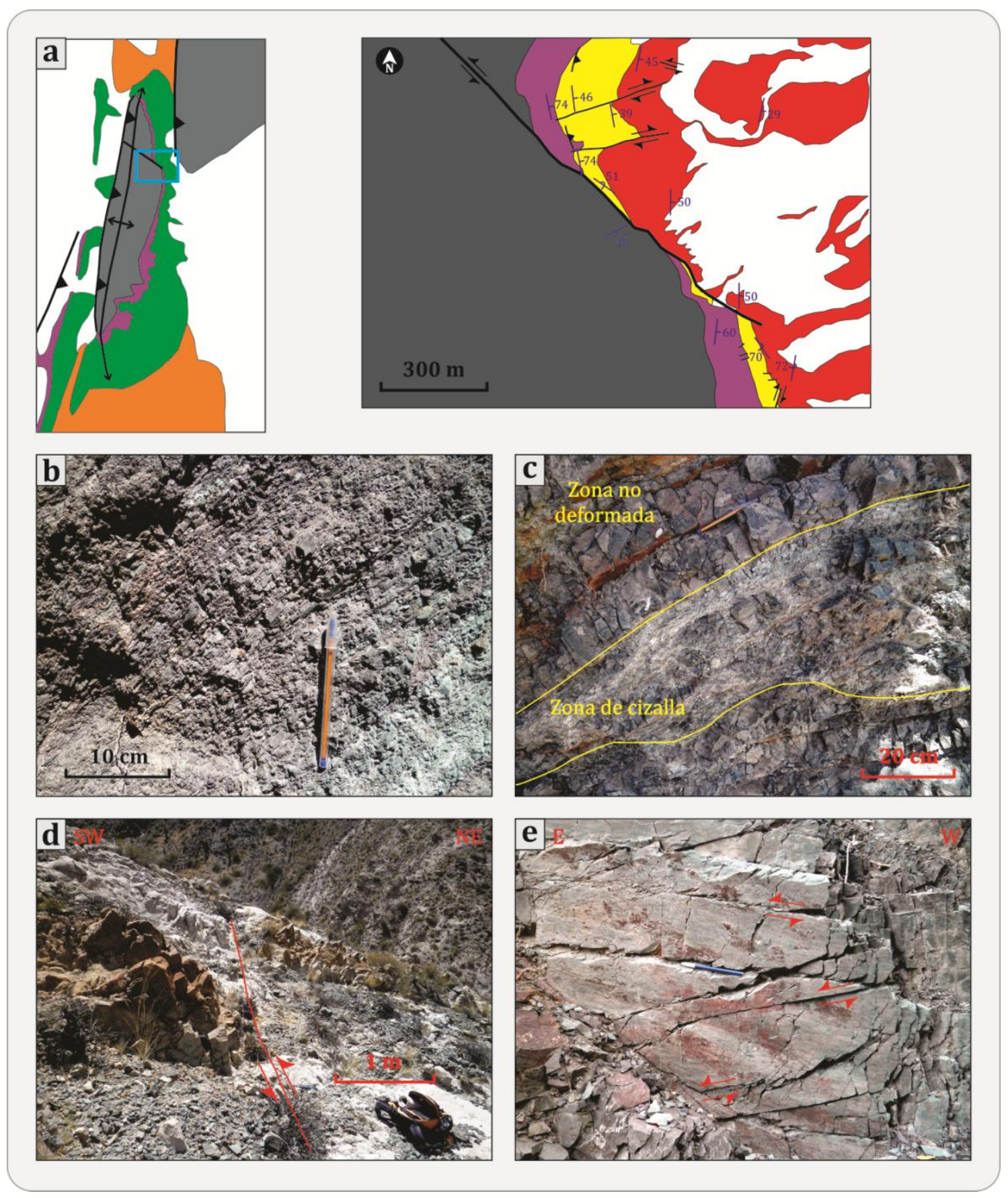

FIGURA 4.9. Zona de falla sinestral: Evidencias de su deformación. 
En el bloque Sur de la falla principal, se midieron en el basamento unas fracturas de cizalla que indican contracción en dirección SE-ESE, en coincidencia con la cinemática de la falla. Éstas se observaron en un plano vertical de rumbo EW con estrías subhorizontales (Figura 4.9e).

\subsubsection{Vertiente occidental}

\section{A) Falla Tin Tin}

La falla Tin Tin (“Falla Tin Tin Este" de del Papa et al., 2013) es la estructura principal que flanquea y levanta al Cerro Tin Tin por su vertiente occidental (Figura 4.3). Tiene un rumbo NNE-SSW, inclinación hacia el Este y cinemática inversa con transporte hacia el Oeste, opuesta a la dirección de migración del frente deformacional andino (Hongn et al., 2011). La estructura muestra desplazamientos variables a lo largo de su rumbo siendo mayor en el núcleo del anticlinal, disminuyendo hacia ambos extremos de inmersión donde el acortamiento es acomodado por pliegues apretados en la cobertura sedimentaria (del Papa et al., 2013). La falla Tin Tin sobrecorre al basamento por sobre los depósitos del Subgrupo Santa Bárbara mayormente, observándose en algunos lugares la presencia del Subgrupo Balbuena en el contacto estructural. La figura 4.10a muestra la presencia de brechas angulosas con clastos de varios centímetros de basamento y material carbonático como cemento en el contacto entre el basamento y los depósitos rojizos del Subgrupo Santa Bárbara. Este contacto tiene la orientación normal NNE-SSW, y, por la disposición de los afloramientos se infiere que el plano inclina hacia el Este con un ángulo de $40^{\circ}$ a $50^{\circ}$ (Figura $4.10 \mathrm{~b}$ ).

En la parte central del cerro se observó un contacto entre el basamento y el Subgrupo Santa Bárbara con un rumbo aproximado E-W, es decir, con alto ángulo respecto de la orientación general de la falla (Figura 4.10c). Este afloramiento presenta una zona de brechamiento intenso compuesta principalmente por clastos angulosos de varios centímetros de longitud, de la Formación Puncoviscana (Figura 4.10d-e). La zona es subvertical o con fuerte inclinación al Sur (Rbz $169^{\circ} / 75^{\circ}$ ) y tiene un ancho de 15 a 20 m (Figura 4.10e). Hacia el Sur de esta zona encontramos al basamento plegado y afectado por pequeñas fallas inversas (Figura 4.10d-f). Las capas y los ejes de estos pliegues tienen una orientación aproximada 
E-W. Estas pequeñas fallas se agrupan en dos sets, uno con $\mathrm{Rbz} 62^{\circ} / 14^{\circ}$ y otro con mayor inclinación de $\mathrm{Rbz} 113^{\circ} / 22^{\circ}$, ambos con cinemática inversa y transporte hacia el Norte. En el contacto entre el basamento plegado y la zona de brecha se pueden ver capas plegadas que se introducen en la zona de rotura con inclinación opuesta y formando un sinclinal, siendo su superficie axial el contacto entre ambas zonas (Figura 4.10g). Esto supone el plano axial pudo haber sido el plano más débil para la generación de la falla (zona de brecha), levantando el bloque Sur (basamento) con respecto al bloque Norte.

En el sector Norte del cerro se pudo observar el contacto del Subgrupo Santa Bárbara con el basamento deformado, con orientación normal NNE-SSW (Figura 4.10h). Dentro del basamento se midió una zona de cizalla con Rbz $215^{\circ} / 81^{\circ}$ de unos 20 centímetros de ancho. Al Sur de este plano el basamento se deforma, formando un pliegue anticlinal de pequeña escala (decenas de centímetros de longitud de onda) con eje de pliegue de $\mathrm{Rbz} 86^{\circ} / 15^{\circ}$. Esta configuración indicaría que el bloque Sur se levanto con respecto al Norte, según el arrastre del pliegue (Figura 4.10i), de manera semejante a lo descripto para la parte central del cerro. Las capas de basamento del bloque Norte tienen un Rbz $159^{\circ} / 27^{\circ}$. También se pueden observar finas zonas de cizalla entre las capas de la Formación Puncoviscana, indicando que la deformación del basamento ha sido posibilitada por cizallamiento interestratal (Figura 4.10j).

En resumen, la Falla Tin Tin no es una estructura continua de orientación NNE-SSW sino que se encuentra segmentada por discontinuidades menores de orientación aproximada E-W, las cuales le confieren un "interdigitamiento" a la estructura general, con movimiento relativo de bloques. En los dos casos descriptos, el bloque Sur ascendió relativamente con respecto del bloque Norte. Estas estructuras de orientación E-W presentes en el basamento coinciden con las orientaciones de ejes de pliegues y planos axiales de similares proporciones descriptos anteriormente (véase Sección 4.1.1.1. Núcleo: Basamento del núcleo del anticlinal Tin Tin), siendo los planos axiales de los mismos las posibles superficies o zonas propicias para la reactivación y movimiento de bloques de basamento. 

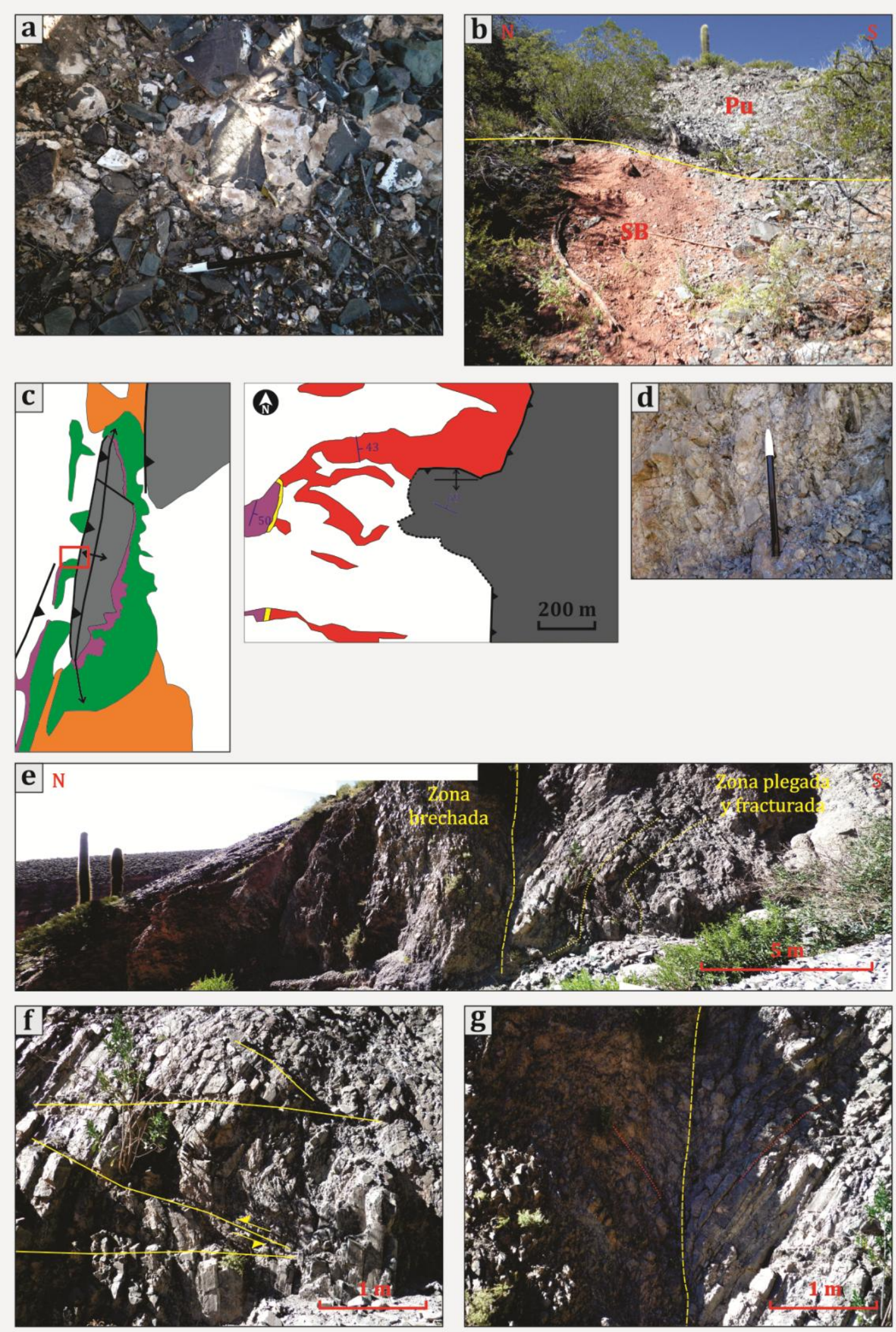

FIGURA 4.10. Falla Tin Tin: Características de deformación en diferentes sectores del cerro. 

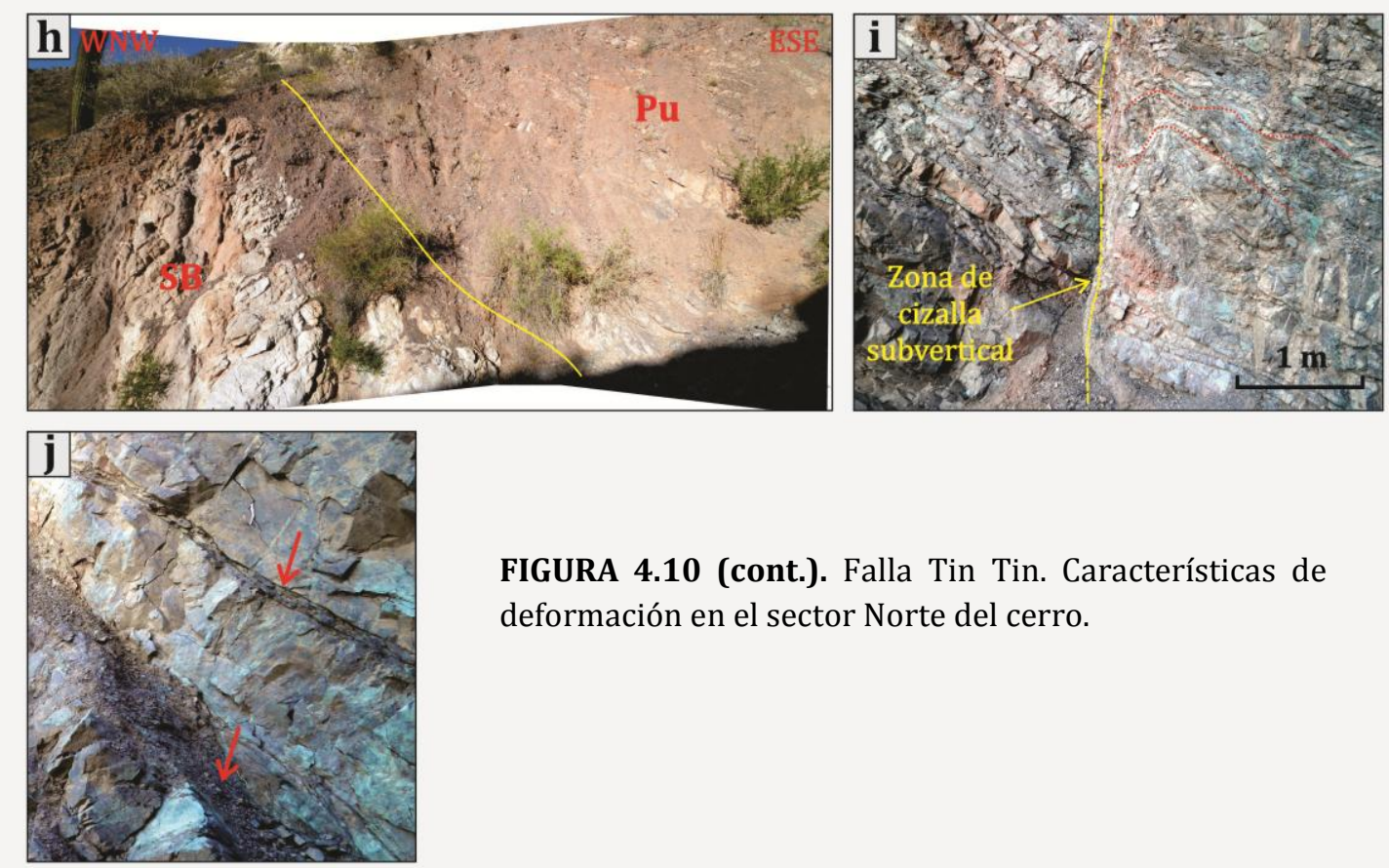

FIGURA 4.10 (cont.). Falla Tin Tin. Características de deformación en el sector Norte del cerro.

B) Afloramientos aislados de la cobertura sedimentaria

Los afloramientos que se encuentran al Oeste del cerro corresponden al bloque basal de la Falla Tin Tin y se encuentran parcialmente cubiertos por depósitos cuaternarios, aflorando en las quebradas de cursos de agua estacionales (Figura 4.3). Haciendo una división a la mitad del cerro, hacia el Sur se encuentran afloramientos de la secuencia completa del Grupo Salta, relacionados a fallas inversas que se encuentran al Oeste de la Falla Tin Tin. Estas capas presentan una orientación general NNE-SSW con una inclinación promedio de $45^{\circ}$ hacia el ESE (Figura 4.11a). Hacia el Norte, aflora principalmente el Subgrupo Santa Bárbara y en menor proporción el Subgrupo Balbuena hacia el extremo Norte del cerro. Aquí las capas tienen un rumbo NNE-SSW con inclinación de $30^{\circ}$ a $35^{\circ}$ hacia el ESE (Figura 4.11b). En este sitio se observó a la Formación Yacoraite fuertemente deformada por la presencia de pliegues con flancos intensamente fracturados (Figura 4.11e-f). Estos afloramientos se relacionan a fallas inversas de bajo ángulo (hacia el Este) dentro de la secuencia sedimentaria en el bloque basal de la falla Tin Tin. Los pliegues medidos arrojaron datos de eje con Rbz $346^{\circ} / 14^{\circ}$ (NNW a NW) y $156^{\circ} / 11^{\circ}$ (SE a SSE), y plano axial de $\mathrm{Rbz} 74^{\circ} / 83^{\circ}$ y $245^{\circ} / 87^{\circ}$, respectivamente, 
desviándose del rumbo general NNE-SSW mencionado (Figuras 4.11c-d). La media longitud de onda (ancho del anticlinal) es aproximadamente 15 metros para ambos pliegues. También se observaron fallas inversas de bajo ángulo que repiten parte de la secuencia aflorante (Figura 4.11g).

La disposición de los afloramientos de la Formación Yacoraite en esta zona sugiere que la falla NW-SE que desplaza sinestralmente al cerro (véase Sección 4.1.1.1. Núcleo: Falla NW-SE sinestral en el basamento del anticlinal Tin Tin) también afecta este sector ya que se observa un desfasaje en la continuidad de los afloramientos coincidente con la cinemática de la estructura (Figura 4.11h). 


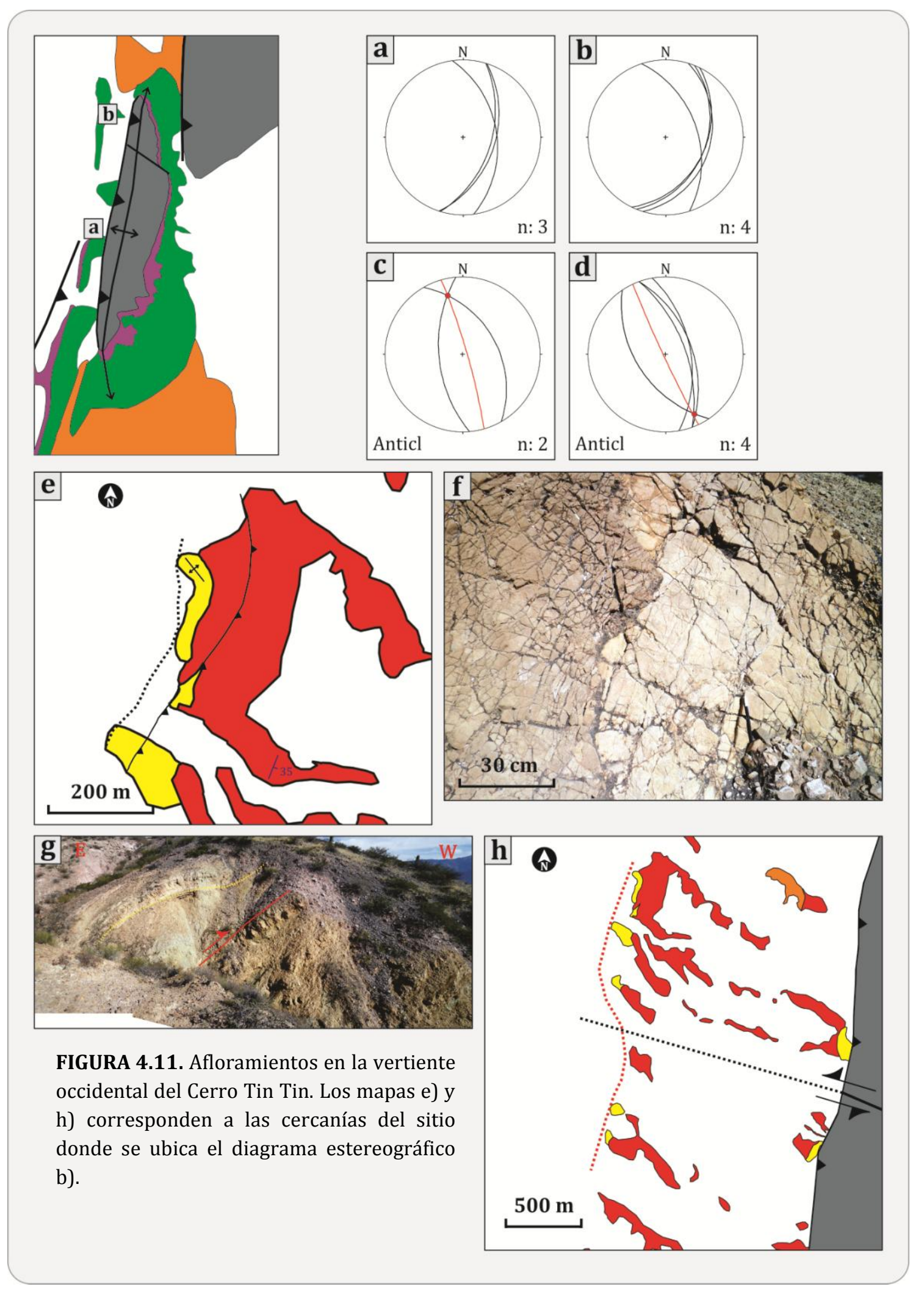




\subsubsection{Vertiente oriental}

\section{A) Flanco dorsal del anticlinal Tin Tin}

El flanco dorsal oriental del anticlinal Tin Tin presenta numerosas estructuras de menor escala, con geometrías y orientaciones consistentes con la orientación NNE-SSW del anticlinal principal. También cuenta con muchas otras estructuras perpendiculares al rumbo mencionado, tanto contraccionales como extensionales, sugiriendo que esfuerzos no coaxiales actuaron en diferentes etapas, resultando en una evolución estructural compleja (Figura 4.3). La cobertura sedimentaria involucrada en la deformación del anticlinal Tin Tin consta de las unidades del Grupo Salta y las del Grupo Payogastilla (Figura 4.1). La orientación de las capas a lo largo del flanco dorsal es bastante homogénea. El sector Norte del cerro presenta un Rbz promedio de $89^{\circ} / 43^{\circ}$, con excepción del extremo de inmersión Norte donde las capas se curvan debido a la terminación del basamento, presentando un Rbz promedio de $34^{\circ} / 50^{\circ}$. En el sector central del cerro, el Rbz promedio de las capas es $111^{\circ} / 56^{\circ}$. Aquí las capas presentan mayor inclinación que en el sector Norte, incluso con dominios de capas volcadas producto de estructuras importantes dentro del flanco (Figura 4.4 y 4.13).

Las estructuras más representativas se encuentran principalmente en los Subgrupos Balbuena y Santa Bárbara del Grupo Salta, y en menor medida en el Subgrupo Pirgua. Las diferencias en los estilos de deformación radica principalmente en las litologías que componen cada unidad, siendo la Formación Yacoraite del Subgrupo Balbuena la más propensa a la deformación debido a la frecuente alternancia de materiales finos y arenosos, que produce un fuerte contraste en las propiedades mecánicas de la secuencia. Las figuras 4.12 y 4.13 muestran los mapas geológicos del flanco dorsal del anticlinal Tin Tin, divididos en los sectores Norte y centro de Cerro Tin Tin, respectivamente. 


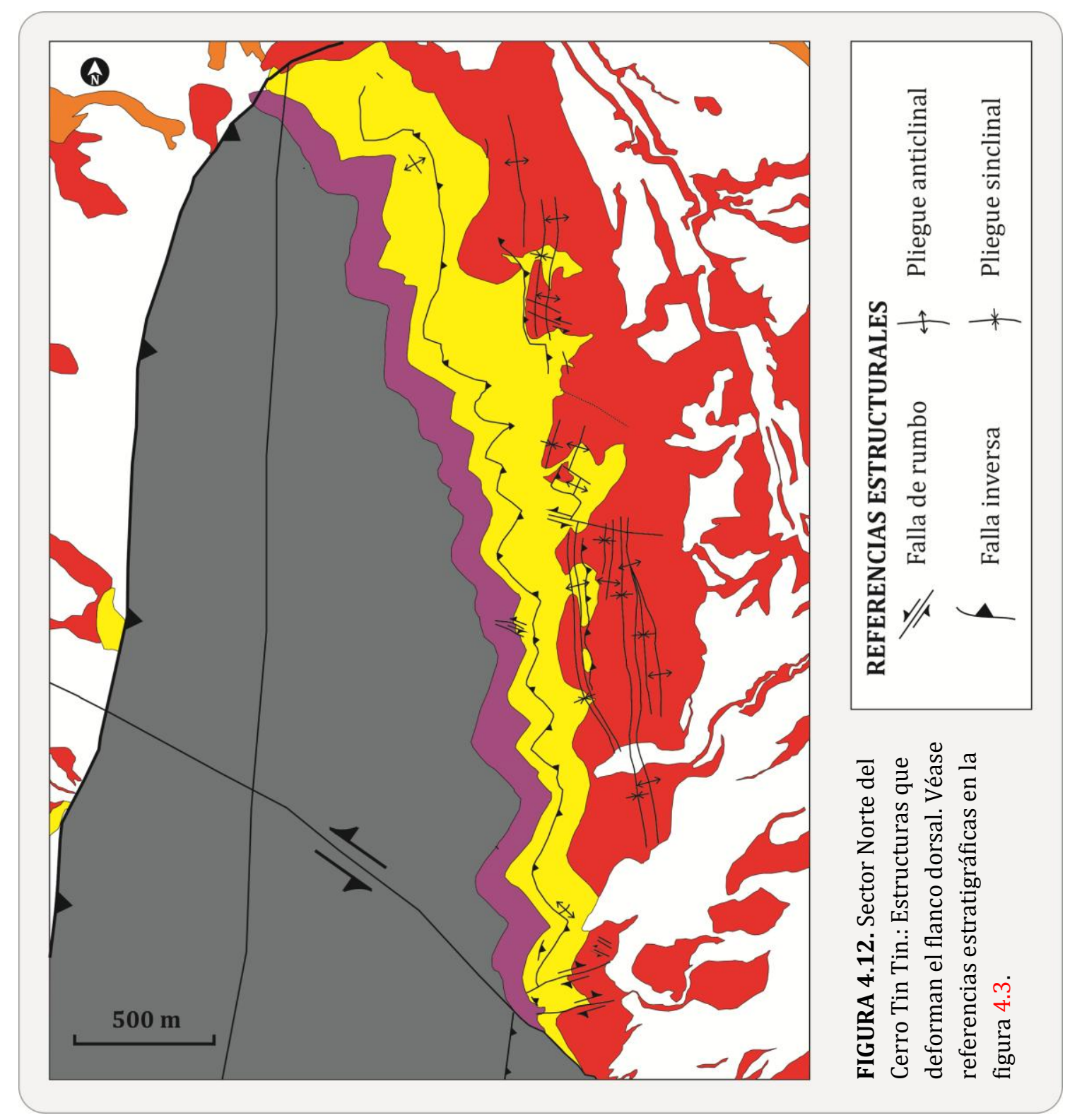

Pliegues en el flanco dorsal del anticlinal Tin Tin

En el sector Norte del cerro se mapearon pliegues que afectan principalmente al Subgrupo Santa Bárbara (Figura 4.12). Son anticlinales y sinclinales con vergencia occidental y ejes de pliegue de rumbo N-S a NNW-SSE y buzamiento de hasta $20^{\circ}$ hacia el Sur y Norte. Las superficies axiales son mayormente verticales con rumbo aproximado N-S. Los ángulos interflanco los clasifican como pliegues suaves a abiertos y presentan zonas charnelares medianamente agudas. Las trazas axiales son sinuosas, con longitudes que superan el kilometro en algunos pliegues. Las longitudes de onda de estos pliegues varían 
entre 60 y 100 metros aproximadamente (Figura 4.14a). La figura 4.14b muestra los datos de Rbz de los ejes de pliegue y planos axiales obtenidos a partir de la medición de capas plegadas.

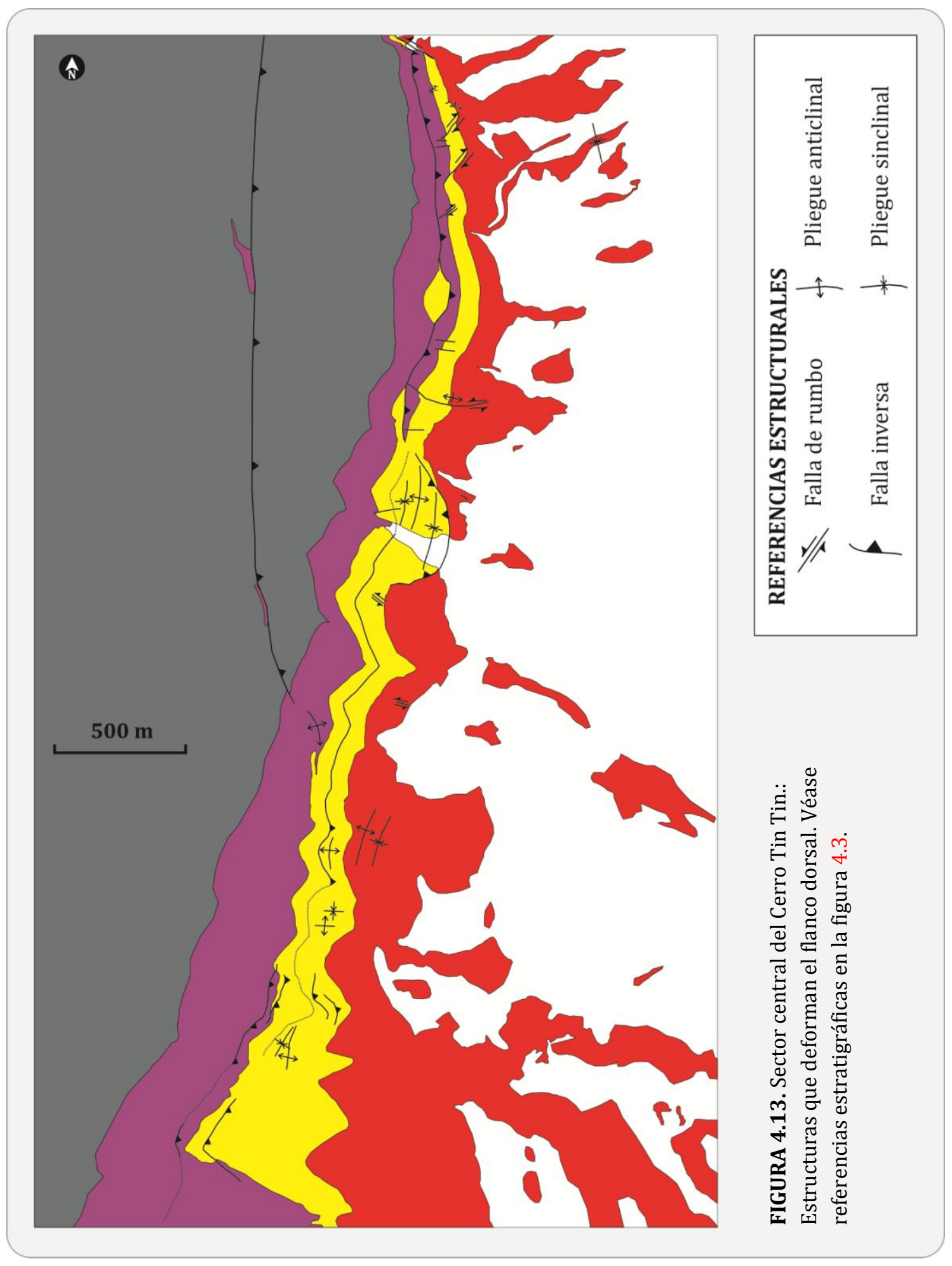


En el contacto entre los Subgrupos Balbuena y Santa Bárbara, donde se ubicarían las pelitas de la Formación Tunal (de escaso desarrollo en el área) se observó una zona de material fino azulado y de aspecto sedoso, producto de molienda, con capas de areniscas finas discontinuas inmersas en la matriz azulada (Figura 4.14c). Esto apuntaría a que los pliegues observados y medidos en el Subgrupo Santa Bárbara (incluyendo la transición con el Subgrupo Balbuena) son producto de la deformación por un corrimiento ubicado entre este subgrupo y el infrayacente, con un importante desacople entre ambos facilitado por los materiales finos de la transición.

El Subgrupo Balbuena presenta pliegues con orientaciones agrupadas en tres direcciones (Figura 4.14d). Los pliegues con ejes de dirección N-S están asociados a los descriptos anteriormente para el Subgrupo Santa Bárbara, ya que éstos afectan a capas ubicadas estratigráficamente en la parte superior de la secuencia sedimentaria, cerca del contacto con el subgrupo suprayacente (Figura 4.14e). Son similares en longitud de onda y vergencia, sus planos axiales son verticales y con ángulos interflanco abiertos. El segundo grupo de pliegues tiene ejes con un $\mathrm{Rbz}$ promedio de $34^{\circ} / 12^{\circ}$, mientras que en el tercer grupo el $\mathrm{Rbz}$ promedio de sus ejes es $54^{\circ} / 34^{\circ}$. Este conjunto de pliegues, de orientación e inclinación hacia el NE, presenta una longitud de onda que oscila entre 30 y 70 metros. Los planos axiales presentan múltiples direcciones de inclinación (Figura 4.14d). Las longitudes de las trazas axiales no superan los 50 metros y presentan ángulos interflanco cerrados hasta abiertos. Estos pliegues están asociados a fallas inversas (corrimientos) en la sección superior de la Formación Yacoraite, generados por la deformación del bloque colgante (Figura 4.14f-g). Otros pliegues con rumbo NE que se encuentran en la sección media de la Formación Yacoraite también se asocian a fallas inversas pero presentan menor escala que los descriptos (Figura 4.14h). 


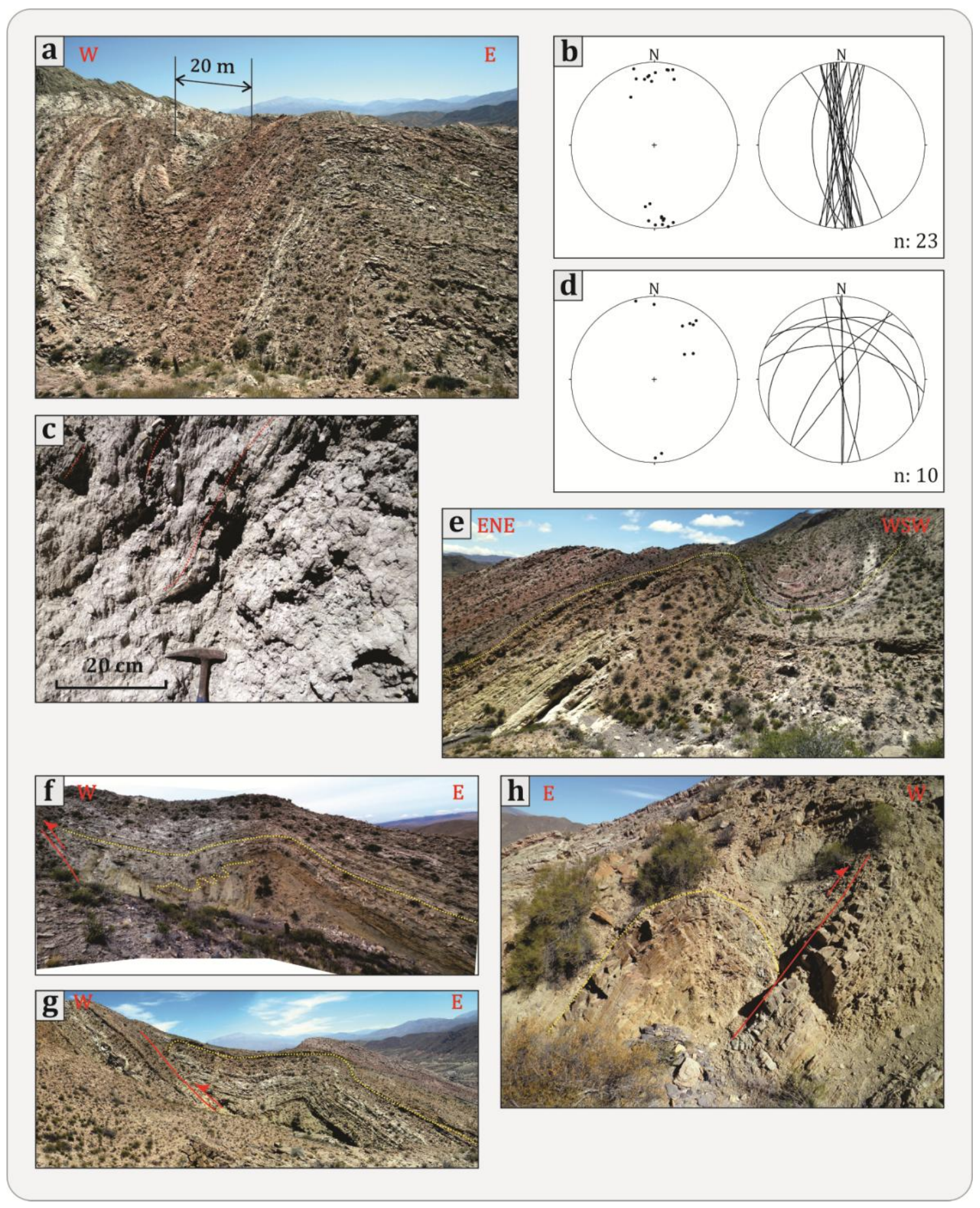

FIGURA 4.14. Pliegues en el flanco dorsal del anticlinal Tin Tin, deformando los subgrupos Balbuena y Santa Bárbara. Sector Norte del cerro.

En el sector central del Cerro Tin Tin (Figura 4.13), los pliegues anticlinales y sinclinales mapeados afectan mayormente a la sección superior de la secuencia de la Formación Yacoraite del Subgrupo Balbuena, y como se mencionó para el sector Norte, muchos de estos se encuentran relacionados a la deformación del 
bloque colgante de fallas inversas de escala mediana. En general presentan vergencia occidental, aunque se encuentran algunos con vergencia opuesta y también pliegues volcados (Figura 4.14i-j). Como muestra la figura 4.14k, la mayoría de los ejes buzan hacia el cuadrante SW, con mayor concentración en las orientaciones $205^{\circ} / 13^{\circ}$ y $189^{\circ} / 7^{\circ}$, siendo estas direcciones coincidentes con los rumbos de las capas sedimentarias de la zona. Los planos axiales presentan rumbos N-S a NE-SW y son mayormente subverticales o de alta inclinación, excepcionalmente con inclinación de bajo ángulo hacia el NW y SE. Estos pliegues tienen una longitud de onda que oscila entre 15 y 40 metros, excepcionalmente 70 metros cuando se relacionan con fallas de mayor escala. Las trazas axiales no superan los 20 metros de longitud (Figura 4.13). Según su ángulo interflanco, la apertura de estos pliegues varía entre suave y cerrada e incluso apretada.

En el Subgrupo Santa Bárbara se midieron tres pliegues. La escala de éstos es mayor que la de los descriptos para el Subgrupo Balbuena, siendo su longitud de onda de 50 a 70 metros (Figura 4.14l). La figura 4.14m muestra los tres ejes de pliegue con sus respectivos planos axiales. La orientación de los ejes sigue el rumbo de las capas sedimentarias de la zona y se va modificando junto con el cambio de rumbo de las mismas. Los planos axiales de baja inclinación indican que los pliegues están volcados. Las trazas de estas estructuras alcanzan los 350 metros de longitud. Su ángulo interflanco los clasifica como pliegues suaves a abiertos.

El Subgrupo Pirgua presenta dos pliegues de gran dimensión, alcanzando los 120 metros de longitud de onda (Figura 4.14ñ). Estos pliegues tienen una orientación NNE-SSW, con ejes subhorizontales y planos axiales verticales con trazas que alcanzan los 90 metros de longitud (Figura 4.14n). A estas estructuras se asocian fallas inversas de bajo ángulo con transporte hacia el Oeste, en el contacto entre este subgrupo y el suprayacente (Figura 4.140). El origen de estos pliegues está relacionado a la terminación de una de las fallas inversas que engrosan el núcleo de basamento, descripta en la sección 4.1.1.1: Núcleo (Figura 4.13). Los pliegues se producen para acomodar y transmitir la deformación cuando la falla entra en la interfase basamento-cobertura sedimentaria. 


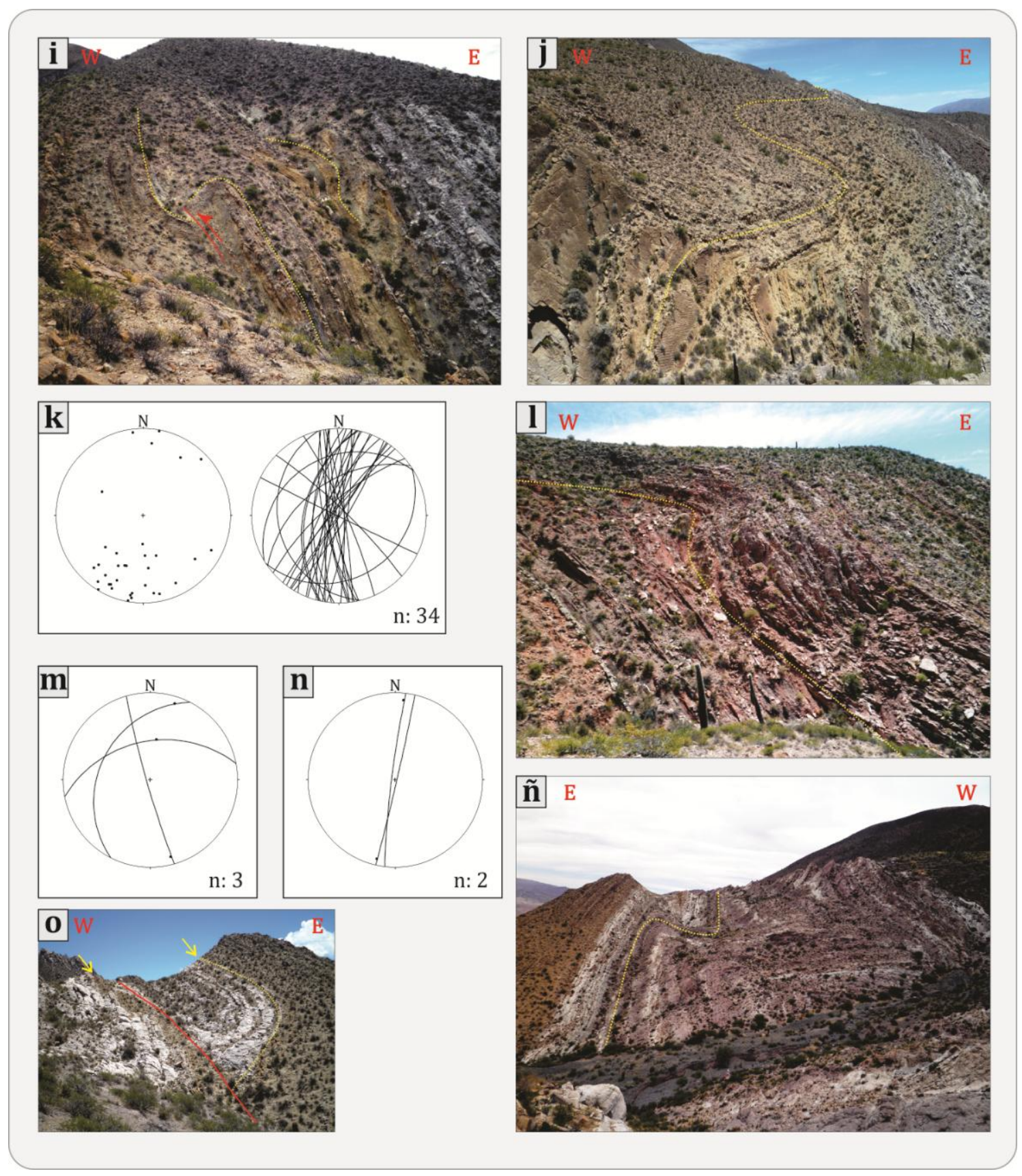

FIGURA 4.14 (cont.). Pliegues en el flanco dorsal del anticlinal Tin Tin, deformando los subgrupos Pirgua, Balbuena y Santa Bárbara. Sector central del cerro.

Fallas en el flanco dorsal del anticlinal Tin Tin

El flanco dorsal del anticlinal se encuentra altamente deformado por fallas y pliegues asociados (descriptos en el apartado anterior). Se encuentran fallas con cinemática normal, inversa, y de rumbo dextral y sinestral (Figura 4.12 y 4.13). 
En el sector Norte de cerro (Figura 4.12), la mayoría de las fallas son inversas y se encuentran en la Formación Yacoraite del Subgrupo Balbuena y en la parte inferior del Subgrupo Santa Bárbara, debido a que presentan numerosas alternancias de capas pelíticas y arenosas. La mayoría de las fallas inversas se encuentran en la sección superior de la Formación Yacoraite, asociadas a los pliegues descriptos anteriormente (véase Figuras 4.14f-g-h). Un ejemplo importante es una falla (o zona de falla) inversa observada en varios sitios ubicados estratigráficamente en la sección media de la secuencia de la Formación Yacoraite. En el sitio donde presenta su mejor exposición, la estructura es paralela a la estratificación local de $\mathrm{Rbz} 86^{\circ} / 45^{\circ}$, es decir, posee una geometría plano-plano (Suppe, 1983) lo que hace difícil su reconocimiento. Aquí se han registrado varios

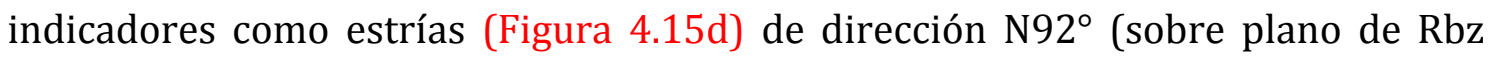
$22^{\circ} / 25^{\circ}$ ) y una zona de brechamiento y reducción de tamaño de grano con granulometría fino y aspecto sedoso (Sibson, 1977) de aproximadamente 1 metro de espesor (Figura 4.15a). Las fallas y pliegues de escala decimétrica observadas dentro de esta zona, indican un transporte hacia el Oeste concordante con la tectónica local y regional. En otros sitios estratigráficamente similares se observaron evidencias de contracción a diferentes escalas, desde una zona de más de $1 \mathrm{~m}$ de espesor de láminas y capas de material fino (pelitas y arena fina) replegadas con yeso involucrado (Figura 4.15b), hasta una zona de falla de escala de decenas de metros, con pliegues de arrastre asociados (véase Figura 4.14h). Esta última presenta un Rbz de $84^{\circ} / 64^{\circ}$. En ambos sitios los pliegues muestran vergencia occidental y transporte hacia el Oeste. Las observaciones y mediciones descriptas sugieren la existencia de una falla inversa de bajo ángulo con respecto a la estratificación, ubicada en la mitad del perfil de la Formación Yacoraite, que recorre gran parte del flanco dorsal del sector Norte del cerro (según se puede inferir a partir del estudio de imágenes satelitales) por aproximadamente 3 kilómetros y que engrosa el espesor de la unidad geológica. Hacia el Sur de este sector, se encuentran los pliegues descriptos anteriormente (véase Sección: Pliegues en el flanco dorsal del anticlinal Tin Tin), con ejes de rumbo NE-SW, indicando una posible dirección de transporte de la falla que varía entre el Oeste y Noroeste. 


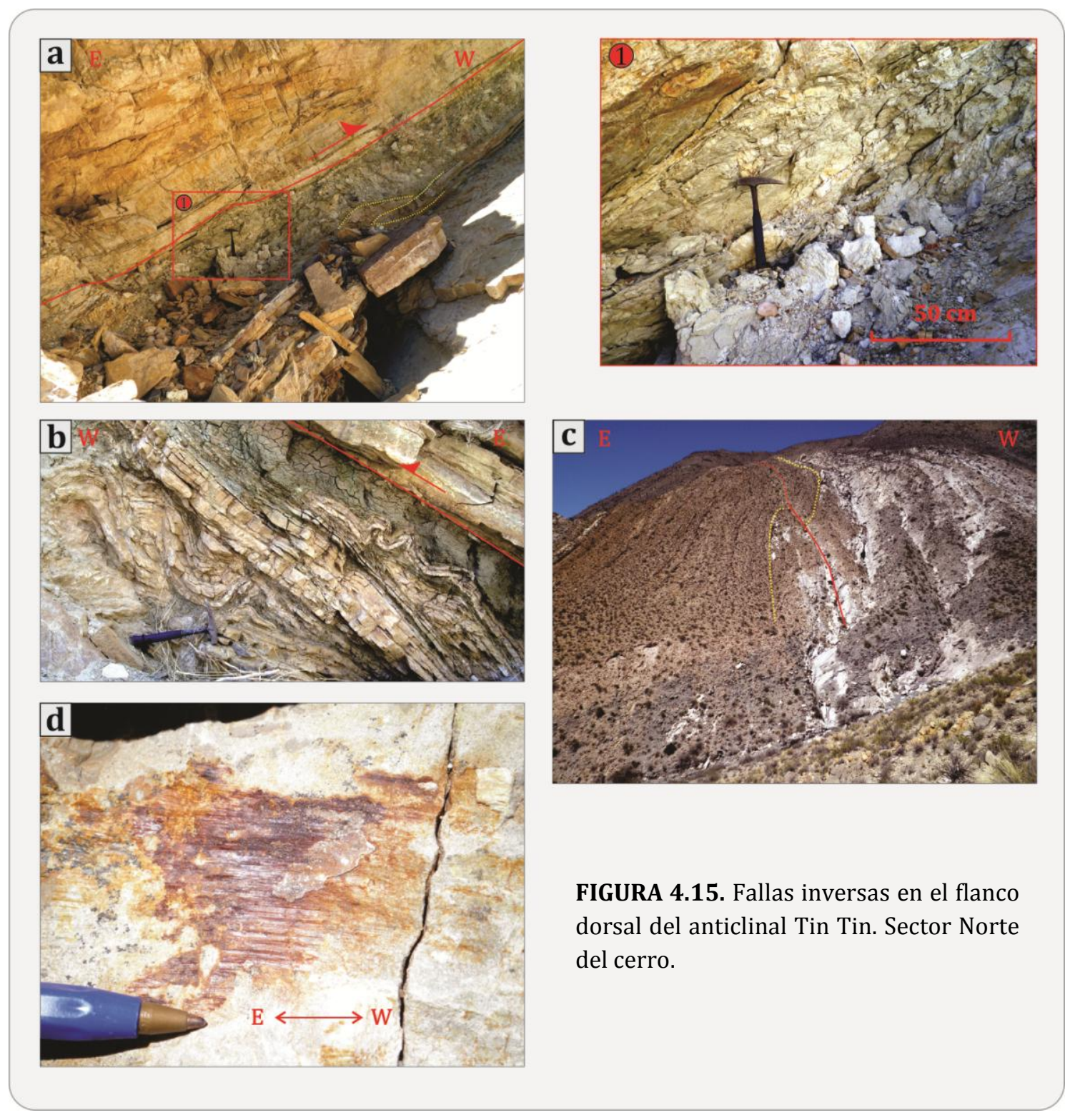

La sección superior de la secuencia de la Formación Yacoraite presenta una estructura (o conjunto de estructuras) de características similares a la descripta para la sección estratigráfica media de la formación, que aflora en diferentes sitios a lo largo del cerro, en ocasiones afectando la parte basal del Subgrupo Santa Bárbara. Estas fallas tienen un rumbo aproximado N-S y se relacionan a los pliegues descriptos para esta posición estratigráfica (véase Figuras 4.14a-c-e). La traza de estas fallas inversas (considerada como una estructura única que aflora en forma discontinua) puede ser mapeada por un par de kilómetros, como en el caso anterior. La relación angular entre las capas a un lado y otro de la falla (piso y techo) sugiere una geometría rampa-plano para el anticlinal colgante (Suppe, 1983), como así también, un estado de evolución y transporte menor a la falla 
anterior. Las trazas individuales de las fallas tienen decenas a centenas de metros de longitud y se hunden para conformar pliegues que se suavizan a la distancia.

En la sección basal de la Formación Yacoraite se mapeó una falla inversa de escala media, con pliegues de arrastre que indican transporte hacia el Oeste, y que contribuyen al aumento de espesor de esta formación (Figura 4.15c). Esta se ubica en cercanías de la falla NW-SE que atraviesa el cerro (véase Sección 4.1.1.1. Núcleo: Falla NW-SE sinestral en el basamento del anticlinal Tin Tin). Su orientación e inclinación es paralela al rumbo de las capas para esa posición, con trazas medibles entre 50 y 90 metros de longitud.

Además de las fallas inversas descriptas, otro tipo de estructura presente en el sector Norte del cerro son fallas de rumbo con orientación ESE-WNW (N120 aproximadamente, en planta) que desplazan sinestralmente otras estructuras como pliegues y/o capas sedimentarias (Figura 4.12). Las estructuras mapeadas se encuentran en la transición entre los Subgrupos Pirgua y Balbuena, en la transición entre los Subgrupos Balbuena y Santa Bárbara, y en la parte basal del Subgrupo Santa Bárbara. En el primer caso, las fracturas afectan a gran parte del Subgrupo Pirgua y desplazan el contacto ( $\mathrm{Rbz} 90^{\circ} / 45^{\circ}$ ) entre este Subgrupo y el suprayacente (Figura 4.15e-f-g). Se mapearon y midieron dos fallas subverticales de orientación $\mathrm{N} 120^{\circ}$ que se encuentran espaciadas en el terreno unos 30 metros en dirección N-S, y presentan un desplazamiento de rumbo sinestral de unos 15 a 20 metros. Un plano arrojó un valor de $\mathrm{Rbz}$ de $210^{\circ} / 83^{\circ}$, con un rake $26^{\circ} \mathrm{E}$ medido en un estriado, indicando una pequeña componente normal de movimiento (el bloque Sur desciende). La traza de las fallas alcanza los 100 metros de longitud. 


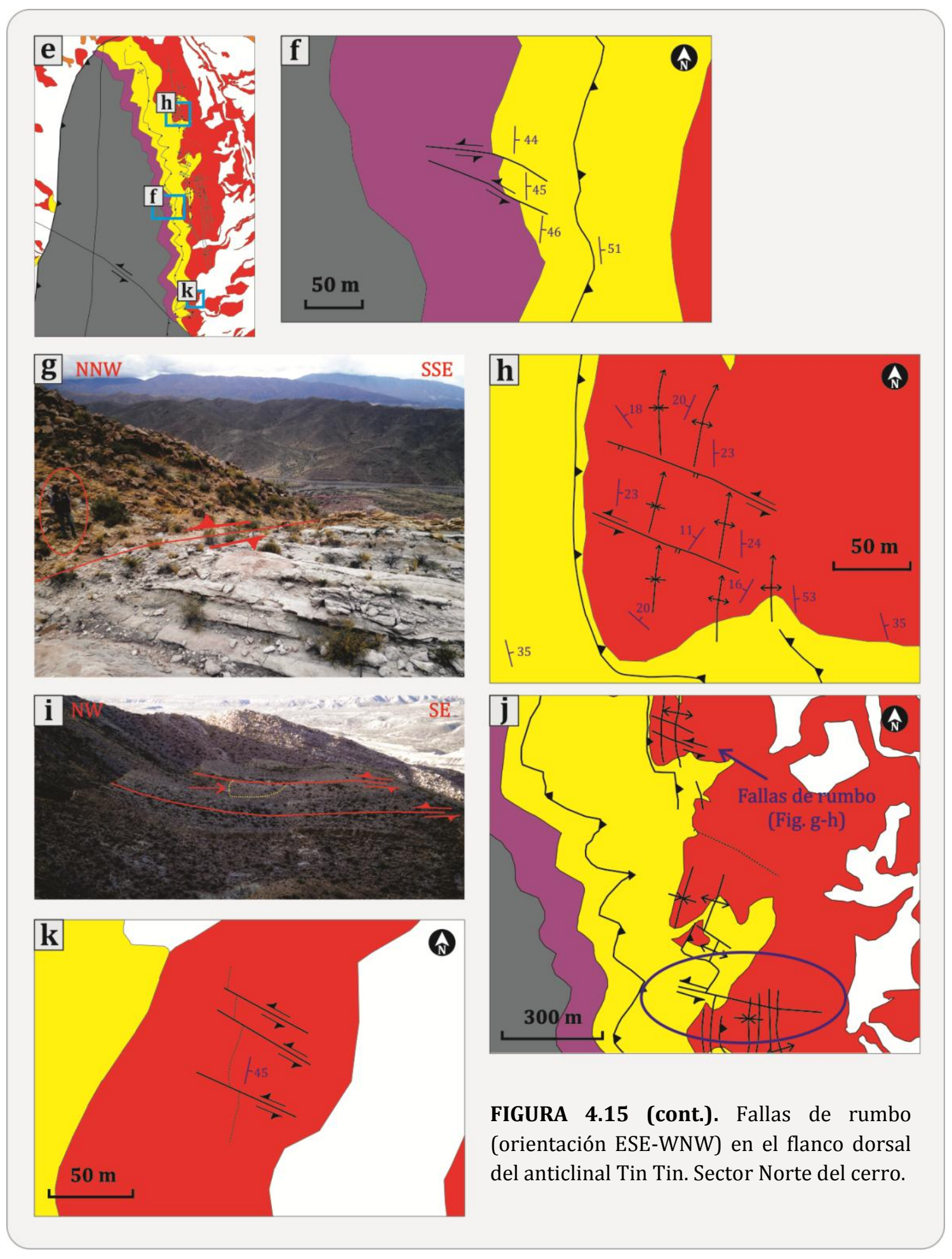

Las fallas de rumbo que se encuentran en la transición entre los Subgrupos Balbuena y Santa Bárbara presentan mayor frecuencia que las anteriores. Un ejemplo de éstas son dos fallas que afectan la base del Subgrupo Santa Bárbara y se encuentran distanciadas unos 45 metros entre sí (distancia perpendicular a su 
rumbo), con trazas de falla que alcanzan los 100 metros de longitud (Figura 4.15eh-i). Estas fallas son subverticales con rumbo ESE-WNW (N120 $)$ y desplazan sinestralmente pliegues suaves por una distancia de 10 a 20 metros. Un plano medido en la superficie de falla arrojó un valor de $\mathrm{Rbz}$ de $218^{\circ} / 60^{\circ}$, pudiendo inclinar con mayor ángulo hasta subvertical según se observó en el afloramiento. Estas estructuras también muestran desplazamiento normal, ya que tienen un rechazo vertical mínimo de 2 metros con descenso del bloque Sur (posible deslazamiento oblicuo). Los núcleos de los pliegues sinclinales desplazados, de origen previo a las fallas, proporcionaron el espacio para la preservación de sedimentos más nuevos en el bloque techo de la falla (Figura 4.15h-i). Unos 700 metros al Sur de las estructuras descriptas se observó una fractura de similar orientación e inclinación de aproximadamente 400 metros de longitud visible de traza (Figura 4.15j). La cinemática sinestral es evidenciada por el desplazamiento de 30 metros de un pliegue anticlinal perteneciente a la parte superior del Subgrupo Balbuena.

En la parte basal del Subgrupo Santa Bárbara, en una posición cercana a la estructura NW-SE que atraviesa el cerro, se encuentran tres fracturas con desplazamiento sinestral en planta (figura 4.15k), de unos $50 \mathrm{~m}$ de longitud visible en su traza y espaciadas entre 15 y 30 metros entre sí (perpendicularmente a su rumbo). El Rbz de uno de los planos arrojó un valor de $210^{\circ} / 90^{\circ}$ (rumbo NW-SE, vertical), con un desplazamiento medido de 5 metros. El Rbz de las capas afectadas es $102^{\circ} / 45^{\circ}$. Otras dos fracturas importantes para esta ubicación son las fallas dextrales ya descriptas en un apartado anterior (véase sección 4.1.1.1. Núcleo: Falla NW-SE sinestral en el basamento del anticlinal Tin Tin).

El sector central del anticlinal Tin Tin es la zona de mayor contracción, donde el basamento se encuentra fallado y corrido sobre sí mismo, y a causa de esto parte de la secuencia sedimentaria se presenta volcada (Figura 4.13). La estructura más conspicua es una falla inversa que recorre gran parte del flanco dorsal en este sector y repite estructuralmente parte del los Subgrupos Pirgua y Balbuena (Figura 4.13 y 4.16a-d). La dirección de transporte de la falla es hacia el Oeste y su posible nivel de despegue se ubica dentro del Subgrupo Pirgua. Esta estructura se caracteriza por poner en contacto diferentes dominios de inclinación 
dentro del Subgrupo Pirgua (Figura 4.16a-b), o en el caso más claro, al Subgrupo Pirgua por encima del Subgrupo Balbuena (Figura 4.16c-d). El Rbz promedio en el bloque basal de la falla es $102^{\circ} / 62^{\circ}$, mientras que en el bloque colgante las capas se encuentran con muy alta inclinación hacia el Este, subverticales o volcadas (Rbz promedio $100^{\circ} / 80^{\circ}$ ), indicando a su vez, la orientación de la falla. La diferencia angular entre los dominios en contacto indican una geometría rampa-plano para la falla (Suppe, 1983). Su traza es sinuosa y sigue el rumbo NNE de la estratificación por aproximadamente 1.5 kilómetros, hasta entrar con geometría de plano en el Subgrupo Balbuena, donde cambia su orientación e inclinación y genera pliegues de gran escala, además de un aumento en el espesor del subgrupo (Figura 4.13).

En forma similar al sector Norte, en una posición estratigráfica media del Subgrupo Balbuena se observan fallas inversas subparalelas a la estratificación que producen pliegues de arrastre en el bloque colgante indicando contracción hacia el Oeste (Figura 4.13). La figura 4.16e muestra un ejemplo de esta estructura y de los pliegues que produce (también véase Figura 4.14i). El Rbz de las capas es $110^{\circ} / 55^{\circ}$, siendo la falla de orientación similar. La traza de la falla puede mapearse, en forma discontinua, por más de 2 kilómetros y es reconocida en el afloramiento por zonas de material brechoso, pliegues quebrados dentro de la zona y los pliegues mencionados sobre el bloque colgante, en ocasiones con geometrías complejas (véase Figura 4.14j).

En el contacto entre los Subgrupos Pirgua y Balbuena se mapearon fallas inversas con transporte hacia el Oeste, que despegan desde el techo del Subgrupo Pirgua y lo sobrecorren sobre la base del Subgrupo Balbuena (Figura 4.16f). Una de las fallas medidas posee un $\mathrm{Rbz}$ de $115^{\circ} / 44^{\circ}$ y su traza alcanza los 300 metros de longitud. Esta estructura es de bajo ángulo con respecto a la estratificación del bloque basal, de $\operatorname{Rbz} 86^{\circ} / 31^{\circ}$ en las cercanías de la falla (Figura 4.16f1). Otra falla inversa mapeada presenta mayor inclinación que la anterior y una traza visible de aproximadamente 200 metros. Los Rbz de las capas en el bloque basal y colgante son $107^{\circ} / 65^{\circ}$ y $120^{\circ} / 75^{\circ}$, respectivamente (Figura $4.16 f 2-g$ ). Este aumento en la inclinación es debido a otro corrimiento observado por debajo del anterior (a la izquierda en el mapa) y que produce un apilamiento de rampas y aumento de la inclinación de las capas involucrada. 


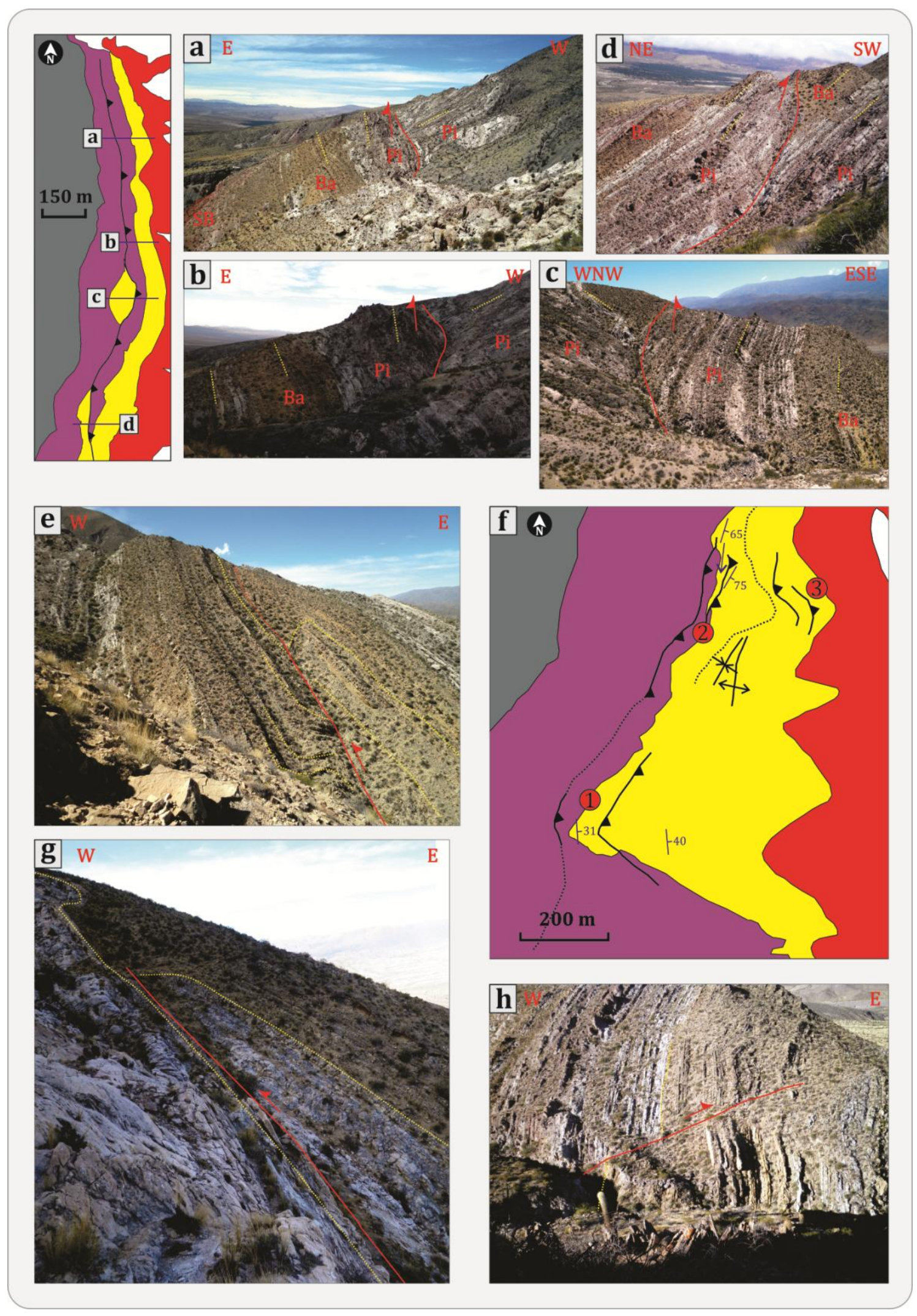

FIGURA 4.16. Fallas inversas en el flanco dorsal del anticlinal Tin Tin. Sector central del cerro. Pi Subgrupo Pirgua: Ba - Subgrupo Balbuena; SB - Subgrupo Santa Bárbara. 
En el techo de la secuencia del Subgrupo Balbuena también se encuentran fallas inversas de bajo ángulo que repiten y pliegan las capas involucradas engrosando la unidad (Figura 4.16f3). El rumbo de las fallas es NNE-SSW y, en general, presentan alta inclinación hacia el Este, es decir, son subparalelas a la orientación de la secuencia sedimentaria, al igual que las fallas de la base del subgrupo. Las trazas de las mismas son discontinuas y se presentan con longitudes de entre 20 y 200 metros, con transporte hacia el Oeste.

En muchas de las quebradas que cortan el cerro transversalmente se observaron fallas inversas de bajo ángulo con transporte de pocos metros hacia el Este (Figura 4.16h). Estas fallas no tienen expresión en una vista en planta, ya que solo se observan en las quebradas, por lo que no se puede determinar la orientación de sus trazas, pero se infiere que tienen un rumbo subparalelo a la estratificación local y al anticlinal principal. Se las asocia a la acomodación por la rotación general del flanco hacia una mayor inclinación.

A una escala aun menor, fallas con desplazamiento de rumbo dextral y sinestral se encuentran a lo largo del flanco dorsal del anticlinal en este sector (Figura 4.13). Estas estructuras se circunscriben a la zona de mayor contracción del pliegue, donde fallas inversas de gran escala repiten estructuralmente el basamento y la cobertura sedimentaria, y específicamente se ubican hacia el Norte del sector central, en las cercanías de la falla NW-SE, descripta en la sección 4.1.1.1. Núcleo (Figura 4.16i). Hacia el Sur de los pliegues que afectan al Subgrupo Pirgua (terminación de la falla de basamento) no se observan fallas con desplazamiento de rumbo. Como se puede ver en la figura 4.16i, la mayoría de estas estructuras son reconocibles debido a que desplazan el techo o la base de la Formación Yacoraite, afectando a las tres unidades del Grupo Salta. Las fallas sinestrales poseen trazas visibles que oscilan entre los 20 y 50 metros de longitud. La separación en el terreno de los puntos homólogos de capas desplazadas es de 1 a 10 metros. La figura 4.16j muestra la orientación de los planos medidos en estas fallas. La mayoría de las fallas tiene un rumbo ESE-WNW a NW-SE, con una orientación media de los planos de $\operatorname{Rbz} 29^{\circ} / 83^{\circ}$. Una estructura en particular (o un posible conjunto de estructuras) afecta a las tres unidades del Grupo Salta y las desplaza sinestralmente unos 10 metros (mínimo visible). La geometría de esta 
estructura no pudo ser determinada. Se observó, en el bloque Norte de la falla un pliegue posiblemente relacionado al movimiento de la misma (Figura 4.16k).

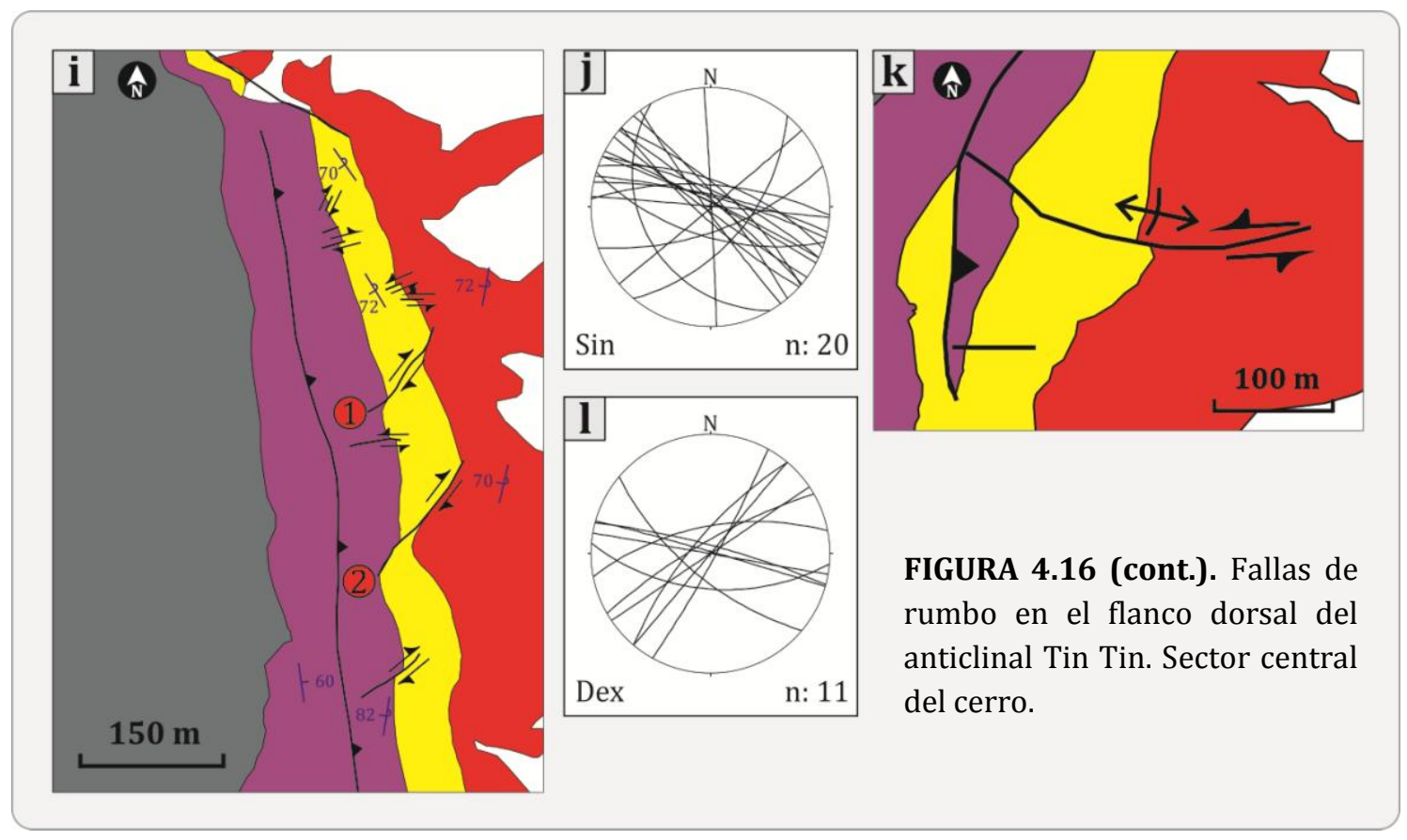

Las fallas dextrales presentan dos grupos de orientaciones: NE-SW y ESEWNW a NW-SE (Figura 4.16l). La fallas de rumbo ESE-WNW a NW-SE, al igual que las fallas sinestrales de similar orientación, comparten las mismas características que éstas en cuanto a su dimensión (longitud de sus trazas de falla) y desplazamiento de las capas en el terreno (Figura 4.16i). Las fallas con rumbo NESW poseen, en general, mayores dimensiones que las sinestrales (Figura 4.16i). Tres de éstas afectan a gran parte del Subgrupo Balbuena produciendo cambios significativos en el ancho de afloramiento de la Formación Yacoraite (Figura 4.16i1-2). Los valores de longitud de traza de falla de estas estructuras oscilan entre 70 y 130 metros, mientras que el desplazamiento medido en el terreno arrojó valores entre 10 y 65 metros. Todos los planos medidos son de alta inclinación, tendiendo a la verticalidad, como muestra la figura 4.16l. Un valor de Rbz medio calculado para estas fallas con rumbo NE-SW es $328^{\circ} / 80^{\circ}$.

\subsubsection{Inmersión Sur}

El sector de inmersión Sur comprende el tercio inferior del Cerro Tin Tin, donde el basamento pierde altura hacia el Sur del cerro y se hunde por debajo de la cobertura sedimentaria (Figura 4.17). Esto se debe a que, como se mencionó 
anteriormente, la falla Tin Tin presenta su máximo desplazamiento en su sector medio y disminuye hacia sus extremos. En este sector se incluyen las estructuras presentes en el flanco dorsal (sector Sur del mismo), zona charnelar y flanco frontal del anticlinal. Las características geométricas generales para este sector se mencionaron al principio de este capítulo.

Pliegues en el sector de inmersión Sur del anticlinal Tin Tin

En este sector se presentan pliegues en las tres unidades del Grupo Salta (Figura 4.17). En el Subgrupo Santa Bárbara las estructuras mapeadas se encuentran en la base del subgrupo, afectando las areniscas de la Formación Mealla en el flanco dorsal del anticlinal. Los pliegues son generalmente asimétricos con vergencia hacia el Noroeste y Nornoroeste (Figura 4.18a). La orientación general de los anticlinales y sinclinales es NE-SW a ENE-WSW, con estructuras que se orientan en dirección $\mathrm{N} 37^{\circ}$ en el Norte del sector y en dirección N70 en el Sur del mismo, donde el basamento se hunde y la cobertura sedimentaria cambia su rumbo. Los ejes de pliegues tienen inmersión general al NE, con un aumento en el buzamiento en la parte Sur del sector (Figura 4.18b). Estos pliegues son suaves a abiertos según su ángulo interflanco, con planos axiales subverticales (Figura 4.18b). Las trazas axiales presentan magnitudes de entre 550 y 850 metros de longitud, hasta un máximo mapeado de 1500 metros en los pliegues de la parte Sur del sector (Figura 4.17). La longitud de onda de estas estructuras varía entre 220 y 280 metros en los pliegues suaves, disminuyendo a menos de 100 metros en los pliegues abiertos, y también dependiendo de la escala de la estructura plegada. La mayoría de los pliegues medidos representan las terminaciones laterales de fallas inversas de bajo ángulo. La asimetría de los mismos se va suavizando a medida que se alejan de la falla. 


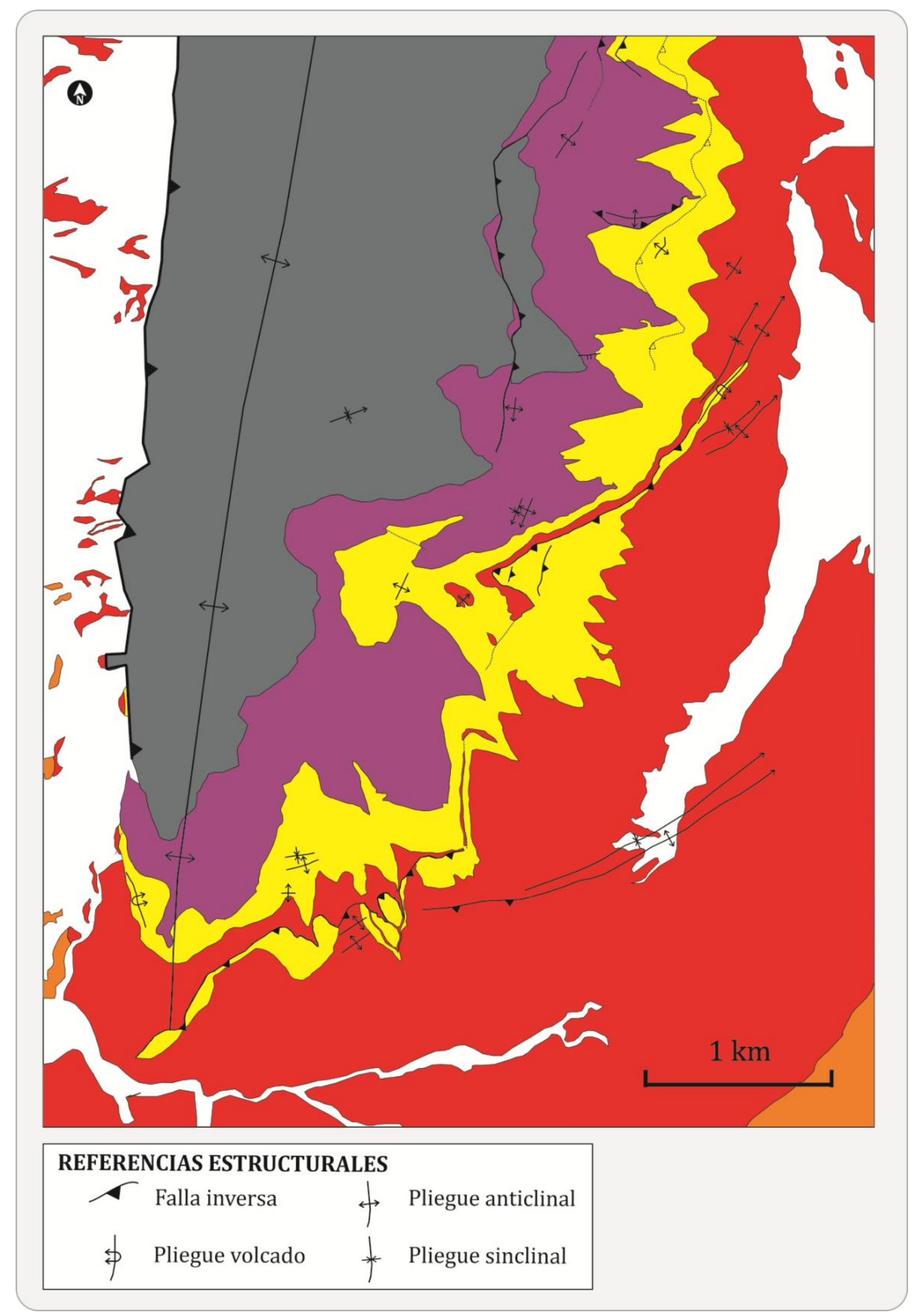

FIGURA 4.17. Sector de inmersión Sur del anticlinal Tin Tin. Estructuras que deforman la charnela y los flancos. Véase referencias estratigráficas en la figura 4.3. 
El Subgrupo Balbuena presenta mayor cantidad de pliegues en relación a los otros subgrupos. Estos afectan principalmente a la Formación Yacoraite y se ubican tanto en el flanco dorsal como en el frontal (Figura 4.17). En esta formación, los ejes de pliegue son variables en dirección y buzamiento (Figura 4.18c). Esto se debe a dos factores importantes. En primer lugar y en forma similar a los pliegues que afectan al Subgrupo Santa Bárbara, la dirección de las estructuras se modifica en concordancia con el cambio el rumbo de la estratificación local como consecuencia de la inmersión del anticlinal, por lo tanto las direcciones generales de los pliegues son NE-SW en el flanco dorsal, E-W a ENE-WSW en las cercanías de la zona charnelar y NW-SE en el flanco frontal del anticlinal Tin Tin (Figura 4.17). El segundo factor importante que influye en la dirección de los ejes de algunos pliegues es la presencia de fallas inversas de gran escala (descripta en la siguiente sección) en donde los pliegues de la Formación Yacoraite pertenecientes al bloque colgante de la falla se alinean con el rumbo de la misma (Figura 4.18d). La figura 4.18c muestra los datos de $\mathrm{Rbz}$ de los planos y ejes de los pliegues medidos. La mayoría de ellos presenta alta inclinación de sus planos axiales y sus ejes buzan hacia el cuadrante Suroeste. La longitud de onda varía generalmente entre los $20 \mathrm{y}$ 40 metros, excepcionalmente 70 metros. Los ángulos interflanco de los pliegues los clasifican como abiertos a suaves, siendo estos últimos los de mayor longitud de onda. Con menor frecuencia, en ambos flancos del anticlinal se midieron pliegues anticlinales con sus ejes orientados en forma perpendicular a la estratificación local. Estos son de pequeña escala, de 10 a 15 metros de longitud de onda, suaves a abiertos, con planos axiales de alta inclinación. 


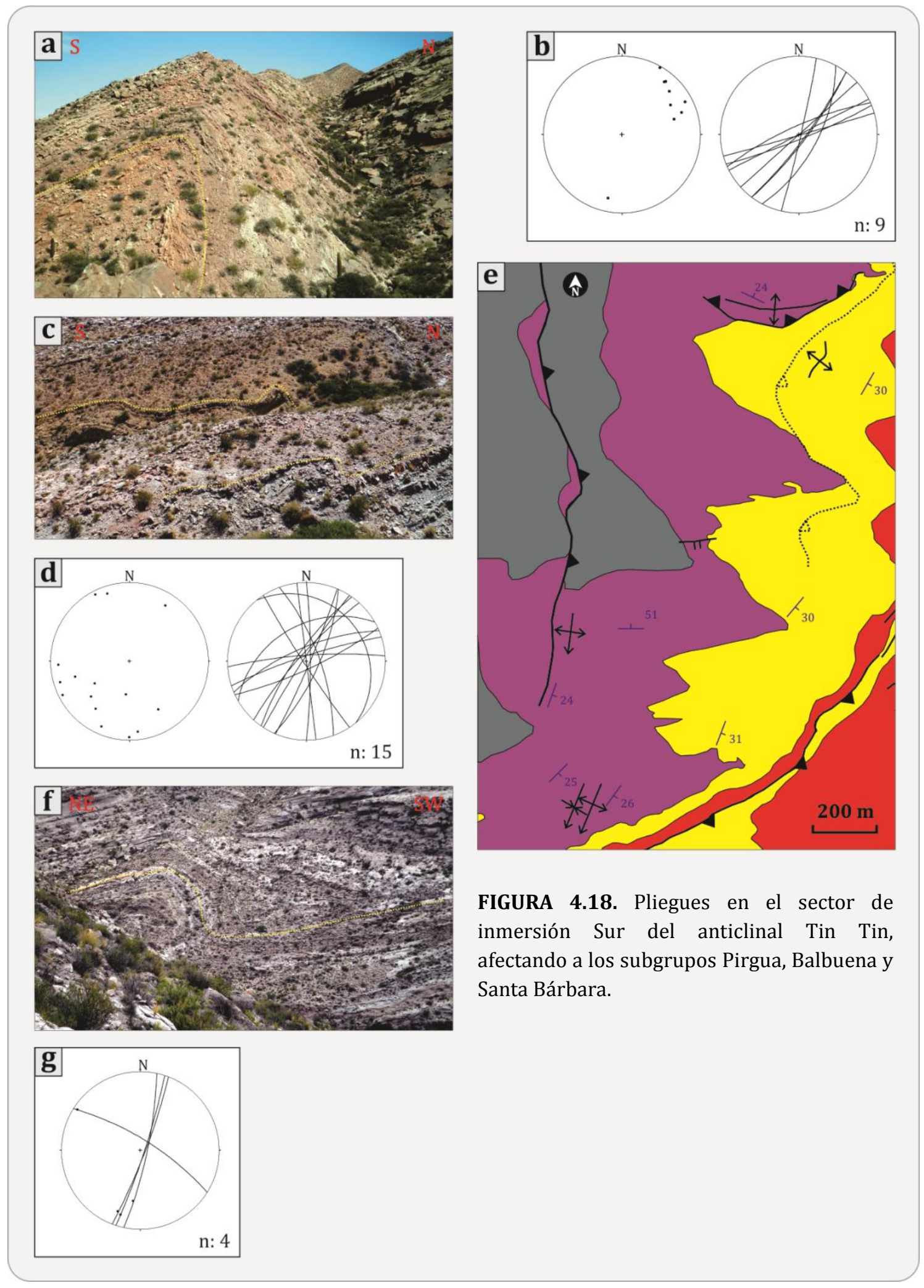

En el Subgrupo Pirgua se midieron cuatro pliegues ubicados en el flanco dorsal del anticlinal (Figura 4.18e). La figura 4.18g muestra la orientación de los ejes de pliegue y de los planos axiales de las cuatro estructuras mapeadas. Tres de éstas presentan orientaciones bien definidas NNE-SSW con sus ejes buzando hacia 
el SSW (Rbz medio $188^{\circ} / 14^{\circ}$ ). La restante se orienta en forma perpendicular a las anteriores (Figura 4.18e). Los pliegues son suaves a abiertos según su ángulo interflanco, con alta inclinación de sus planos axiales. Uno de los pliegues de orientación NNE-SSW se relaciona directamente con una falla inversa que adquiere alto ángulo en la cobertura sedimentaria y que despega en el basamento (Figura 4.18e). El pliegue se ubica en el bloque colgante y posee vergencia occidental, al igual que el transporte de la falla. Su longitud de onda es de aproximadamente 90 metros. No se pudo medir su traza axial debido al grado de erosión en las cercanías de la falla. El par de pliegues anticlinal-sinclinal de orientación NNE-SSE presenta una longitud de las trazas axiales que alcanza los 100 metros, con una longitud de onda de aproximadamente 130 metros (Figura 4.18f). Dada su alineación con el pliegue anterior y con la falla inversa, estos pliegues podrían estar asociados a la terminación lateral de la misma (Figura 4.18e). El pliegue de dirección ESE-WNW, asimétrico y con vergencia hacia el Sur, está asociado a una falla inversa que pone al Subgrupo Pirgua en contacto con el Subgrupo Balbuena. Esta falla podría interpretarse como producto de la activación (o reactivación) de una discontinuidad del basamento, como se ha explicado en la sección 4.1.1.1 Núcleo: Pliegues en el basamento del núcleo del anticlinal Tin Tin. A pesar de el daño por falla y la erosión local, se pudo estimar una longitud de onda de alrededor de 100 metros o más.

Fallas en el sector de inmersión Sur del anticlinal Tin Tin

Una estructura de gran escala se destaca en el flanco dorsal del sector Sur del Cerro Tin Tin (Figura 4.17). Esta es una falla inversa de bajo ángulo con transporte hacia el Noroeste que sobrecorre y repite la sección estratigráfica superior del Subgrupo Balbuena por sobre la sección inferior del Subgrupo Santa Bárbara. Esta repetición de unidades se puede identificar claramente en el campo y en imágenes satelitales debido a las coloraciones características de las mismas. A grandes rasgos, la falla presenta una extensión aproximada de 5 kilómetros en dirección $\mathrm{N} 40^{\circ}$ (NE-SW) con inclinación hacia el Sureste. La repetición de unidades se observó claramente hacia las terminaciones Noreste y Suroeste de la falla, mientras que en una posición aproximadamente intermedia en su traza, esta característica no es clara (Figura 4.17). En este tramo se observaron evidencias de 
fallamiento (capas totalmente volcadas, afloramientos aislados del Subgrupo Santa Bárbara, material brechado con reducción de tamaño de grano y coloraciones solo observadas en presencia de zonas de falla) pero no se ve la repetición estructural en sí misma. Esto podría indicar que gran parte de los afloramientos representan la zona de falla propiamente dicha. Dadas las características tanto geométricas como de escala, esta falla es considerada como una única estructura. En el sector Sur del cerro, la dirección de la traza de la falla es ENE-WSW (aproximadamente N60) y la misma puede mapearse a lo largo de 2100 metros (Figura 4.19a). El plano de falla fue medido en seis afloramientos diferentes arrojando un valor de Rbz resultante de $154^{\circ} / 29^{\circ}$ (Figura 4.19e). Los pliegues en su bloque colgante (véase sección anterior: Pliegues del sector de inmersión Sur del anticlinal Tin Tin) indican un transporte hacia el Noroeste. La figura 4.19c-d muestra afloramientos de la falla en diferentes posiciones, donde se pueden ver las relaciones entre el techo y piso de la misma. En algunos sectores se observa un paralelismo entre el plano de falla y las capas que se encuentran por debajo (Figura 4.19d), mientras que en otros existe una marcada angularidad entre las capas y la falla (Figura 4.19c), indicando que la falla actuó posteriormente al inicio del plegamiento, posiblemente en un estado avanzado del pliegue, cortando a la secuencia sedimentaria del Subgrupo Santa Bárbara en forma oblicua. El bajo ángulo con el que el bloque colgante apoya sobre la falla (relación rampa colgante-plano basal, con ángulo $\beta$ muy bajo y $2 \gamma$ muy alto, Suppe, 1983), indica que el ángulo de corte es bajo también, de acuerdo al modelo teórico de Suppe (1983) para pliegues por flexión de falla. Otra observación importante es que, dada la inclinación medida del plano de falla, se puede inferir que la estructura no sufrió una deformación posterior importante (rotación de la falla debido al crecimiento del pliegue). Hacia la terminación Norte de la falla, la traza adquiere una orientación de azimut aproximado $\mathrm{N} 45^{\circ}$, con una longitud de 1200 metros (Figura 4.19a). Aquí la falla representa la continuación lateral de pliegues volcados y apretados con vergencia hacia el Oeste (Figura 4.19b). Un dato de $\mathrm{Rbz}$ tomado en la zona de falla arrojó un valor de $106^{\circ} / 31^{\circ}$, en concordancia con las inclinaciones de las capas en el techo de la misma a lo largo de la estructura. El espesor de la lamina repetida del Subgrupo Balbuena es de aproximadamente 30 metros. 


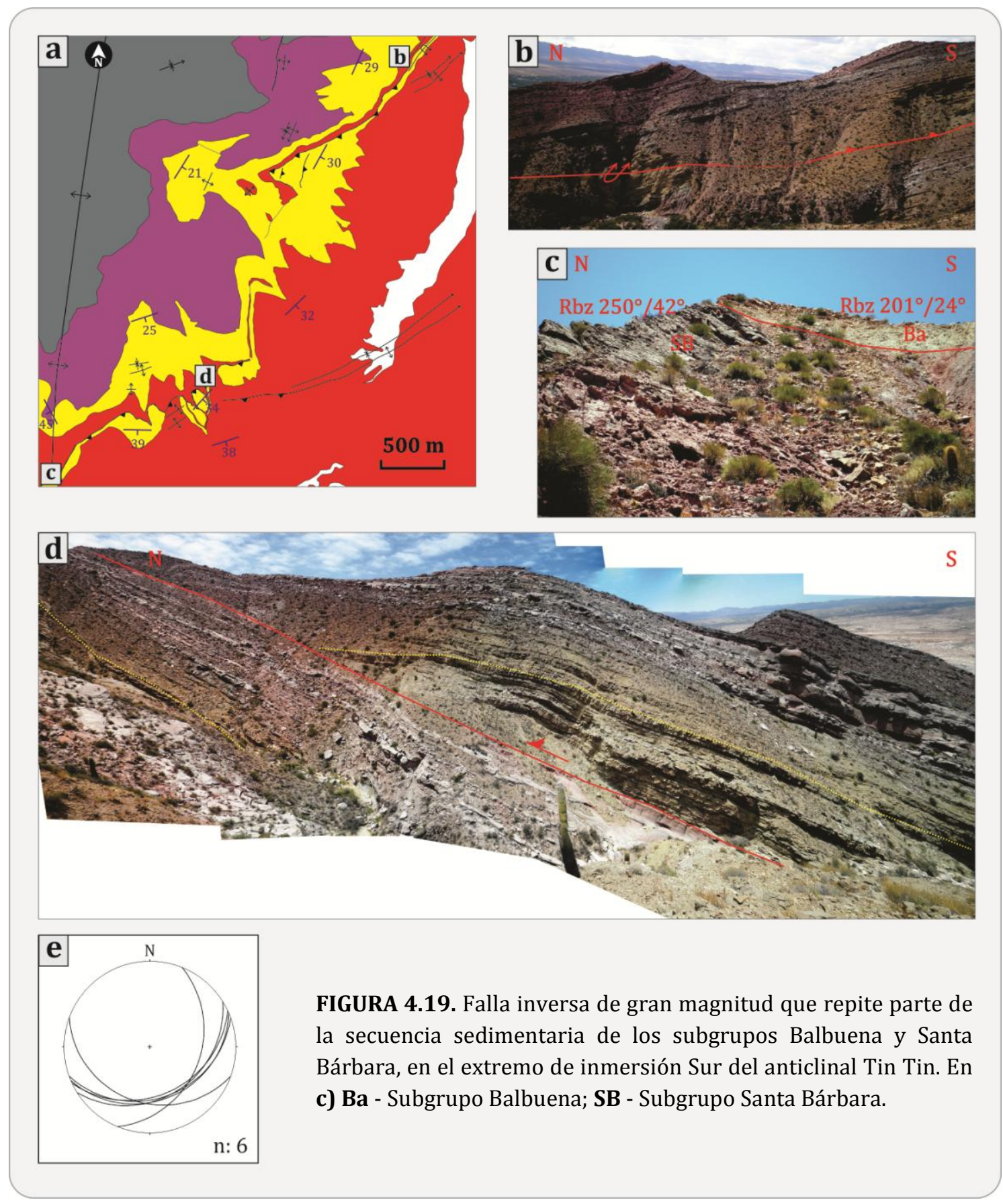

Otras fallas inversas de bajo ángulo presentes en el área responden a despegues locales y, por lo tanto, con dimensiones muy inferiores a las descriptas anteriormente. Como ejemplo puede citarse un grupo de fallas con transporte hacia el Oeste que repiten capas del Subgrupo Balbuena y se ubican en el techo de la falla principal (Figura 4.19f - recuadro azul). El desplazamiento visible (mínimo) es relativamente escaso, alcanzando unos 10 a 20 metros. Para la falla de mayor dimensión se midió una longitud de traza de 250 metros. La orientación medida sobre el plano de una de las estructuras arrojó un valor de $110^{\circ} / 25^{\circ}$. Otra 
estructura similar se observó en la charnela del pliegue, donde las capas son plegadas por arrastre debido al transporte hacia el Oeste de la falla (Figura 4.19g). En el Subgrupo Santa Bárbara se observó una falla inversa de bajo ángulo con transporte hacia el Noroeste como continuación lateral del pliegue de similar vergencia (véase Figura 4.18a). El azimut de la traza es $N 75^{\circ}$ y coincide con la quebrada que sigue su rumbo.

Fracturas con desplazamiento normal de alta inclinación se observan en varias posiciones de este sector afectando individualmente a las tres unidades del Grupo Salta. Con excepciones, la mayoría de estas estructuras tienen una orientación aproximadamente E-W y alta inclinación hacia el Norte (Figura 4.19h). Este tipo de fallas sólo pueden observarse en el corte de las quebradas, donde la sección muestra el desplazamiento (probablemente aparente) de las capas, lo que no hace posible determinar todas sus dimensiones. Las figuras $4.19 \mathrm{i}-\mathrm{j}-\mathrm{k}$ muestran algunas de las fallas medidas, donde se puede ver el desplazamiento de las capas, que varía entre decenas de centímetros hasta dos metros en el caso de la fractura que atraviesa la secuencia superior del Subgrupo Pirgua (Figura 4.19i). En la figura 4.19j se muestra una fractura que afecta al Subgrupo Santa Bárbara. Aquí se puede notar que la correspondencia entre las capas a un lado y otro de la falla no es exacta. Esto se debe a que, además de el corte no es perpendicular al rumbo de la estructura, las fallas podrían presentar desplazamiento de rumbo en concordancia con otras fracturas de menor escala (fracturas de cizalla y diaclasas cizalladas) presentes en la zona (descriptas en el capítulo siguiente). Ninguna de estas estructuras muestra evidencias claras de cizallamiento y/o brechamiento significativo, lo que sugeriría que su origen está relacionado al desarrollo de diaclasas de gran magnitud (o conjunto de diaclasas conectadas) reactivadas como fallas.

El mapeo de los Subgrupos Balbuena y Santa Bárbara sobre los escasos afloramientos del flanco frontal sugiere un control estructural sobre los cambios de espesor observados principalmente en la Formación Yacoraite (Figura 4.19l). 


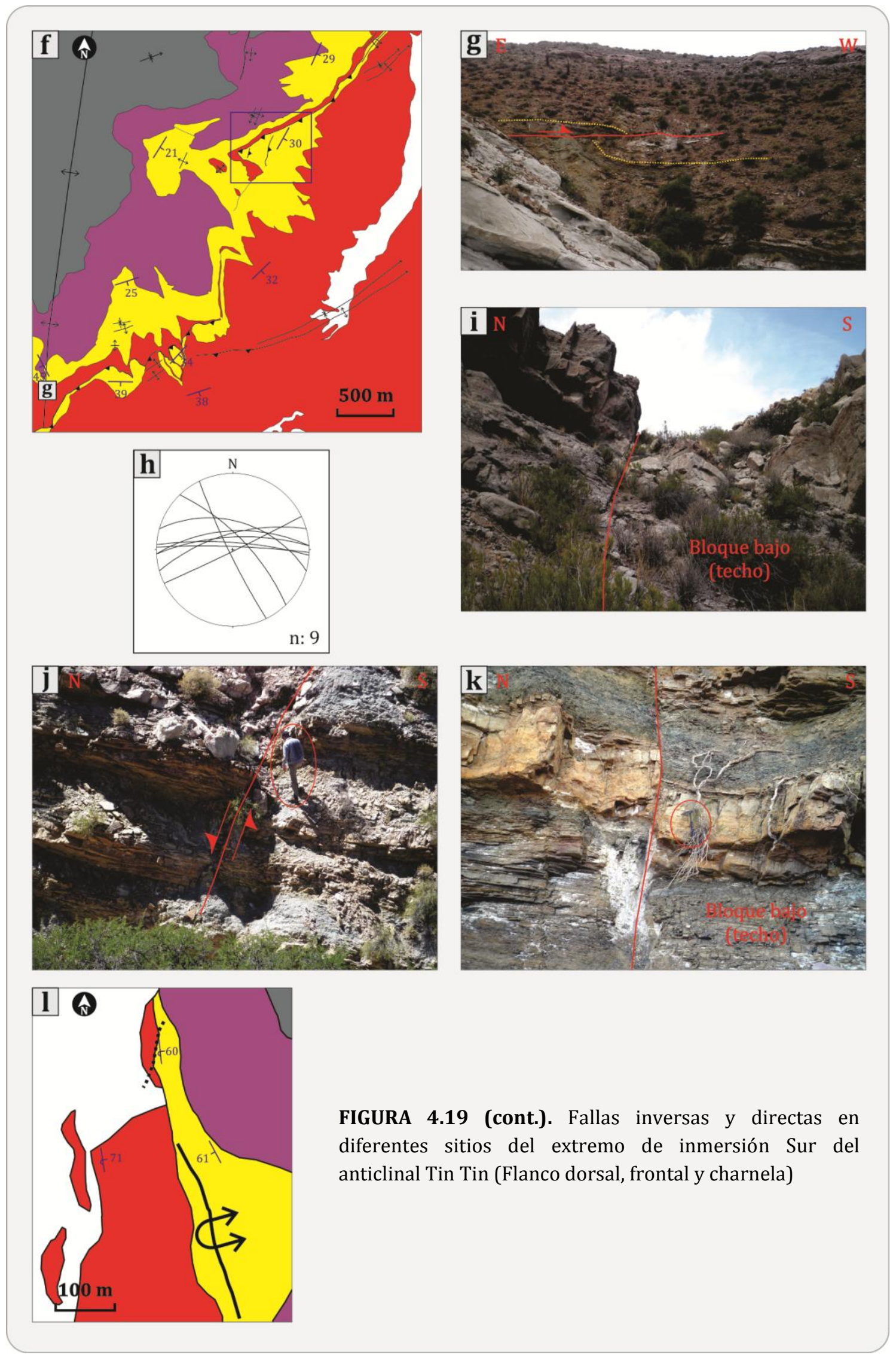




\subsubsection{Observaciones estructurales en un bloque de basamento en las cercanías del Cerro Malcante}

Este sector corresponde a un bloque de basamento de la Formación Puncoviscana con características similares al Cerro Tin Tin. Este bloque es levantado por una falla inversa de inclinación hacia el Este dentro de la zona correspondiente al alto o dorsal Salto- Jujeña (Figuras 1.2 y 1.3). Sobre la vertiente oriental del bloque apoya la secuencia sedimentaria correspondiente al postrift del Grupo Salta, los Subgrupos Balbuena y Santa Bárbara (Figura 4.20a). Este bloque fue mapeado en forma expeditiva con el fin de complementar los datos zonales. La secuencia sedimentaria presenta una inclinación hacia el Este con valores angulares que oscilan entre los $37^{\circ}$ y $60^{\circ}$. La secuencia se encuentra afectada por una falla inversa de bajo ángulo que recorre gran parte del flanco de este bloque (Figura 4.20a). Esta falla despega en la Formación Yacoraite y sobrecorre la parte superior de esta formación por encima de la secuencia basal del Subgrupo Santa Bárbara (Figura 4.20a-b). A una escala menor, se observaron capas plegadas dentro de la secuencia, con ejes de pliegue paralelos a la estructura general (Figura 4.20c). Otra observación importante son fallas inversas dentro del basamento, de orientación paralela a la estructura general y bajo ángulo (inferido) hacia el Este, en concordancia con la estructuración zonal. Estas fallas son evidentes porque afectan a la Formación Yacoraite, dejando afloramientos aislados dentro del basamento (Figura 4.20a-e). Es importante destacar que la estructuración interna del basamento presenta características similares al del Cerro Tin Tin, con pliegues de orientación E-W, de flancos rectos y charnelas agudas (Figura 4.20d). 


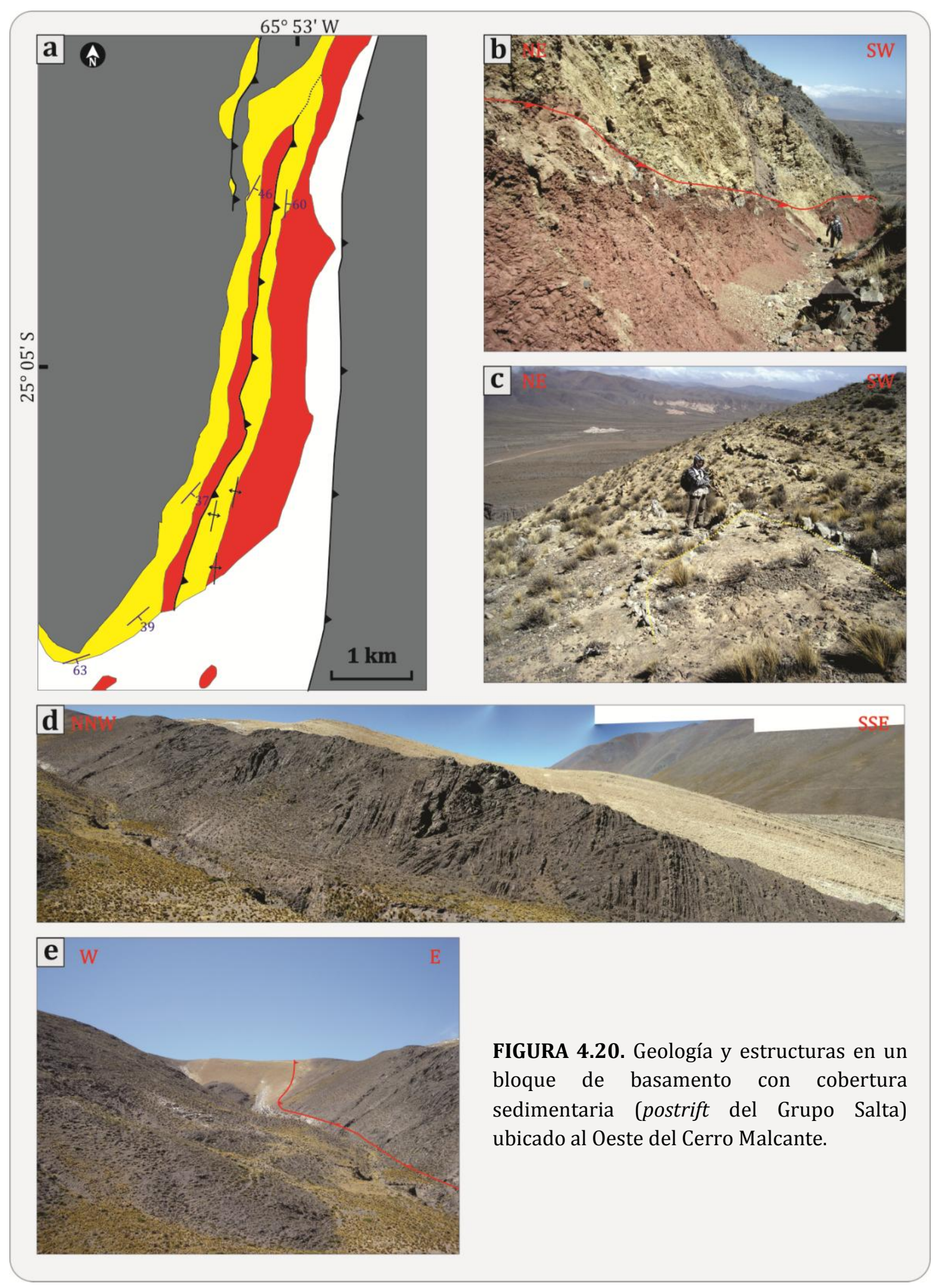




\subsection{Anticlinal Cerro Bayo}

Con el objetivo de establecer un marco más regional para la deformación y comparar las características estructurales en diferentes sectores de la zona de Valles Calchaquíes, se llevó a cabo un estudio estructural en el anticlinal Cerro Bayo, localizado entre el paraje Isonza y la localidad de Amblayo (Figura 4.3). El anticlinal presenta una forma arqueada en planta, cóncava hacia el Este, con inmersión en ambos extremos. En su sector central, la estructura presenta un rumbo general N-S mientras que en sus extremos cambia el rumbo curvándose hacia el Este. En el extremo Sur la curvatura es más suave, pasando de rumbo N-S a NNW-SSE. Su extremo Norte presenta una curvatura más compleja, ya que se produce un cambio de rumbo de N-S a NE-SW y luego a ESE-WSW (Figura 4.21). Esta complejidad sería el resultado de una falla extensional de rumbo E-W e inclinación hacia el Norte, interpretada por Carrera et al. (2009) como una falla con desplazamiento de rumbo (tear fault). Al Norte de esta falla, las capas aflorantes del Subgrupo Santa Bárbara se pliegan conformado dos anticlinales con un sinclinal de por medio, como muestra el mapa de la figura 4.21.

Este pliegue es descripto por Carrera et al. (2009) como un anticlinal con basamento involucrado en su formación (basement-involved fold), asimétrico y con vergencia occidental. Su origen está relacionado a la actividad de una falla inversa de rumbo aproximado N-S y alta inclinación hacia el Este que lo flanquea en su vertiente occidental y pone su flanco frontal por encima de sedimentos sinorogénicos cenozoicos (Carrera et al., 2009). A pesar de ser definido como un pliegue con basamento involucrado, su relación con el basamento no es tan evidente como en el anticlinal Tin Tin, ya que éste se encuentra a mayor profundidad en este sector. Sin embargo, sus características discontinuas (doble inmersión) y el marco geológico/estructural de la zona hacen que la definición sea válida. Otra clasificación aceptable dado el marco geológico, es la de un pliegue por propagación de falla, pero sus características geométricas estarían relacionadas a una falla inversa de mediano ángulo de inclinación (Suppe y Medwedeff, 1990), que contrastarían con las descripciones del anticlinal. Un resultado posible es la combinación de las definiciones mencionadas. 
Las dimensiones del anticlinal son menores a las del anticlinal Tin Tin, con una longitud aproximada de 9 kilómetros en la dirección de su rumbo y un ancho de 3 a 4 kilómetros en dirección W-E en su parte central (Figura 4.21). Estratigráficamente está compuesto por el Grupo Salta y en una posición más externa, la parte inferior del Grupo Payogastilla, aunque las unidades que resaltan y que conforman el alto topográfico (Cerro Bayo) son el Subgrupo Pirgua en el núcleo del anticlinal, y en los flancos el Subgrupo Balbuena y parte basal del Subgrupo Santa Bárbara (Figura 4.21).

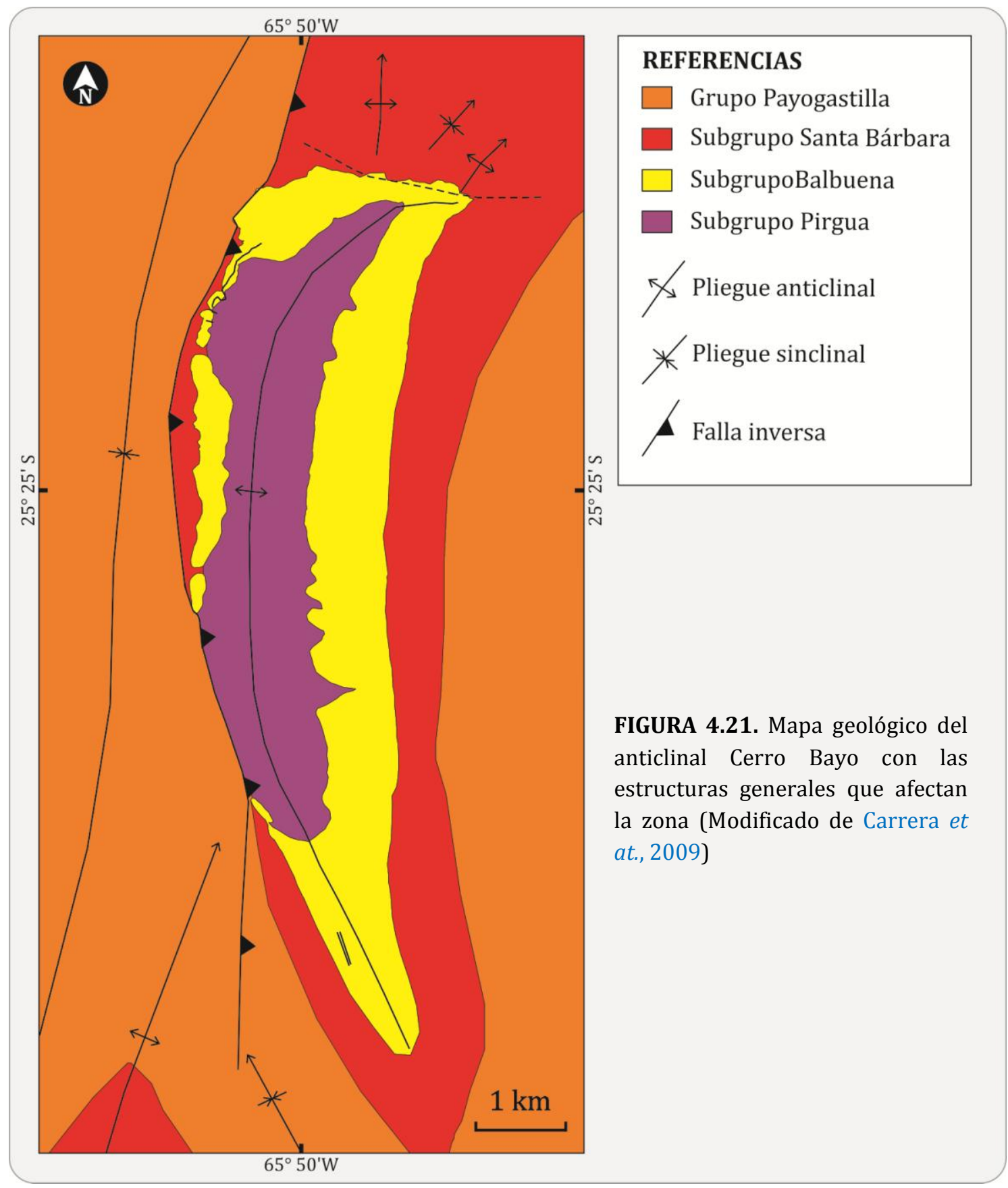


El flanco frontal del anticlinal se encuentra parcialmente erosionado (en el sector Suroeste del pliegue) y presenta inclinaciones que van desde los $20^{\circ}$ hasta los $84^{\circ}$ hacia el W-WNW (promedio de $59.5^{\circ}$ ), además de capas subverticales y volcadas debido a estructuraciones internas del flanco (Figura 4.22a). En general las menores inclinaciones se presentan en las cercanías de los extremos de inmersión, mientras que en el sector central del pliegue las inclinaciones son las máximas medidas. El flanco dorsal es más tendido y se encuentra completo. Las mediciones de orientación (Rbz) de capas en este flanco muestran más uniformidad en sus valores a lo largo de toda la estructura, con inclinaciones que van desde los $24^{\circ}$ hasta los $47^{\circ}$ hacia el E-ESE, con un promedio de $33^{\circ}$ (Figura 4.22b).
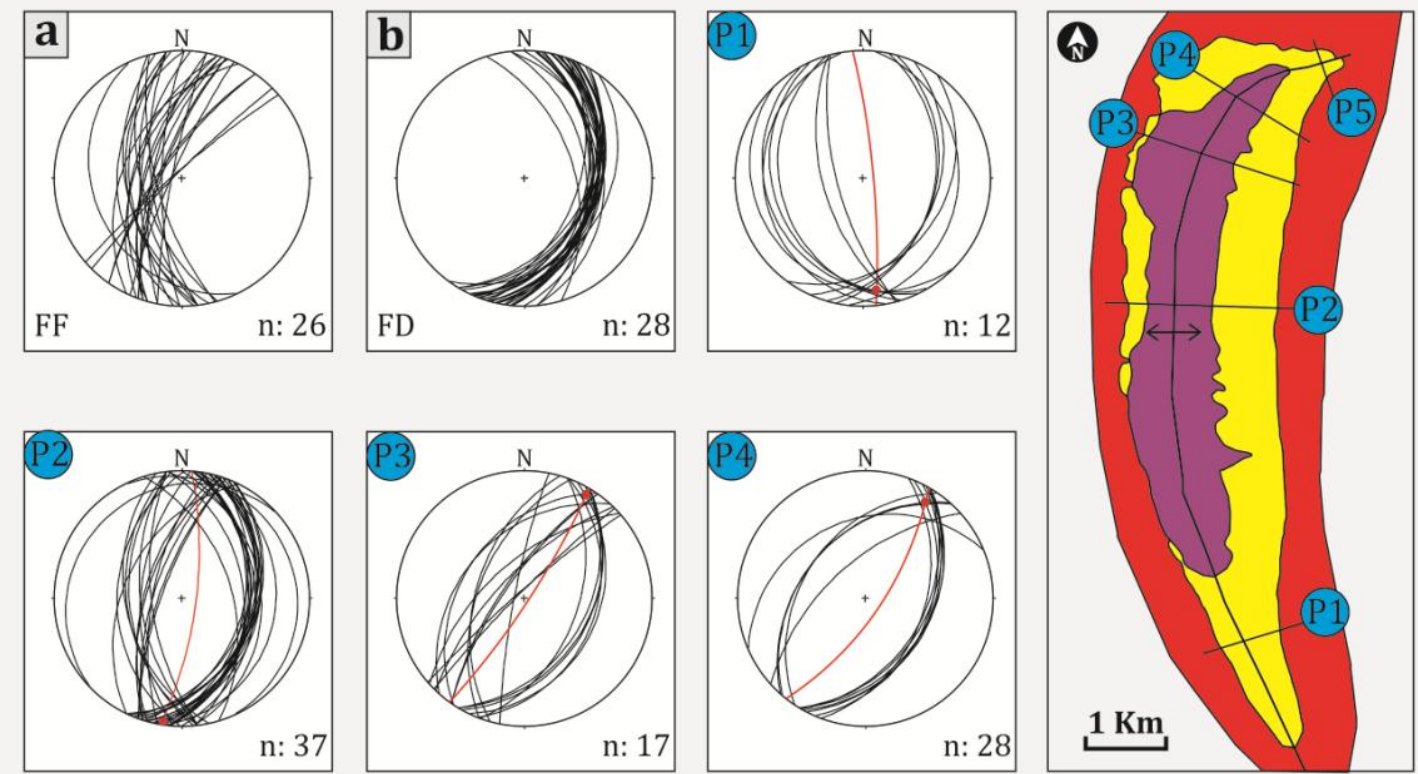

FIGURA 4.22. Diagramas estereográficos del a) flanco frontal y b) flanco dorsal del anticlinal Cerro Bayo. Las transectas P1 a P5 marcan los sectores donde se tomaron los datos para los cálculos de elementos geométricos (eje de pliegue, plano axial, ángulo interflanco).

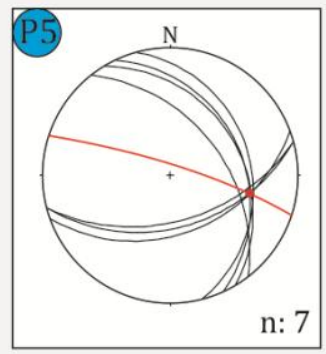

Las características geométricas del anticlinal Cerro Bayo (orientación del eje de pliegue, orientación del plano axial, ángulo interflanco) se determinaron a partir de mediciones de $\mathrm{Rbz}$ en capas sedimentarias sobre ambos flancos, principalmente sobre la Formación Yacoraite del Subgrupo Balbuena. Las 
mediciones se realizaron en diferentes posiciones del pliegue ya que éste muestra cambios en su rumbo. En el extremo de inmersión Sur (Figura 4.22-P1) las mediciones arrojaron un valor de $\mathrm{Rbz}$ de $168^{\circ} / 5^{\circ}$ para el eje de pliegue, con un plano axial de $\mathrm{Rbz} 79^{\circ} / 70^{\circ}$ y un ángulo interflanco de $110^{\circ}$ (pliegue abierto). En el centro del pliegue (Figura 4.22-P2) las mediciones arrojaron un valor de Rbz de $188^{\circ} / 1^{\circ}$ para el eje de pliegue, con un plano axial de $\mathrm{Rbz} 102^{\circ} / 78^{\circ}$ y un ángulo interflanco de $95^{\circ}$ (pliegue abierto). En el sector Norte del anticlinal se realizaron mediciones en tres posiciones cercanas entre sí, para describir mejor los cambios en el rumbo (Figura 4.22-P3-P4-P5). En la posición P3, las mediciones arrojaron un valor de $\mathrm{Rbz}$ de $33^{\circ} / 3^{\circ}$ para el eje de pliegue, con un plano axial de $\mathrm{Rbz} 123^{\circ} / 82^{\circ}$ y un ángulo interflanco de $79.5^{\circ}$ (pliegue abierto). En la posición P4, las mediciones arrojaron un valor de $\mathrm{Rbz}$ de $37^{\circ} / 7^{\circ}$ para el eje de pliegue, con un plano axial de $\mathrm{Rbz} 124^{\circ} / 73^{\circ}$ y un ángulo interflanco de $78^{\circ}$ (pliegue abierto). En la posición P5, las mediciones arrojaron un valor de $\mathrm{Rbz}$ de $103^{\circ} / 25^{\circ}$ para el eje de pliegue, con un plano axial de $\mathrm{Rbz} 18^{\circ} / 81^{\circ}$ y un ángulo interflanco de $125^{\circ}$ (pliegue suave). Estos valores indican un eje de pliegue subhorizontal o de baja inclinación para el sector central del pliegue y un leve aumento de inclinación en los extremos (mayor en el extremo Norte), como se describió anteriormente. El plano axial presenta, mayormente, inclinación hacia el Este, con alto ángulo a lo largo de todo el anticlinal, mancando su vergencia occidental.

\subsubsection{Características mesoestructurales}

En comparación con en anticlinal Tin Tin, el Cerro Bayo presenta un número mucho menor de estructuras de mediana escala (pliegues y fallas) que afectan a los flancos y charnela. La observación realizada sobre imágenes satelitales resaltó irregularidades estratigráficas y estructurales (cambios de espesor, terminaciones abruptas en secuencias sedimentarias, variaciones en las inclinaciones de capas) principalmente en el flanco frontal, mientras que sobre el flanco dorsal no se detectaron estructuras importantes. Estas observaciones fueron luego constatadas a través del relevamiento de campo y mapeo geológico de las unidades del anticlinal. La Formación Yacoraite del Subgrupo Balbuena fue la unidad mas estudiada debido al objetivo comparativo de la fracturación de mesoescala (de afloramiento) sobre ambos anticlinales. En esta unidad se 
encuentra la mayoría de las estructuras de deformación, posiblemente por la presencia de facies areno-arcillosas y arcillosas (Ruiz Huidobro, 1955) que constituyen posibles planos de debilidad y facilitan la deformación.

\subsubsection{Flanco frontal del anticlinal Cerro Bayo}

El flanco frontal se caracteriza por capas con alta inclinación hacia el Oeste (posición normal), capas subverticales y capas volcadas (inclinación hacia el Este) evidenciadas por estructuras estromatolíticas en las calizas.

El primer sector de descripción se ubica en el centro-norte del cerro (Figura 4.23a). En este afloramiento se registró un par anticlinal-sinclinal, siendo el anticlinal una estructura volcada. La longitud de onda aproximada de los pliegues en conjunto es de 25 metros y afectan a capas del techo de la Formación Yacoraite, cerca del contacto con el Subgrupo Santa Bárbara.

El anticlinal volcado, determinado por capas estromatolíticas (Figura 4.23bc), tiene un eje de pliegue de $\mathrm{Rbz} 23^{\circ} / 24^{\circ}$, con plano axial de $\mathrm{Rbz} 69^{\circ} / 34^{\circ}$ y ángulo interflanco de $46^{\circ}$ (pliegue cerrado). El plano axial del anticlinal volcado podría corresponder a un plano de falla que produce el volcamiento, ya que se observó una zona de material brechoso en su núcleo. El sinclinal tiene un eje de pliegue de $\mathrm{Rbz} 355^{\circ} / 24^{\circ}$, plano axial de $\mathrm{Rbz} 84^{\circ} / 86^{\circ}$ y ángulo interflanco de $145^{\circ}$ (pliegue suave). Como dato adicional para este sitio, se midió una ondulación de mayor escala (70 metros de longitud de onda aproximadamente) en las capas superiores de la Formación Yacoraite (Figura 4.23d). Este pliegue anticlinal tiene un eje de $\operatorname{Rbz} 212^{\circ} / 41^{\circ}$, con plano axial de $\operatorname{Rbz} 169^{\circ} / 50^{\circ}$ y ángulo interflanco de $141^{\circ}$ (pliegue suave). 

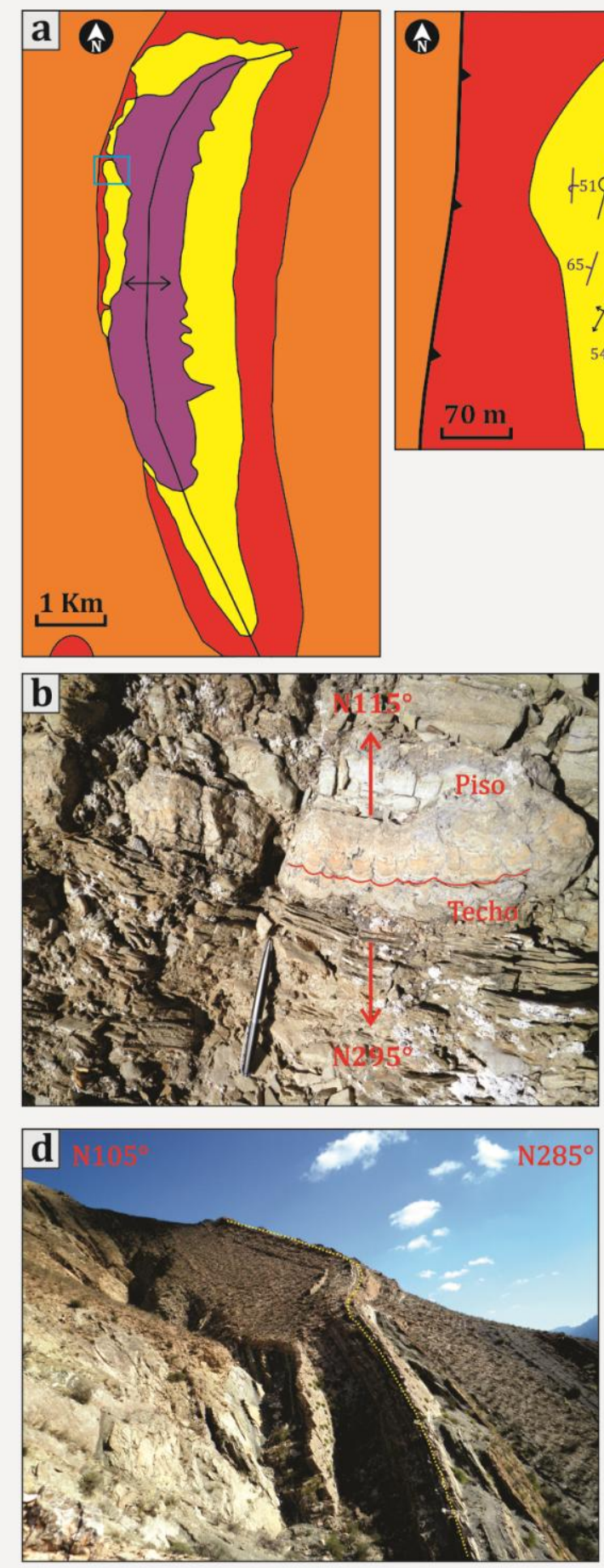

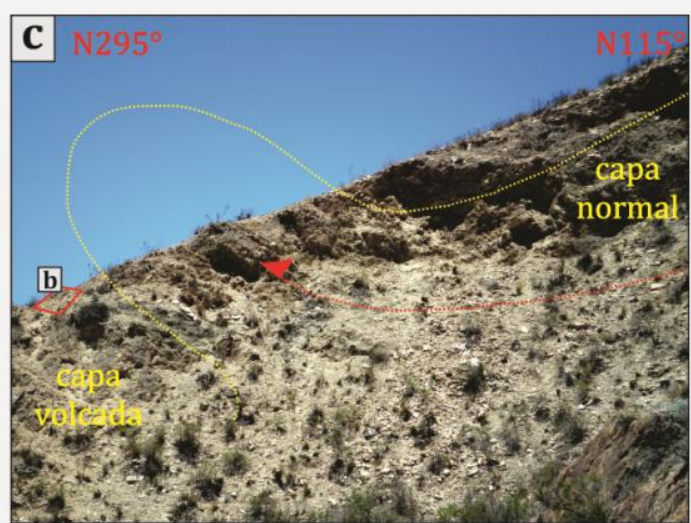

FIGURA 4.23. Sector del flanco frontal. a) Mapa geológico del sitio estudiado. b) Estromatolitos indicando el volcamiento de las capas. c) Anticlinal volcado. d) Pliegue en la secuencia sedimentaria del Subgrupo Balbuena.

En otro sector del anticlinal se observó la zona de falla principal vinculada con la formación y levantamiento del anticlinal Cerro Bayo (Figura 4.24a-b-c-d). La falla pone el flanco frontal del anticlinal (subgrupos Balbuena y Santa Bárbara) por encima de sedimentos sinorogénicos cenozoicos (Grupo Payogastilla), que al Oeste de la falla (bloque basal) presentan alta inclinación hacia el SE, con $\mathrm{Rbz} 136^{\circ} / 72^{\circ}$ (Figura 4.24a). 
La zona del bloque colgante de la falla (sector de flanco frontal) está altamente estructurada como se puede ver en la fotografía de la figura 4.24a-b. En este sitio la secuencia sedimentaria correspondiente a la sección superior de la Formación Yacoraite y la inferior del Subgrupo Santa Bárbara se encuentra invertida y en contacto por falla (principal) con los sedimentos anaranjados del Grupo Payogastilla (Figura 4.24b). Por encima de esta secuencia invertida y por medio de una falla de muy bajo ángulo, se encuentra nuevamente la Formación Yacoraite con una orientación diferente a las capas que se encuentran por debajo. Los datos de Rbz de capa recolectados se muestran el mapa de la figura 4.24b. La fotografía de la figura 4.24e muestra capas plegadas en la Formación Yacoraite que evidencian un transporte hacia el Noroeste por encima de la falla de muy bajo ángulo. Hacia el Sur de la quebrada se midieron capas invertidas de la Formación Yacoraite adyacentes a capas normales de la misma formación (Figura 4.24a). El contacto entre las dos secuencias de capas no se puede observar debido a su cobertura por derrubio. 

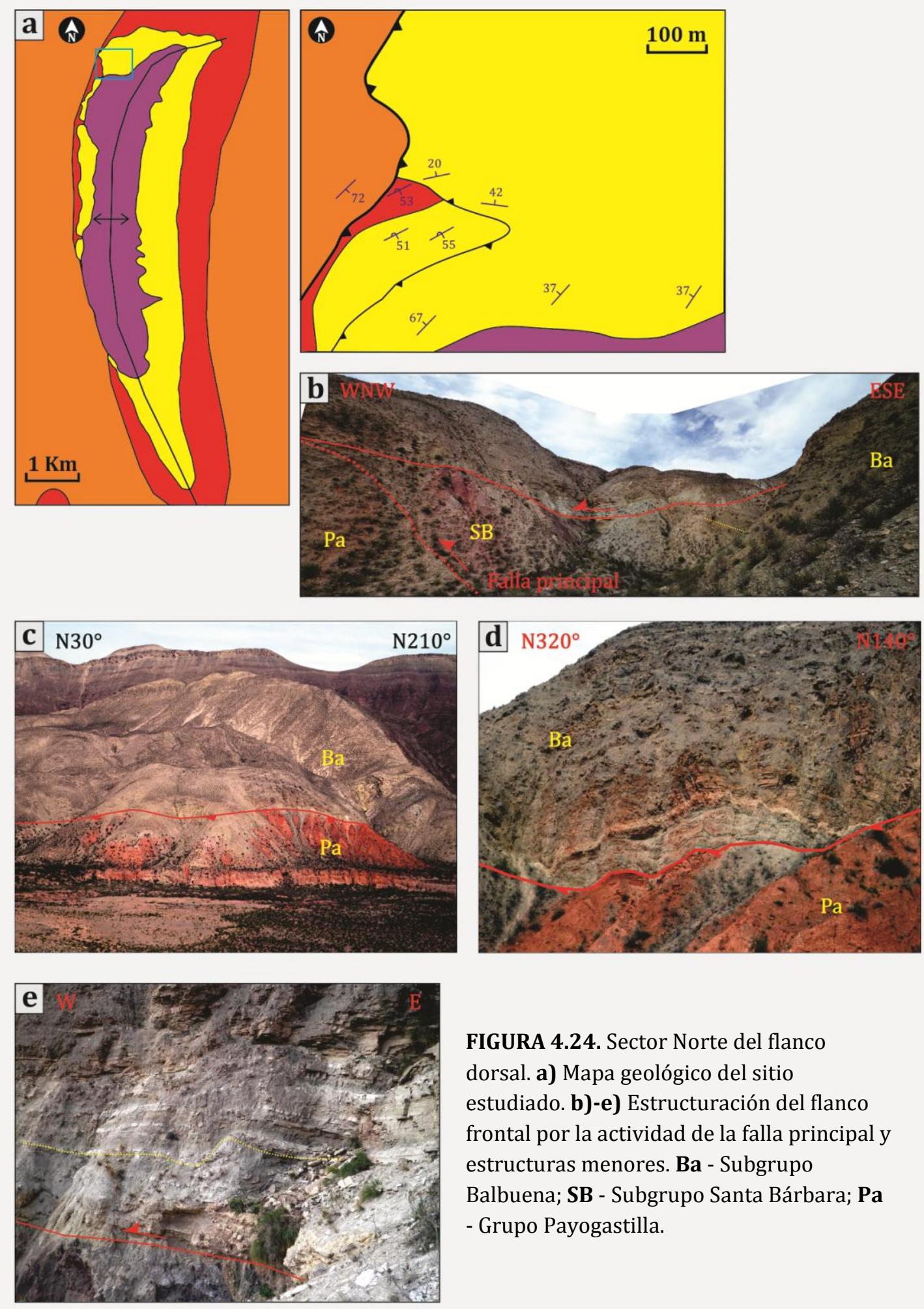

FIGURA 4.24. Sector Norte del flanco dorsal. a) Mapa geológico del sitio estudiado. b)-e) Estructuración del flanco frontal por la actividad de la falla principal y estructuras menores. Ba - Subgrupo Balbuena; SB - Subgrupo Santa Bárbara; Pa - Grupo Payogastilla.

Hacia el Sur de la zona descripta anteriormente, en otro sitio del flanco frontal, las características estructurales se mantienen (Figura 4.25a). Se mapearon capas de alta inclinación a subverticales hacia el núcleo del anticlinal y capas invertidas hacia afuera del mismo, pero no se observó la relación entre ambos 
dominios por la cobertura de derrubios. También se observaron fallas que desplazan el contacto en entre calizas amarillentas y las sedimentitas azuladas de la sección basal del Subgrupo Balbuena (Figura 4.25b).

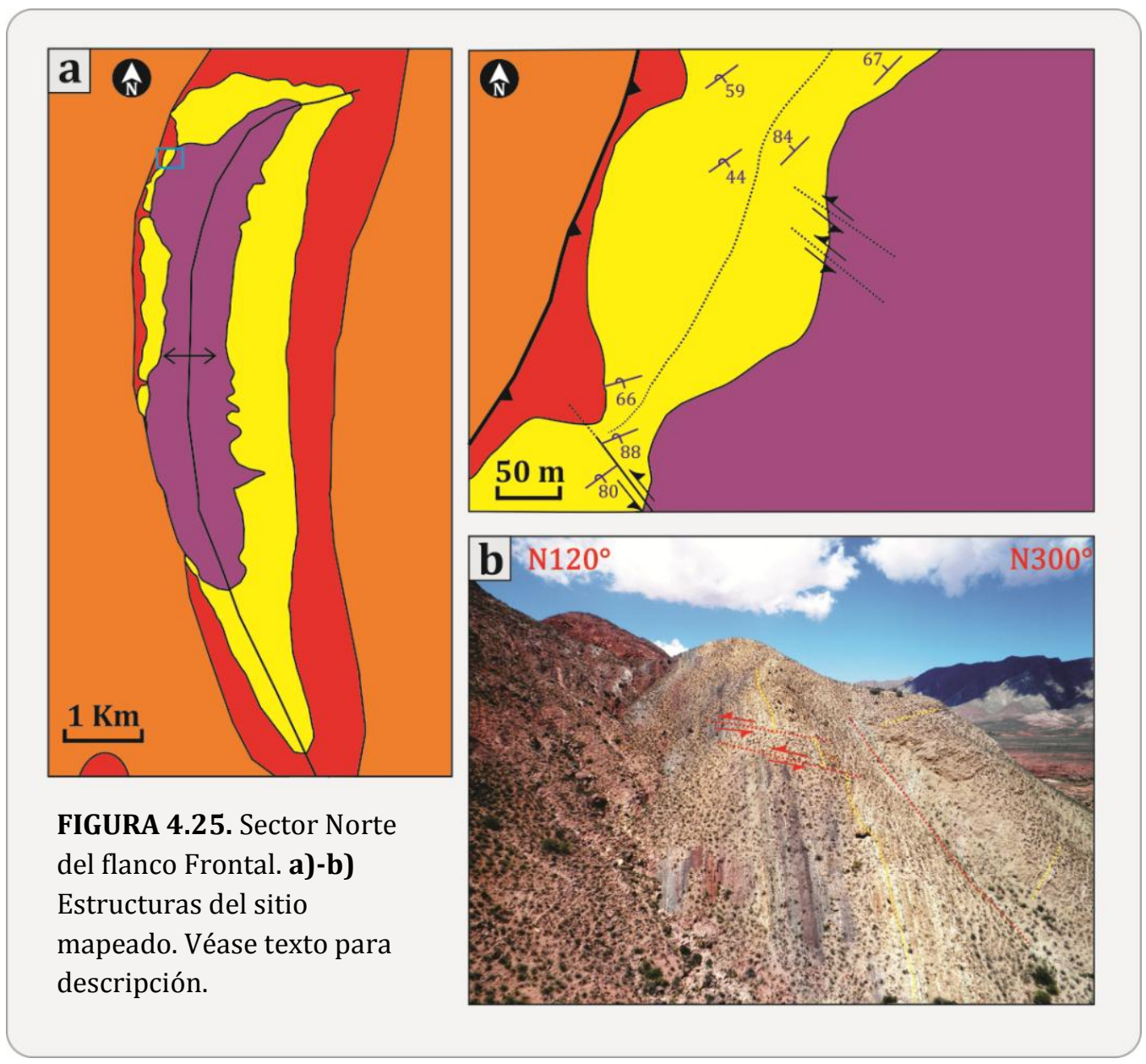

En otro sitio de medición y mapeo sobre el flanco frontal se observó y midió un conjunto de fallas que afectan a los Subgrupos Balbuena y Pirgua (Figura 4.26a). Se observó una falla con una traza de aproximadamente 90 metros, que en planta desplaza sinestralmente la secuencia sedimentaria en la transición entre los dos subgrupos (Figura 4.26b). La falla tiene un rumbo NW-SE, subvertical o con inclinación hacia el Suroeste. El desplazamiento es de 25 a 30 metros y muestra un arrastre de las capas afectadas. Hacia el Sur de este sitio se observó una estructura similar en dimensiones y cinemática (Figura 4.26a). Otra estructura importante es una falla inversa que posiciona capas del Subgrupo Pirgua por encima de capas verticales de las sedimentitas finas transicionales entre ambos subgrupos (Figura 4.26a-c-d). Se midió el plano de falla, arrojando un valor de $\mathrm{Rbz}$ de $164^{\circ} / 65^{\circ}$. 
En las cercanías de la segunda falla de rumbo de este sector, se encontró una zona de falla inversa, donde se pudo medir un Rbz de 83\% $/ 27^{\circ}$ (Figura 4.26a). Se considera que esta falla es la que separa las capas normales y volcadas dentro de la secuencia de la Formación Yacoraite.

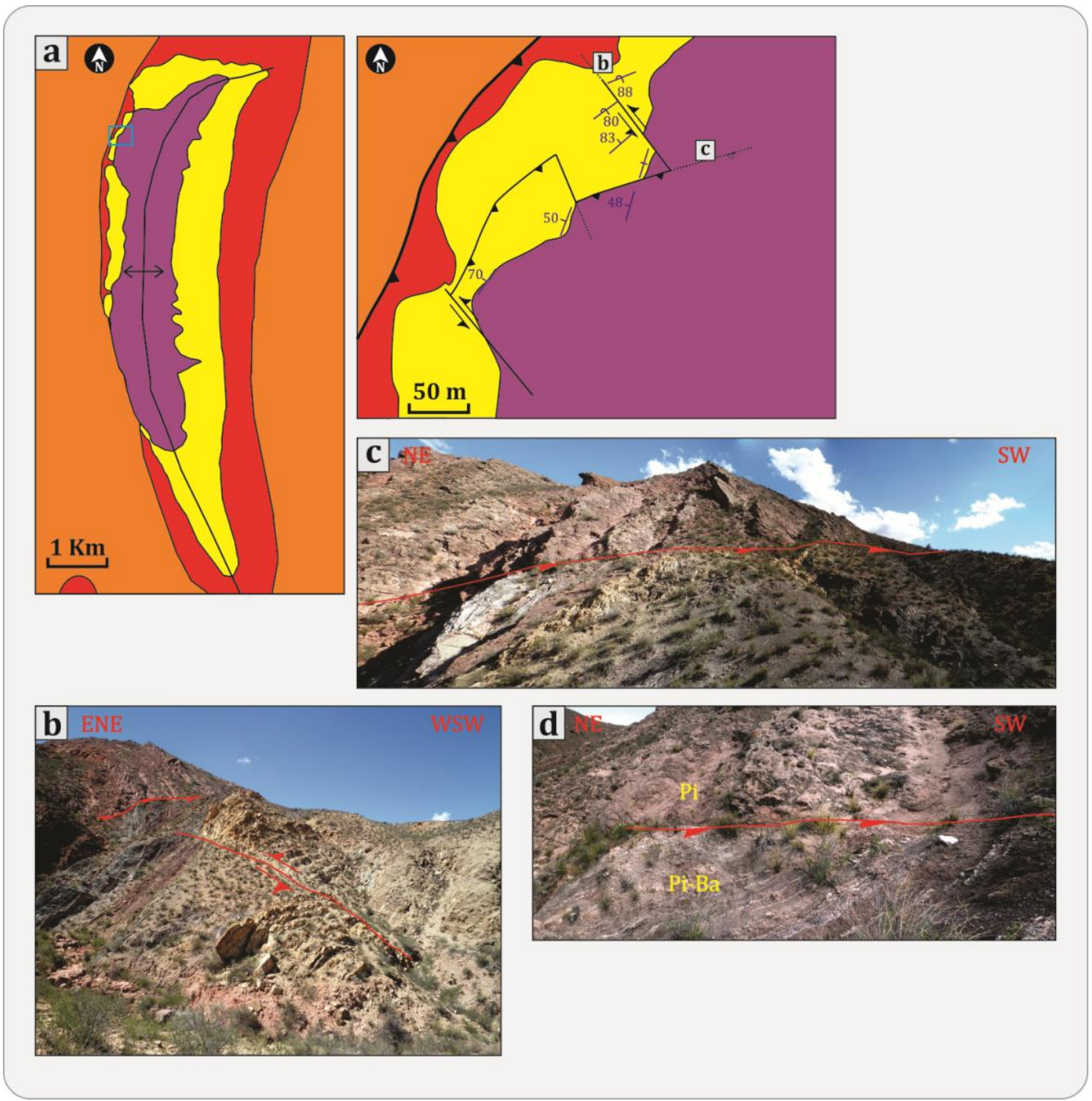

FIGURA 4.26. Sector Norte del flanco frontal. a)-d) Fallas inversas y estructuras con desplazamiento de rumbo. Véase texto para descripción. Pi - Subgrupo Pirgua; Pi-Ba - Transición entre los subgrupos Pirgua y Balbuena.

En el centro del anticlinal, sobre su flanco frontal se observaron deformaciones en la sección media de la secuencia de la Formación Yacoraite (Figura 4.27a). Las capas sedimentarias correspondientes al Subgrupo Balbuena en este sector presenta alta inclinación hacia el Oeste. La fotografía de la figura 
4.27b muestra como las capas cambian su inclinación en una posición más interna del flanco frontal. Dentro de la secuencia sedimentaria se observaron capas verticales en contacto con capas que inclinan hacia el Oeste con bajo ángulo (Figura 4.27a-c). La secuencia está compuesta por intercalaciones de material fino y capas de areniscas y calizas, con un brechamiento importante en las zonas de contacto entre ambos dominios de inclinación. Esta estructuración se asemeja a las descriptas para los otros sectores de este flanco.

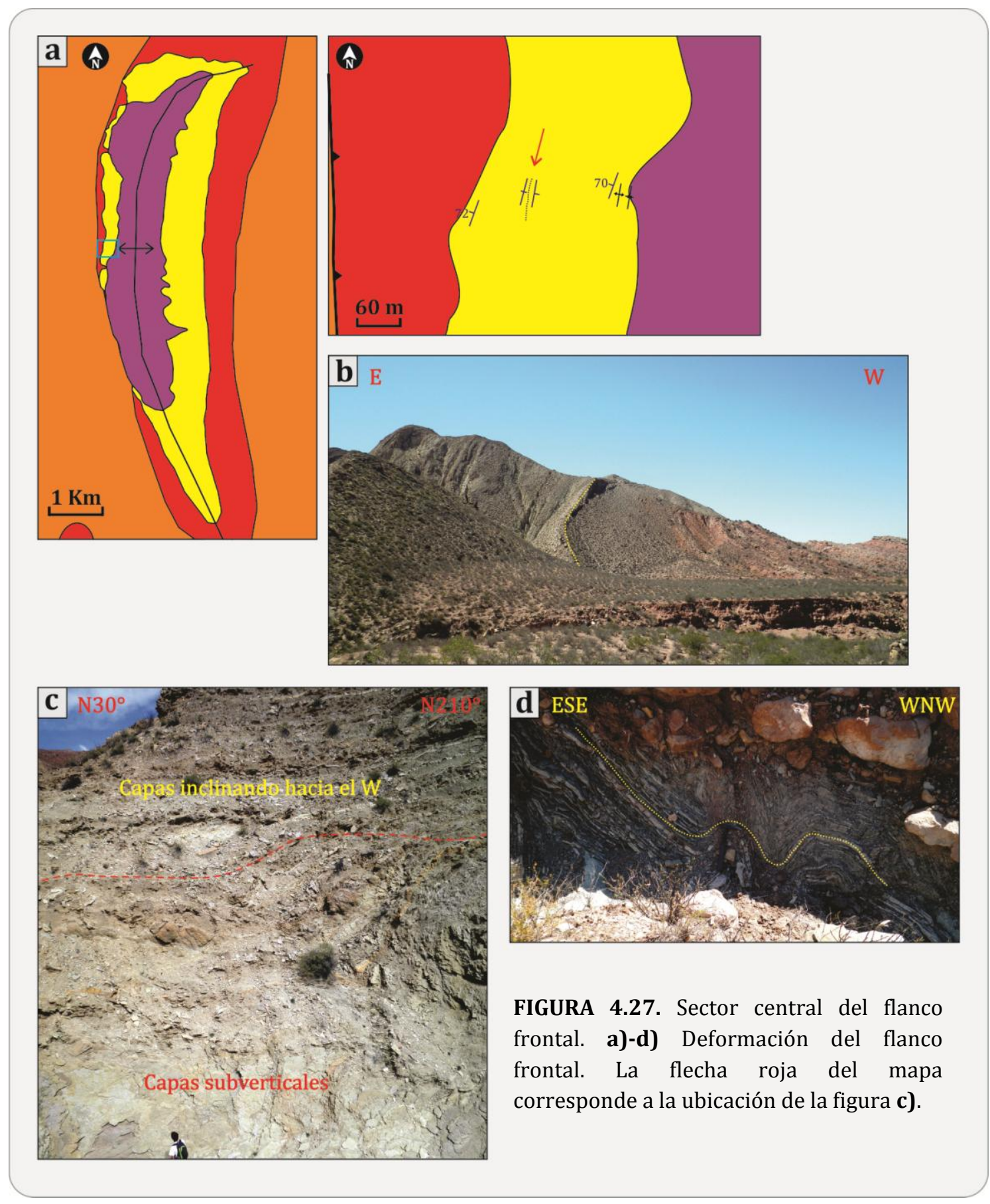


En la base del Subgrupo Balbuena, en transición con el Subgrupo Pirgua, se observaron pliegues con vergencia occidental (Figura 4.27d). Esta cinemática concuerda con el mecanismo de deslizamiento flexural (flexural slip) para este flanco como parte del crecimiento del anticlinal.

\subsubsection{Extremo de inmersión Sur del anticlinal Cerro Bayo}

En este sector se midió y mapeó un par de pliegues anticlinal-sinclinal afectando a la sección superior de la Formación Yacoraite (Figura 4.28a-b), donde las rocas son calizas oolíticas, estromatolíticas. Las características geométricas del par de pliegues son idénticas, por lo que se infiere una formación simultanea. Para el anticlinal, las mediciones arrojaron un valor de $\mathrm{Rbz}$ de $166^{\circ} / 2^{\circ}$ para el eje de pliegue, con un plano axial de $\operatorname{Rbz} 256^{\circ} / 86^{\circ}$ y un ángulo interflanco de $130^{\circ}$ (pliegue suave). El sinclinal presenta un eje de pliegue de $\mathrm{Rbz} 166^{\circ} / 2^{\circ}$, con un plano axial de $\mathrm{Rbz} 77^{\circ} / 88^{\circ}$ y ángulo interflanco de $126^{\circ}$ (pliegue suave). Con respecto a las dimensiones de estas estructuras, la longitud de onda (compuesta por ambos pliegues) es de aproximadamente 65 metros. La traza axial mínima, debido a erosión, puede ser seguida por 500 metros. 


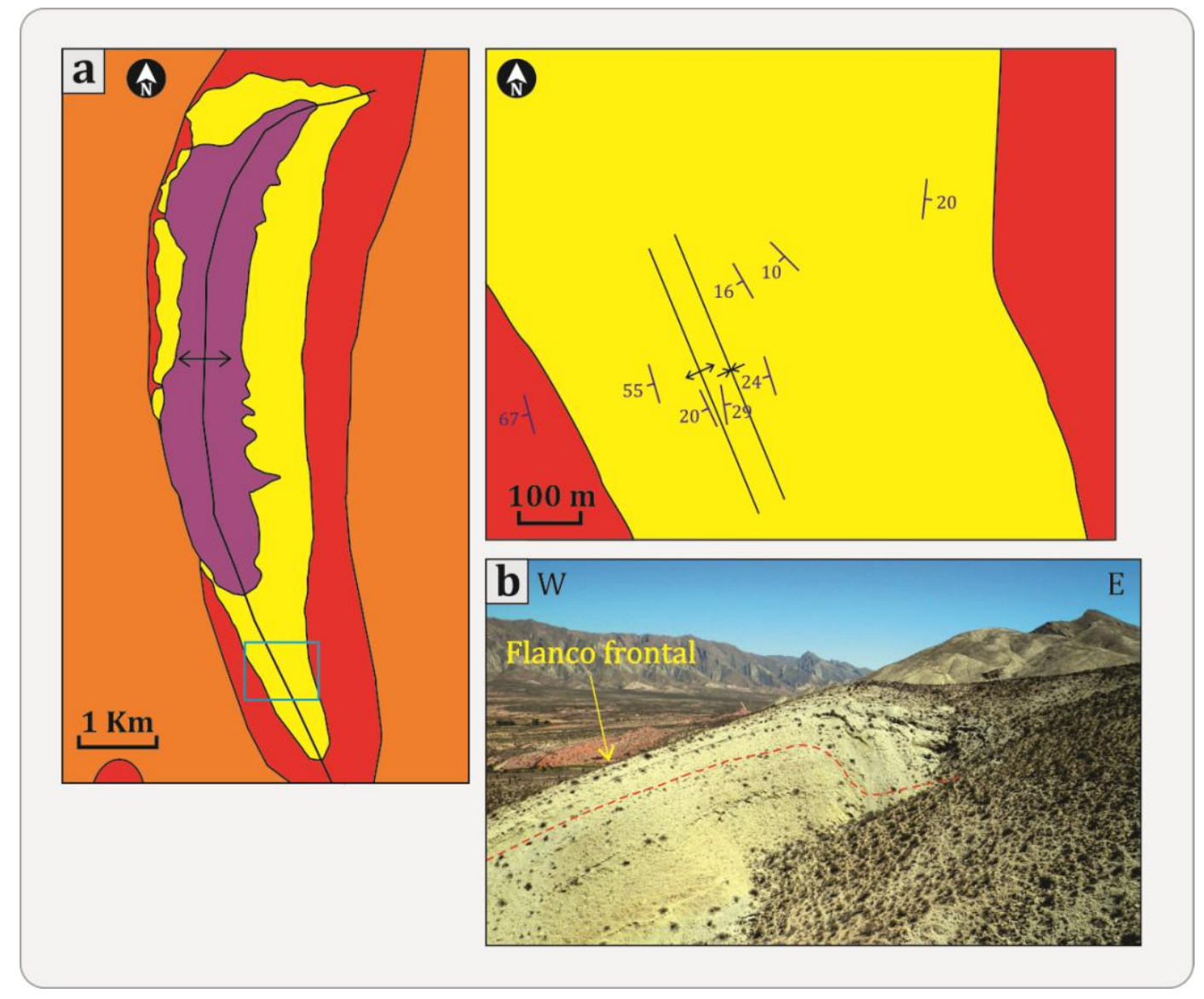

FIGURA 4.28. Sector de inmersión Sur del anticlinal Cerro Bayo. Pliegues en el flanco frontal.

A pesar de las diferencias en escala, las características geométricas de este par de pliegues se asemejan a las de la estructura general (anticlinal Cerro Bayo) para este sector, por lo que se infiere que se formaron durante su crecimiento. 


\section{CAPÍTULO 5 \\ FRACTURAS A ESCALA DE AFLORAMIENTO}




\section{CAPITULO 5 - FRACTURAS A ESCALA DE AFLORAMIENTO}

\subsection{Introducción}

De todas las estructuras de deformación presentes en el anticlinal Tin Tin y Cerro Bayo, las fracturas que se observan en los afloramientos de roca (escala mesoscópica) son por mucho las más abundantes. Estas afectan a todas las unidades geológicas que conforman el anticlinal, siendo la Formación Yacoraite del Subgrupo Balbuena la más afectada por este tipo de deformación frágil. Estas estructuras son las diaclasas, venas y fracturas de cizalla (Engelder, 1987). En general ocurren en gran número, con similar orientación y arreglo espacial, formando familias o sets de fracturas. Cuando un mismo volumen de roca es afectado por dos o más sets, se lo denomina sistema de fracturas (Twiss y Moores, 2007). Las diaclasas son fracturas de apertura, en la que el movimiento de sus superficies es perpendicular a su plano. Las venas son diaclasas rellenas por material (en general calcáreo o cuarzoso) depositado por fluidos circulantes. Las fracturas de cizalla son rupturas a través de un plano con desplazamiento paralelo (Price y Cosgrove, 1990; Ramsay y Huber, 1987), y dependiendo de su magnitud, pueden ser clasificadas como fracturas de cizalla si es escaso o como una falla si el desplazamiento es significativo. En términos de esfuerzos, se puede decir que las diaclasas se forman y orientan paralelas al esfuerzo principal máximo $\sigma_{1}$ y por lo tanto, en forma perpendicular al esfuerzo principal mínimo $\sigma_{3}$. A su vez, es requerido que este último sea tensional (Engelder, 1987). Las fracturas de cizalla se forman en un campo de esfuerzos netamente compresivo y se orientan aproximadamente a $30^{\circ}$ del esfuerzo principal máximo $\sigma_{1}$ (Engelder, 1987).

El estudio de estas estructuras de escala media requiere de una detallada descripción para su entendimiento dentro de un sistema estructural complejo (pliegue anticlinal). En el presente trabajo, las mediciones y descripciones se organizaron en estaciones de medición ubicadas en distintas posiciones estructurales (flanco, extremo de inmersión, charnela) a lo largo de los pliegues estudiados (anticlinal Tin Tin y anticlinal Cerro Bayo; figura 4.1). Las estaciones comprenden las mediciones realizadas en dicho punto y en sitios cercanos (auxiliares). Para la completa caracterización de los sistemas de fracturas 
presentes en cada estación se midieron y describieron las orientaciones de las fracturas individuales ( $\mathrm{Rbz}$ del plano o dirección de su traza), las relaciones angulares entre los diferentes sets de fracturas, sus relaciones espaciales (espaciado entre fracturas), relaciones de corte (cronología de formación entre diferentes sets) y las características morfológicas visibles de la fractura (geometría de la terminación, morfología de las superficies) y de su relleno (composición y textura). Otros parámetros, como la longitud de la traza de las fracturas y su apertura, son poco confiables para caracterizar el sistema de fracturas en el afloramiento. El primero está condicionado por las dimensiones del afloramiento, ya que fracturas grandes no pueden medirse más allá de la extensión del afloramiento, y por lo tanto la longitud real no se puede determinar. El segundo parámetro está condicionado por efectos topográficos locales, erosivos, biológicos (plantas), no representando una relación directa con los esfuerzos que las formaron. Sin embargo, en muchos casos se realizaron mediciones y observaciones para adicionar información relevante. Por último, también se registraron las características de la roca afectada (orientación, litología, espesor). La técnica de muestro utilizada fueron scan lines lineales y mediciones aleatorias (Marshak y Mitra, 1988), dependiendo de las posibilidades que ofreciera el afloramiento. Cabe mencionar que el análisis microscópico de gabinete (información microtectónica) descartó la presencia significativa de microestructuras (microvenas, microfracturas), por lo que la descripción de cortes delgados pertenecientes a las muestras de roca no se incluye dentro de la información estructural relevante.

\subsection{Las fracturas del Anticlinal Tin Tín}

La figura 5.1 muestra una representación esquemática de anticlinal Tin Tin con la ubicación de 18 estaciones de medición de fracturas. 


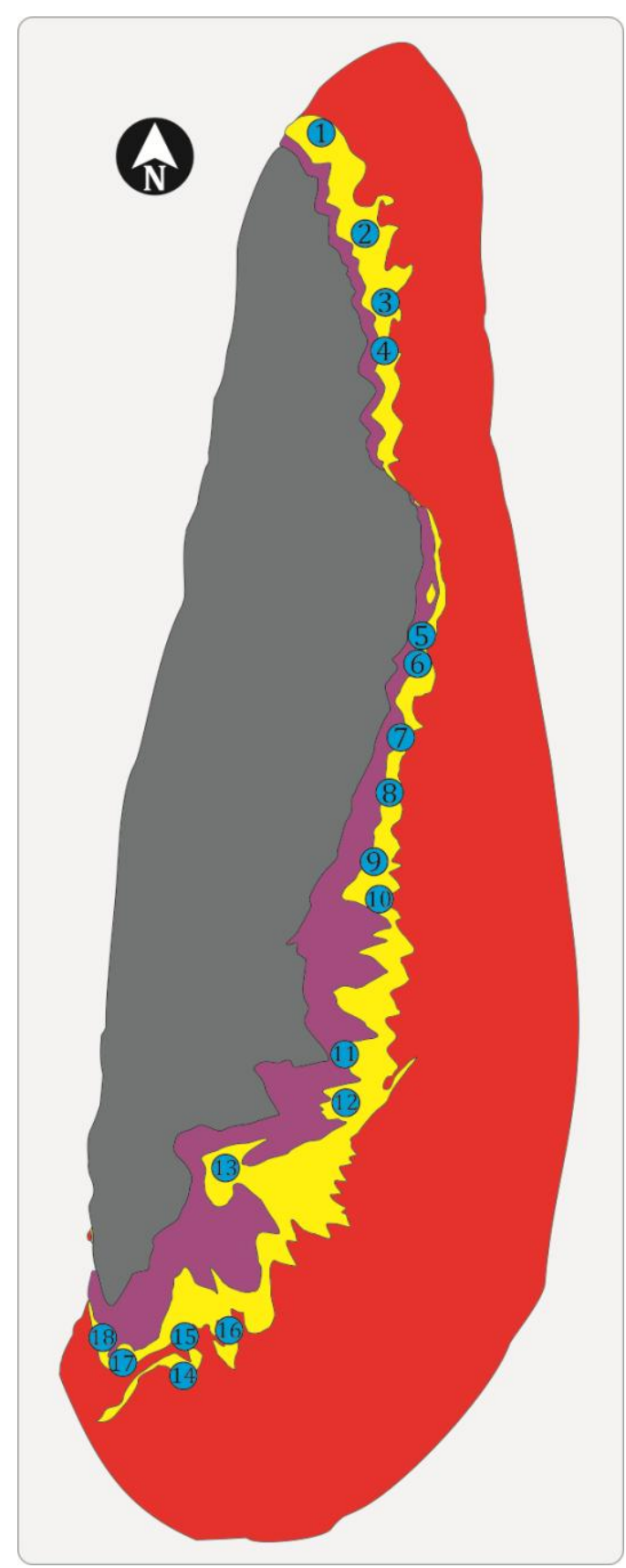

FIGURA 5.1. Mapa

esquemático del anticlinal Tin Tin. Ubicación de las estaciones de medición. Ejemplo de nomenclatura: 12 - Estación de medición $12 \mathrm{TT}$.

\subsubsection{Estación de medición 1TT}

La estación de medición 1 TT se ubica estratigráficamente en la sección superior de la Formación Yacoraite, en el extremo de inmersión Norte del anticlinal Tin Tin (Figura 5.2a). La capa es una caliza oolítica con contenido clástico cuarzoso de tamaño arena gruesa a sabulita, con presencia de óndulas en su techo. El Rbz de la capa es $14^{\circ} / 52^{\circ}$. Se midieron sólo las orientaciones de fracturas principales que se clasificaron como diaclasas y venas. La figura $5.2 \mathrm{~b}$ muestra un 
diagramas de rosas de las mediciones de trazas de fracturas y un diagrama estereográfico con las cuatro orientaciones principales de fracturas, con planos relativamente perperdiculares a la capa. El set de fracturas de rumbo aproximado $\mathrm{E}-\mathrm{W}\left(\mathrm{N} 100^{\circ}\right)$ corresponde a venas, algunas reabiertas posteriormente. Estas venas presentan las trazas más continuas del afloramiento (Figura 5.2c). El resto de las fracturas termina contra el set E-W, indicando que este último tuvo una formación temprana con respecto a los otros sets. Este set E-W y el set NNW-SSE (N155) presentan desplazamiento por cizalla dextral de pocos milímetros, posiblemente por reactivación (Figura 5.2d).

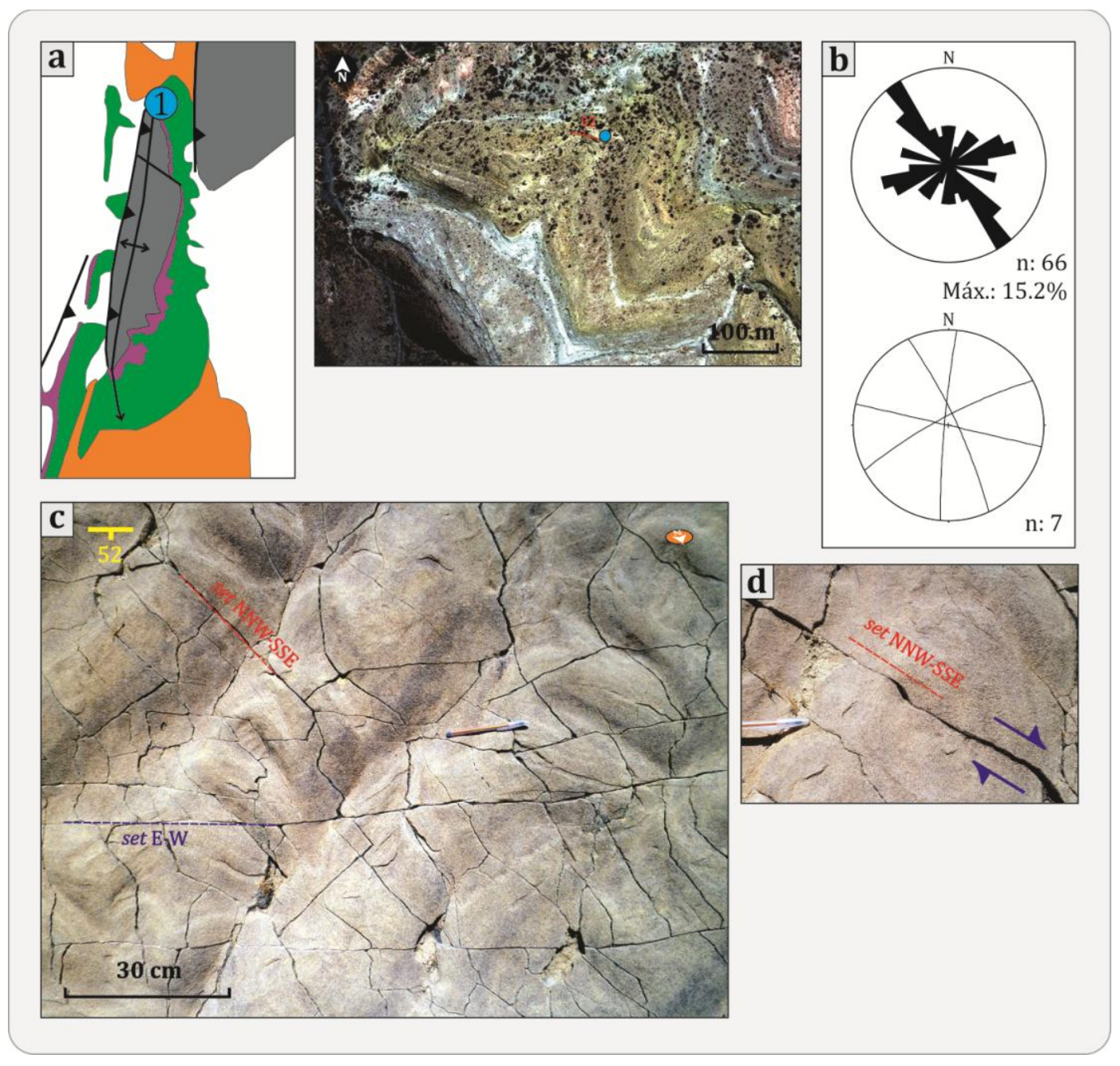

FIGURA 5.2. Estación de medición 1TT. a) Ubicación de la estación en el anticlinal. b) Diagramas de datos de fracturas. c)-d) Fracturas en el afloramiento (diaclasas). 


\subsubsection{Estación de medición 2 TT}

La estación de medición 2TT se encuentra ubicada estratigráficamente en la sección superior de la Formación Yacoraite, sobre el flanco dorsal del anticlinal Tin Tin (Figura 5.3a). La capa es una caliza oolítica con clastos de cuarzo de tamaño arena gruesa a sabulita y el Rbz de su techo es $72^{\circ} / 38^{\circ}$. Las fracturas medidas en forma aleatoria se clasificaron como diaclasas al no observar desplazamientos ni estructuras relacionadas con cizalla. En la figura $5.3 \mathrm{~b}$ se muestra el diagrama estereográfico de los planos medidos en el afloramiento. El gráfico muestra dos grupos principales de orientaciones de planos correspondientes a los sets ENEWSW $\left(\mathrm{N}^{\circ} 7^{\circ}\right)$ y NW-SE $\left(\mathrm{N} 143^{\circ}\right)$, con un promedio de inclinación de 80', es decir, con alta inclinación con respecto a la capa que las contiene. El set de fracturas predominante es el de rumbo ENE-WSW, con trazas continuas de decenas de metros de longitud (Figura 5.3c). Algunas fracturas de este set presentan una disposición en echelon izquierdo (cinemática dextral), mientras que el set NW-SE presenta una disposición inversa (cinemática sinestral) en algunas de sus fracturas. De acuerdo a la longitud de sus trazas se podría inferir que el set ENEWSW es más antiguo, ya que no se observa su terminación contra otras fracturas.

En capas ubicadas estratigráficamente en el techo de la Formación Yacoraite se midieron fracturas de bajo ángulo (con respecto a la estratificación), clasificadas como fracturas de cizalla originadas por contracción en capas subhorizontales (Figura 5.3d-e-f). El Rbz de las fracturas es $108^{\circ} / 21^{\circ}, 279^{\circ} / 28^{\circ}$ y $287^{\circ} / 19^{\circ}$, indicando una dirección de contracción ESE-WNW para este sector. En otros sectores también se midieron fracturas similares, pero con estriados de rake bajo (movimiento oblicuo y de rumbo), posiblemente por una reactivación posterior. 

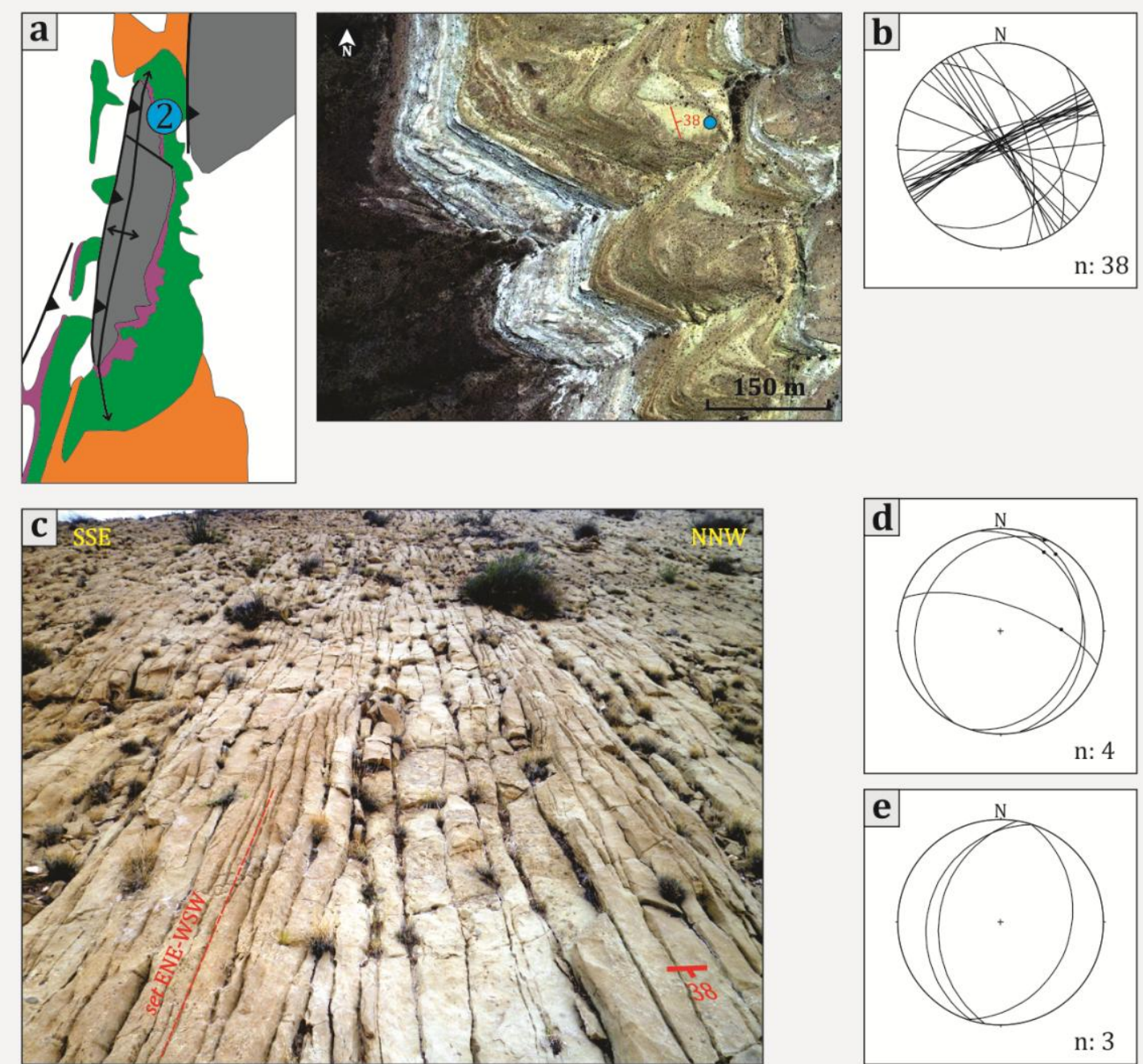

$\mathrm{n}: 4$
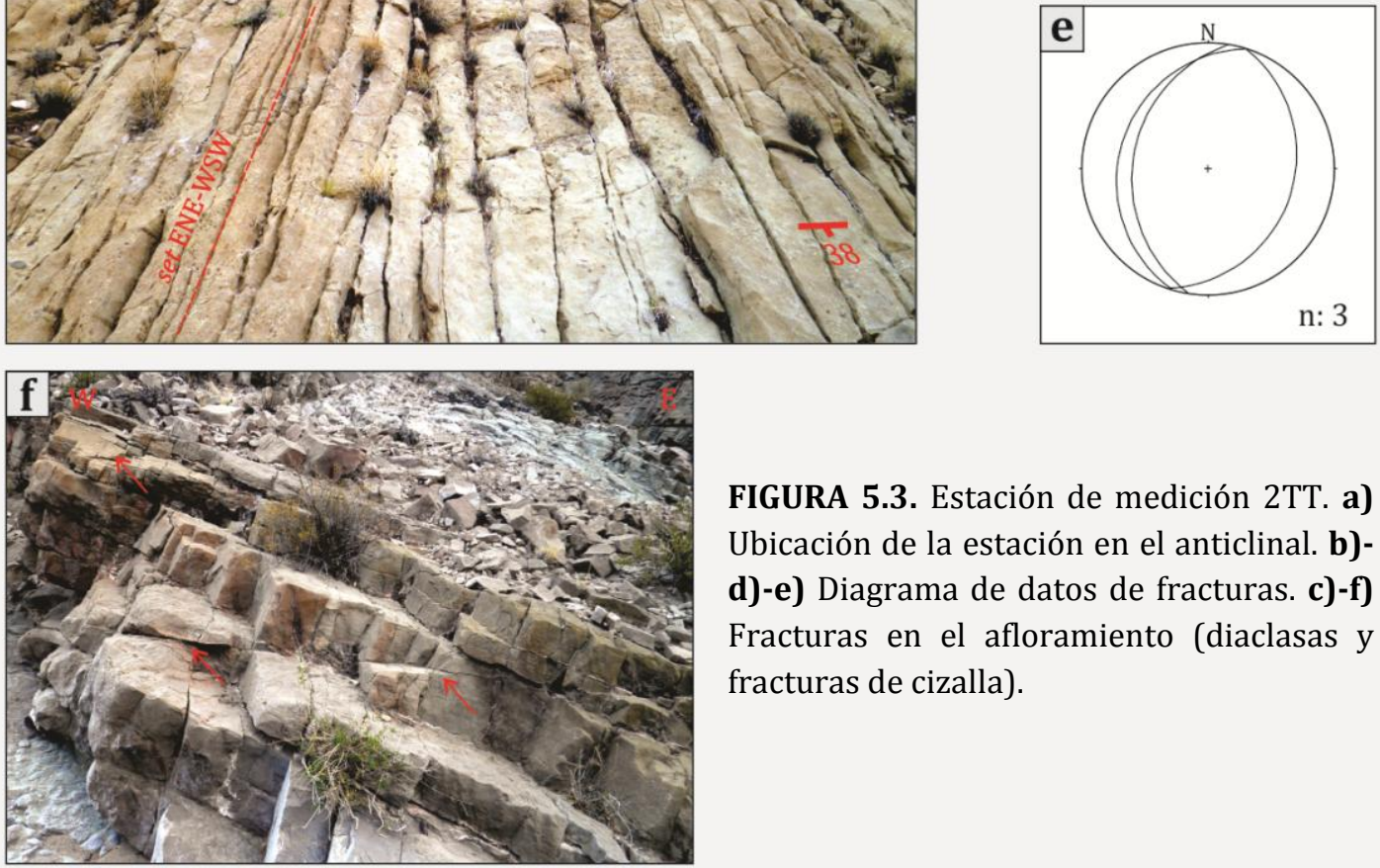

FIGURA 5.3. Estación de medición 2TT. a) Ubicación de la estación en el anticlinal. b)d)-e) Diagrama de datos de fracturas. c)-f) Fracturas en el afloramiento (diaclasas y fracturas de cizalla).

\subsubsection{Estación de medición $3 T$ T}

La estación de medición 3TT se ubica estratigráficamente en el techo de la Formación Yacoraite, sobre el flanco dorsal del anticlinal Tin Tin (Figura 5.4a). La capa medida es una caliza grisácea oolítica con estromatolitos. El Rbz es 93\% $/ 35^{\circ}$ y sólo presenta su techo expuesto, por lo que no se pudo determinar su espesor. Se 
realizó un scan line lineal y las fracturas presentes se clasificaron como diaclasas y venas. La mayoría de las diaclasas son venas reabiertas, por lo que se infiere que la formación y orientación de las diaclasas estuvo condicionada por la orientación de las venas. Otro tipo de estructura observada fueron estilolitas paralelas al techo de la capa en capas carbonáticas cercanas (Figura 5.4g). La figura 5.4b muestra el diagrama estereográfico y de contornos de los planos medidos, correspondientes al scan line lineal. Se observa un gran abanico de planos que según el diagrama de contornos puede ser dividido en dos direcciones principales, $\mathrm{N}^{\circ}{ }^{\circ}$ (set E-W) y N143 ${ }^{\circ}$ (set NW-SE). Secundariamente se observa un conjunto de planos con direcciones que oscilan entre $\mathrm{N} 92^{\circ}$ y N116 ${ }^{\circ}$ (set ESE-WNW). Con menor frecuencia hay planos con direcciones hacia el cuadrante NE. La inclinación general de los planos varía entre $61^{\circ}$ y $90^{\circ}$. También se midieron planos con bajo ángulo de inclinación. La figura 5.4c muestra una fotografía del afloramiento, donde se puede observar que las fracturas de los sets principales E-W y NW-SE son relativamente más continuas y rectas que las fracturas de otros sets, pudiendo indicar que fueron las primeras en formarse. Con respecto a estas dos direcciones, se observó que una fractura del set NW-SE se termina en forma curvada contra una fractura del set E$\mathrm{W}$, indicando que esta última se formó primero. El resto de las fracturas presentan variadas direcciones y son relativamente cortas en longitud de traza, indicando que se formaron posteriormente a los sets mencionados.

A partir del scan line lineal realizado en el afloramiento se obtuvieron la frecuencia y espaciado promedio de los sets de fracturas medidos (ver ANEXO). El parámetro Frecuencia arrojó un valor de 9.11 para el set E-W (espaciado promedio de 18.74 centímetros), 7.51 para el set NW-SE (espaciado promedio de 17 centímetros), 3.74 para el set ESE-WNW (espaciado promedio de 45.11 centímetros) y 2.84 para las fracturas del cuadrante NE (espaciado promedio de 19.33 centímetros).

En un sitio cercano se realizó una estación de medición auxiliar sobre una capa del techo de la Formación Yacoraite (Figura 5.4a). Esta capa se encuentra plegada y conforma un anticlinal de mesoescala. Sobre el flanco dorsal oriental y la charnela de la estructura se midieron fracturas en forma aleatoria, clasificadas como diaclasas y venas. Los diagramas estereográficos se muestran en la figura 
5.4e. La capa deformada es una caliza oolítica con estromatolitos, característica del techo de esta formación. La figura 5.4d muestra las fracturas del flanco dorsal del anticlinal, cuyo $\mathrm{Rbz}$ es $94^{\circ} / 30^{\circ}$. El diagrama del flanco muestra cuatro sets de fracturas con rumbos aproximados E-W, N-S, NE-SW y NW-SE (Figura 5.4e FD). Estas direcciones corresponden tanto a diaclasas como venas, siendo algunas venas reabiertas como diaclasas. Las observaciones del afloramiento sugieren que el set E-W es el más antiguo, ya que los otros sets terminan contra éste o lo cortan posteriormente, además de presentar trazas continuas y de mayor longitud con respecto a los demás sets de fracturas (Figura 5.4d). Las diaclasas del set N-S, paralelas al rumbo de la capa y del anticlinal (en este sector del anticlinal Tin Tin), presentan las trazas más cortas y se ubican entre los sets anteriores, indicando su formación posterior. Los sets de fracturas NE-SW y NW-SE son, por lo tanto, posteriores al set E-W y anteriores al set N-S. Se observó que una diaclasa de rumbo E-W corta y abre a una vena de rumbo NE-SW. De esto se desprende que las diaclasas son posteriores a las venas, y que posiblemente reutilizaron sus planos. El diagrama estereográfico de las fracturas medidas en la charnela del anticlinal muestra, particularmente, fracturas de bajo ángulo orientadas aproximadamente en dirección N-S e inclinado unos $30^{\circ}$ hacia el E (Figura 5.4e Ch). Estas fracturas se interpretan como fracturas de cizalla (fallas pequeñas) y se asocian a los estadios iniciales de contracción horizontal, indicando a su vez que son previas al plegamiento, formadas cuando las capas aun se encontraban en posición subhorizontal. Estas fracturas se observan también en capas de los alrededores, afectando tanto a la Formación Yacoraite como a capas basales del Subgrupo Santa Bárbara (Figura 5.4f-h-i). Una observación importante es mostrada por el detalle de la figura 5.4j, donde una diaclasa vertical de rumbo aproximado $\mathrm{N}-\mathrm{S}$ corta a una fractura de cizalla de bajo ángulo. La relación de corte sugiere que la fractura vertical es posterior (sino sería desplazada por la cizalla) y que la fractura de cizalla es una estructura cerrada (para poder ser atravesada por otra fractura). 

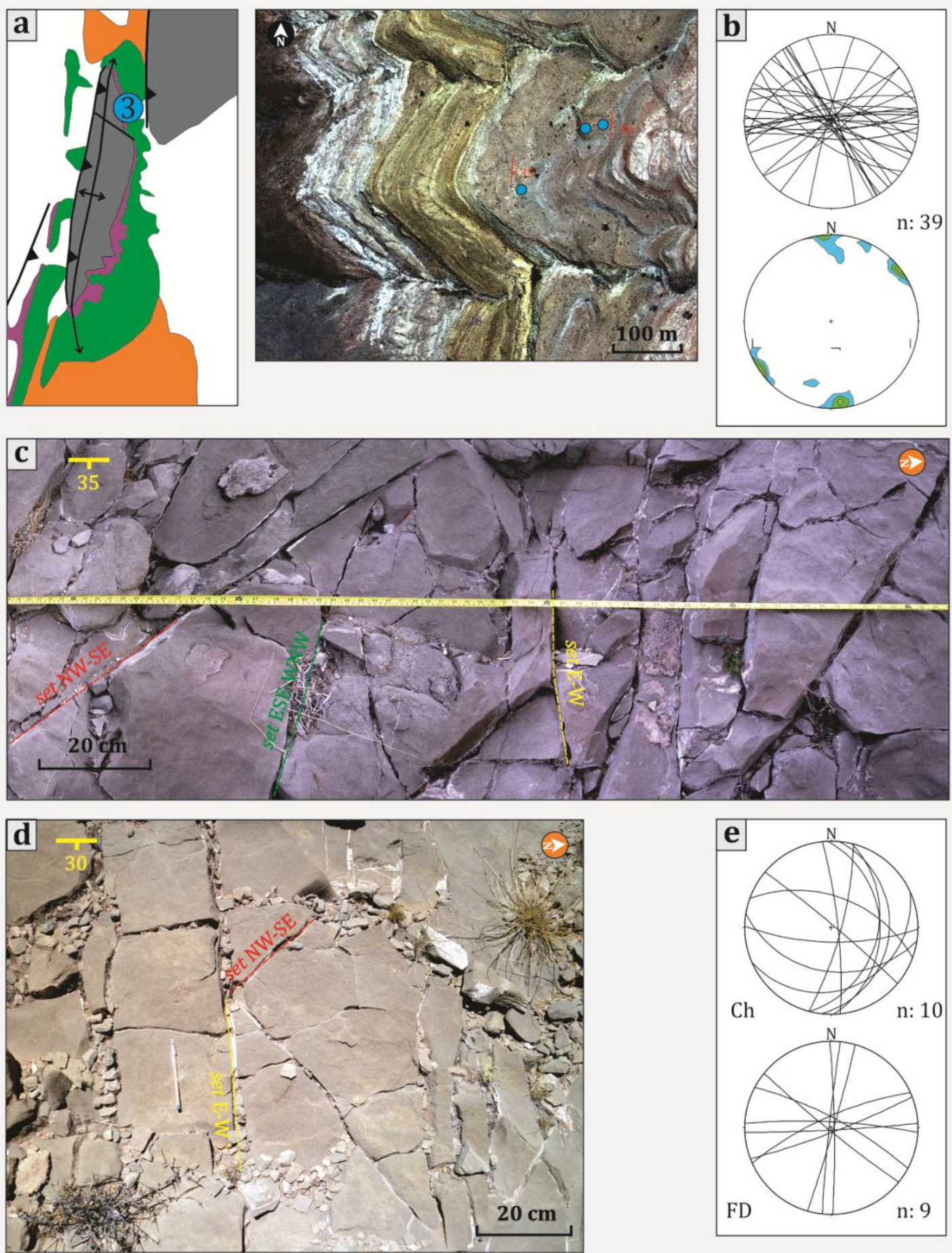

FIGURA 5.4. Estación de medición 3TT. a) Ubicación de la estación en el anticlinal. b) Diagramas de datos del scan line. c) Scan line en el afloramiento. d) Fracturas en el flanco dorsal de un anticlinal de mesoescala cercano al sitio donde se realizó el scan line. e) Diagramas de datos correspondientes al anticlinal de mesoescala. 

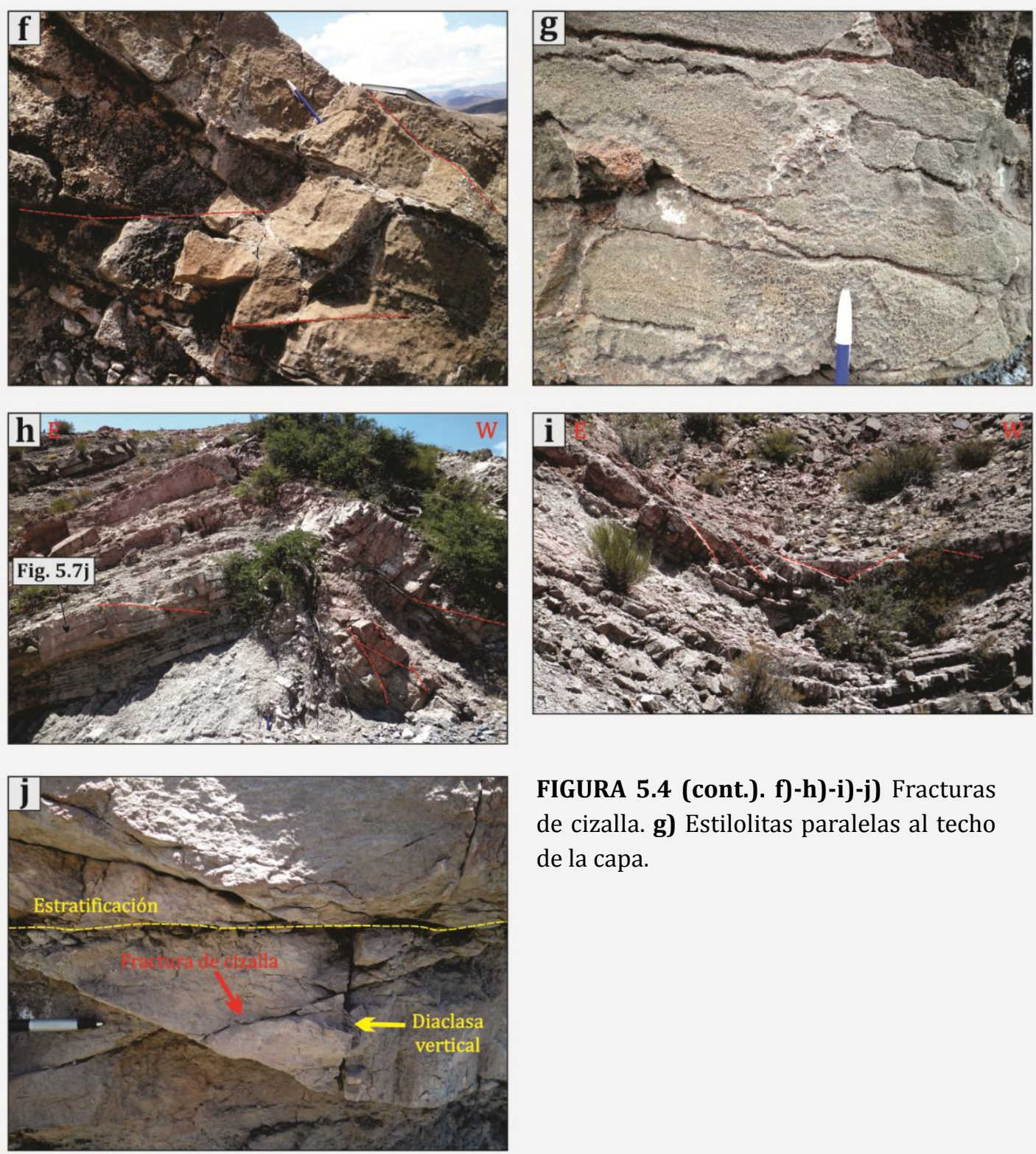

FIGURA 5.4 (cont.). f)-h)-i)-j) Fracturas de cizalla. g) Estilolitas paralelas al techo de la capa.

\subsubsection{Estación de medición 4TT}

Esta estación de medición está compuesta por tres sitios de relevamiento de fracturas principales en diferentes unidades, ubicados sobre el flanco dorsal del anticlinal Tin Tin (Figura 5.5a). El primer sitio de medición corresponde a una capa de arenisca cuarzosa de la parte basal del Subgrupo Santa Bárbara, con un Rbz $88^{\circ} / 49^{\circ}$ (Figura 5.5c). El diagrama estereográfico (Figura 5.5b) muestra la orientación de los tres sets de diaclasas principales, con rumbos E-W (N100), NESW (N42 $)$ y NW-SE $\left(\mathrm{N}_{145^{\circ}}\right)$, siendo el set E-W el más antiguo ya que los otros terminan contra éste. En capas cercanas a este sitio de relevamiento se observaron 
estructuras plumosas sobre la superficie de una diaclasa correspondiente al set NE-SW.
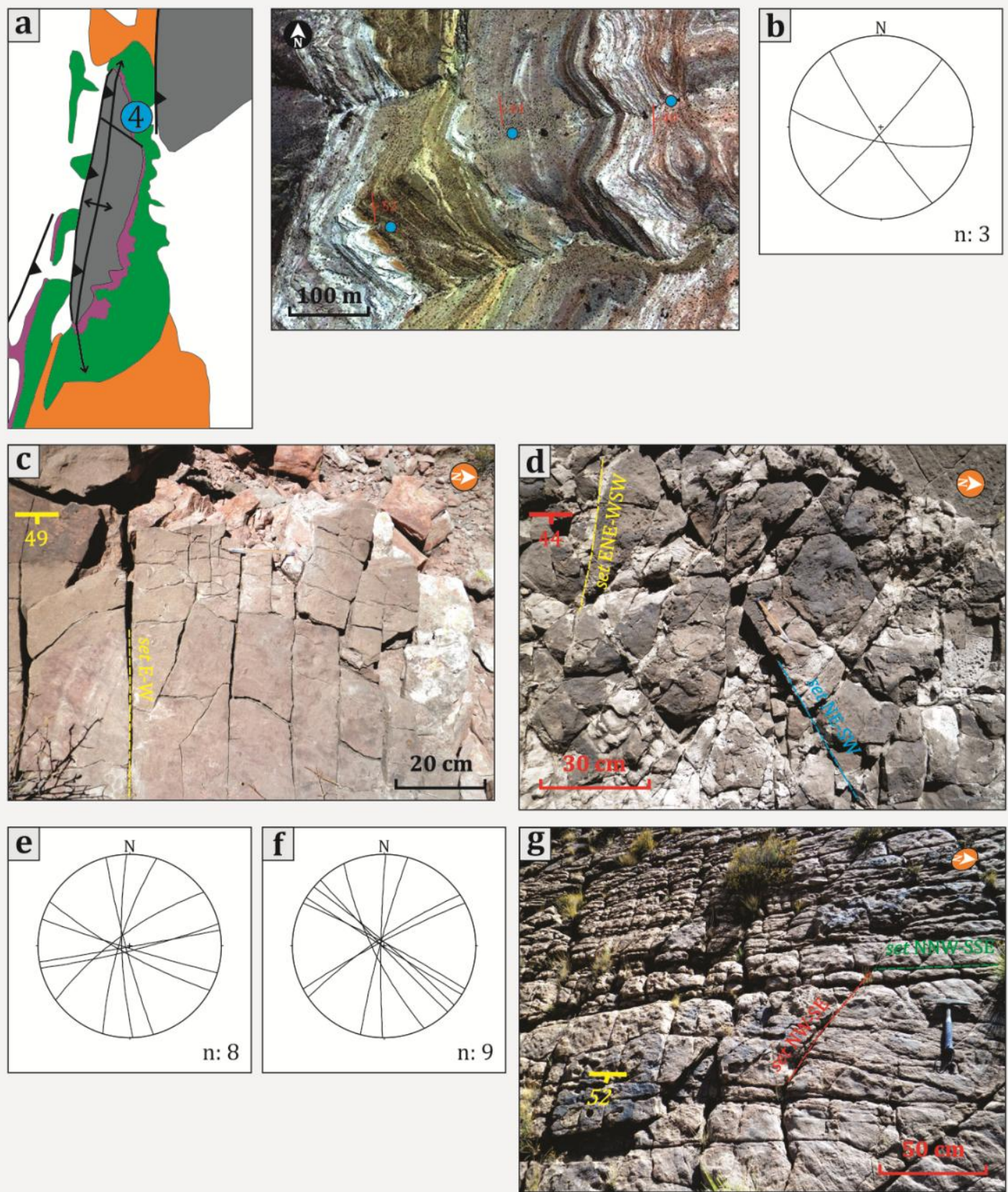

FIGURA 5.5. Estación de medición 4TT. a) Ubicación de la estación en el anticlinal. b)-e)-f) Diagramas de datos correspondientes a diferentes sitios de medición de fracturas. c)-d)-g) Diaclasas en afloramiento.

En el segundo sitio de relevamiento también corresponde a la parte basal del Subgrupo Santa Bárbara. La capa es una arenisca grisácea con Rbz $84^{\circ} / 44^{\circ}$. Se 
midieron cuatro sets principales de diaclasas (Figura 5.5e), de los cuales los sets ENE-WSW y NE-SE, que presentan las trazas de fractura más continuas, se infieren más antiguos ya que los sets ESE-WNW y N-S (aprox.) se ubican entre los primeros (Figura 5.5d).

El tercer sitio de relevamiento se ubica estratigráficamente en la base de la Formación Yacoraite. La capa es una arenisca cuarzosa de grano medio, con Rbz $83^{\circ} / 52^{\circ}$. En la fotografía del afloramiento (Figura $5.5 \mathrm{~g}$ ) y en el diagrama estereográfico (Figura 5.5f) se puede observar que las fracturas (diaclasas) se agrupan en tres sets principales, NW-SE a NNW-SSE, NE-SW y N-S a NNE-SSE. Las observaciones del afloramiento no son concluyentes. Sólo se puede mencionar que el set $\mathrm{N}$-S es posterior a los demás, como se ha registrado en muchos afloramiento a los largo del anticlinal.

Los tres sitios de relevamiento presentan diaclasas con orientaciones similares y alta inclinación con respecto a la capa. Es posible, y en concordancia con otros sitios de medición aledaños, que los sets E-W y/o NE-SW sean los más antiguos en formarse y el set N-S el más moderno para este sector.

\subsubsection{Estación de medición 5TT}

La estación se ubica en el techo de la Formación Yacoraite, sobre el flanco dorsal del anticlinal Tin Tin (Figura 5.6a). La capa medida es una caliza fina, con contenido cuarzoso de granulometría arena gruesa a sabulítica, color gris oscuro, y contenido fosilífero. La capa tiene aproximadamente 1 metro de espesor y su Rbz es $115^{\circ} / 62^{\circ}$. Esta presenta fracturas sistemáticas del tipo diaclasas y venas. Las diaclasas son las estructuras predominantes y de mayor impacto visual en el afloramiento, ya que lo atraviesan completamente (Figura 5.6c). Las venas por su parte, son discontinuas y de decenas de centímetros de longitud. El diagrama estereográfico de la figura 5.6b muestra la orientación de los planos medidos (con capa horizontalizada). Aquí se observan tres direcciones de fracturas bien definidas, con azimuts promedio $\mathrm{N} 20^{\circ}$ (set NNE-SSW), $\mathrm{N} 100^{\circ}$ (set E-W) y $\mathrm{N} 140^{\circ}$ (set NW-SE), e inclinación aproximadamente perpendiculares a la estratificación, con promedio de $81.5^{\circ}$. En capas cercanas a la estación se observaron estructuras plumosas en superficies de diaclasas de los sets E-W y NW-SE. 
Las fracturas del set E-W atraviesan todo el afloramiento, con trazas continuas y rectas, que van desde los 30 hasta los 250 centímetros, con 126.8 centímetros de promedio. Las fracturas del set NW-SE son más cortas, presentando longitudes desde 30 hasta 200 centímetros, con promedio de 81.6 centímetros. Las fracturas del set NNE-SSW son pocas (el scan line sólo atravesó dos fracturas) y cortas, con longitudes de 40 a 45 centímetros. Las venas observadas son paralelas a los sets E-W y NW-SE (Figura 5.6d). Por último, se observó una zona de brechamiento correspondiente con la dirección NW-SE. Esta zona presenta características similares a la falla sinestral ubicada próxima a este afloramiento, además de presentar una cinemática recurrente para esta dirección. Las relaciones de corte indican que las fracturas del set E-W se formaron primero, ya que las fracturas del set NW-SE las cortan o terminan contra éstas, a veces con desplazamiento sinestral milimétrico. Por último, se forma el set NNE-SSW, paralelo al eje del anticlinal Tin Tin, ubicándose entre las fracturas de los sets anteriores. La mayoría de las venas son cortadas por las diaclasas, indicando que las diaclasas fueron posteriores, y posiblemente reactivadas a partir de la orientación de las venas debido al paralelismo mencionado entre ambos tipos de fracturas.

De los datos obtenidos a partir de un scan line lineal realizado en el afloramiento (ver ANEXO) se obtuvo el parámetro Frecuencia $\left(\mathrm{F}=\mathrm{n}^{\circ} \mathrm{de}\right.$ fracturas/longitud del scan line), arrojando un valor de 2.27 para el set NNE-SSW, 2.13 para el set NW-SE, y 4.86 para el set E-W, indicando un mayor número de fracturas por unidad de longitud en la última dirección, como se puede observar en la fotografía de la figura 5.6c. 


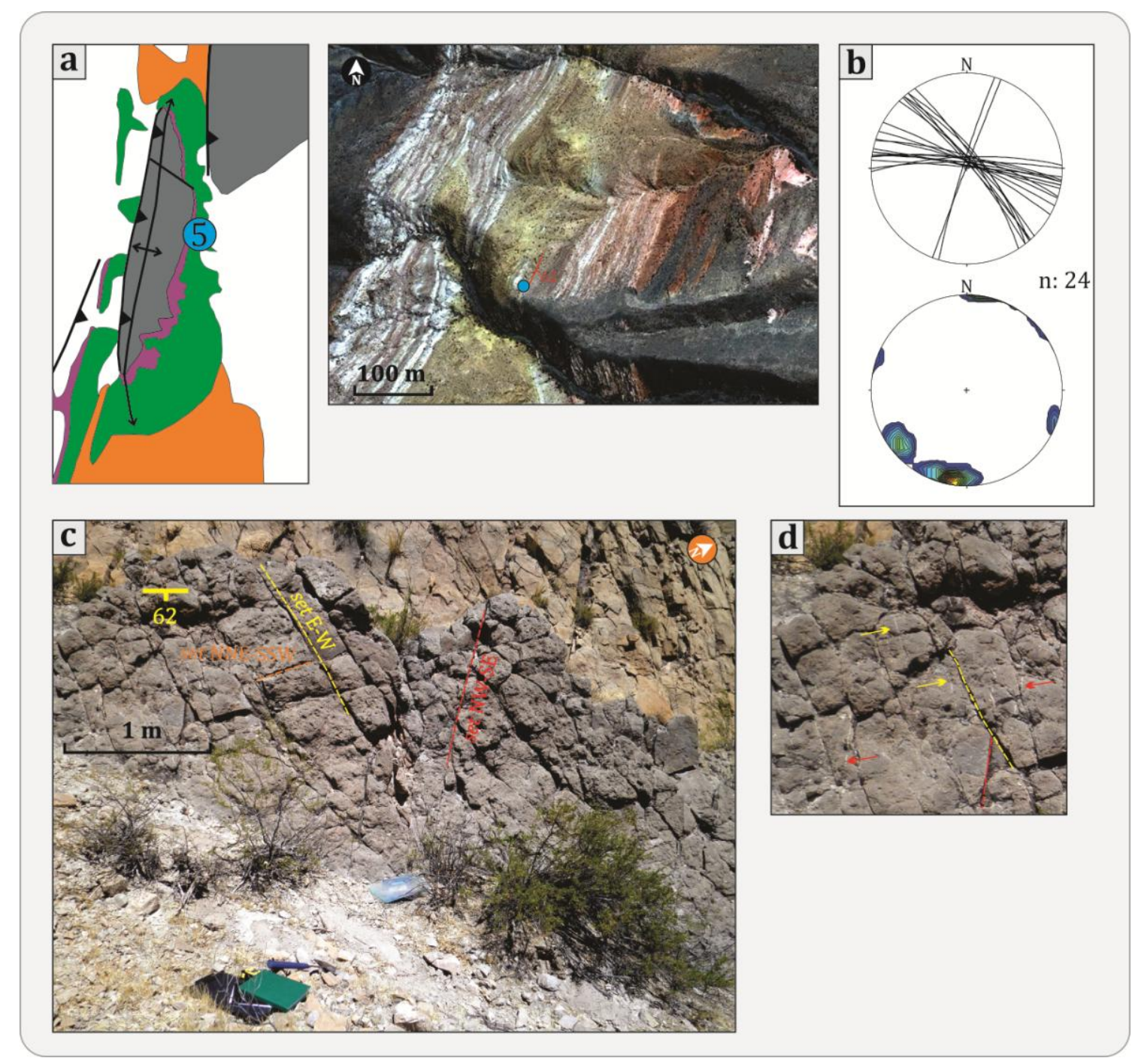

FIGURA 5.6. Estación de medición 5TT. a) Ubicación de la estación en el anticlinal. b) Diagramas de datos del scan line. c)-d) Diaclasas en afloramiento.

\subsubsection{Estación de medición 6TT}

La estación de medición 6TT se ubica en la sección superior de la Formación Yacoraite (subgrupo Balbuena), sobre el flanco dorsal del anticlinal Tin Tin (Figura 5.7a). La capa medida es una arenisca cuarzosa de granulometría fina a media, tiene $50 \mathrm{~cm}$ de espesor y su techo, donde se midieron las fracturas, presenta un $\operatorname{Rbz}$ de $108^{\circ} / 55^{\circ}$. La gran mayoría de las fracturas del afloramiento se clasificaron como diaclasas ya que no se observaron indicios ruptura sobre sus planos. En menor medida se registraron fracturas pequeñas dispuestas en echelon, posiblemente asociadas a cizalla. El diagrama estereográfico de la figura $5.7 \mathrm{~b}$ 
muestra la orientación de los planos relevados, posteriormente a la restauración de la capa a su posición horizontal original. Aquí se observan dos direcciones predominantes, con azimuts promedio $\mathrm{N} 80^{\circ}$ (set E-W) y $\mathrm{N} 140^{\circ}$ (set NW-SE), e inclinaciones aproximadamente perpendiculares a la estratificación, con un promedio de $82.9^{\circ}$. Las fracturas del set E-W generalmente atraviesan todo el afloramiento, con trazas continuas y rectas, presentando las mayores longitudes medidas (200 centímetros). Las fracturas del set NW-SE son más cortas (hasta 100 centímetros, en general entre 20 y 53 centímetros), discontinuas, con trazas levemente sinuosas, y presentan una mayor dispersión en sus orientaciones (Figura 5.7b). En algunos sectores del afloramiento se observan fracturas pequeñas y menos marcadas, con disposición en echelon, en dirección paralela a las direcciones de fracturas mencionadas (Figura 5.7d). Las fracturas del set E-W muestran una cinemática dextral, mientas que las del set NW-SE muestran una cinemática sinestral. Estas pequeñas fracturas son atribuidas a cizallamiento y por lo tanto son diferentes en origen a las descriptas como diaclasas. Las relaciones de corte entre los grupos de fracturas muestran que las diaclasas del set E-W son cronológicamente más antiguas que las diaclasas del set NW-SE. Se observa que el set NW-SE corta y abre al set E-W, indicando posterioridad en su formación. Otra evidencia de esta cronología es la terminación curvada de algunas diaclasas del set NW-SE al arremeter contra las del set E-W (Figura 5.7e). Esta curvatura se produce cuando una diaclasa en propagación se aproxima a otra más antigua (previa y abierta) con un ángulo no perpendicular $\left(<90^{\circ}\right)$. La diaclasa previa, al encontrarse abierta representa una discontinuidad y su superficie libre reorienta localmente el esfuerzo principal $\sigma_{1}$ (Engelder, 1987). Una consecuencia de ésto es la mayor variación en la orientación de los planos que presenta el set NW-SE (Figura 5.7b). $\mathrm{Al}$ ser posterior en formación, estas diaclasas se acomodan entre las primeras (set E-W) y dependiendo del espaciado de las mismas tendrán más o menos espacio para desarrollarse. 


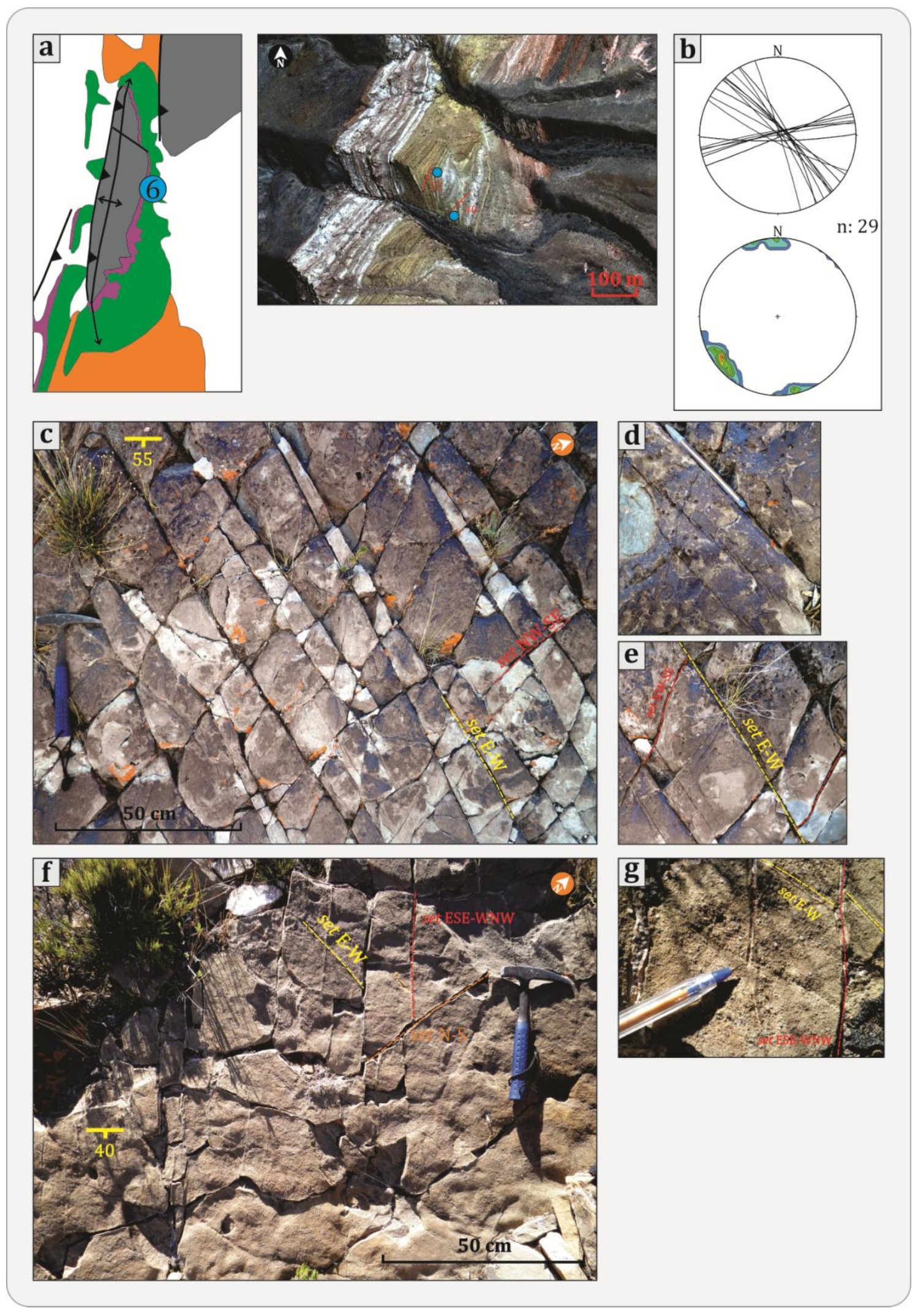

FIGURA 5.7. Estación de medición 6TT. a) Ubicación de la estación en el anticlinal. b) Diagramas de datos del scan line. c)-d)-e) Diaclasas en afloramiento y relaciones de corte entre los diferentes sets. f)-g) Fracturas correspondientes a un anticlinal cercano al sitio donde se realizó el scan line. 
De los datos obtenidos a partir de un scan line lineal realizado en el afloramiento (ver ANEXO) se obtuvo el parámetro Frecuencia $\left(F=n^{\circ}\right.$ de fracturas/longitud del scan line), arrojando un valor de 7.19 para el set E-W y 6.44 para el set NW-SE, indicando un mayor número de fracturas por unidad de longitud en la primera dirección.

Se midieron planos de fracturas en una estación auxiliar cercana (Figura 5.7a). La capa medida, de $\mathrm{Rbz} 135^{\circ} / 40^{\circ}$, es una arenisca gruesa a sabulita, cuarzosa, con cemento carbonático y presencia de diaclasas y venas (Figura 5.7f). Esta capa representa el flanco dorsal de un pliegue de pequeñas dimensiones (pocos metros de longitud de onda). Aquí se midieron los planos principales de venas en las que se observaron claras relaciones de corte. Como en el caso anterior, las fracturas de dirección $\mathrm{N} 80^{\circ}$ a $\mathrm{N}^{\circ} 0^{\circ}$ (set E-W) son anteriores a las fracturas de dirección $\mathrm{N} 120^{\circ}$ (set ESE-WNW). Este último set termina contra el set E-W y/o lo corta y desplaza sinestralmente por unos pocos milímetros (Figura 5.7g). En este afloramiento se midió un set N-S a NNE-SSW de fracturas y venas que por relaciones de corte fueron las ultimas en formarse. Estas son paralelas al eje del pliegue menor y al anticlinal mayor. En la charnela del pliegue menor hay dos juegos de venas de orientaciones $\mathrm{N} 20^{\circ}-\mathrm{N} 200^{\circ}$ y $\mathrm{N} 110^{\circ}-\mathrm{N} 290^{\circ}$.

\subsubsection{Estación de medición 7TT}

La estación de medición 7TT se ubica estratigráficamente en la sección media de la Formación Yacoraite, sobre flanco dorsal del anticlinal Tin Tin (Figura 5.8a). La capa medida es una caliza oolítica, con contenido cuarzoso de granulometría arena gruesa a sabulita. El espesor de la capa es 15 centímetros, pero las fracturas continúan hacia abajo estratigráficamente (con diferente frecuencia), afectando a un paquete de más de 1 metro. La orientación de su techo, donde se midieron las fracturas, es de $\mathrm{Rbz} 112^{\circ} / 49^{\circ}$. Las fracturas medidas en el afloramiento, mediante scan line lineal, se clasificaron como diaclasas ya que no se observo ningún tipo de desplazamiento paralelo a los planos ni otras evidencias de cizalla (por ejemplo, fracturas en echelon). Sólo unos planos de bajo ángulo con respecto a la estratificación medidos aleatoriamente, se clasificaron como de fracturas de cizalla formados por contracción paralela a la capa. Considerando el diagrama de contornos de la figura 5.8b (scan line), las orientaciones de los planos 


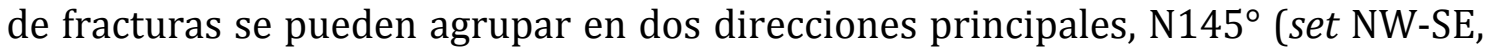

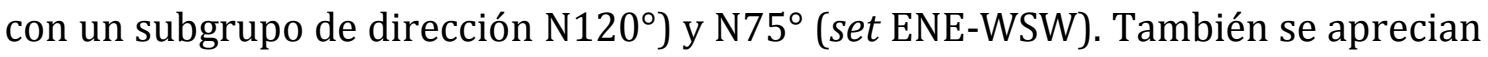
fracturas aisladas con rumbos NNE-SSW (paralela al rumbo del anticlinal Tin Tin) y NNW-SSE. La mayoría de las fracturas medidas presentan un alto ángulo con respecto a la estratificación (promedio $82.4^{\circ}$, subperpendiculares a la capa), con excepción de las fracturas de bajo ángulo mencionadas (Figura 5.8b-d). Ambos sets de fracturas presentan trazas irregulares en mayor o menor medida, y este efecto es realzado por la erosión del techo de la capa (Figura 5.8c). El set NW-SE presenta las fracturas más largas, con 300 centímetros de longitud de traza (110 centímetros en promedio), mientras que el set ENE-WSW tiene un máximo de 150 centímetros (57.17 centímetros en promedio). Dada la irregularidad en la traza de las fracturas, las relaciones de corte entre ambos sets principales no se pudieron determinar. Sin embargo, se pudo observar que las fracturas paralelas al eje de plegamiento (set NNE-SSW) son cortas ( $<10$ centímetros) y terminan contra las fracturas principales, indicando que se formaron posteriormente a los sets mencionados.

De los datos obtenidos a partir del scan line lineal realizado en el afloramiento se obtuvo el parámetro Frecuencia (véase ANEXO), arrojando un valor de 6.15 para el set NW-SE y 4.26 para el set ENE-WSW, indicando un mayor número de fracturas por unidad de longitud para el primer set. Esta configuración se refleja en el espaciado promedio entre las fracturas de ambos sets, 17.61 centímetros para la dirección NW-SE y 24.36 centímetros para la dirección ENEWSW.

El diagrama estereográfico de las fracturas medidas aleatoriamente en el mismo sitio muestra un conjunto de planos de baja inclinación, además de las direcciones ya mencionadas (Figura 5.8d). Estos planos tienen la dirección del rumbo de la capa (y de la estructura general) e inclinan unos $24^{\circ}$ al SE. Se interpretan como fracturas de cizalla (fallas inversas de bajo ángulo, de pequeña escala) producto de la contracción horizontal, formadas previamente al plegamiento de las capas del anticlinal. 

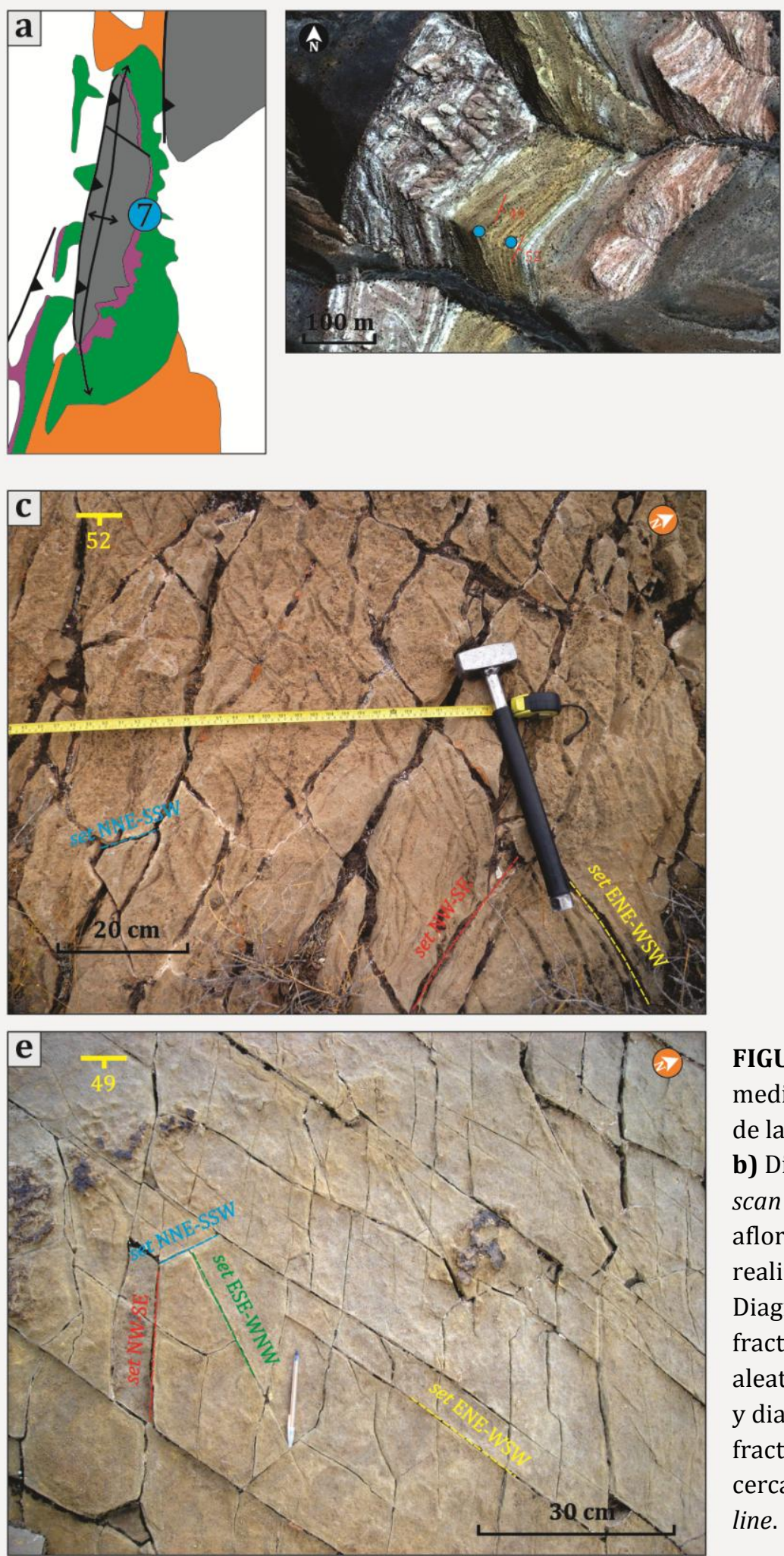
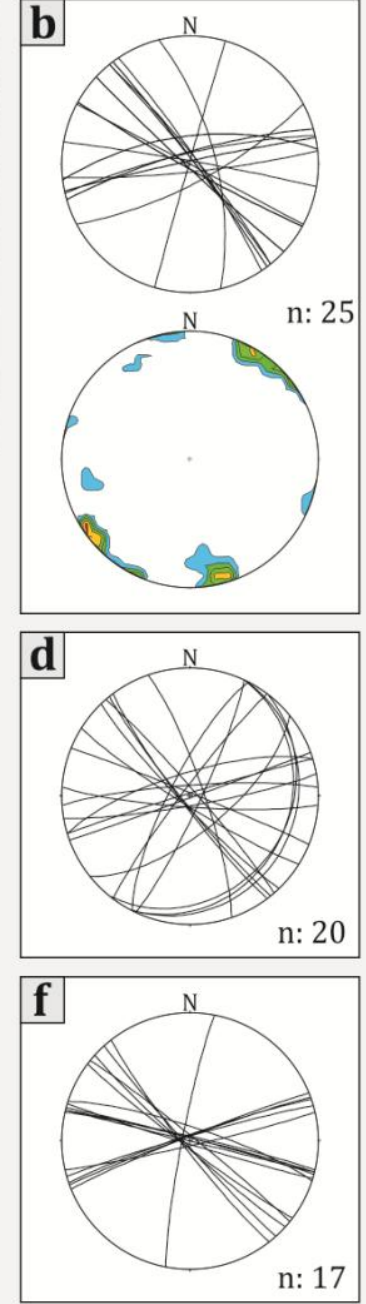

FIGURA 5.8. Estación de medición 7TT. a) Ubicación de la estación en el anticlinal. b) Diagramas de datos del scan line. c) Fracturas en afloramiento donde se realizó el scan line. d) Diagrama de datos de fracturas medidas en forma aleatoria. e)-f) Afloramiento y diagrama de datos de fracturas medidas en un sitio cercano a la estación del scan line.

Se midieron fracturas en forma aleatoria pertenecientes a una capa ubicada en la misma columna estratigráfica, posicionada en el techo de la Formación Yacoraite (Figura 5.8e). La roca es una arenisca cuarzosa de granulometría media a 
gruesa, con clastos aislados sabulíticos. Contiene cemento carbonático y su Rbz es $115^{\circ} / 52^{\circ}$. El diagrama estereográfico de la figura 5.8f muestra la orientación de los planos de fracturas medidos con direcciones definidas $\mathrm{N} 12^{\circ}$ (set NNE-SSW,

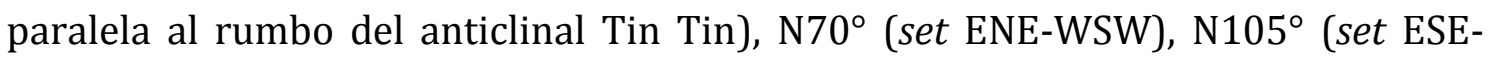
WNW) y ${\mathrm{N} 135^{\circ}}^{\circ}$ (set NW-SE), todos ellos clasificados como diaclasas. En el

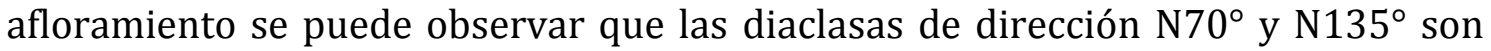
las predominantes. La diaclasas de dirección $\mathrm{N} 70^{\circ}$ presentan más continuidad y muchas de las diaclasas de dirección $\mathrm{N} 135^{\circ}$ terminan contra ésta, indicando que se formaron cronológicamente primero. En set de fracturas de dirección N135 (NWSE) presenta en algunas diaclasas un desplazamiento sinestral milimétrico. Los sets de diaclasas de dirección $\mathrm{N} 12^{\circ}$ y $\mathrm{N} 105^{\circ}$ son más cortos y terminan contra los sets anteriores, indicando una posterioridad relativa en su formación.

\subsubsection{Estación de medición 8TT}

La estación de medición 8TT se encuentra ubicada estratigráficamente en la sección inferior de la Formación Yacoraite, sobre flanco dorsal del anticlinal Tin Tin (Figura 5.9a). La capa medida es una arenisca cuarzosa de granulometría media, con poco contenido carbonático. Su espesor es de 20 centímetros y su Rbz es $106^{\circ} / 49^{\circ}$. Las fracturas medidas mediante scan line lineal y mediciones aleatorias, se clasificaron como diaclasas y venas tensionales, algunas de ellas con disposición en echelon (Figura 5.9d). El diagrama estereográfico de la figura 5.9b muestra dos abanicos de direcciones (o sets), E-W a NE-SW y N-S a NW-SE. El diagrama de contornos de la misma figura 5.9b, muestra que el set E-W a NE-SW presenta una continuidad en el abanico de orientaciones, con dos picos de frecuencia, ${\mathrm{N} 89^{\circ}}^{\circ}$ (set E-W) y N66 (set ENE-WSW). El set N-S a NW-SE no es tan continuo como el caso anterior y se puede dividir en las direcciones promedio $\mathrm{N} 123^{\circ}$ (set ESE-WNW) y $\mathrm{N} 168^{\circ}$ (set NNW-SSE). Con respecto a las inclinaciones de los planos de fracturas, la gran mayoría presenta valores entre $73^{\circ}$ y $89^{\circ}$, es decir, subperpendiculares a la capa que las contiene. 


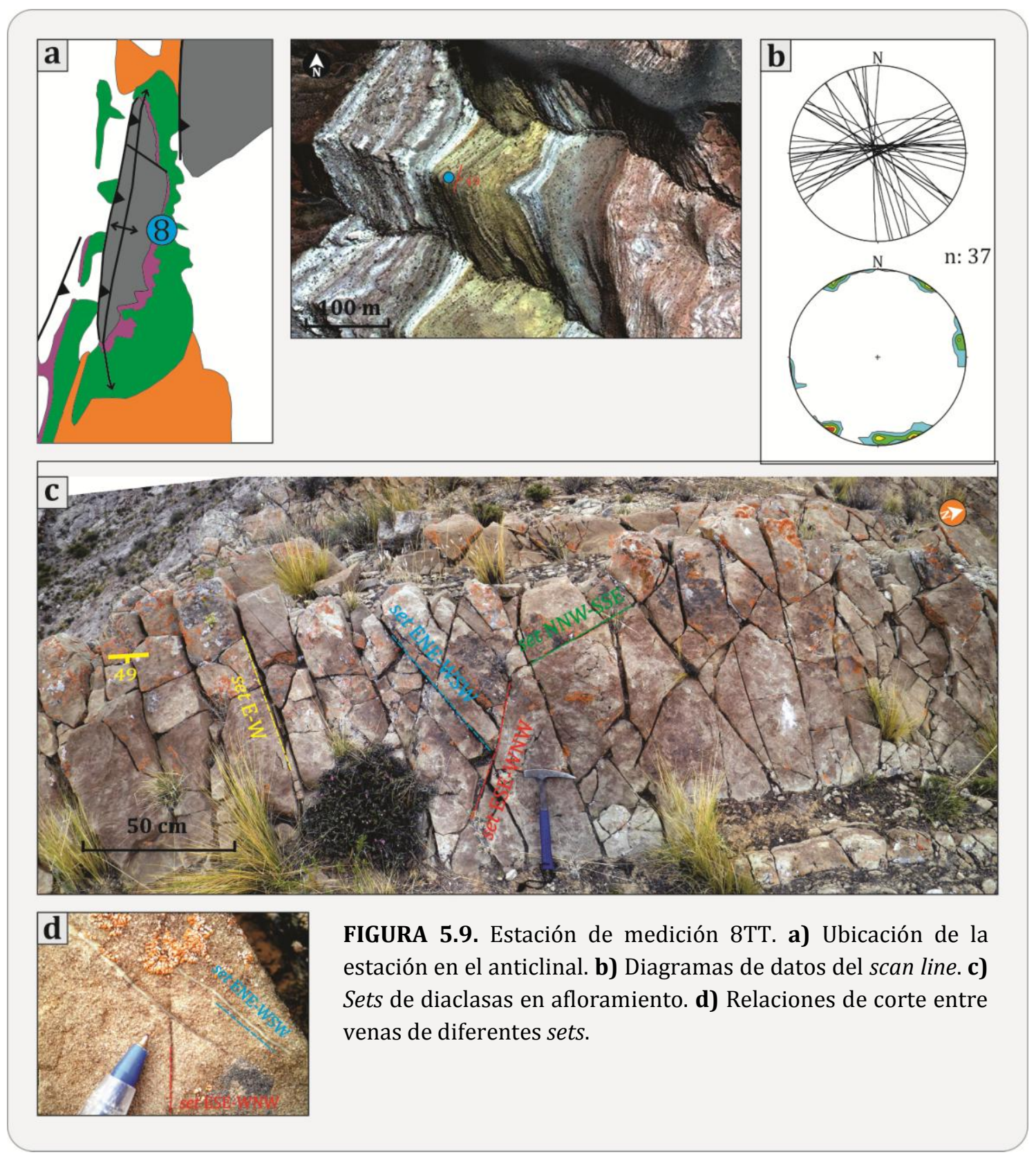

Las observaciones del afloramiento indican que las cuatro direcciones de fracturas (discriminadas en el diagrama de contornos) corresponden a diferentes tipos de fracturas superpuestas. El set E-W está conformado principalmente por diaclasas. Estas son las más continuas y atraviesan todo el afloramiento (Figura 5.9c). El set ENE-WSW presenta diaclasas y venas. Las diaclasas presentan características similares a las diaclasas del set E-W y se ubican entre estas. Las venas tienen 2 a 3 milímetros de ancho y hasta 30 centímetros de longitud, algunas dispuestas en echelon izquierdo. Los sets NNW-SSE y ESE-WNW presentan fracturas pequeñas, de menos de 10 centímetros de longitud y cerradas, y también diaclasas grandes que se ubican entre los dos primeros sets (Figura 5.9c). 
Cronológicamente, se observó que venas en echelon del set ENE-WSW cortan y abren a las fracturas pequeñas de los sets NNW-SSE y ESE-WNW, indicando su posterioridad (Figura 5.9d). En un solo lugar se observó la relación opuesta, donde una vena del set NNW-SSE corta a una vena del set ENE-WSW. Estas venas y fracturas pequeñas son también atravesadas por las diaclasas principales del set E$\mathrm{W}$, indicando que todas las diaclasas son posteriores a las fracturas pequeñas y venas. Dada la coincidencia entre la dirección de las diaclasas mayores y la dirección de las venas y fracturas pequeñas, es probable la reutilización de sus planos para la formación de las nuevas diaclasas. Considerando la ubicación y longitud relativa de cada uno de los sets de diaclasas mayores, se puede inferir que las diaclasas del set E-W son las más antiguas, en conjunto con las del set ENEWSW. Posteriormente y ubicándose entre las anteriores se forman los sets de fracturas NNW-SSE y ESE-WNW, con una longitud relativa menor (Figura 5.9c).

Los datos obtenidos a partir del scan line lineal realizado en el afloramiento arrojaron resultados correlacionables con las observaciones y descripciones de los párrafos anteriores (véase ANEXO). El parámetro Frecuencia arrojó un valor de 4.74 para el set ENE-WSW (espaciado promedio de 23.46 centímetros), 3.93 para el set E-W (espaciado promedio de 22.3 centímetros), 4.51 para el set ESE-WNW (espaciado promedio de 16.15 centímetros) y 5.65 para el set NNW-SSE (espaciado promedio de 13.83 centímetros). Estos valores indican un mayor número de fracturas (potencial) para el set NNW-SSE y se pueden relacionar a la formación última de este set, rellenando espacios entre otras fracturas anteriores.

\subsubsection{Estación de medición 9TT}

La estación de medición 9TT se encuentra ubicada estratigráficamente en la sección inferior de la Formación Yacoraite, sobre el flanco dorsal del cerro Tin Tin (Figura 5.10a). La capa medida es una arenisca cuarzosa de granulometría media, con poco cemento carbonático. Su espesor es de 15 centímetros y el Rbz de su techo, es $125^{\circ} / 64^{\circ}$. Las fracturas medidas en la capa, mediante scan line lineal y medición aleatoria, se clasificaron como diaclasas. En la figura 5.10b se muestra el diagrama estereográfico con los planos medidos y el diagrama de contornos correspondiente a los polos de los respectivos planos. Los diagramas muestran cuatro grupos de orientaciones de planos, con azimut promedio N18 ${ }^{\circ}$ (set NNE- 
SSW), ${\mathrm{N} 76^{\circ}}^{(\text {set ENE-WSW), N122 }}{ }^{\circ}$ (set ESE-WNW), y N165 (set NNW-SSE). Las inclinaciones de los planos de fracturas son altas con respecto al techo de la capa, en promedio entre $80^{\circ}$ y $83.5^{\circ}$. El set de diaclasas predominante es el de dirección ENE-WSW, como se puede observar en la figura 5.10c. Este set presenta trazas relativamente continuas que atraviesan todo el afloramiento. Los demás sets de diaclasas presentan menor continuidad en sus trazas, generalmente ubicándose entre las primeras. No se observaron relaciones de corte claras, pero la ubicación y continuidad de las fracturas del set ENE-WSW indicaría que son cronológicamente las más antiguas, y las correspondientes a los sets NNE-SSW y ESE-WNW las más modernas, es decir, las últimas en formarse. Se observó que algunas fracturas del set ENE-WSW desplazan dextralmente a fracturas del set NNW-SSE, por una distancia menor a 1 centímetro. Al no haber evidencias origen por cizalla, este desplazamiento sería una reactivación posterior del set.

Los datos obtenidos a partir del scan line lineal realizado en el afloramiento arrojaron los siguientes resultados (véase ANEXO). El parámetro Frecuencia arrojó un valor de 10.93 para el set NNE-SSW (espaciado promedio de 8.4 centímetros), 5.96 para el set ENE-WSW (espaciado promedio de 13.93 centímetros), 1.53 para el set WNW-ESE (espaciado promedio de 79.23 centímetros) y 3.48 para el set NNW-SSE (espaciado promedio de 18.37 centímetros). Estos valores indican un mayor número de fracturas (potencial) para el set NNE-SSW (dirección paralela al rumbo del anticlinal Tin Tin) y se puede relacionar a la formación última de este set, rellenando espacios entre otras fracturas anteriores.

El diagrama estereográfico de la figura 5.10e muestra mediciones aleatorias de planos de fracturas realizadas en una capa ubicada en la misma columna estratigráfica, separada por 4 metros de material pelítico de la capa donde se realizó el scan line. Se puede observar que la misma presenta los mismos sets de fracturas. Lo mismo se observó en capas supra e infrayacentes. 

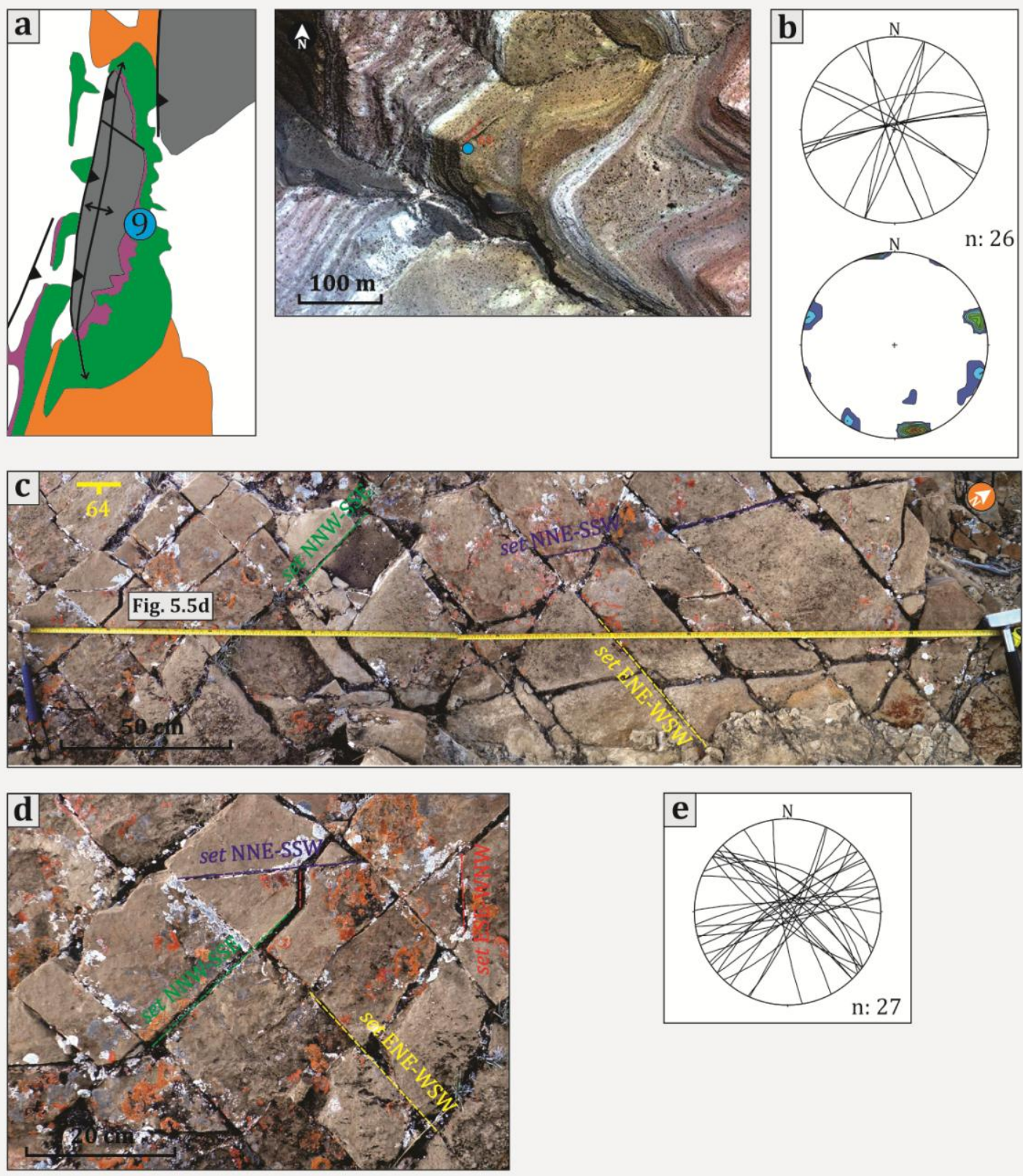

FIGURA 5.10. Estación de medición 9TT. a) Ubicación de la estación en el anticlinal. b) Diagramas de datos del scan line. c)-d) Diaclasas en afloramiento y relaciones de corte entre los diferentes sets. e) Diagrama de datos de fracturas medidas en forma aleatoria en una capa cercana al sitio donde se realizó el scan line.

\subsubsection{Estación de medición 10TT}

La estación de medición 10TT se encuentra ubicada estratigráficamente en el techo de la Formación Yacoraite, en transición con el Subgrupo Santa Bárbara, sobre el flanco dorsal del anticlinal Tin Tin (Figura 5.11a). La capa medida es una 
caliza gris oolítica con contenido de clastos de cuarzo sabulíticos, con $\mathrm{Rbz} 93^{\circ} / 74^{\circ}$. Las fracturas medidas en forma aleatoria se clasificaron como diaclasas y venas. El diagrama estereográfico de la figura 5.11b muestra la orientación de los planos de fracturas medidos en el afloramiento. Las direcciones de estos sets son $\mathrm{N}^{\circ}{ }^{\circ}$ (set

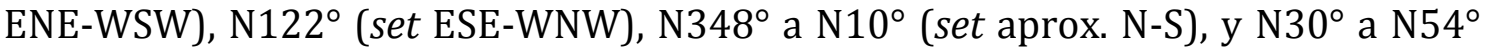
(set aprox. NE-SW). Los planos presentan alta inclinación con respecto a la capa que las contiene, con un promedio de $83,5^{\circ}$. En capas cercanas a la estación se observaron estructuras plumosas en superficies de diaclasas del set NE-SW y en otros sets con rumbos NW-SE y E-W, no representados en esta estación de medición. Las fracturas más prominentes en el afloramiento son las correspondientes a los sets NE-SW y ENE-WSW (Figura 5.11c). Las trazas de las fracturas del set NE-SW son más continuas que las del set ENE-WSW, por lo que este último set tiende a ubicarse entre el primero, en algunos casos terminando contra éste, indicando su posterioridad. Los sets mencionados y el set WNW-ESE están conformados por diaclasas y venas paralelas a las diaclasas. El set WNW-ESE presenta un gran número de fracturas que atraviesan y terminan contra los sets mencionados, indicando su posterioridad. Las fracturas del set N-S se presentan con menor frecuencia y son posiblemente las últimas en formarse. Se pudo observar que todas las diaclasas cortan a las venas del afloramiento. Dado el paralelismo entre ambas estructuras, es posible que las diaclasas hayan reutilizado el plano de debilidad generado por las venas previas al momento de su formación.

En las superficies de las diaclasas de rumbo NE-SW y ENE-WSW se observaron estrías en material carbonático. Estas estrías presentan dos ángulos de rake distintos. En el set NE-SW se midieron estrías paralelas al techo de la capa (rake: $0^{\circ}$ ). En el set ENE-WSW se midió un estriado de rake $15^{\circ} \mathrm{W}$. En un afloramiento cercano se observaron diaclasas de los sets NE-SW y ENE-WSW desplazando dextralmente a las fracturas de rumbo WNW-ESE (Figura 5.11d). Los datos de estrías y las otras observaciones sugieren la reactivación de venas tensionales como diaclasas con componentes de cizalla. Los diferentes ángulos de rake indican diferentes inclinaciones de la capa (antes del plegamiento y durante el plegamiento principal) al momento de la reactivación. 
En una capa estratigráficamente inferior (sección superior del perfil de la Formación Yacoraite) se midieron fracturas aleatorias. La roca es una arenisca cuarzosa de $\mathrm{Rbz} 103^{\circ} / 41^{\circ}$. El diagrama estereográfico de la figura 5.11e muestra los planos medidos. Se observa que las direcciones de las fracturas se mantienen con una orientación similar, con una inclinación promedio menor $\left(76^{\circ}\right)$. En este afloramiento, las fracturas de los sets ENE-WSW y NE-SW son las más continuas (Figura 5.11f), con predominio de las primeras. El resto de las direcciones se ubican entre las anteriores, indicando posterioridad cronológica de formación. 


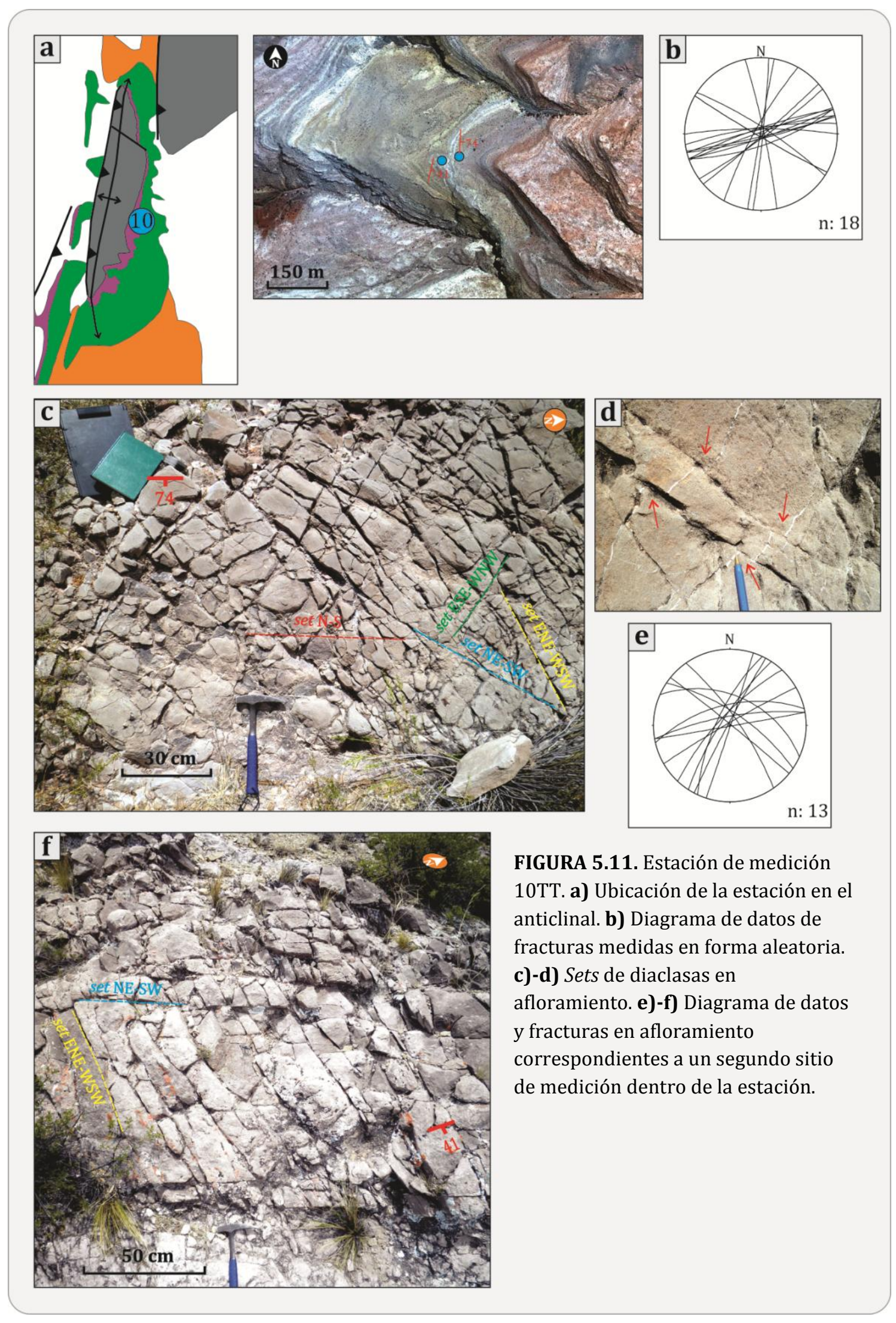




\subsubsection{Estación de medición 11TT}

La estación de medición 11TT se ubica estratigráficamente en la base de la Formación Yacoraite, sobre el flanco dorsal del anticlinal Tin Tin (Figura 5.12a). La capa medida es una arenisca cuarzosa de granulometría media, con contenido micáceo. El espesor de la misma es aproximadamente 1 metro, y el Rbz de su techo es $111^{\circ} / 27^{\circ}$. Las fracturas medidas mediante scan line lineal se clasificaron mayormente como diaclasas (Figura 5.12b). La figura 5.12b muestra el diagrama estereográfico y de contornos de los planos medidos, donde se observan tres sets bien definidos, $\mathrm{N} 70^{\circ}$ (set ENE-WSW), $\mathrm{N} 108^{\circ}$ (set ESE-WNW), y N165 (set NNWSSE). Estos presentan en general alta inclinación con respecto al techo de la capa, con promedio entre $81^{\circ}$ y $86^{\circ}$. Una de las fracturas del set NNW-SSE presenta baja inclinación hacia el Este. El set E-W contiene estrías paralelas a la superficie de la fractura $\left(\right.$ rake $0^{\circ}$ ), y en algunos casos se observó con movimiento sinestral. Hay diaclasas pequeñas, cerradas y ortogonales entre sí, con rumbos NNW-SSE y ENEWSW (Figura 5.12c). No son claras las relaciones de corte (cronología de formación) entre los sets ENE-WSW y ESE-WNW, pero se puede decir que el set NNW-SSE es posterior a los sets mencionados ya que se ubica entre ellos. Las fracturas de baja inclinación tienen escalones pequeños y estrías en su superficie, que indican que el bloque faltante superior se movió hacia el Oeste, con deslizamiento de inclinación (dip-slip). Estas fracturas se interpretan como fracturas de cizalla contraccionales.

Los datos obtenidos a partir del scan line lineal realizado en el afloramiento arrojaron los siguientes resultados (véase ANEXO): El parámetro Frecuencia arrojó un valor de 5.89 para el set ENE-WSW (espaciado promedio de 18.41 centímetros), 6 para el set NNW-SSE (espaciado promedio de 18.07 centímetros), y 8.64 para el set ESE-WNW (espaciado promedio de 11.17 centímetros). 


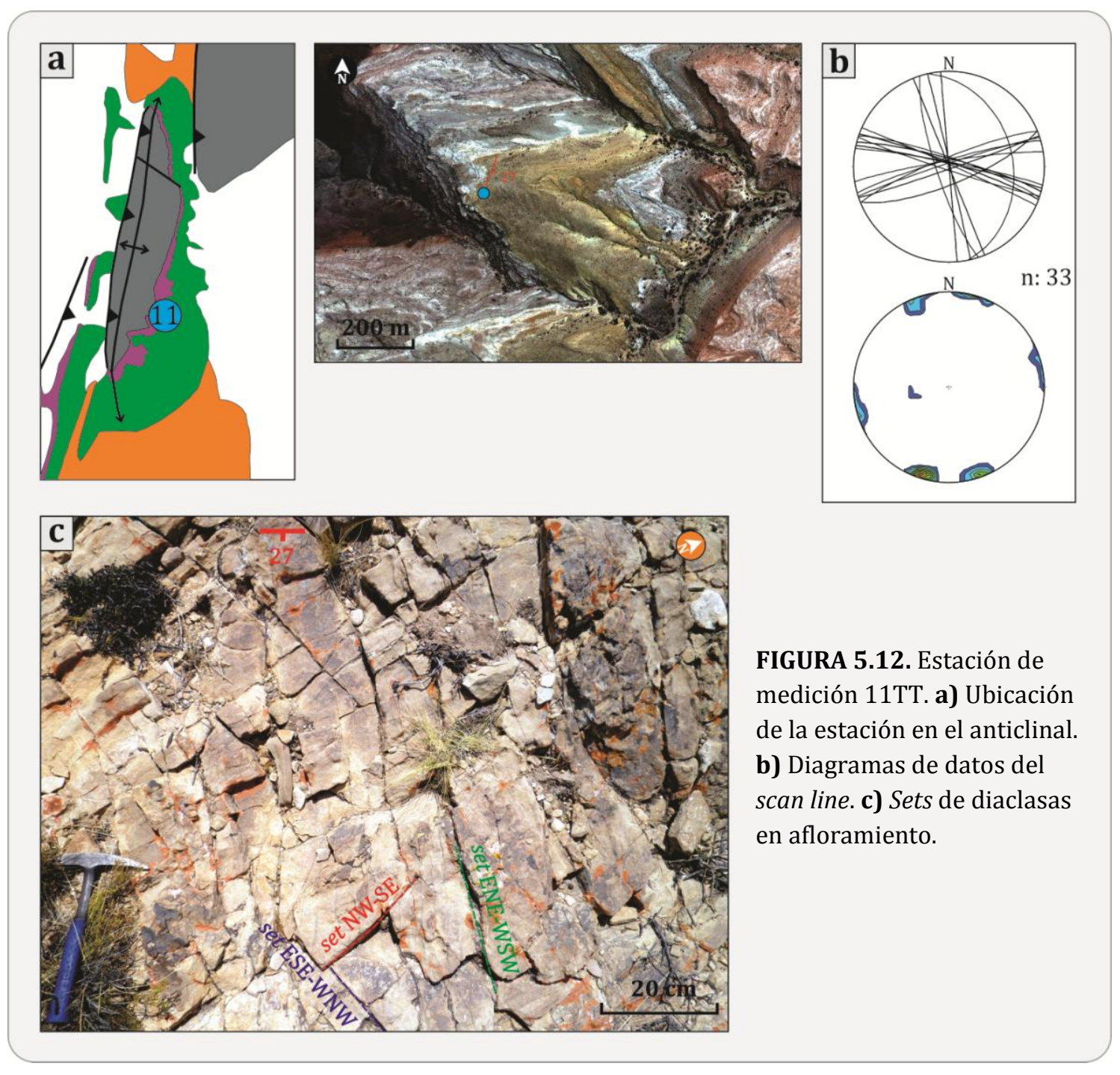

\subsubsection{Estación de medición $12 T T$}

Esta estación de medición está conformada por tres sitios de relevamiento de fracturas aleatorias y se encuentra ubicada sobre el flanco dorsal del anticlinal Tin Tin (Figura 5.13a). El primer sitio de medición corresponde al mismo nivel estratigráfico (sección basal de la Formación Yacoraite) que la estación anterior (Estación 11TT). En la capa se midió $\mathrm{Rbz}$ de $115^{\circ} / 31^{\circ}$ y las fracturas relevadas se clasificaron como diaclasas y venas, estas últimas generalmente con disposición en echelon (Figura 5.13c-d-e). La figura 5.13b muestra el diagrama estereográfico de los planos relevados, donde se puede ver que el sistema de fracturas tiene una disposición similar a la estación de medición anterior, es decir, se mantienen las direcciones de los sets, además de algunas direcciones nuevas. En el afloramiento se observó un conjunto de venas en echelon derecho (cinemática sinestral). La 
dirección del conjunto de venas es E-W, mientras que la dirección de las venas individuales es NE-SW (Figura 5.13e). Inversamente, se observaron conjuntos de venas en echelon izquierdo (cinemática dextral) con dirección NE-SW y fracturas individuales de dirección E-W. Los sets de dirección ESE-WNW y NW-SE presentan fracturas dispuestas en echelon derecho (sinestral). Las diaclasas, estructuras principales del afloramiento, son paralelas a la mayoría de las direcciones de venas descriptas (Figura 5.13d-e). Las observaciones y mediciones en el afloramiento indican que los grupos de venas en echelon preceden a las diaclasas, y que las diaclasas siguen las direcciones de las venas (reutilización de planos) cortándolas y abriéndolas, tanto de las venas individuales como de los grupos en echelon (Figura 5.13d-e).

El segundo sitio de medición corresponde a una capa ubicada estratigráficamente en la sección media de la Formación Yacoraite (Figura 5.13f). La capa medida es una arenisca calcárea, ya que está compuesta por clastos de cuarzo de granulometría media a gruesa, oolitas y estructuras estromatolíticas. El $\mathrm{Rbz}$ de la capa es $114^{\circ} / 29^{\circ}$ y las fracturas medidas se identificaron como diaclasas. El diagrama estereográfico de la figura 5.13g muestra, al igual que la fotografía del afloramiento, dos sets principales de diaclasas, N-S (N176 $)$ a NNW-SSE (N165) y $\mathrm{E}-\mathrm{W}\left(\mathrm{N} 87^{\circ}\right)$. La cronología de formación no es clara ya que las relaciones de corte y terminaciones son mutuas. 


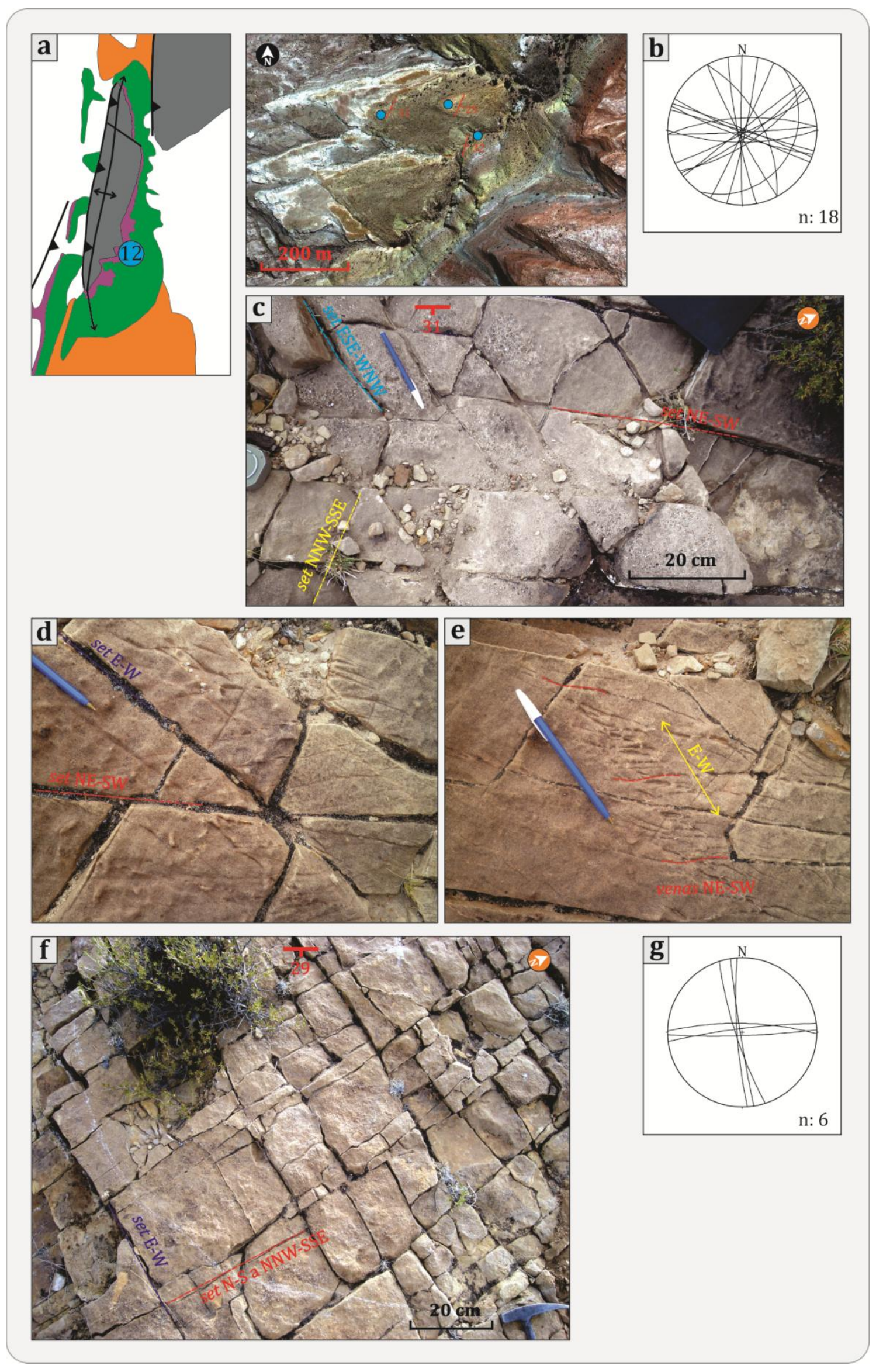


FIGURA 5.13. Estación de medición 12 TT. a) Ubicación de la estación en el anticlinal. b) Diagrama de datos de fracturas medidas en forma aleatoria. c)-d)-e) Sets de diaclasas y venas en echelon en afloramiento. f)-g) Fracturas en afloramiento y diagrama de datos correspondientes al segundo sitio de medición.

El tercer sitio de medición corresponde a la sección superior de la Formación Yacoraite, sobre una capa de $\mathrm{Rbz} 105^{\circ} / 32^{\circ}$. La roca es una arenisca cuarzosa de coloración gris, de granulometría media a fina, con contenido micáceo. Las fracturas medidas se identificaron como diaclasas y venas (Figura 5.13i). La figura $5.13 \mathrm{~h}$ muestra el diagrama de rosas con las orientaciones medidas en la capa, siendo las direcciones de fracturas $\mathrm{N70}{ }^{\circ}$ (set ENE-WSW), $\mathrm{N} 90^{\circ}$ a $\mathrm{N} 100^{\circ}$ (set E-W), $\mathrm{N} 125^{\circ}$ (set NW-SE) y N160 (set NNW-SSE). Se observó un conjunto de venas en echelon derecho (cinemática sinestral) de dirección $\mathrm{N} 100^{\circ}$, con venas individuales del set $\mathrm{N} 70^{\circ}$. Estas son cortadas por venas más finas del set $\mathrm{N} 160^{\circ}$ (Figura 5.13j-k). Otro conjunto de venas en echelon derecho (sinestral) tiene dirección $\mathrm{N} 109^{\circ}$ con venas individuales de orientación $\mathrm{N} 90^{\circ}$. Inversamente, un conjunto de venas en echelon izquierdo (cinemática dextral) con dirección $\mathrm{N}^{\circ} 7^{\circ}$ presenta venas individuales de dirección N105․ Estas venas se encuentran unidas entre sí por fracturas pequeñas (Figura 5.13l-m), como propone el modelo de cizalla de Riedel (Twiss y Moores, 2007). Como se observa en las fotografías del afloramiento, todas las venas son cortadas y abiertas por diaclasas, indicando que las diaclasas son posteriores a las venas y que reutilizaron sus planos. La figura 5.13i muestra la fotografía del afloramiento con los planos principales de diaclasas. Las direcciones de los planos corresponden a los sets $\mathrm{N} 60^{\circ}, \mathrm{N} 100^{\circ}$ y N160 ${ }^{\circ}$ y el orden cronológico de formación no es claro. Es posible que si las diaclasas se formaron a partir de planos de debilidad, se hayan formado durante un mismo episodio de deformación.

Como observación adicional, en capas cercanas a esta estación de medición se observaron estructuras plumosas en superficies de diaclasas de los sets E-W y NE-SW. 


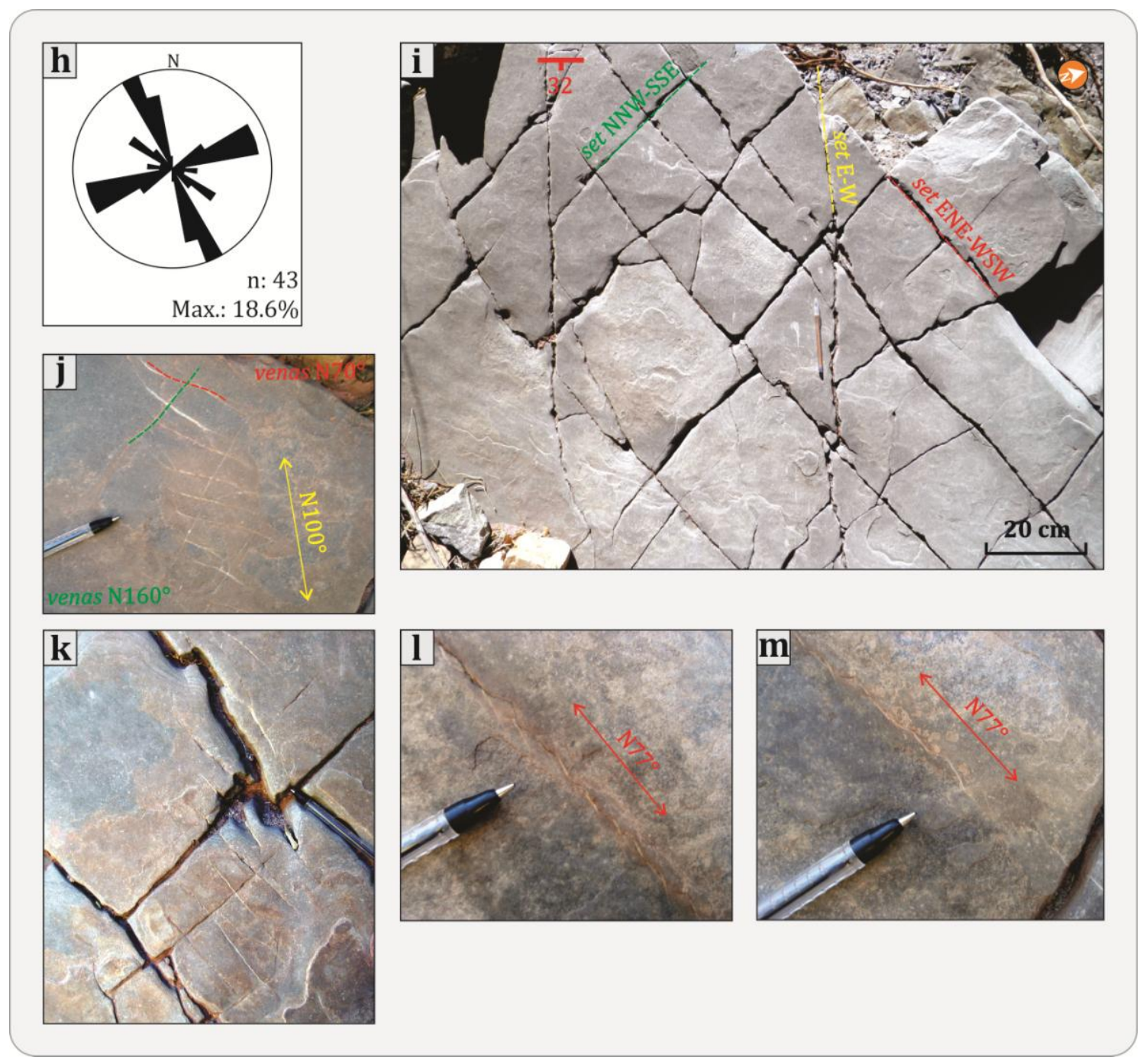

FIGURA 5.13 (cont.). h) Diagrama de datos de fracturas medidas en forma aleatoria. i)-j)-k)-l)-m) Sets de diaclasas y venas en echelon en afloramiento.

\subsubsection{Estación de medición $13 T$ T}

La estación de medición 13TT se ubica en la zona crestal del anticlinal Tin Tin (Figura 5.14a) y cuenta con cuatro sitios de relevamiento de fracturas principales aleatorias dentro de la Formación Yacoraite.

En un primer sitio de relevamiento se midieron fracturas sobre una capa de caliza oolítica con contenido clástico cuarzoso, de aproximadamente 1.3 metros de espesor y orientación subhorizontal $\left(\mathrm{Rbz} 28^{\circ} / 7^{\circ}\right)$. Las fracturas presentes son mayormente diaclasas y en general presentan alta inclinación con respecto a la estratificación. También se midieron fracturas de bajo ángulo que se interpretan como fracturas de cizalla (fallas pequeñas) contraccionales. La figura 5.14b 
muestra el diagrama estereográfico de los planos medidos, con rumbos N-S, NESW, E-W y NW-SE. Las fracturas de bajo ángulo corresponden al set NE-SW, e inclinan entre $34^{\circ}$ y $39^{\circ}$ hacia el Sureste, indicando el sentido de la contracción hacia el Noroeste (Figura 5.14c). La cronología de formación no es clara para todos los sets, pero se observó que una fractura del set NE-SW se curva y termina contra dos fracturas del set E-W (Figura 5.14d). En una capa subhorizontal cercana a este sitio sólo se encuentran los sets NW-SE y NE-SW (diagrama de rosas de figura $5.14 b)$, siendo el primero el más continuo en traza de fracturas.

El segundo sitio de relevamiento corresponde a la parte basal de la Formación Yacoraite. La roca es una arenisca cuarzosa de granulometría media a gruesa, con $\mathrm{Rbz} 105^{\circ} / 30^{\circ}$ y con fracturas se clasificaron como diaclasas (Figura 5.14e). La figura 5.14f muestra el diagrama estereográfico de los planos medidos y la fotografía del afloramiento. Los rumbos de diaclasas que se midieron son NNESSW, ENE-WSW, E-W, NW-SE y NNW-SSE. Las observaciones del afloramiento no arrojan datos concluyentes sobre la cronología de formación, ya que tres de los cuatro sets principales terminan curvándose entre ellos. Las diaclasas abiertas siguen el rumbo de diaclasas de menor magnitud y cerradas.

El tercer sitio de relevamiento se encuentra ubicado sobre una arenisca cuarzosa de granulometría media a fina, con clastos dispersos de granulometría mayor, media a gruesa. El Rbz de la capa es $121^{\circ} / 20^{\circ}$ y las fracturas medidas se clasificaron como diaclasas. La figura 5.14g muestra el diagrama de rosas con las direcciones de las trazas de fracturas medidas, de planos subperpendiculares a la capa. El diagrama muestra tres sets de diaclasas principales, $\mathrm{N}^{\circ} 5^{\circ}$ (set ENE-WSW), $\mathrm{N} 120^{\circ}$ (set ESE-WNW) y $\mathrm{N} 175^{\circ}$ (set N-S). También aparecen fracturas en la

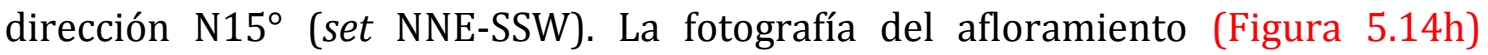
muestra el predominio de los sets $\mathrm{N}^{\circ} 5^{\circ}$ y N175 . Ambos sets terminan uno contra el otro, pero para el set $\mathrm{N} 65^{\circ}$ se observaron más terminaciones que para el set $\mathrm{N} 175^{\circ}$, por lo que se infiere que el set $\mathrm{N} 175^{\circ}$ fue el primero en formarse, aunque ambos sets podrían haber tenido un desarrollo contemporáneo, es decir, durante el mismo evento de deformación (Bahat et al., 2005). Los demás sets no se observan con la misma frecuencia que los anteriores, por lo que se propone una formación tardía relativa. 


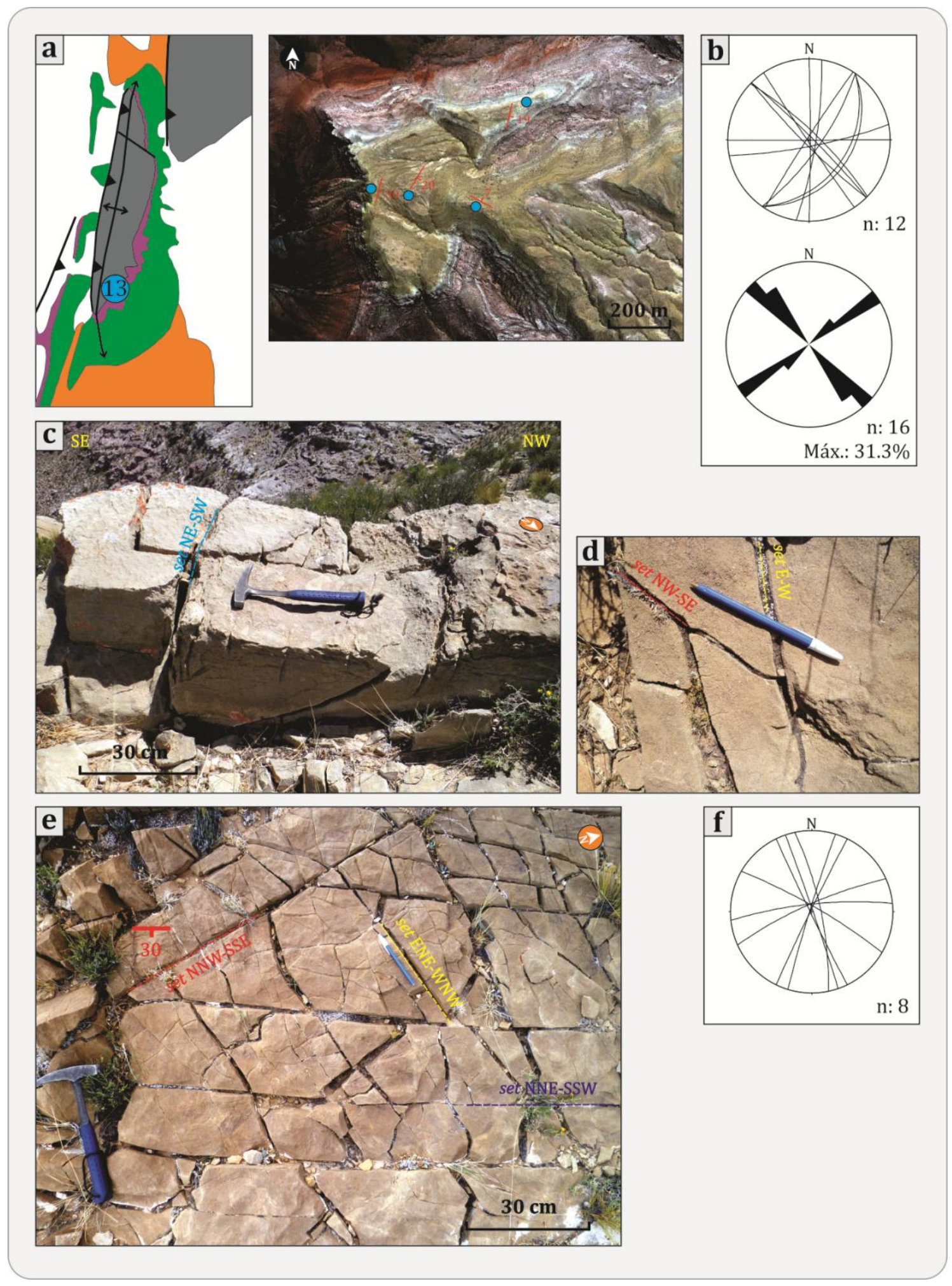

FIGURA 5.14. Estación de medición 13TT. a) Ubicación de la estación en el anticlinal. b) Diagrama de datos de fracturas medidas en forma aleatoria. c)-d) Sets de diaclasas y terminaciones curvadas. e)-f) Fracturas en afloramiento y diagrama de datos correspondientes al segundo sitio de medición. 

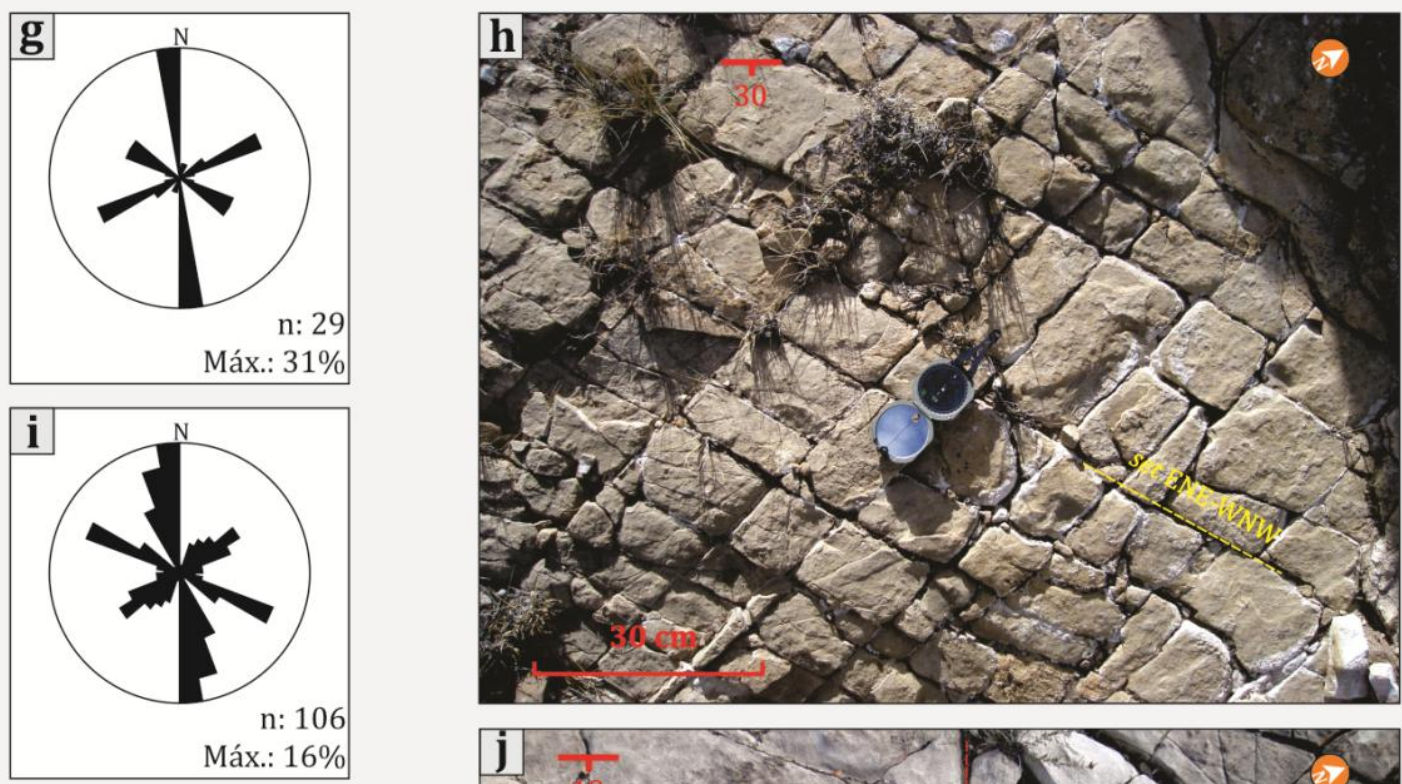

FIGURA 5.14 (cont.). g)-h)

Fracturas en afloramiento y diagrama de datos correspondientes al tercer sitio de medición. i)-j) Fracturas en afloramiento $y$ diagrama de datos correspondientes al cuarto sitio de medición.

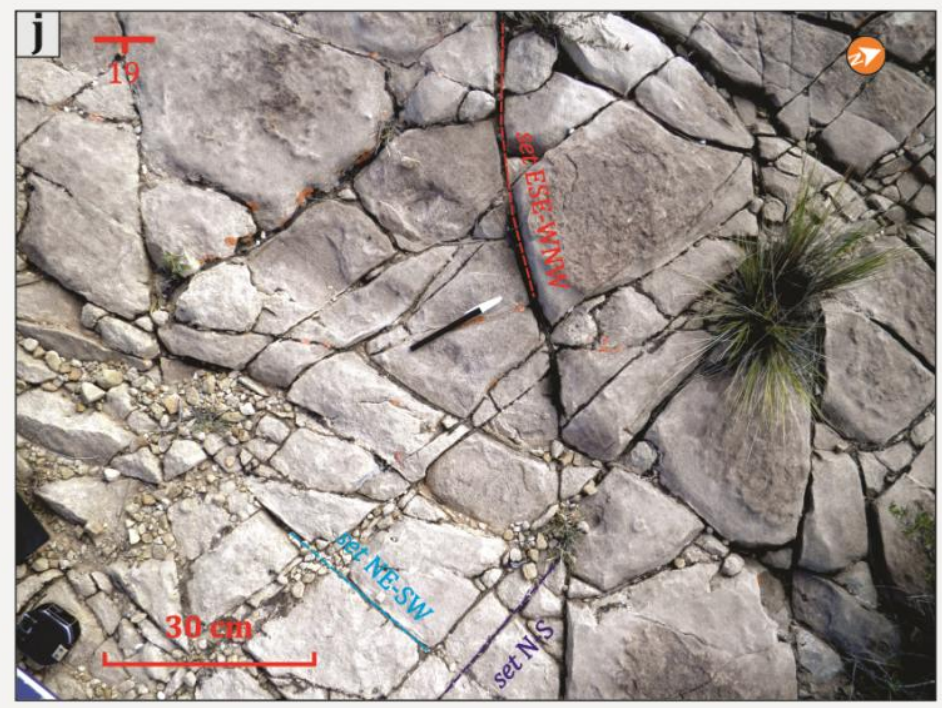

El cuarto sitio de relevamiento se ubica al Norte del sitio anterior. La capa corresponde a la sección inferior de la Formación Yacoraite y tiene un Rbz de $103^{\circ} / 19^{\circ}$. La roca es una arenisca cuarzosa de granulometría media a gruesa, con clastos sabulíticos dispersos y contenido micáceo. La figura 5.14i muestra el diagrama de rosas con las direcciones de las trazas de fracturas medidas, clasificadas como diaclasas, de planos subperpendiculares a la capa. El diagrama

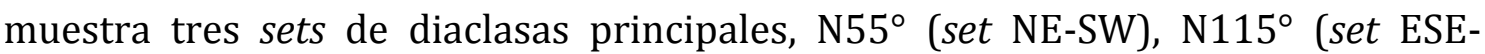
WNW) y $\mathrm{N} 170^{\circ}$ (set $\mathrm{N}-\mathrm{S}$ ), en forma similar al sitio de medición anterior. La fotografía del afloramiento (Figura 5.14j) muestra al set $\mathrm{N} 115^{\circ}$ con trazas continuas y largas, mientras que los otros dos sets presentan características similares al sitio de relevamiento anterior, donde las relaciones de corte son mutuas. En este afloramiento, los dos últimos sets (N-S y NE-SW) en ciertos lugares 
terminan contra el set ESE-WNW $\left(\mathrm{N} 115^{\circ}\right)$, y en la mayoría de los casos lo atraviesan.

\subsubsection{Estación de medición 14TT}

Esta estación de medición está conformada por cinco sitios de relevamiento de fracturas aleatorias que corresponden a la sección superior de la Formación Yacoraite (repetida por falla), y se encuentra ubicada en el extremo de inmersión Sur del anticlinal Tin Tin, en el bloque techo (colgante) de la falla inversa que afecta a la secuencia sedimentaria en esta parte de la estructura (Figura 5.15a).

El primer sitio de relevamiento se realizó sobre el techo de una capa de arenisca cuarzosa de granulometría media a gruesa, de $\mathrm{Rbz} 181^{\circ} / 39^{\circ}$. Las fracturas medidas se clasificaron como diaclasas, algunas con relleno calcáreo pulverulento. La figura 5.15b muestra el diagrama de rosas de las trazas de las diaclasas medidas y un diagrama estereográfico de algunos de sus planos medidos, mostrando la alta inclinación de los mismos con respecto a la estratificación. El diagrama de rosas muestra dos direcciones principales de diaclasas, $\mathrm{N} 145^{\circ}$ a $\mathrm{N} 165^{\circ}$ (set NNW-SSE) y ${\mathrm{N} 65^{\circ}}^{\circ}$ (set ENE-WSW), y secundariamente $\mathrm{N} 80^{\circ}$ a $\mathrm{N} 100^{\circ}$ (set E-W). Algunas diaclasas del set NNW-SSE presentan desplazamiento milimétrico sinestral (Figura 5.15e-f). En diaclasas del set ENE-WSW se observó un desplazamiento similar pero con cinemática dextral (Figura 5.15d). Estos movimientos indican un vector de esfuerzo contraccional aproximadamente E-W. Las relaciones de corte son difíciles de interpretar en este afloramiento. 


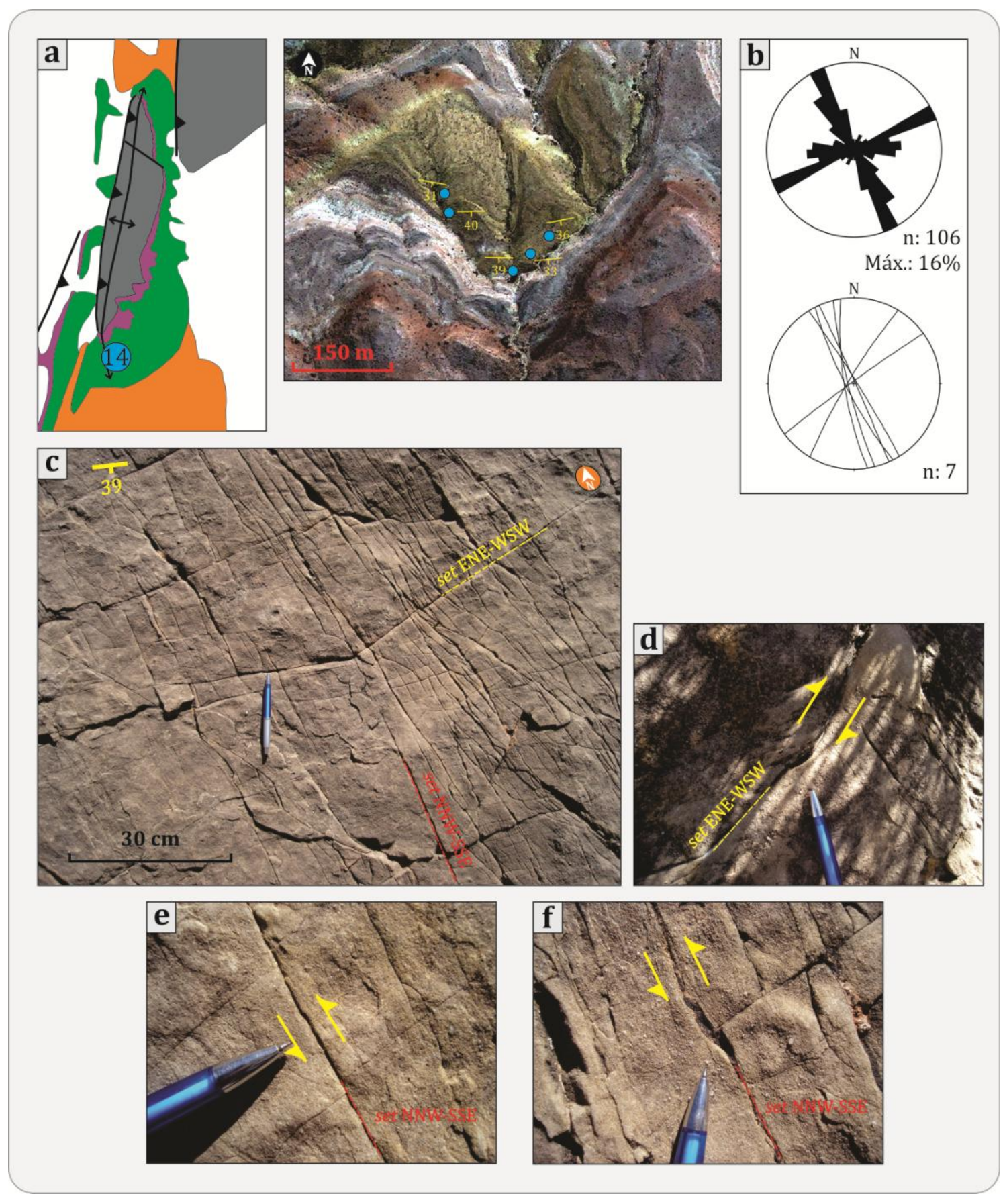

FIGURA 5.15. Estación de medición 14TT. a) Ubicación de la estación en el anticlinal. b) Diagramas de datos de fracturas medidas en forma aleatoria. c)-d)-e)-f) Sets de diaclasas y evidencias de desplazamiento. 


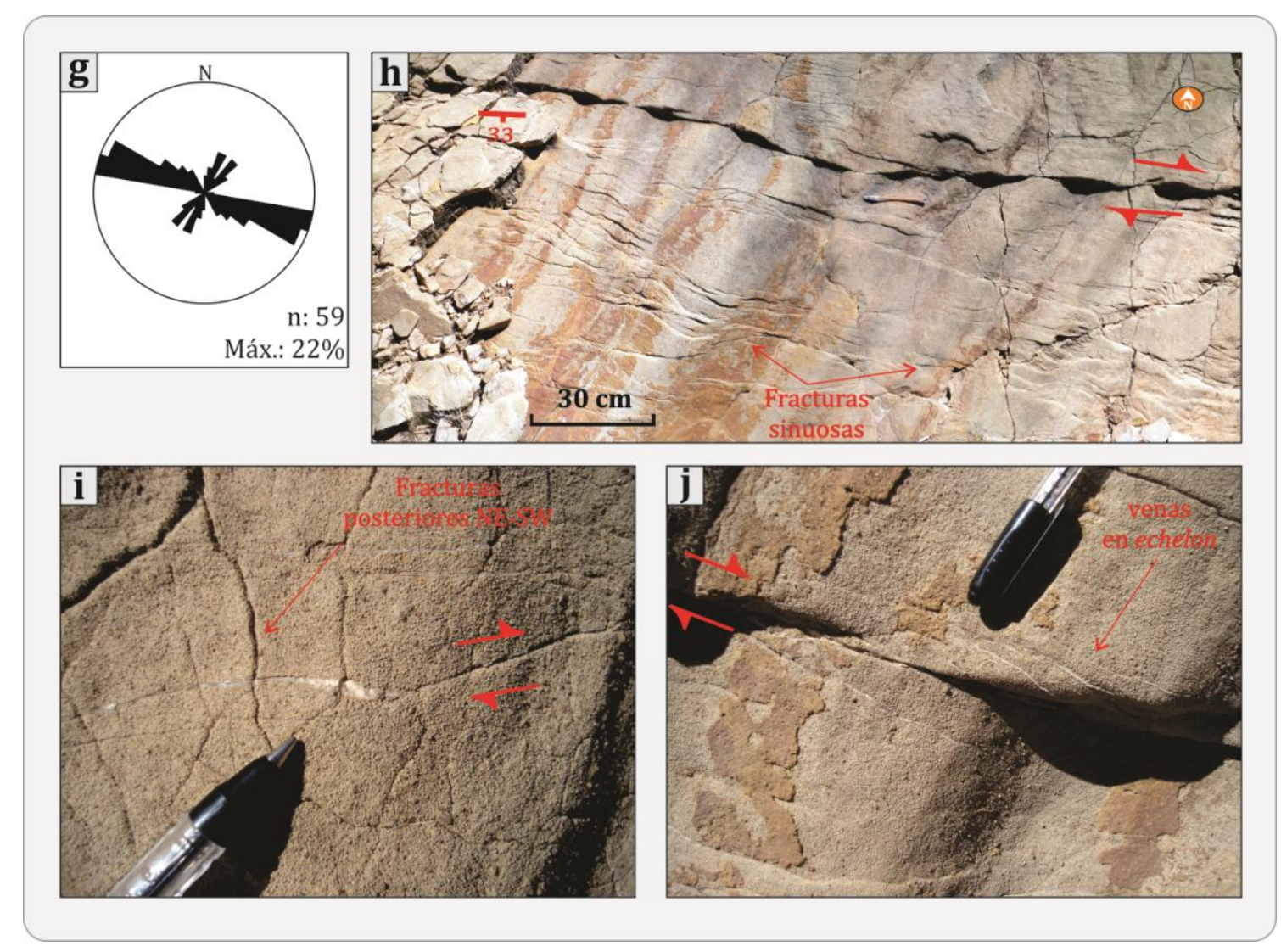

FIGURA 5.15 (cont.). g) Diagrama de datos de fracturas medidas en forma aleatoria en el segundo sitio de medición. h)-i)-j) Fracturas con desplazamiento de cizalla y venas en echelon.

El segundo sitio de relevamiento se realizó sobre una capa ubicada estratigráficamente por debajo de la anterior. La misma es una caliza oolítica con contenido clástico cuarzoso de granulometría arena media a gruesa y sabulítica, con óndulas en su techo. El Rbz de la capa es $174^{\circ} / 33^{\circ}$. Las fracturas medidas son venas de calcita y diaclasas que en conjunto se asocian y definen fracturas de cizalla que desplazan las ondulas de la capa (Figura 5.15h). El diagrama de rosas de la figura $5.15 \mathrm{~g}$ muestra un predominio de fracturas con dirección $\mathrm{N} 100^{\circ}$ a $\mathrm{N} 120^{\circ}$ (set ESE-WNW). Dentro de este grupo se encuentra la fractura de cizalla dextral que desplaza unos 10 centímetros las ondulas del techo (Figura 5.15h), como así también venas con movimiento de rumbo dextral, del tipo pull-apart con relleno calcítico (Figura 5.15i). La fractura principal (que desplaza óndulas) tiene asociadas venas de calcita con disposición en echelon izquierdo y forman parte de la cinemática de la misma (Figura 5.15j). La dirección de estas venas es $\mathrm{N} 130^{\circ}$, 
aproximadamente, y dentro de un esquema de Riedel serian una transición entre las fracturas R (Riedel) y T (tensión). Esta disposición podría indicar que la dirección del esfuerzo principal máximo $\sigma_{1}$ (al momento de formación de las fracturas) seria SE-NW y que la fractura dextral (y sus venas asociadas) esté relacionada a la falla inversa que afecta este sector. La fotografía del afloramiento (Figura 5.15h) muestra que este grupo de dirección N130 tiene una configuración compleja, de aspecto ramificado, con fracturas y venas agrupadas con trazas sinuosas y relativamente cortas (decenas de centímetros), pero que si se conectan pueden alcanzar una longitud mayor. Otro grupo de fracturas se observan con una disposición perpendicular a las anteriores, con dirección general NE-SW (Figura 5.15i). Estas fracturas son presumiblemente posteriores, ya que cortan y abren a las anteriores, y no son desplazadas por el movimiento de cizalla (Figura 5.15i).

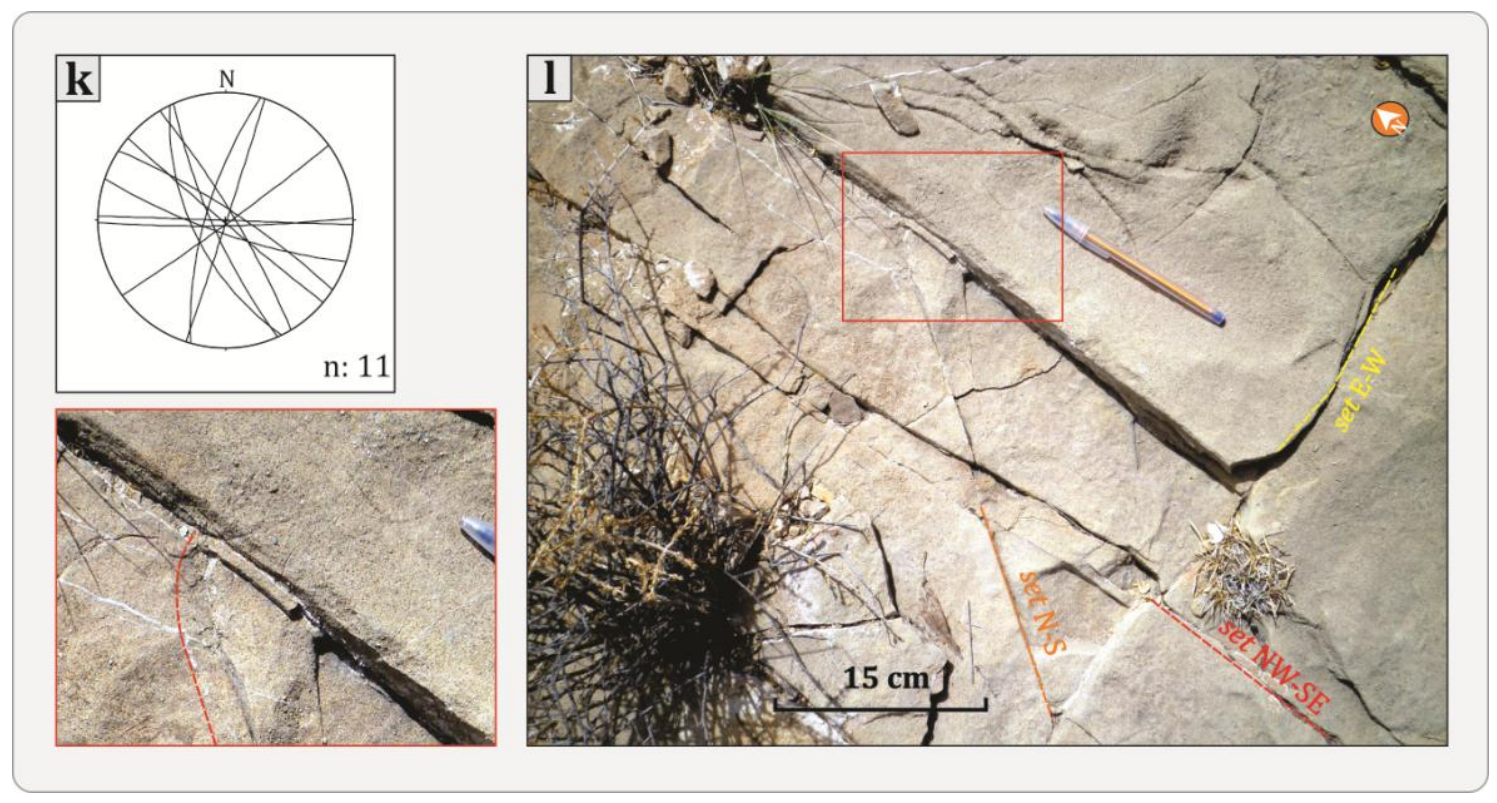

FIGURA 5.15 (cont.). k)-l) Diagrama de datos y fracturas en afloramiento correspondientes al tercer sitio de medición. Relaciones de corte y terminación.

El tercer sitio de relevamiento está ubicado al Norte del sitio anterior. El Rbz de la capa medida es $169^{\circ} / 36^{\circ}$ y presenta diaclasas y algunas venas de calcita en donde hay predominio de oolitas. Este afloramiento cuenta con muy variadas direcciones de fracturas, lo que hace difícil su interpretación (Figura 5.15k). Según las observaciones realizadas en el afloramiento, se puede concluir que las fracturas del set $\mathrm{NW}-\mathrm{SE}\left(\mathrm{N} 145^{\circ}\right)$ son posiblemente las más antiguas, ya que en dos 
afloramientos adyacentes, la mayoría de las fracturas terminan curvándose contra estas, además de cortarlas (Figura 5.15l). Con respecto a las fracturas del set E-W, en dos afloramientos se presentan con trazas cortas y se ubican entre las demás, indicando posterioridad. El resto de los sets no son concluyentes, pero se habrían formado entre los estadios anteriores de fracturación.

El cuarto sitio de relevamiento representa una de las últimas capas del tope de la Formación Yacoraite. La roca es una arenisca cuarzosa de granulometría media a gruesa, y el $\mathrm{Rbz}$ de su techo es $179^{\circ} / 40^{\circ}$. Las fracturas medidas se clasificaron como diaclasas (Figura 5.15m). En los diagramas de la figura 5.15n y la fotografía del afloramiento se pueden observar diferentes direcciones de diaclasas, con planos subperpendiculares a la capa. De la observación sobre la disposición espacial de las diaclasas y sus relaciones de corte se puede inferir que las diaclasas de dirección aproximada $\mathrm{N}^{\circ} 5^{\circ} \mathrm{N} 245^{\circ}$ (set ENE-WSW) son las primeras en formase relativamente, ya que la mayoría de las fracturas terminan contra éstas en forma curvada y perpendicular, además de ser continuas en el afloramiento (Figura 5.15m-ñ-o). En este set se observó un desplazamiento dextral de aproximadamente un centímetro, posiblemente por reactivación. Otros sets de diaclasas importantes, como los sets E-W y NNE-SSW se acomodan entre las fracturas antiguas y son más cortos en longitud de traza (Figura 5.15m-ñ-o).

El último sitio de relevamiento consiste en una capa similar a la del segundo sitio de relevamiento (probablemente la misma, con diferente ubicación). Esta es una caliza oolítica, con contenido clástico cuarzoso de granulometría arena gruesa a sabulítica. La superficie de la capa es ondulosa y el patrón de fracturación complejo (Figura 5.15p). El Rbz de la misma es $190^{\circ} / 31^{\circ}$. Dada la naturaleza carbonática de la capa, se observan presenta diaclasas y venas. Los diagramas de la figura $5.15 \mathrm{q}$ muestran las direcciones de fracturas medidas. Las fracturas de dirección $\mathrm{N} 111^{\circ}$ corresponden a venas de calcita. El resto de las fracturas son diaclasas. 

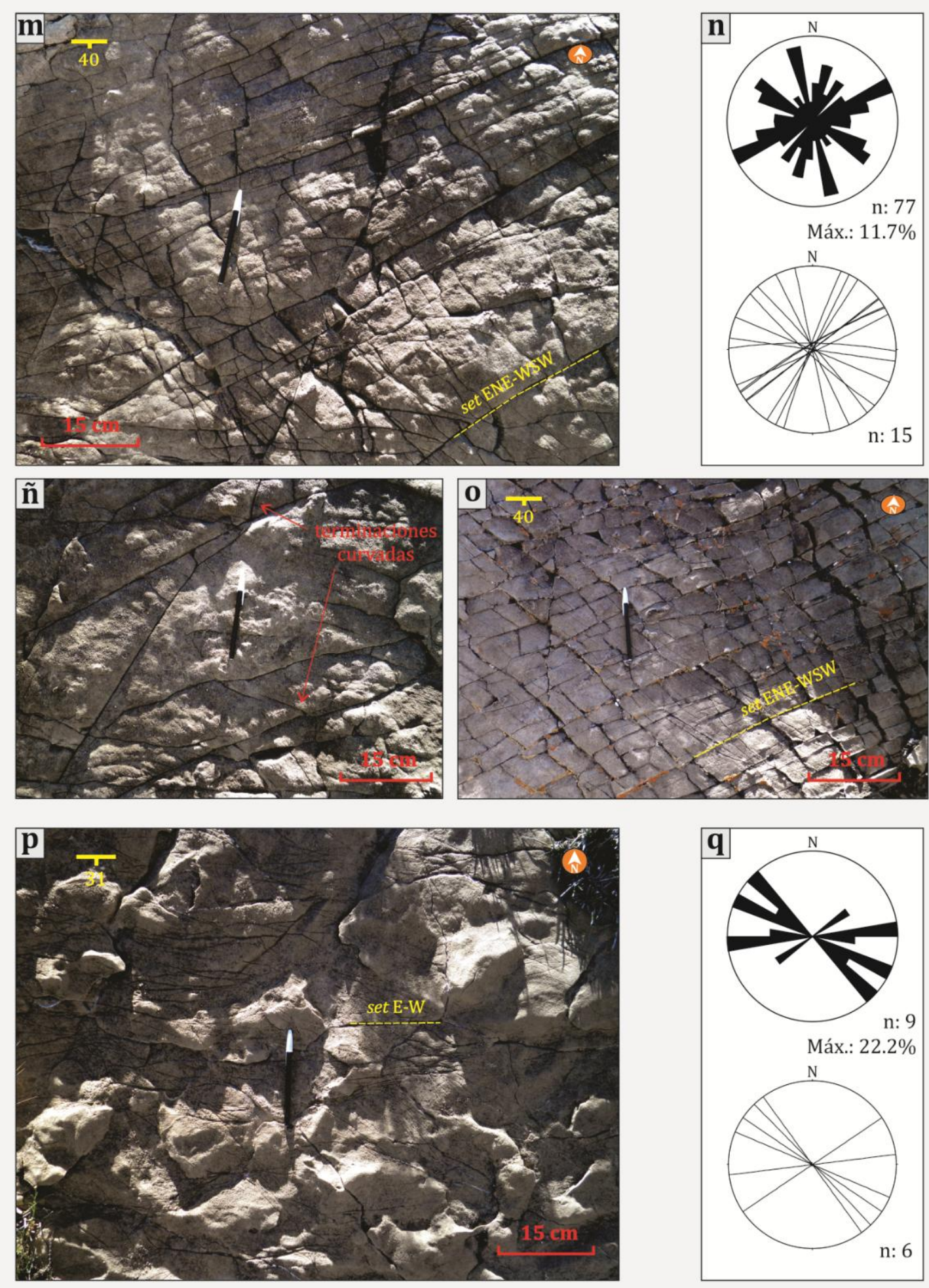

FIGURA 5.15 (cont.). m)-n)-ñ)-o) Fracturas en afloramiento y diagrama de datos correspondientes al cuarto sitio de medición. p)-q) Fracturas en afloramiento y diagramas de datos correspondientes al quinto sitio de medición. 
En el área de la estación de medición 14TT, la sección basal del Subgrupo Santa Bárbara también presenta una gran cantidad de venas y diaclasas, ya que presenta contenido carbonático importante. Aquí es importante mencionar un conjunto de fracturas de bajo ángulo ( $\mathrm{Rbz}$ del plano $148^{\circ} / 21^{\circ}$, con estriado de rake $88^{\circ} \mathrm{NE}$ ). Estas fracturas son posteriores a las demás y podrían estar relacionadas directamente a la falla inversa local. En las superficies de estratificación de este sector se observaron escalones de calcita que indican cizalla interestratal, con direcciones $\mathrm{N} 175^{\circ}, \mathrm{N} 204^{\circ}, \mathrm{N} 105^{\circ}$.

\subsubsection{Estación de medición $15 T$ T}

Esta estación de medición está conformada por dos sitios de relevamiento de fracturas aleatorias que corresponden a la sección superior de la Formación Yacoraite y se encuentra ubicada en el extremo de inmersión Sur del anticlinal Tin Tin, sobre bloque piso (basal) de la falla inversa que afecta la secuencia sedimentaria en esta parte de la estructura (Figura 5.16a).

El primer sitio de relevamiento corresponde a una caliza oolítica gris con clastos de cuarzo dispersos, de $\mathrm{Rbz} 170^{\circ} / 26^{\circ}$ y aproximadamente 40 centímetros de espesor. Las fracturas medidas se clasificaron como diaclasas y venas. La figura 5.16b muestra el diagrama de rosas con las direcciones de trazas recolectadas en el afloramiento y un diagrama estereográfico con planos principales, los cuales presentan alta inclinación con respecto a la capa. En el diagrama de rosas se observan tres grupos de direcciones predominantes, agrupadas en los sets NE-SW

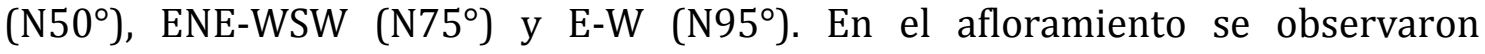
fracturas de dirección $\mathrm{N} 75^{\circ}$ desplazando sinestral y dextralmente a fracturas de

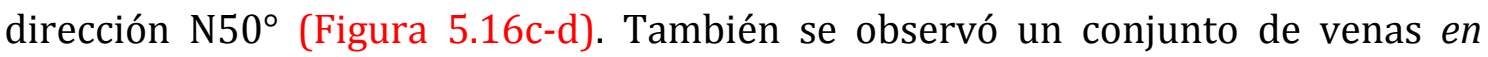
echelon (derecho) sinestral con orientación $\mathrm{N} 115^{\circ}$ y venas individuales de aspecto sigmoidal, de orientación ${\mathrm{N} 75^{\circ}}^{\circ}$. Por lo observado, se puede concluir que las fracturas del afloramiento se formaron en diferentes episodios de deformación debido a las relaciones de cortes entre los sets.

El segundo sitio de relevamiento corresponde a una capa de caliza oolítica con clastos cuarzosos. El Rbz de la misma es $159^{\circ} / 30^{\circ}$. Las fracturas de este afloramiento se clasificaron como diaclasas. En la figura $5.16 \mathrm{f}$ se muestra el 
diagrama estereográfico con los planos medidos de las fracturas principales. La observación del afloramiento muestra dos direcciones de diaclasas principales, $\mathrm{N}^{\circ} 3^{\circ}$ (set E-W) y $\mathrm{N}^{\circ}$ (set NE-SW), marcados y continuos, y un tercer set NNWSSE $\left(\mathrm{N} 160^{\circ}\right)$ más irregular. Se observó que el set NE-SW es cronológicamente posterior al set E-W ya que se curva y termina contra este último (Figura 5.16g). Las fracturas restantes tienen orientaciones subperpediculares a los sets mencionados, y se ubican y terminan contra estos, indicando una formación posterior relativa.

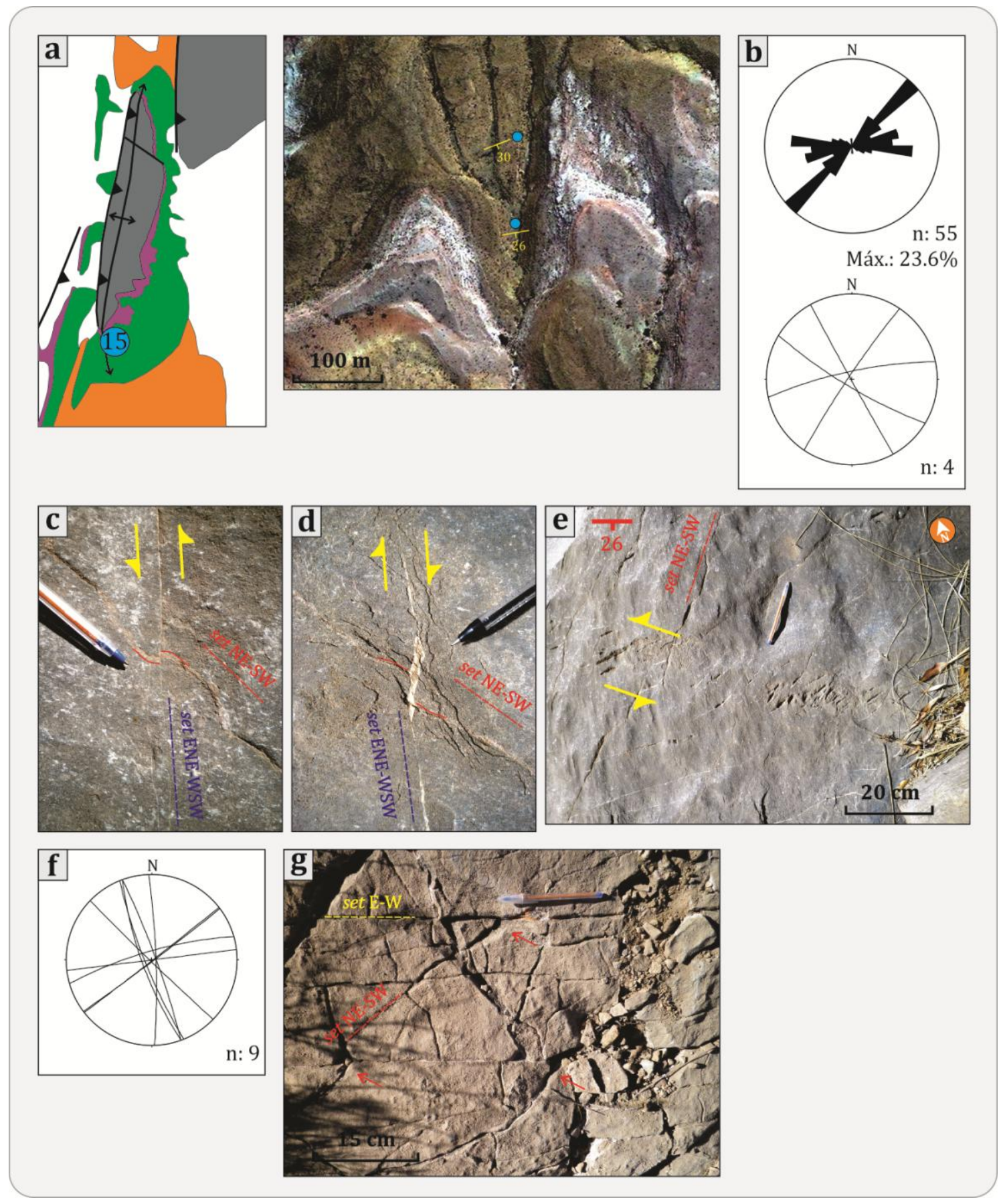


FIGURA 5.16. Estación de medición 15TT. a) Ubicación de la estación en el anticlinal. b) Diagramas de datos de fracturas medidas en forma aleatoria. c)-d)-e) Venas desplazadas y con disposición en echelon. f)-g) Diagrama de datos y fracturas en afloramiento correspondientes al segundo sitio de medición.

Como observación complementaria, se observaron venas con dirección $\mathrm{N} 105^{\circ}$ en otro afloramiento similar.

\subsubsection{Estación de medición 16TT}

Esta estación de medición está conformada por tres sitios de relevamiento de fracturas aleatorias que corresponden a la sección superior de la Formación Yacoraite, y se encuentra ubicada en el extremo de inmersión Sur del anticlinal Tin Tin (Figura 5.17a). Los sitios de medición se realizaron sobre el bloque basal y colgante de la falla inversa de bajo ángulo que afecta este sector, y constituyen un complemento a las estaciones de medición 14 y 15.

El primer sitio de relevamiento de fracturas, clasificadas como diaclasas, se realizó en una capa de caliza oolítica de $\mathrm{Rbz} 175^{\circ} / 32^{\circ}$, sobre el piso de la falla inversa. El diagrama estereográfico de la figura $5.17 \mathrm{~b}$ muestra los planos principales, con direcciones $\mathrm{N} 30^{\circ}$ (set NNE-SSW), N62 ${ }^{\circ}$ (set ENE-WSW), N83 ${ }^{\circ}$ (set $\mathrm{E}-\mathrm{W}$ ), $\mathrm{N} 120^{\circ}$ (set ESE-WNW) y $\mathrm{N} 148^{\circ}$ (set NNW-SSE). Las relaciones de corte y continuidad de las fracturas indican que las diaclasas del set E-W se formaron relativamente primero. Los demás sets de fracturas son posteriores y se ubican entre el set E-W, algunas con terminación curvada (Figura 5.17c).

El segundo sitio de relevamiento se ubica sobre el bloque colgante de la falla, y corresponde a una arenisca cuarzosa blanquecina, con presencia de restos de moluscos fósiles, característica de la sección superior de la formación, cercana a su techo. El Rbz de capa es $165^{\circ} / 23^{\circ}$ y las fracturas medidas se clasificaron como diaclasas. Como se puede observar en el diagrama estereográfico (Figura 5.17e) y en la fotografía del afloramiento (Figura 5.17d), los sets de diaclasas presentan direcciones definidas $\mathrm{N}^{\circ} 9^{\circ}$ (set NE-SW), N84 ${ }^{\circ}$ (set E-W), N138 ${ }^{\circ}$ (set NW-SE) y $\mathrm{N} 170^{\circ}$ (set $\mathrm{N}-\mathrm{S}$ ). De la observación del afloramiento surge que las diaclasas de los sets E-W y NE-SW son las más prominentes y continuas en longitud de traza; los demás sets se acomodan entre los sets mencionados (Figura 5.17d). Las diaclasas 
del set NE-SW muestran una curvatura cuando se aproximan y terminan contra las diaclasas del set E-W, indicando que este último set es el más antiguo, siendo las diaclasas del set NE-SW las siguientes en formación.

El tercer sitio de relevamiento se ubica sobre el bloque colgante de la falla inversa, y las fracturas medidas se clasificaron mayormente como diaclasas. El Rbz de la estratificación del sitio es $147^{\circ} / 24^{\circ}$. La figura $5.17 \mathrm{f}$ muestra el diagrama estereográfico de los planos medidos. Se pudo determinar que las diaclasas del set E-W y/o ESE-WNW fueron las primeras en formarse, de acuerdo a la longitud y continuidad de sus trazas y a las relaciones de corte con los demás sets, que terminan contra estas, en ocasiones en forma curvada. Es importante destacar la presencia de fracturas de bajo ángulo (Figura 5.17g), interpretadas como fracturas de cizalla (fallas de pequeña escala) asociadas a contracción horizontal y a pliegues locales con cinemática similar (vergencia hacia el Sur). También se observaron estructuras plumosas en capas diaclasas correspondientes a los sets N-S y ESEWNW (Figura 5.17h). 


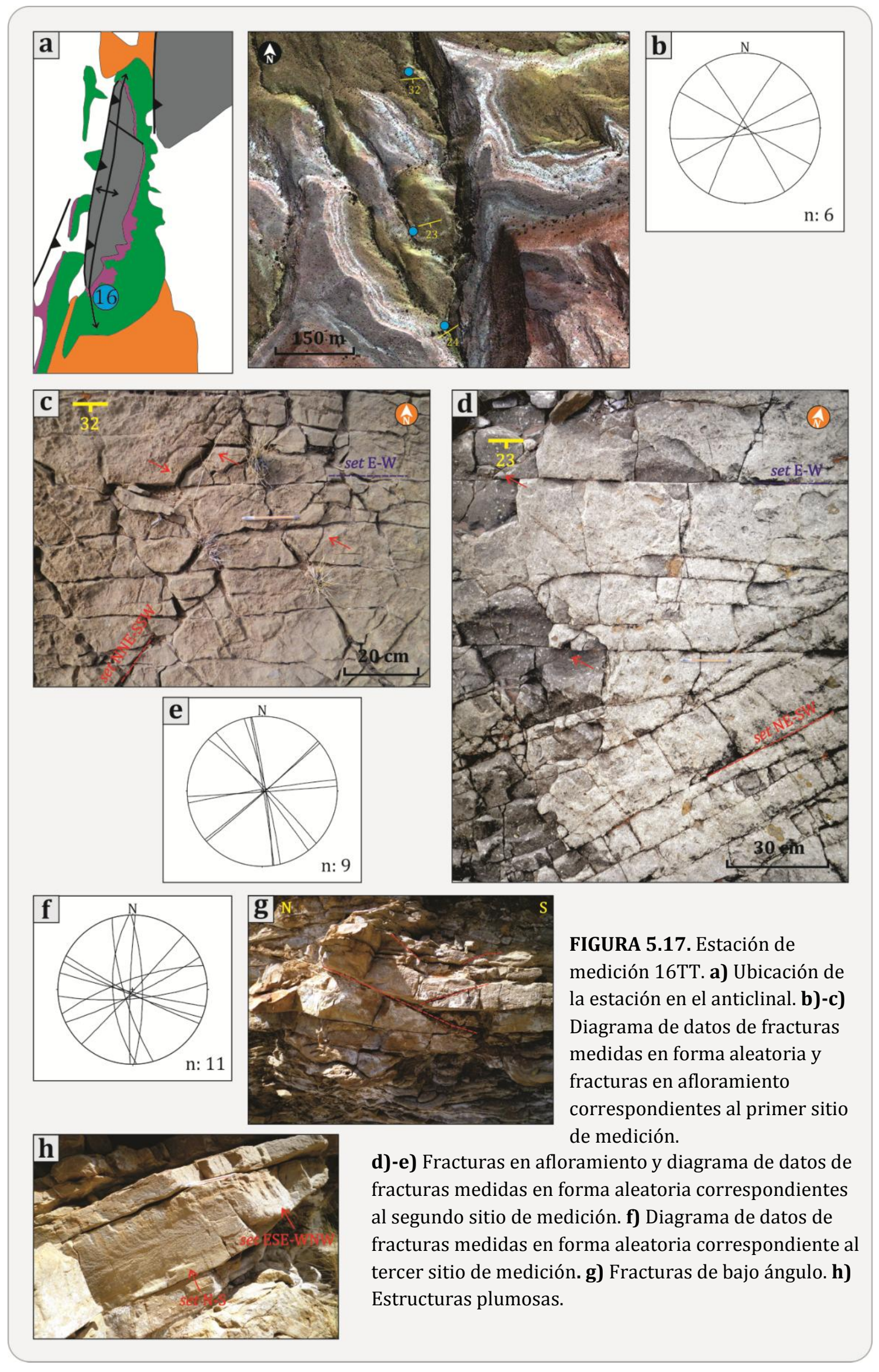




\subsubsection{Estación de medición 17TT}

Esta estación de medición se ubica estratigráficamente en la sección superior del perfil de la Formación Yacoraite, sobre el extremo de inmersión Sur del anticlinal Tin Tin y corresponde a la charnela de la estructura (Figura 5.18a). La capa medida es una arenisca cuarzosa de granulometría gruesa a sabulítica, con contenido oolítico. El espesor de la capa es 55 centímetros y su Rbz es $180^{\circ} / 30^{\circ}$. Las fracturas medidas mediante un scan line lineal se clasificaron como diaclasas. La figura 5.18b muestra el diagrama estereográfico de los planos de fracturas medidos y su correspondiente diagrama de contornos. Se observan dos grupos de direcciones definidas, con azimuts promedio N36 ${ }^{\circ}$ (set NE-SW), y N108 ${ }^{\circ}$ (set ESEWNW). Este último set presenta un subgrupo de planos con azimut N95 ${ }^{\circ}$ (set E-W) según el diagrama de contornos (Figura 5.18b). También se observan algunas fracturas con azimuts $\mathrm{N} 4^{\circ}$ (set N-S) y N17 ${ }^{\circ}$ (set NNE-SSW). Todos los planos presentan altas inclinaciones con respecto a la capa que las contiene. Estos ángulos oscilan entre $72^{\circ}$ y $89^{\circ}$, con un promedio de $85^{\circ}$. Como se observa en la figura 5.18c, las trazas de fracturas con mayor continuidad pertenecen al set ESE-WNW, siendo las más abundantes en el afloramiento. Entre éstas se ubican las fracturas del set E-W, que se presentan con menor frecuencia ya que no aparecen homogéneamente distribuidas en la capa. Ambos sets de fracturas presentan sus respectivas fracturas perpendiculares, correspondientes al set NE-SW, que se ubican entre las anteriores, con una traza de longitud reducida (Figura 5.18c). Por las longitudes relativas de las trazas de las fracturas se puede concluir que los sets ESE-WNW y E-W fueron los primeros en formarse. Se puede inferir, dadas las ubicaciones relativas de ambos sets, que el E-W fue el segundo en formarse. Por último, las fracturas correspondientes al set NE-SW ocuparon los espacios entre los sets anteriores, orientándose perpendicularmente a sus superficies (Figura 5.18c). Los sets restantes se proponen también como últimos en formarse, aunque sin precisión sobre su cronología relativa. 

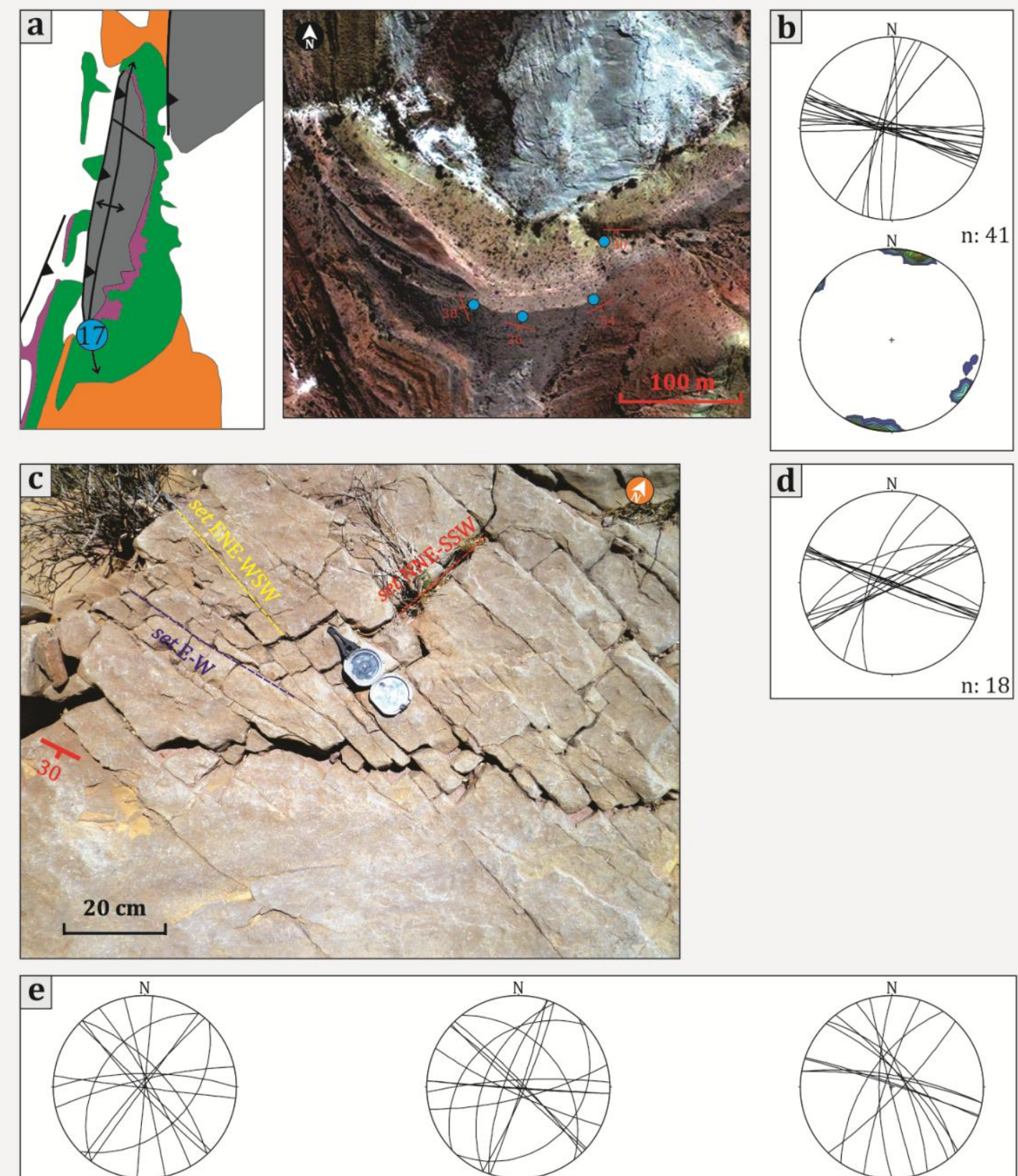

$\mathrm{n}: 18$

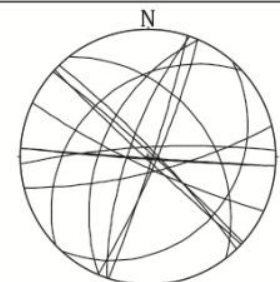

Charnela

n: 18

Flanco dorsal

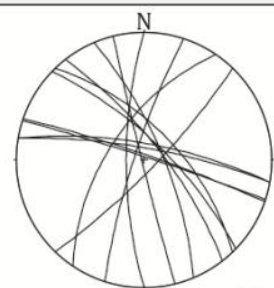

$\mathrm{n}: 18$

Flanco frontal

FIGURA 5.18. Estación de medición 17TT. a) Ubicación de la estación en el anticlinal. b) Diagramas de datos del scan line. c) Sets de diaclasas en afloramiento. d) Diagrama de datos de fracturas en una capa adyacente. e) Diagramas de datos de fracturas correspondientes a tres sitios que cubren la charnela del anticlinal (capas del Subgrupo Santa Bárbara).

A partir del scan line lineal realizado en el afloramiento se obtuvieron la frecuencia y espaciado promedio de los sets de fracturas medidos (véase ANEXO). El parámetro Frecuencia arrojó un valor de 4.81 para el set NE-SW (espaciado 
promedio de 16.12 centímetros), 2.65 para el set E-W (espaciado promedio de 41.49 centímetros), y 7.31 para el set ESE-WNW (espaciado promedio de 12.76 centímetros). Estos valores se correlacionan con las descripciones de las fracturas en el afloramiento (Figura 5.18c).

Medidas aleatorias de fracturas sobre una capa adyacente estratigráficamente por arriba se muestran en el diagrama estereográfico de la figura 5.18d. En este gráfico se ven planos de fracturas principalmente en las direcciones $\mathrm{N} 113^{\circ}$ y $\mathrm{N}^{\circ}$, y unos pocos planos en la dirección $\mathrm{N} 30^{\circ}$ aproximadamente. Las direcciones $\mathrm{N} 113^{\circ}$ y N30 se correlacionan directamente con los sets ESE-WNW y NE-SW de la capa anterior, respectivamente. La dirección N65 ${ }^{\circ}$ podría corresponder a una desviación del set E-W de la misma capa.

Una capa correspondiente a la base del Subgrupo Santa Bárbara se utilizó como estación de medición auxiliar, cercana a la estación principal anteriormente descripta (Figura 5.18a). Esta capa representa la verdadera charnela del anticlinal Tin Tin (se puede seguir su curvatura) y por esto se midieron fracturas aleatorias en tres posiciones cubriendo toda la charnela. La capa medida es una caliza fina de color gris, con estromatolitos en su techo, de aproximadamente 1.5 metros de espesor. Las fracturas presentes se clasificaron como diaclasas y venas. Los diagramas estereográficos de la figura 5.18e corresponden a las tres posiciones medidas, con su correspondiente corrección (rotación) de inclinación. Aquí se puede observar fracturas con direcciones hacia todos los cuadrantes, en general con alto ángulo de inclinación. El set NE-SW presenta fracturas de baja inclinación hacia el NW y SE en dos de las posiciones medidas. En uno de estos planos de baja inclinación $\left(\operatorname{Rbz} 317^{\circ} / 30^{\circ}\right)$ se midió un estriado $\left(\mathrm{Rbz} 323^{\circ} / 30^{\circ}\right)$ que indica desplazamiento de inclinación puro (rake $85^{\circ} \mathrm{E}$ ). Las observaciones del afloramiento indican que las fracturas más antiguas podrían ser las de los sets NWSE y NE-SW, ya que muchas terminan contra éstas, pero el arreglo temporal entre ambos sets resulta inconcluso. Hay diaclasas que siguen direcciones de venas y otras diaclasas que cortan y abren venas, sugiriendo que las diaclasas son posteriores a las venas y que podrían haber reutilizado sus planos, como se ha visto en otros afloramientos. De la comparación de las direcciones de fracturas en los diagramas estereográficos (Figura 5.18e) se puede decir que las fracturas son 
aproximadamente constantes en orientación cuando la capa se restituye a su posición horizontal, lo cual indica que las fracturas se formaron con anterioridad al plegamiento (curvatura) de la capa.

\subsubsection{Estación de medición 18TT}

En esta estación se midieron fracturas aleatorias en diferentes partes (sitios de relevamiento) del flanco frontal del anticlinal Tin Tin, en capas correspondientes a la Formación Yacoraite del Subgrupo Balbuena (Figura 5.19a). En la primer sitio de medición, la capa corresponde a una arenisca gruesa cuarzosa de la parte basal de la formación, y presenta un $\mathrm{Rbz}$ de $242^{\circ} / 61^{\circ}$. Las fracturas medidas se clasificaron como diaclasas. Las cuatro direcciones principales se muestran en el diagrama estereográfico de la figura 5.19b. Estas direcciones son $\mathrm{N} 2^{\circ}$ (set $\mathrm{N}-\mathrm{S}$ ), ${\mathrm{N} 60^{\circ}}^{(\text {set ENE-WSW), N93 }}{ }^{\circ}$ (set E-W), N150 (set NNW-SEE). En el afloramiento se observó que las trazas de las fracturas del set ENE-WSW son las más continuas. El set N-S presenta características similares pero en algunos casos termina contra el set ENE-WSW, indicando una posible posterioridad. El set NNWSSE es claramente posterior ya que son cortas en longitud y se ubican entre las primeras, al igual que el set E-W (Figura 5.19c).

El segundo sitio de relevamiento se realizó sobre una capa de caliza oolítica con contenido clástico cuarzoso, de $\mathrm{Rbz} 235^{\circ} / 40^{\circ}$, donde se midieron diaclasas y venas (Figura 5.19d). El diagrama de rosas de la figura 5.19h muestra tres direcciones principales: $\mathrm{N} 120^{\circ}$ a $\mathrm{N} 130^{\circ}$ (set NW-SE, con diaclasas y venas), $\mathrm{N} 30^{\circ}$ (set NNE-SSW, con diaclasas) y $\mathrm{N}^{\circ}$ (set E-W, con venas). Las fracturas del set NWSE son cronológicamente las más antiguas ya que son cortadas y abiertas por fracturas del set NNE-SSW (Figura 5.19d-1). Las fracturas del set E-W son las más modernas ya que se ubican entre las anteriores, en ocasiones curvándose para terminan contra los sets mencionados (Figura 5.19d-2). 

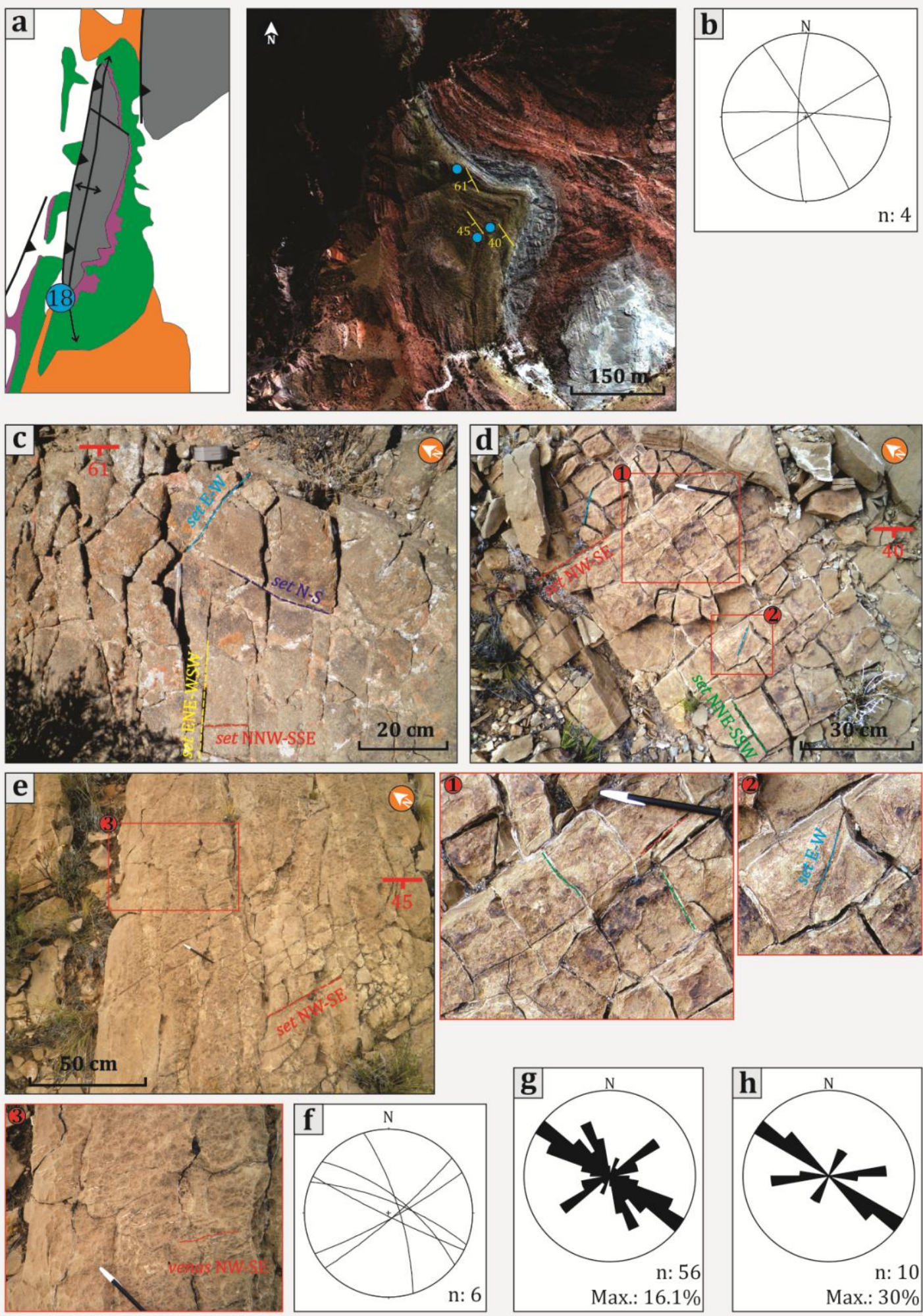

FIGURA 5.19. Estación de medición 18TT. a) Ubicación de la estación en el anticlinal (flanco frontal) b)-c) Diagrama de datos y fracturas principales en afloramiento correspondientes al primer sitio de medición. d)-h) Fracturas en afloramiento y diagrama de datos correspondientes al segundo sitio de medición. e)-f)-g) Diaclasas y venas en afloramiento y diagramas de datos correspondientes al tercer sitio de medición. 
En el tercer sitio de relevamiento del flanco frontal se midieron principalmente las direcciones de las trazas de las fracturas, y algunos planos disponibles. La capa es una caliza amarillenta, oolítica-estromatolítica, con un Rbz de $234^{\circ} / 45^{\circ}$. Las fracturas presentes en la misma se clasificaron como diaclasas y venas. Las direcciones se muestran en el diagrama de rosas de la figura 5.19g, junto a un diagrama estereográfico de algunos planos medidos, mostrando la alta inclinación de los planos con respecto a la capa (Figura 5.19f). Las direcciones de fracturas predominantes, como muestra el diagrama de rosas y como se puede observar en la fotografía del afloramiento (Figura 5.19e), son $\mathrm{N} 125^{\circ}$ (set NW-SE), $\mathrm{N} 155^{\circ}$ (set $\mathrm{NNW}-\mathrm{SSE}$ ) y N55 (set NE-SW), siendo las primeras las más abundantes. Se observó un conjunto de venas en echelon derecho (cinemática sinestral) con dirección $\mathrm{N} 174^{\circ}$. Las venas individuales corresponden al set NW-SE y tienen geometría sigmoidal evidenciando cierta ductilidad (comportamiento frágil-dúctil) en su formación (Figura 5.19e-3). Las fracturas del set NE-SW cortan y abren a las diaclasas y venas anteriores, indicando su posterioridad. También se observaron venas del set NNW-SSE desplazado dextralmente a las fracturas NE-SW, sugiriendo una reactivación de las venas más antiguas, con la misma cinemática.

\subsection{Las fracturas del Anticlinal Cerro Bayo}

Para el relevamiento de datos en el anticlinal Cerro Bayo se midieron principalmente la orientación de las trazas de fracturas sobre diferentes capas de la Formación Yacoraite, mediante scan lines lineales y mediciones aleatorias. Las orientaciones se representaron en diagramas de rosas a fin de realizar un análisis comparativo con las direcciones de fracturación en diferentes posiciones estructurales del anticlinal Tin Tin. También se midieron algunos planos (con buena exposición) correspondientes a los sets principales para determinar la angularidad de las fracturas con respecto a la estratificación. La figura 5.20 muestra esquemáticamente en anticlinal Cerro Bayo con la ubicación de las 13 estaciones de medición de fracturas. 


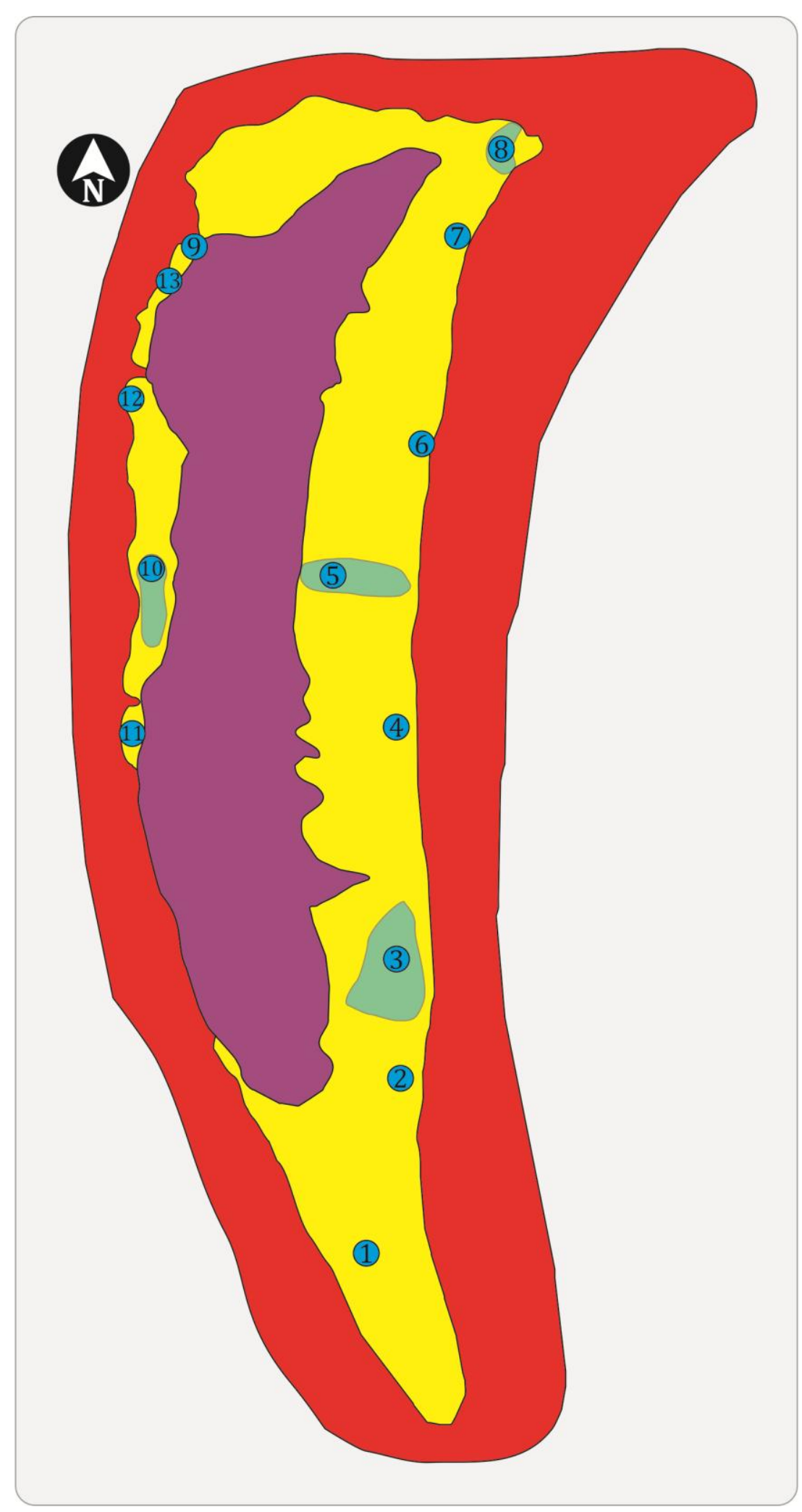

FIGURA 5.20. Mapa esquemático del anticlinal Cerro Bayo. Ubicación de las estaciones de medición. Ejemplo de nomenclatura: 3 - Estación de medición 3СB. 


\subsubsection{Estación de medición $1 C B$}

La estación de medición 1CB se ubica en el sector de inmersión Sur del anticlinal Cerro Bayo y consta de cuatro sitios de medición de fracturas aleatorias, abarcando el flanco frontal, la charnela y el flanco dorsal del anticlinal (Figura 5.21a).

El primer sitio de medición se ubica sobre unas calizas estromatolíticas subhorizontales, en unos pliegues del flanco frontal (véase Figura 4.28). Las fracturas predominantes son venas verticales, algunas dispuestas en echelon. Como muestra el diagrama de rosas de la figura 5.21b la dirección predominante de las venas es N65 $^{\circ}$ (set ENE-WSW; Figura 5.21c). Se observaron dos conjuntos de venas en echelon. Uno de ellos presenta un escalonado derecho (cinemática sinestral) con

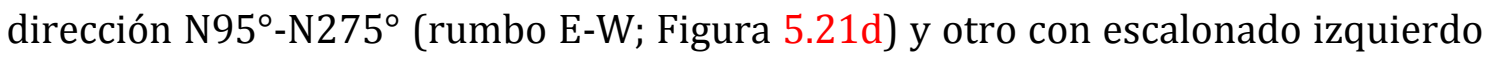
(cinemática dextral) con dirección N22-N202 (rumbo NNE-SSW; Figura 5.21e).

El segundo sitio de medición también corresponde al flanco frontal, donde la capa es una arenisca media a fina, cuarzosa con contenido micáceo. El Rbz de la capa es $240^{\circ} / 16^{\circ}$. En este sitio se realizó un scan line lineal en donde se midieron las trazas de las fracturas que se plotearon en el diagrama de rosas de la figura 5.21g. El diagrama muestra una mayor frecuencia para el set ENE-WSW (N75) y en segundo lugar para el set NNW-SSE (N165). Las observaciones del afloramiento indican que las diaclasas de traza más continúa son las del set NNWSSE, mientras que las trazas del set ENE-WSW son más cortas y se ubican entre las primeras con arreglo ortogonal (Figura 5.21f), sugiriendo que estas últimas se formaron después de las del set NNW-SSE. Con mucha menor frecuencia aparecen otros sets, NE-SW y NW-SE, ortogonales entre si y posteriores a las primeras.

Sobre la charnela subhorizontal del anticlinal Cerro Bayo (tercer sitio de medición) se midieron fracturas con la misma orientación que en las estaciones previas (Figura 5.21h). También se observó un conjunto de venas en echelon derecho (cinemática sinestral) de dirección N110-N290 (Figura 5.21j).

El cuarto sitio de medición se realizó sobre una capa del flanco dorsal del anticlinal, de $\mathrm{Rbz} 96^{\circ} / 16^{\circ}$. Las direcciones de fracturas medidas se muestran en el diagrama de rosas de la figura 5.21i. 

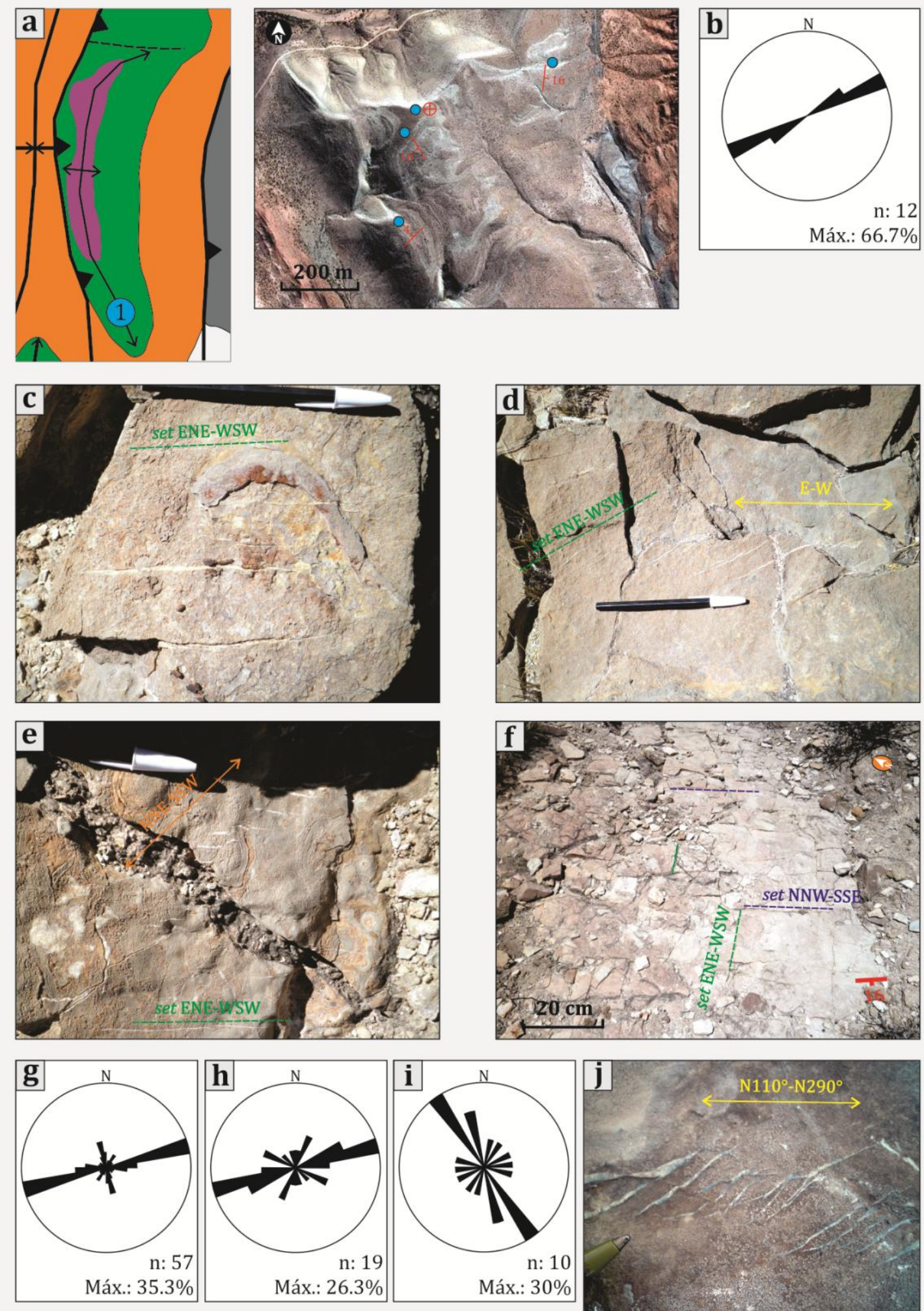

FIGURA 5.21. Estación de medición 1CB. a) Ubicación de la estación en el anticlinal. b) Diagrama de datos de fracturas correspondiente al primer sitio de medición. c) Venas predominantes. d)-e) Venas en echelon. f)-g) Fracturas en afloramiento y diagrama de datos correspondientes al segundo sitio de medición. h)-j) Diagrama de datos correspondientes al tercer sitio de medición, con presencia de venas en echelon. i) Diagrama de datos correspondientes al cuarto sitio de medición. 


\subsubsection{Estación de medición 2 CB}

La estación de medición 2CB se ubica en la sección superior de la formación Yacoraite, sobre el flanco dorsal del anticlinal en el sector Sur del cerro Bayo (Figura 5.22a). La capa es una caliza estromatolítica, con mucho contenido oolítico y clástico cuarzoso de granulometría arenosa. El Rbz de la capa es $102^{\circ} / 31^{\circ}$ y las fracturas medidas mediante scan line lineal se clasificaron como diaclasas. Como se observa en la fotografía del afloramiento (Figura 5.22c) y en el diagrama de rosas (Figura 5.22b), las diaclasas con dirección $\mathrm{N} 135^{\circ}$ (set NW-SE) son las predominantes. Por su continuidad y relaciones de corte se las propone como las más antiguas en cronología de formación. Las diaclasas con dirección N160 (set NNW-SSE) son posteriores en formación ya que se curvan en forma perpendicular al acercarse al set NW-SE (Figura 5.22d). Diaclasas cronológicamente posteriores se acomodan en forma perpendicular a los sets mencionados anteriormente. La inclinación de todos los sets de alto ángulo con respecto a la estratificación.

Otras diaclasas, con orientaciones y cronología de formación similar al sitio descripto, fueron observadas en sitios cercanos a la estación 2CB (Figura 5.22e). 


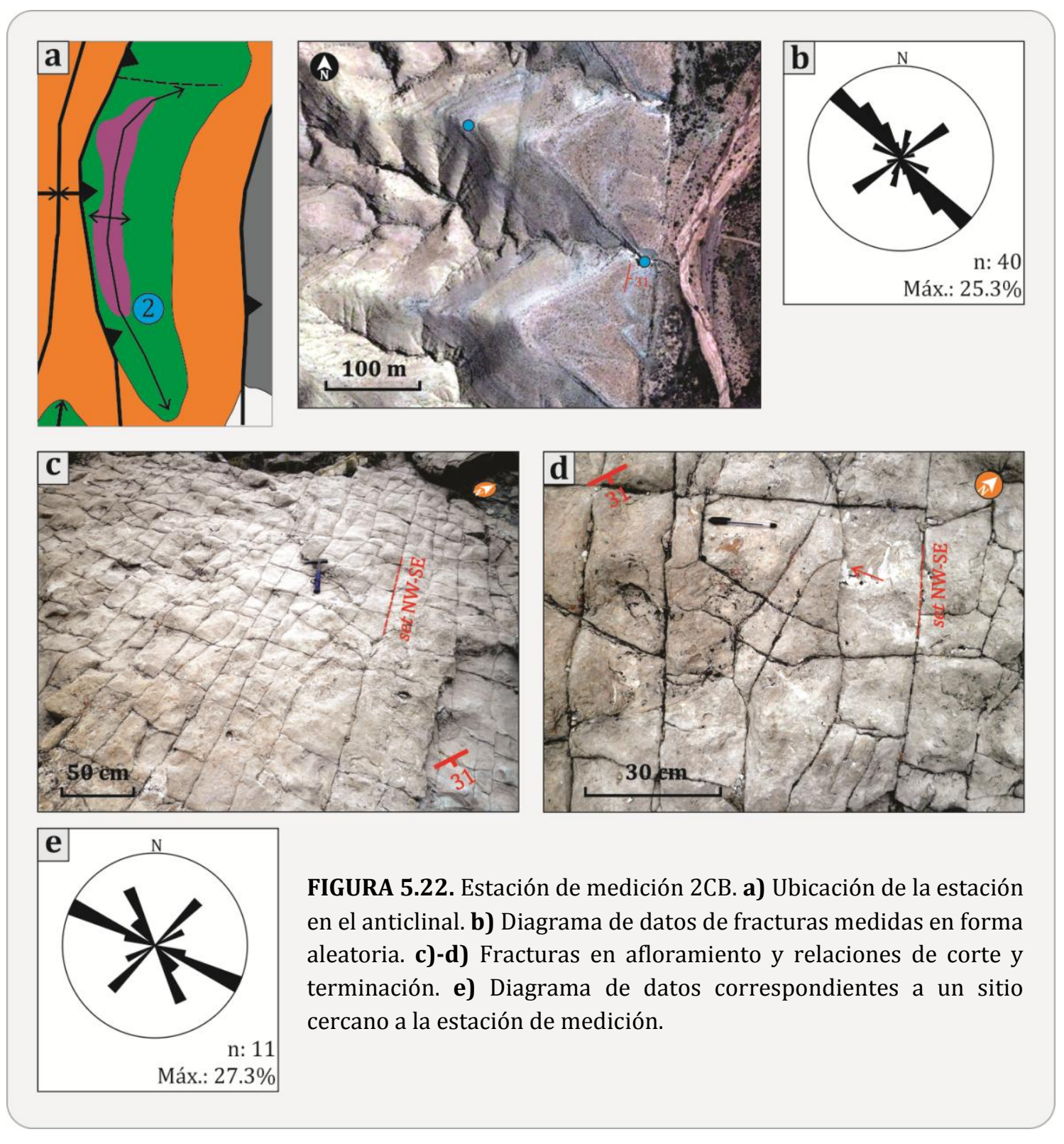

\subsubsection{Estación de medición $3 C B$}

La estación de medición 3CB se ubica en una capa estratigráficamente similar a la estación anterior, en una posición más al Norte de la anterior (Figura 5.23a). La capa es una caliza oolítica-estromatolítica con $\mathrm{Rbz} 95^{\circ} / 33^{\circ}$, con fracturas que se clasificaron como diaclasas. El diagrama de rosas de la figura $5.23 \mathrm{~b}$ muestra tres sets predominantes con direcciones $\mathrm{N} 40^{\circ}$ (set NE-SW), $\mathrm{N}^{\circ} 15^{\circ}$ (set ESE-WNW) y $\mathrm{N} 170^{\circ}$ (set $\mathrm{N}-\mathrm{S}$ ), y como se puede observar en la fotografía del afloramiento, las fracturas de set ESE-WNW son las más continuas (Figura 5.23c). Las diaclasas presentes en la capa son subperpendiculares a la misma según se pudo observar. 
Se realizaron mediciones en sitios cercanos a la estación. En el primer sitio de medición, la capa es una arenisca cuarzosa de granulometría media a fina, con contenido micáceo. El Rbz de la misma es $84^{\circ} / 38^{\circ}$. En este sitio se midieron los planos de los sets principales de fracturas, definidas como diaclasas. Hay cuatro sets, N-S, E-W, NNW-SSE y ENE-WSW (Figura 5.23d). Las observaciones de afloramiento indican que los sets N-S y E-W son los primeros en formarse, mientras que las fractura de los sets oblicuos son posteriores, ya que se ubican y terminan contra los anteriores, algunas con la curvatura característica (Figura 5.23f). Es importante remarcar que el set E-W presenta fracturas rectas y continuas, con longitudes de decenas de metros, y con igual magnitud en altura (Figura 5.23g-h), posiblemente debido al escaso contraste litológico (y reológico) a través de la secuencia de la Formación Yacoraite.

En otro sitio de medición ubicado al Oeste del anterior muestra patrones de fracturas similares (Figura 5.23e). En este afloramiento se constató que el set E-W mantiene su extensa longitud, y que los demás sets terminan contra este, indicando que el set $\mathrm{E}-\mathrm{W}$ fue cronológicamente el primero en formarse.

FIGURA 5.23. Estación de medición 3CB. a) Ubicación de la estación en el anticlinal. b) Diagramas de datos de fracturas. c) Sets de fracturas en afloramiento. d)-f) Diagrama de datos y fracturas en afloramiento en un sitio cercano a la estación principal. e) Diagrama de datos de fracturas. g)-h) Características del set E-W. 


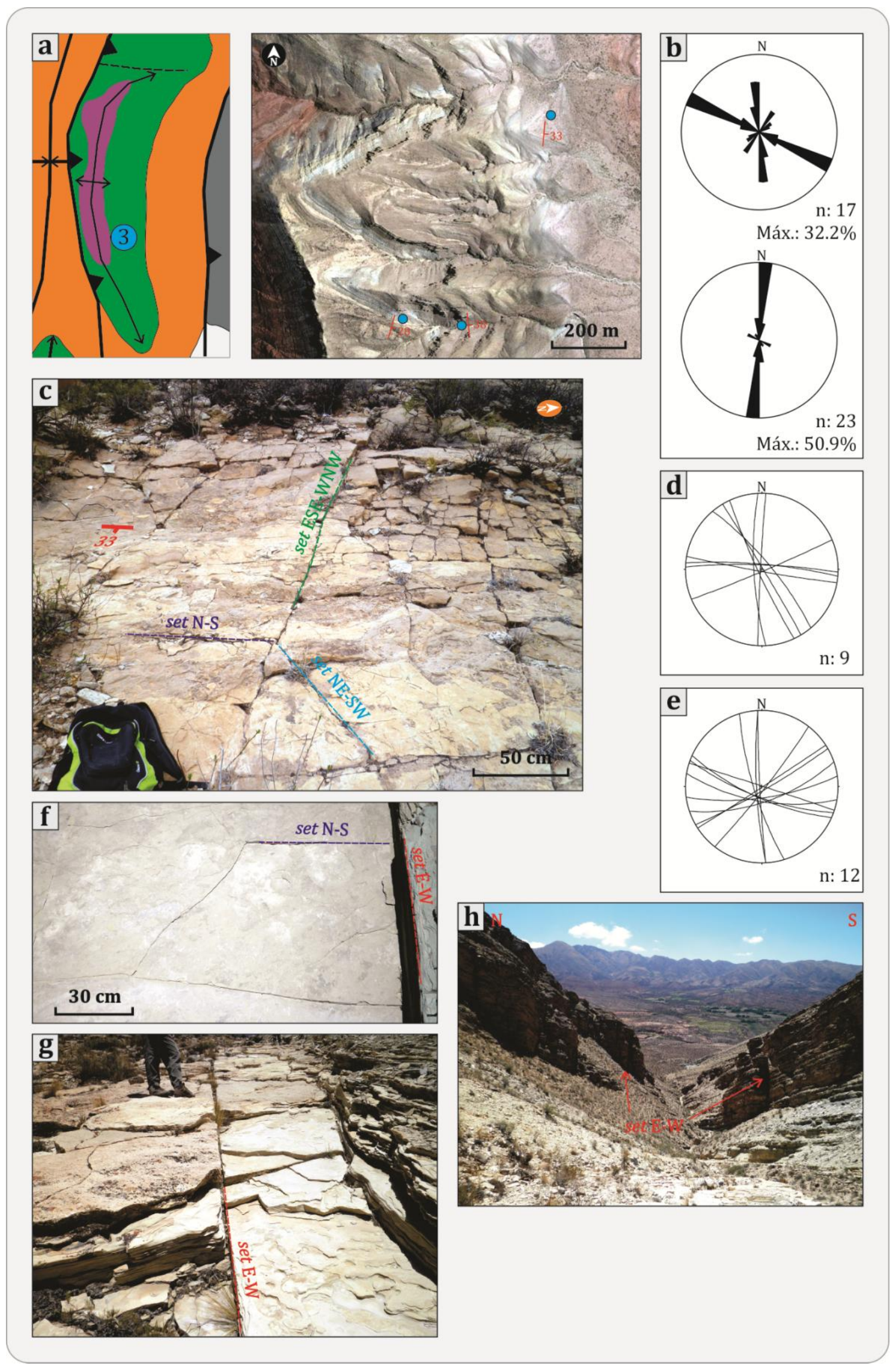




\subsubsection{Estación de medición $4 C B$}

Esta estación de medición se ubica en la sección superior de la Formación Yacoraite, sobre el flanco dorsal del anticlinal, en el sector medio del cerro Bayo (Figura 5.24a). La capa es estratigráficamente similar a las de las estaciones anteriores y corresponde a una caliza oolítica con $\mathrm{Rbz} 99^{\circ} / 37^{\circ}$. Las fracturas, clasificadas como diaclasas, se midieron con scan lines lineales. La figura 5.24b muestra los diagramas de rosas correspondientes a dos scan lines realizados sobre el afloramiento. Al igual que en la figura $5.24 \mathrm{c}$, se observan dos sets principales, N-S y NW-SE. Las relaciones de corte entre las fracturas no son claras, pero las trazas de las diaclasas del set NW-SE tienden a ser más continuas que las trazas del set N$S$, por lo que podría sugerir que se formó primero. Se midieron fracturas con dirección NE-SW, con mucha menor frecuencia.

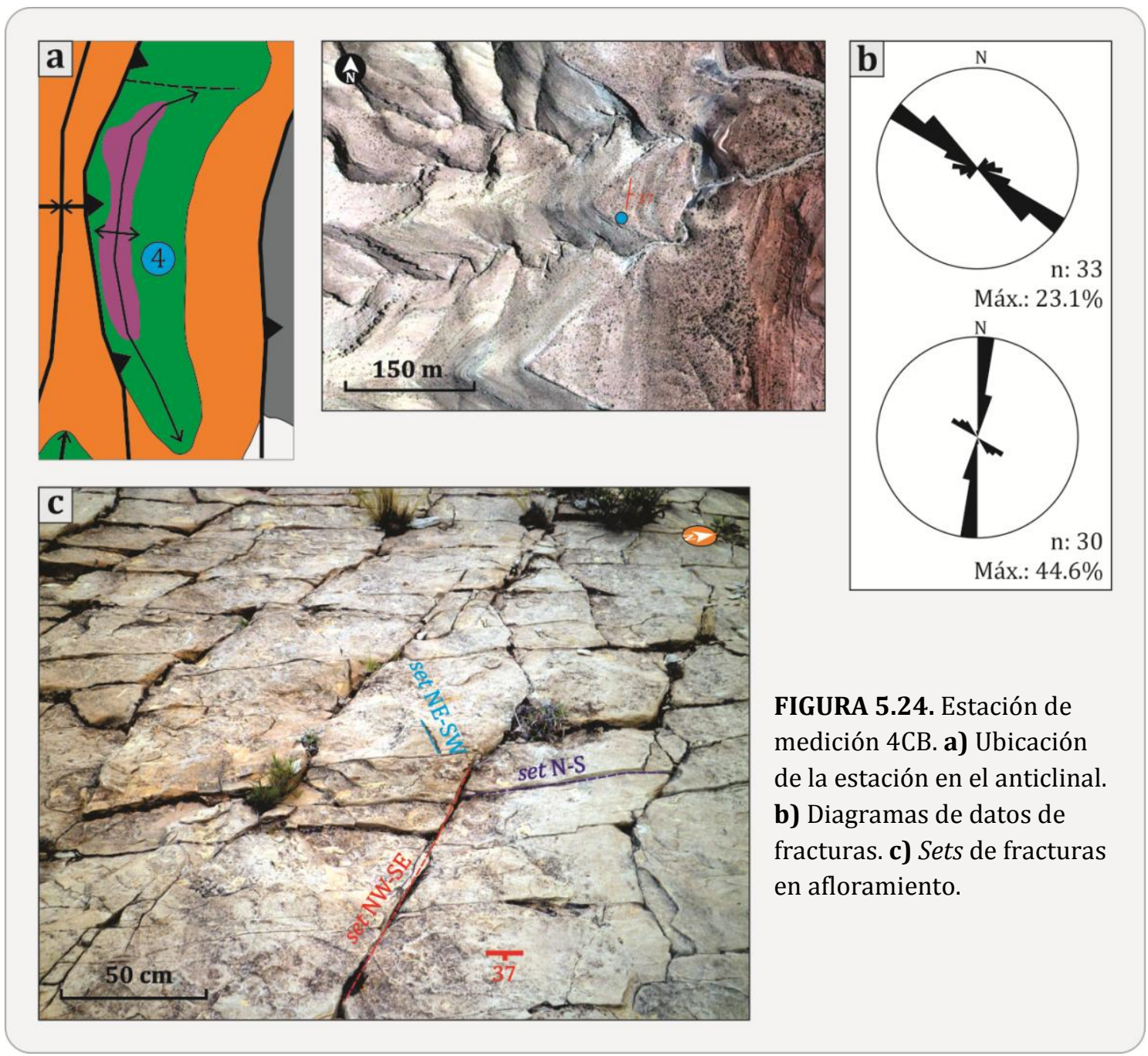




\subsubsection{Estación de medición $5 C B$}

Esta estación se ubica en el sector medio del anticlinal Cerro Bayo sobre su flanco dorsal y consta de cuatro sitios de medición de fracturas aleatorias, abarcando gran parte de la secuencia de la Formación Yacoraite (Figura 5.25a). Las capas medidas son en general areniscas de granulometría media a fina, cuarzosas y laminadas, algunas con ondulas en su techo. El Rbz medido en los cuatro sitios varia de $102^{\circ}$ a $114^{\circ}$, con $27^{\circ}$ a $30^{\circ}$ de inclinación. Estos datos indican poca variación de rumbo a lo largo de la secuencia de la Formación Yacoraite para este sector del flanco dorsal, y posiblemente poca deformación interna dentro del flanco. Las figuras 5.25b-c-d-e (ubicadas de Oeste a Este) muestran los cuatro diagramas estereográficos correspondientes a las fracturas medidas, que fueron definidas como diaclasas. Se observan sets de fracturas con diferentes direcciones que se mantienen aproximadamente constantes a lo largo de la secuencia sedimentaria. Las observaciones de afloramiento indican que el set NW-SE es cronológicamente más antiguo con respecto a los demás sets de diaclasas, ya que muchas fracturas se curvan para terminar contra éste (Figura 5.25f-g-h). Además presenta un espaciado regular en todos los sitios de medición. 


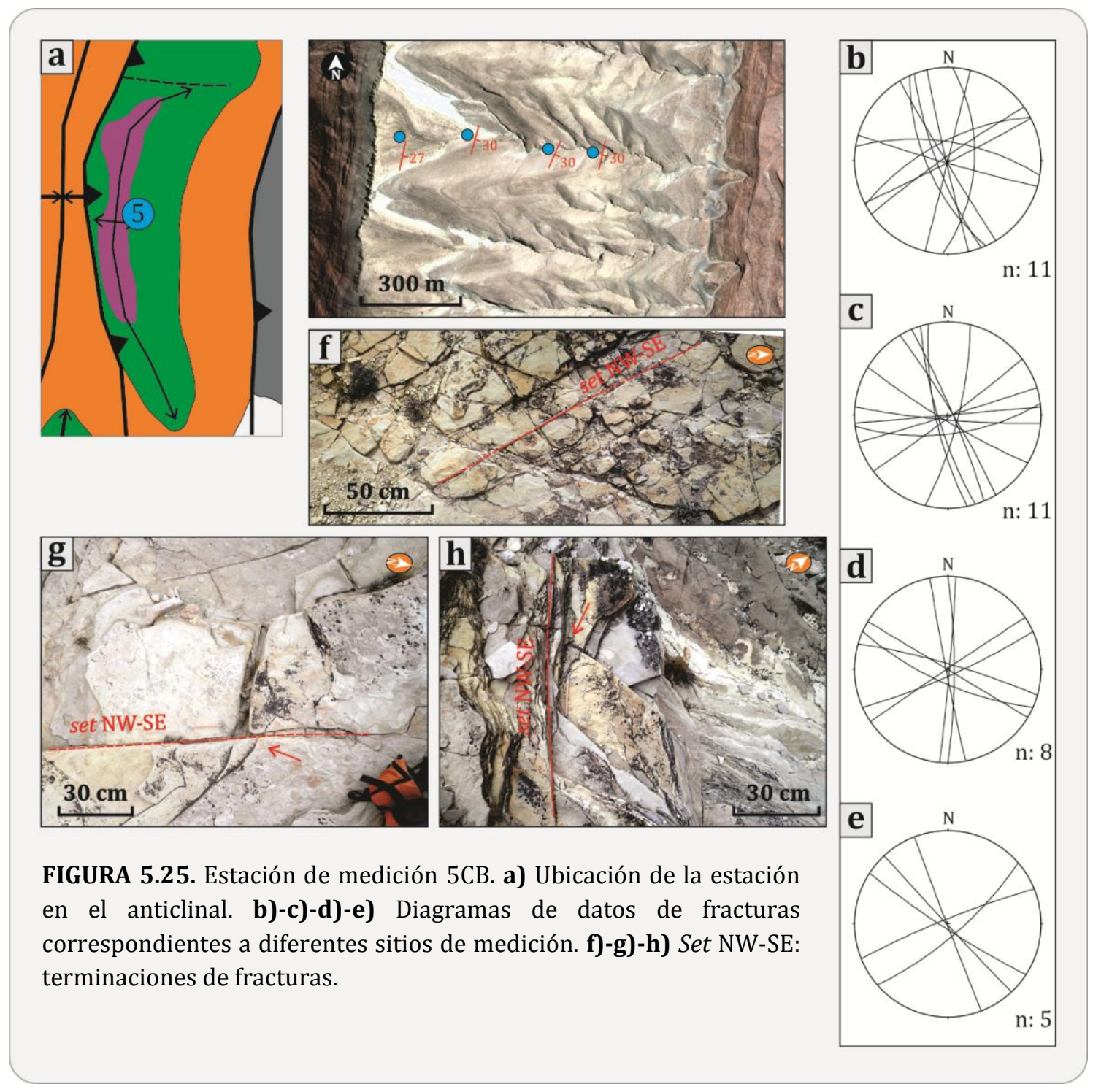

\subsubsection{Estación de medición $6 C B$}

La estación de medición 6CB se ubica estratigráficamente en la parte superior de la Formación Yacoraite, cerca del contacto con el Subgrupo Santa Bárbara, y corresponde al sector medio del anticlinal Cerro Bayo, sobre su flanco dorsal (Figura 5.26a). La capa es una caliza oolítica con una matriz carbonática fina, que en sectores sólo es matriz con oolitas aisladas. Presenta grietas de desecación, techo onduloso y contenido micáceo. $\mathrm{Su} \mathrm{Rbz}$ es $111^{\circ} / 31^{\circ}$. Las fracturas, clasificadas como diaclasas y venas, se midieron con scan lines lineales. La figura 5.26b muestra los diagramas de rosas correspondientes a dos scan lines realizados sobre el afloramiento. Estos gráficos muestran tres sets de fracturas principales, NE-SW, NW-SE y E-W. Las relaciones de corte son difíciles de 
identificar debido a cortes y terminaciones mutuas entre los sets, por lo que no se pudo determinar la cronología de formación (Figura 5.26c).

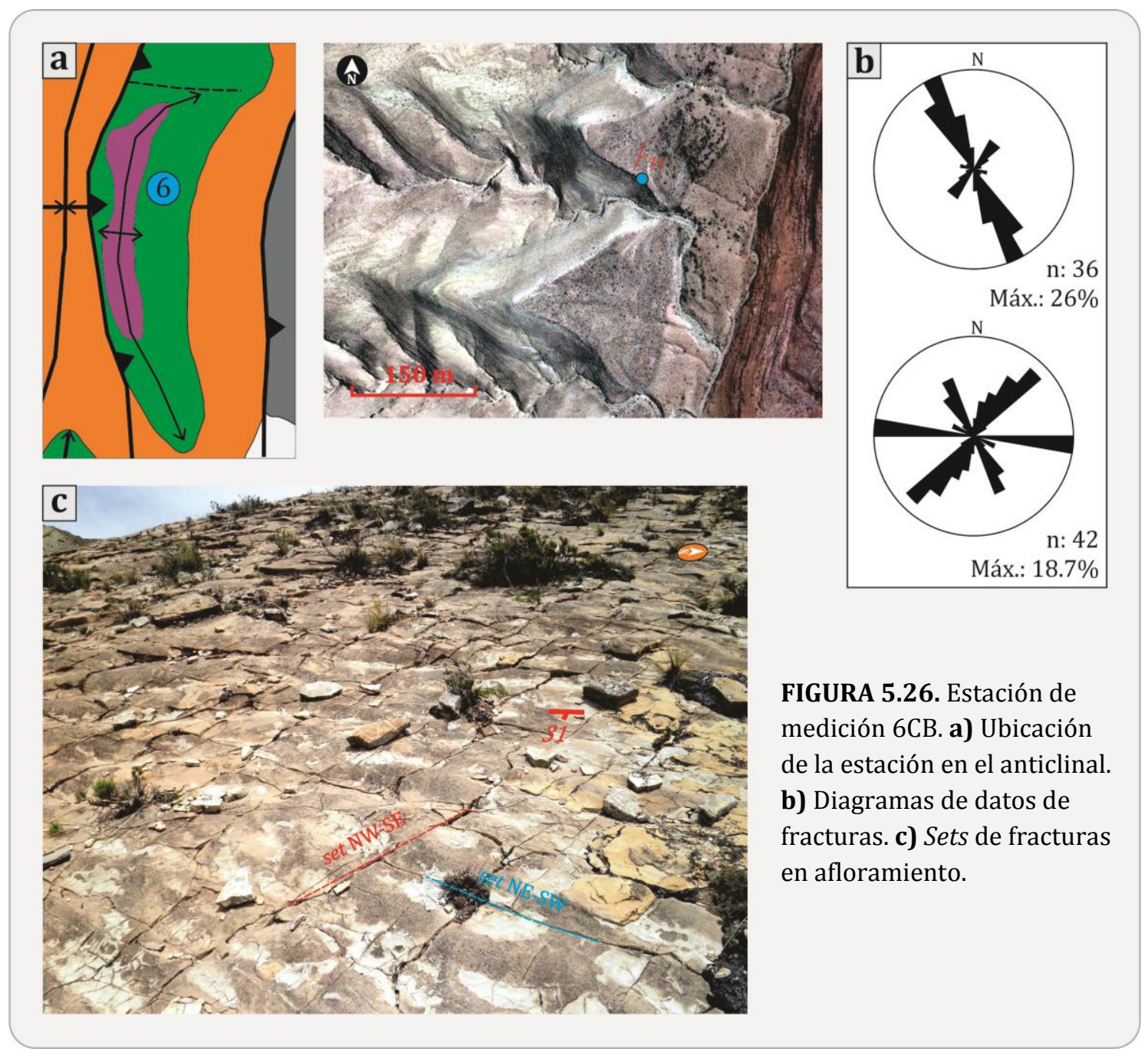

\subsubsection{Estación de medición 7CB}

La estación de medición 7CB se ubica estratigráficamente en la parte superior de la Formación Yacoraite, cercana al contacto con el Subgrupo Santa Bárbara, sobre el flanco dorsal del anticlinal Cerro Bayo en el sector Norte del cerro (Figura 5.27a). La capa es una caliza oolítica, con mucho cemento carbonático y su $\mathrm{Rbz}$ es $119^{\circ} / 34^{\circ}$ (Figura 5.27c). Las fracturas medidas se clasificaron como diaclasas y todas presentan alta angularidad con respecto a la capa. Los diagramas de rosas de la figura 5.27b muestran las direcciones de las trazas medidas en dos scan lines. De la observación del afloramiento se puede concluir que, como en otros sitios de medición, el set NNW-SSE es 
cronológicamente el más antiguo ya que muchas diaclasas de otros sets terminan contra éste.

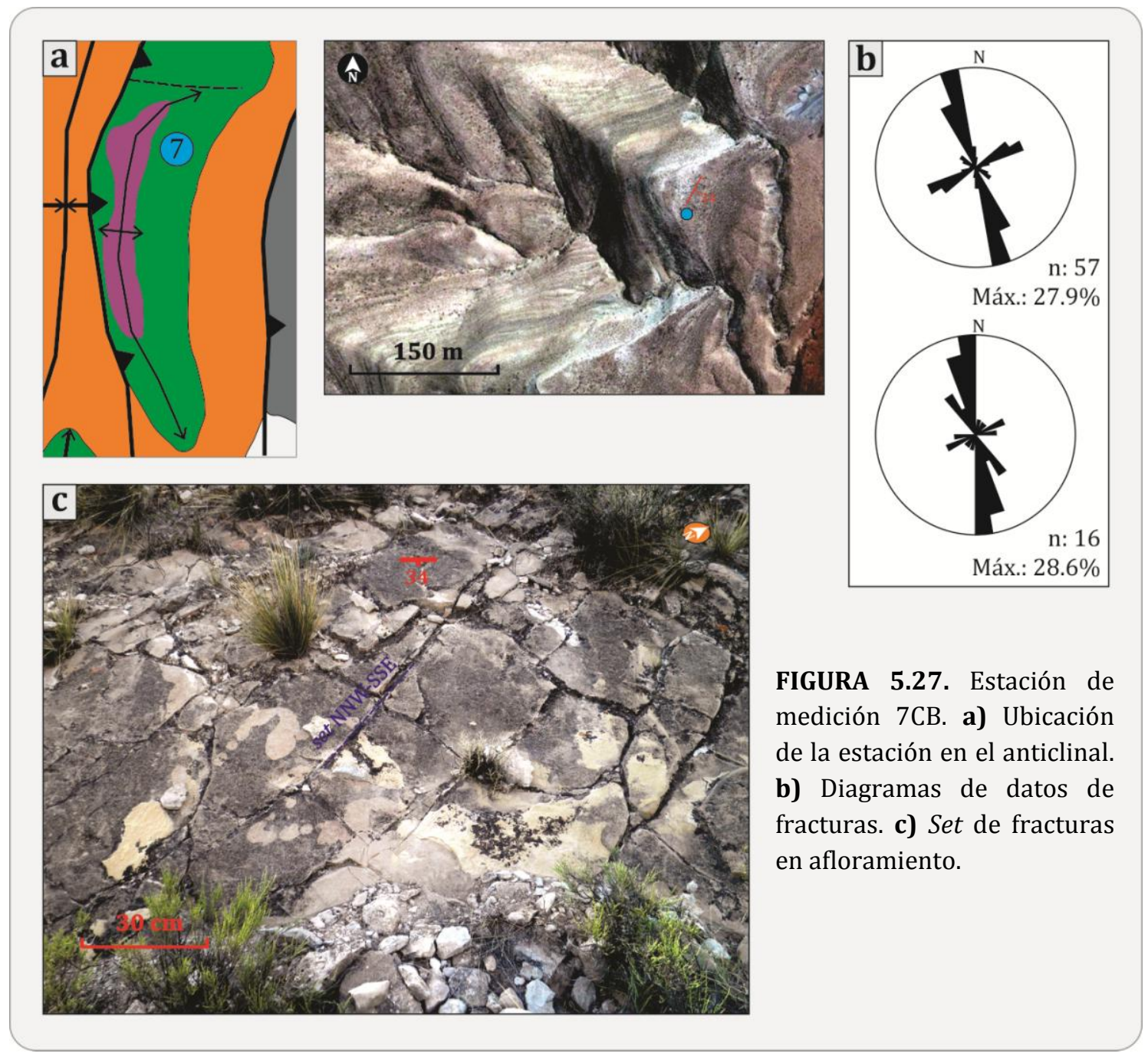

\subsubsection{Estación de medición $8 C B$}

Esta estación de medición concentra varios sitios de relevamiento que cubren ambos flancos (dorsal y frontal) del anticlinal Cerro Bayo en su extremo de inmersión Norte (Figura 5.28a). Todos los sitios de medición se realizaron sobre la Formación Yacoraite del Subgrupo Balbuena, donde la roca consiste una arenisca de granulometría media, con grado variable en su contenido carbonático. Los Rbz de las capas del flanco dorsal (en los sitios de medición) son $110^{\circ} / 40^{\circ}$ y $117^{\circ} / 35^{\circ}$, es decir, no presentan una variación sustancial en orientación. El diagrama estereográfico de las fracturas medidas en este flanco se muestra en la figura 5.28b. Las mismas se definieron como diaclasas y presentan muchas direcciones de ocurrencia y alta inclinación con respecto a las capas. Por relaciones de corte y 
continuidad de trazas se constató que las diaclasas del set NNW-SSE son las primeras en formarse (Figura 5.28d).

Sobre el flanco frontal las capas tienen un $\mathrm{Rbz}$ de $52^{\circ} / 45^{\circ}$ cerca de la charnela y $75^{\circ} / 25^{\circ}$ en una posición más alejada. El diagrama estereográfico correspondiente muestra direcciones de diaclasas similares a las del flanco dorsal (Figura 2.28c). También se constató (en dos sitios de tres) que las fracturas del set NNW-SSE son las primeras en formarse ya que los demás sets terminan contra este (Figura 5.28e). En un solo sitio se observó que las diaclasas del set NE-SW se formaron previamente a las del set NNW-SSE.

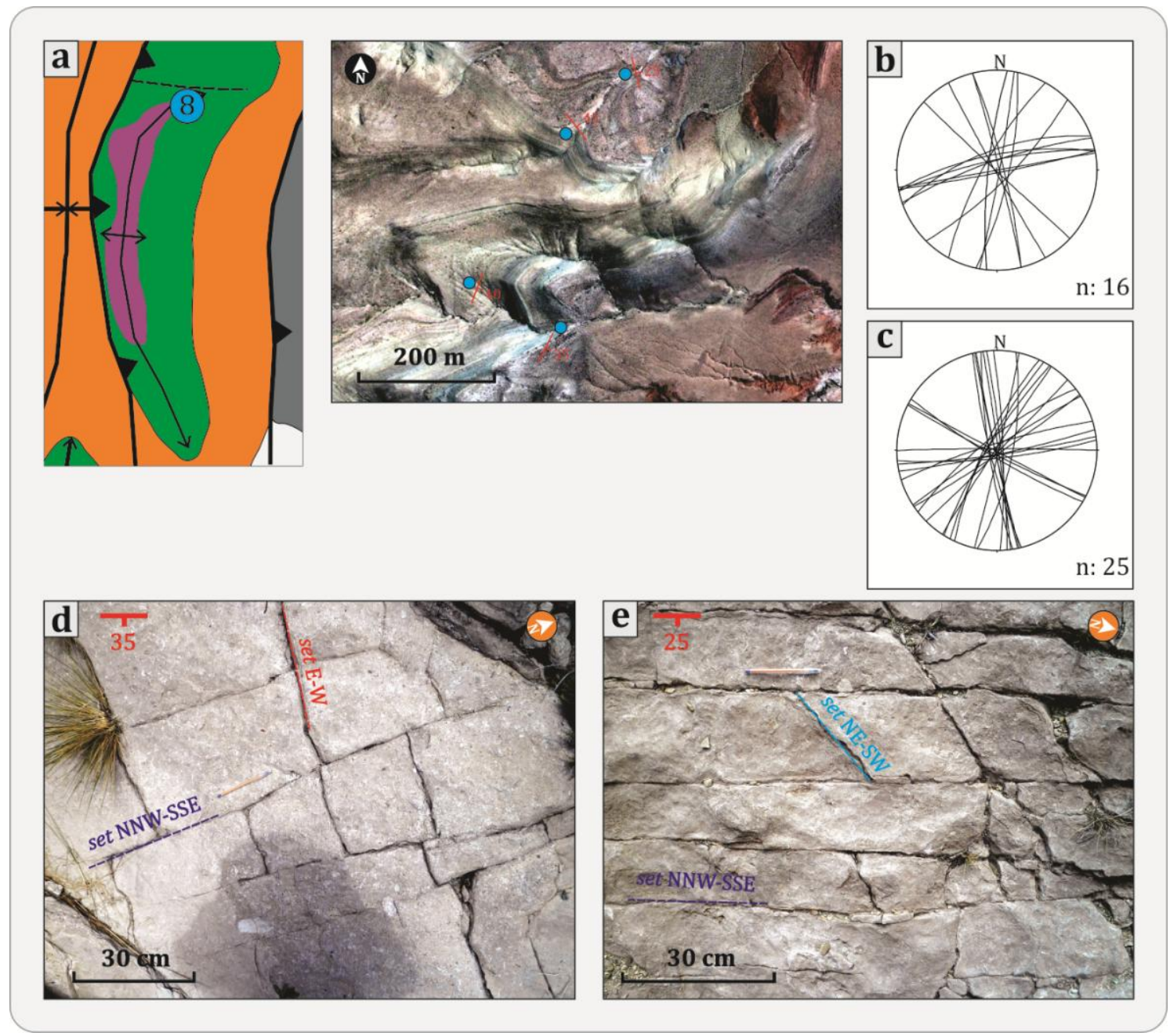

FIGURA 5.28. Estación de medición 8CB. a) Ubicación de la estación en el anticlinal. b)-d) Diagrama de datos y fracturas en afloramiento correspondientes al flanco dorsal. c)-e) Diagrama de datos y fracturas en afloramiento correspondientes al flanco frontal. 
Es importante destacar que los sistemas de diaclasas se mantienen en ambos flancos del anticlinal, indicando que la mayoría de los sets son previos al pliegue o se formaron durante los primeros estadios de deformación.

\subsubsection{Estación de medición 9 CB}

La estación de medición 9CB se ubica estratigráficamente en la sección inferior de la Formación Yacoraite, sobre el flanco frontal del anticlinal, en el sector medio-Norte del cerro (Figura 5.29a). La capa se conforma por intercalaciones de capas clásticas de granulometría arenosa y calizas oolítico-estromatolíticas, también con contenido clástico cuarzoso. El Rbz de la capa es $315^{\circ} / 84^{\circ}$, es decir, de apariencia subvertical. Las fracturas medidas, definidas como diaclasas, se midieron mediante scan line lineal. Como muestra el diagrama estereográfico de la figura 5.29b y la fotografía del afloramiento (Figura 5.29c), se observan principalmente dos sets de fracturas con rumbos (restituidas) NW-SE y ENE-WSW, y alta inclinación con respecto a la capa. El primer set presenta mayor continuidad en sus trazas mientras que el segundo, de longitud de traza menor que se ubica y termina contra el primero, indicando posterioridad cronológica. Diaclasas del set ENE-WSW (paralelas a la estratificación local, posteriores) muestran desplazamiento de cizalla, probablemente por la rotación de la capa durante el crecimiento del pliegue (Figura 5.29d).

Se midieron diaclasas en un sitio cercano donde se presentan los mismos sets de fracturas. Se pudo confirmar que el set NW-SE tiene más continuidad en la traza de sus fracturas, sugiriendo a los otros sets como posteriores (Figura 5.29e-f). 

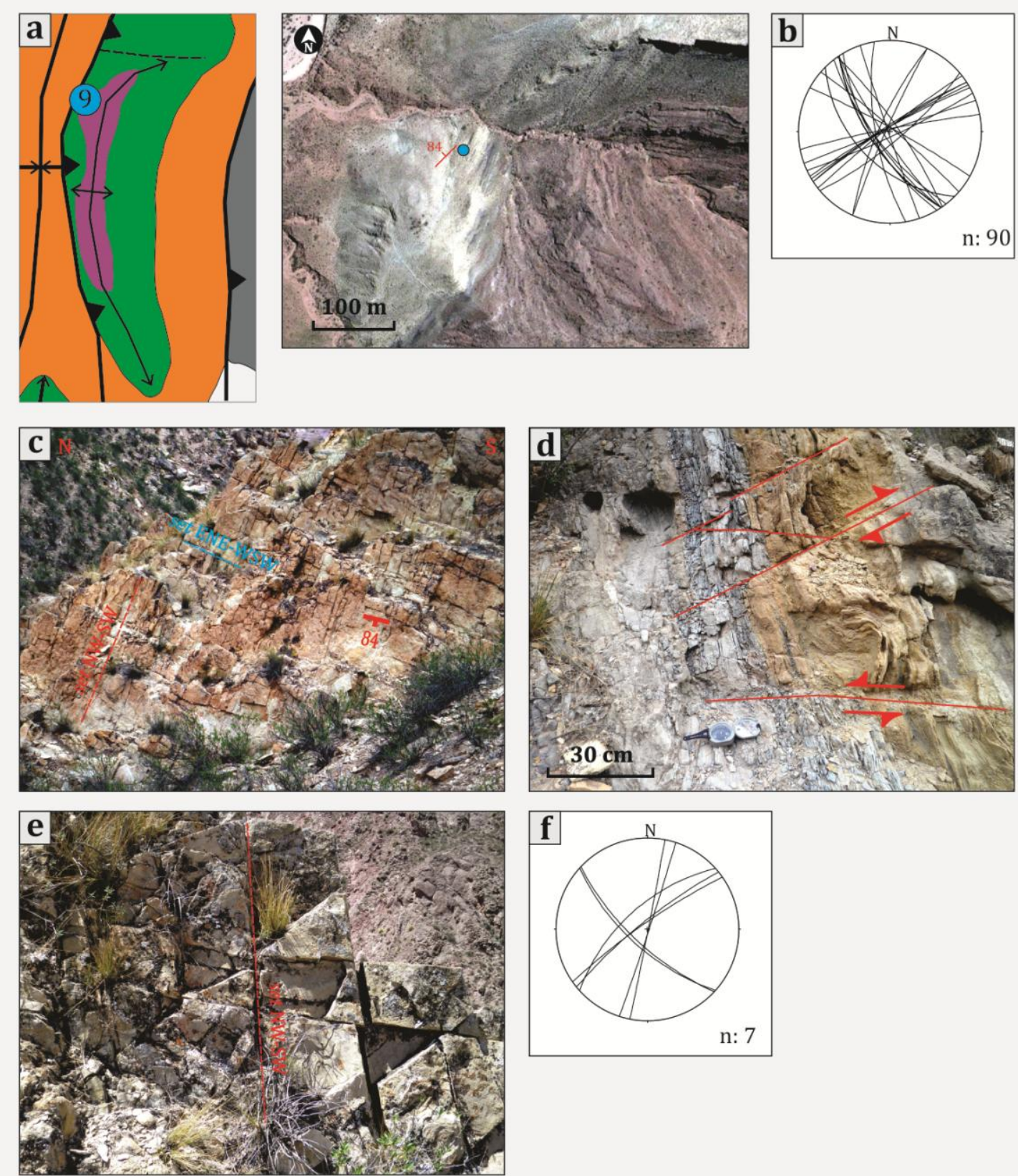

FIGURA 5.29. Estación de medición 9CB. a) Ubicación de la estación en el anticlinal. b)-c) Diagrama de datos y fracturas en afloramiento. d) Diaclasas con desplazamiento. e)-f) Fracturas en afloramiento y diagrama de datos correspondientes a un sitio cercano a la estación de medición.

\subsubsection{Estación de medición $10 C B$}

Esta estación se ubica estratigráficamente en la sección media de la Formación Yacoraite, en el sector medio del anticlinal Cerro Bayo sobre su flanco frontal (Figura 5.30a). La capa es una arenisca fina a media de coloración gris, con cemento carbonático. El $\mathrm{Rbz}$ de la misma es $274^{\circ} / 54^{\circ}$. Las fracturas medidas 
mediante un scan line lineal se clasificaron como diaclasas. Los diagramas de la figura 5.30b y la fotografía del afloramiento (Figura 5.30c) muestran que las diaclasas predominantes son las de rumbo NNW-SSE, siendo éste set el mas continuo y probablemente el más antiguo cronológicamente. Los demás sets ocupan posiciones entre las primeras, cortándolas en ocasiones, indicando posterioridad. Las inclinaciones de las diaclasas son altas con respecto a la capa medida, como se muestra en el diagrama estereográfico donde se midieron planos de fracturas en forma aleatoria (Figura 5.30b).

En un sitio de medición ubicado unos $500 \mathrm{~m}$ al Sur, se constató que se mantienen las mismas relaciones cronológicas, con los sets más modernos curvándose para terminar en forma perpendicular contra el set NNW-SSE (Figura 5.30d-e). 


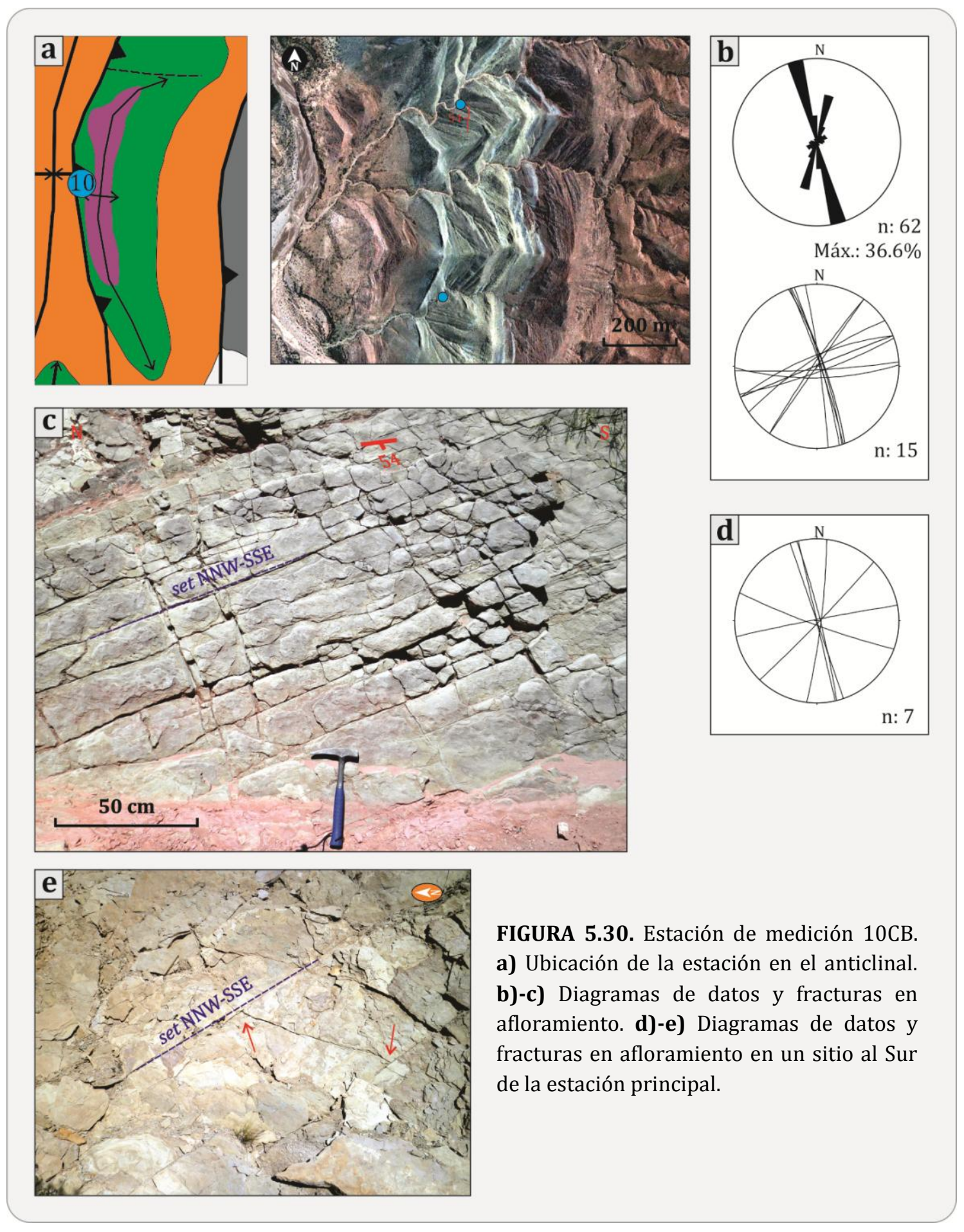

\subsubsection{Estación de medición $11 C B$}

La estación de medición 11CB se ubica estratigráficamente en la sección inferior de la Formación Yacoraite, en el sector medio del anticlinal Cerro Bayo sobre su flanco frontal (Figura 5.31a). La capa es una caliza oolítica con granos de cuarzo de tamaño arena gruesa a sabulítica. La capa se encuentra invertida, siendo el $\mathrm{Rbz}$ de su base $91^{\circ} / 70^{\circ}$. Las fracturas medidas se clasificaron como diaclasas 
(Figura 5.31c). La figura 5.31b muestra el diagrama estereográfico de las fracturas relevadas. Este afloramiento presenta orientaciones similares a los sets de fracturas de las estaciones anteriores correspondientes al flanco frontal. La cronología de formación es difícil de observar, pero es posible una concordancia con otras estaciones.

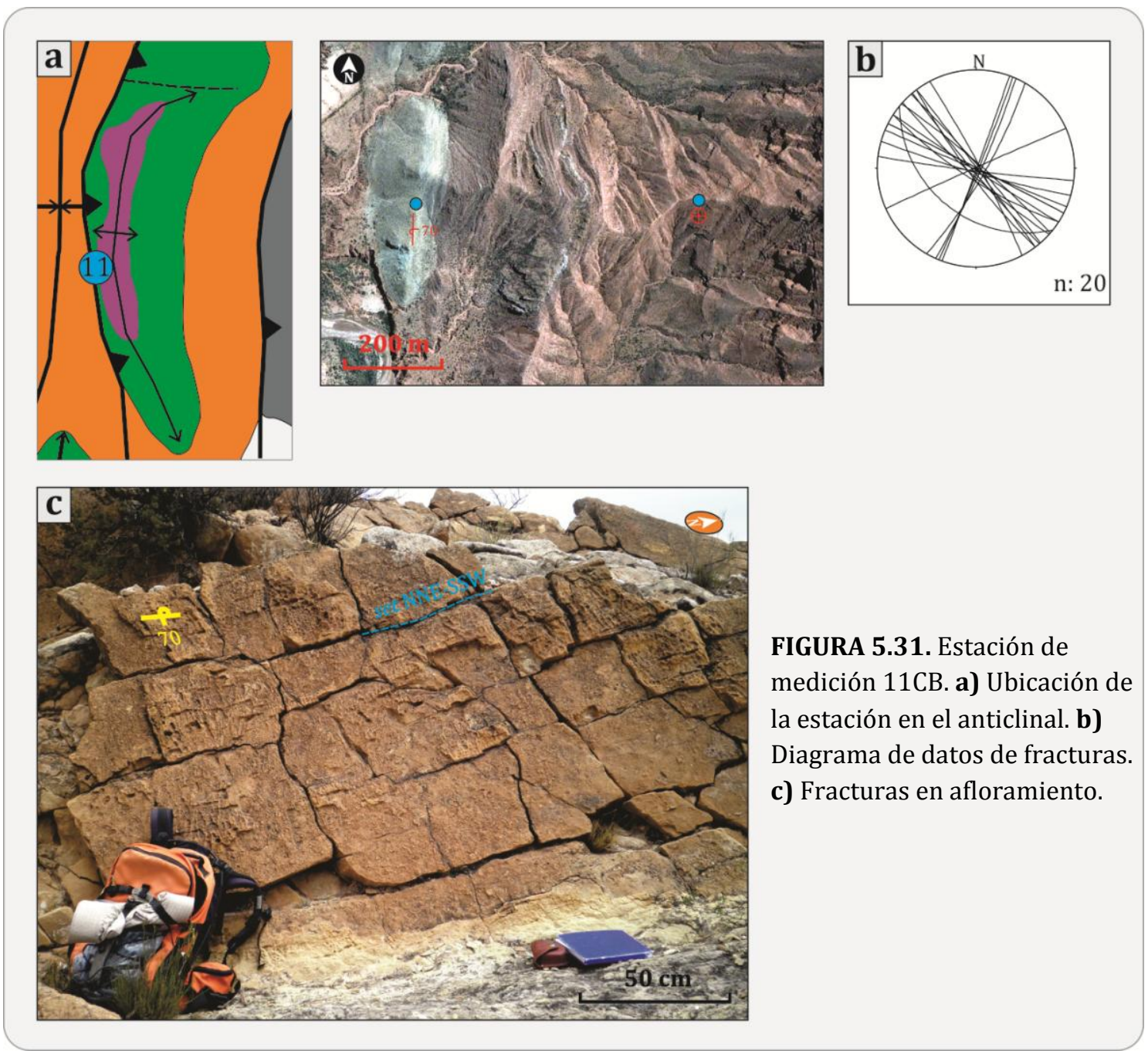

Se midieron fracturas sobre una capa subhorizontal del Subgrupo Pirgua ubicada del núcleo del anticlinal (charnela) y se constató que las orientaciones de las fracturas son similares a las del sitio descripto.

\subsubsection{Estación de medición $12 C B$}

La estación de medición 12CB se ubica estratigráficamente en la sección superior de la Formación Yacoraite, en el sector medio del anticlinal Cerro Bayo, sobre su flanco frontal (Figura 5.32a). La capa es una caliza fina de color gris con 
clastos de cuarzo aislados de tamaño arena gruesa a sabulita, micas, y restos de moluscos fósiles. El Rbz de la misma es $281^{\circ} / 64^{\circ}$. Las fracturas medidas mediante un scan line lineal se clasificaron como diaclasas. La figura $5.32 \mathrm{~b}$ muestra el diagrama de rosas con las orientaciones de las trazas de las fracturas medidas, y un diagrama estereográfico con planos correspondientes a algunas trazas. Como se puede observar en los diagramas y en la fotografía del afloramiento (Figura 5.32c), las fracturas principales se pueden agrupar en dos sets de direcciones N-S y ESEWNW, con fracturas en otras direcciones que presentan menor frecuencia. Como en la mayoría de los afloramientos, la inclinación de las diaclasas con respecto a la capa es alta. La cronología de formación no se pudo determinar ya que las relaciones de corte no son claras.

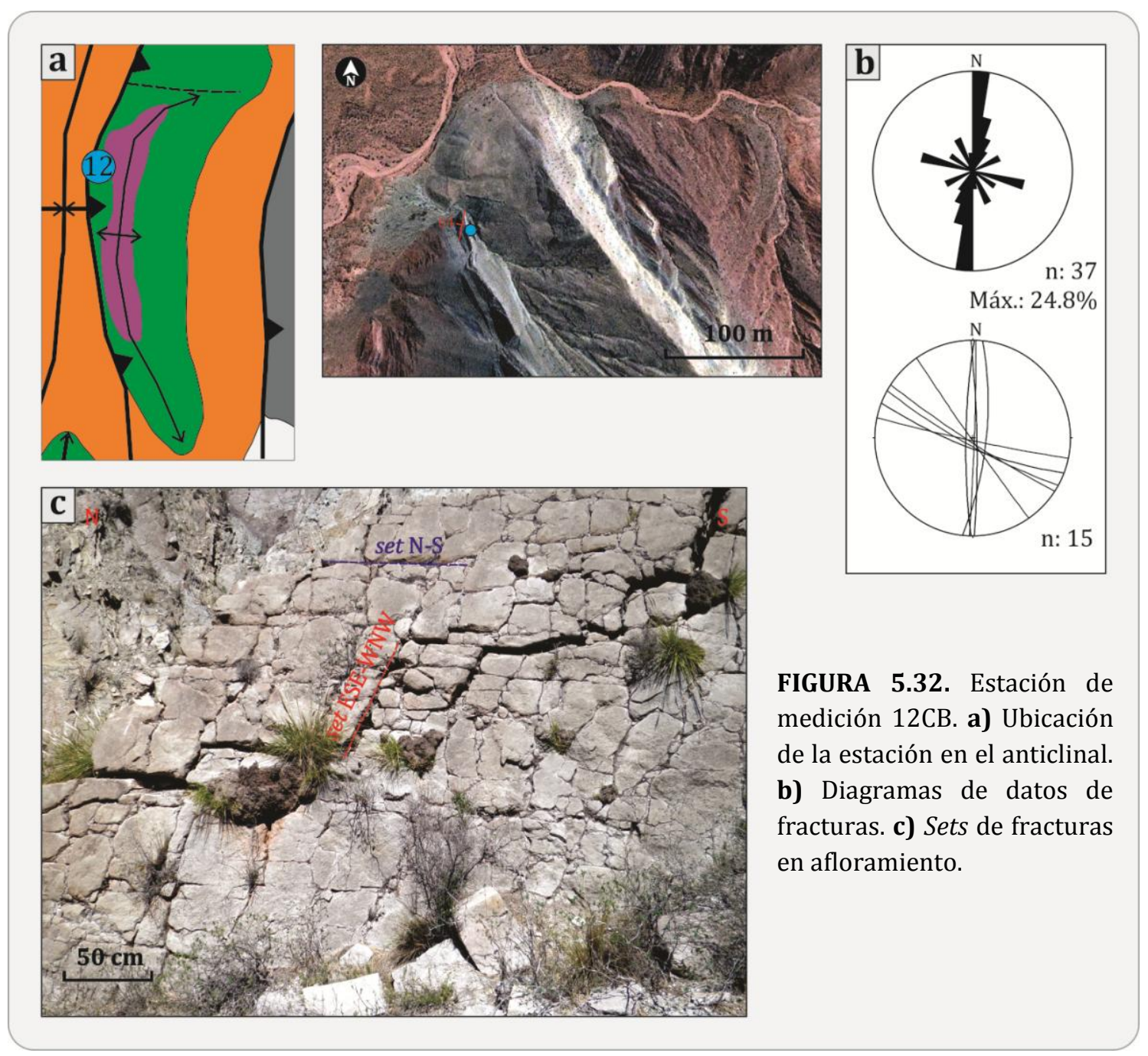




\subsubsection{Estación de medición $13 C B$}

Esta estación se ubica estratigráficamente en la sección inferior de la Formación Yacoraite, en el sector medio del anticlinal Cerro Bayo sobre su flanco frontal (Figura 5.33a). La misma está conformada por tres sitios de medición de fracturas aleatorias.

En el primer sitio de medición, donde el Rbz de la capa es $305^{\circ} / 72^{\circ}$, se midieron fracturas que, al rotarlas a su posición horizontal, presentan bajo a medio ángulo con respecto a la capa. Estas fracturas corresponden a un set NE-SW e inclinan hacia el Sureste (Figura 5.33b).

En el segundo sitio de medición, de $\mathrm{Rbz} 319^{\circ} / 83^{\circ}$, se midieron fracturas del set NE-SW (en este caso con dirección ENE-WSW a E-W por curvatura de la capa, pero corresponden al mismo set). Los planos se muestran en la figura 5.33c-d.

En el tercer sitio de medición se relevaron diaclasas sobre una capa invertida de $\mathrm{Rbz} 150^{\circ} / 87^{\circ}$. El diagrama estereográfico de la figura 5.33e muestra los planos medidos. Se destaca la similitud en la orientación de los planos con respecto a los sistemas de fracturas de los alrededores. La fotografía de la figura 5.33g muestra al set ENE-WSW (Figura 5.33f) con planos reactivados, posiblemente durante la rotación del flanco del anticlinal. 


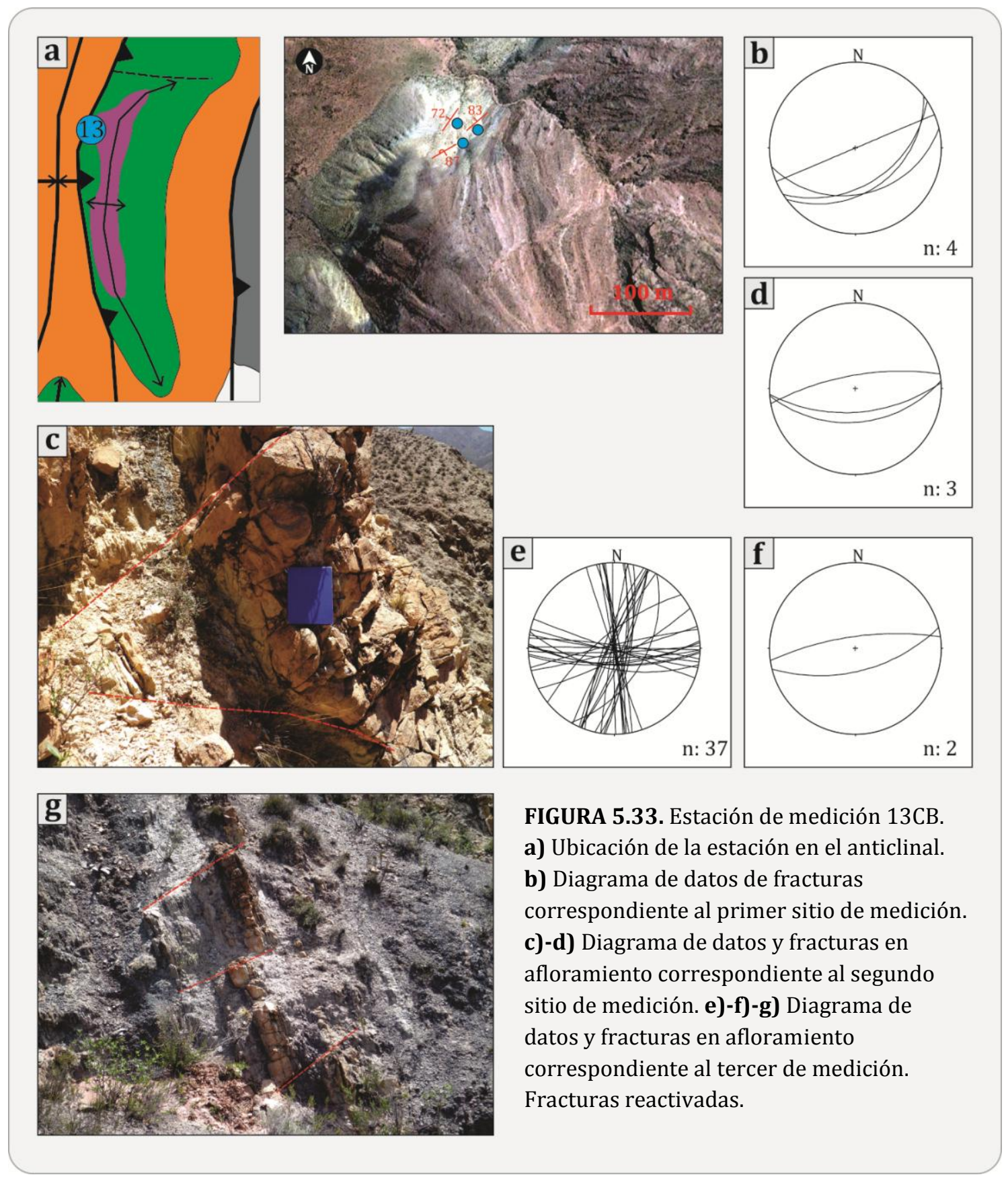




\section{CAPÍTUL0 6 DISCUSIÓN}




\section{CAPITULO 6 - DISCUSIÓN}

Los anticlinales, sinclinales, fallas inversas y bloques de basamento presentes en la zona de estudio son las estructuras contraccionales que se generaron durante el periodo de deformación andina cenozoica. Estas estructuras exponen en sus flancos o núcleos la estratigrafía de la zona (Grupo Salta y Grupo Payogastilla), que ha sido objeto de numerosos estudios ya que contiene las evidencias para descifrar la historia deformacional de la región (Grier y Dallmeyer, 1990; Grier et al., 1991; del Papa et al., 2004, 2013a, 2013b; Deeken et al., 2006; Hongn et al., 2007, 2008, 2011; Mortimer et al., 2007; Carrera y Muñoz, 2008, 2013; Payrola Bosio et al., 2009; Carrapa et al., 2011, 2012; DeCelles et al., 2011; Hain et al., 2011; Payrola Bosio et al., 2011a, 2012; Strecker et al., 2011; Aramayo et al., 2012; Santimano y Riller, 2012).

Además de la importancia geológica desde el punto de vista académico que tiene el entendimiento geológico de una región, estos eventos deformacionales revisten importancia económica de primer orden ya que muchas de las estructuras resultantes (particularmente los anticlinales) están directamente relacionados al transporte y entrampamiento de fluidos de interés económico como son los hidrocarburos (Mon y Salfity, 1995; Urien et al., 1995; McGroder et al., 2014).

En los capítulos anteriores se describieron las estructuras menores (mesoescala) que forman parte del anticlinal Tin Tin y en menor medida y a modo

comparativo de sectores aledaños al anticlinal y del anticlinal Cerro Bayo, con el objetivo de obtener una visión más amplia sobre las características deformacionales y evolutivas del anticlinal Tin Tin. Los datos y observaciones recolectadas se enmarcaran en un contexto de deformación a fin de explicar su origen y ocurrencia.

\subsection{Características estructurales del anticlinal Tin Tin}

El anticlinal Tin Tin presenta estructuras deformacionales de diferentes escalas y geometrías y que expresan la cinemática y evolución del plegamiento. Estas estructuras son fallas, pliegues y fracturas de pequeña escala (diaclasas, venas, 
fracturas de cizalla) y en conjunto evidencian el proceso de crecimiento de la estructura principal.

\subsubsection{Estructuración del basamento, Falla Tin Tin y falla sinestral NW-SE}

El anticlinal Tin Tin presenta un núcleo de rocas metamórficas de bajo grado conocido como Formación Puncoviscana, que también aflora como altos de basamento en las inmediaciones del anticlinal (Cajoncillo, zona del Cerro Malcante; véase Figura 1.3). De acuerdo a lo observado en varios sitios, las estructuras identificadas en el basamento como pliegues, fracturas de mesoescala (diaclasas y venas) y fallas inversas de bajo ángulo tienen una ocurrencia en toda la zona, es decir, la deformación podría considerarse relativamente constante para el basamento aflorante este sector del Valle Calchaquí (desde el cerro Tin Tin hacia el Este).

Los datos recolectados sobre la Formación Puncoviscana que indican pliegues de orientación E-W en el área del cerro Tin Tin y alrededores (véase Figura 4.6) concuerdan con las descripciones realizadas por Ruiz Huidobro (1955) tanto en la geometría como en la orientación de los pliegues del basamento. Por lo tanto se puede confirmar que esta zona presenta características estructurales diferentes con respecto a zonas de basamento plegado con rumbo aproximado N-S, comúnmente descripto para otras partes del Noroeste argentino (Mon y Hongn, 1991, 1996) o para el área de la localidad de Alemanía, hacia el centro de la subcuenca (Carrera y Muñoz, 2013). Estos pliegues E-W, en concordancia con gran parte de la estratificación medida en el basamento (véase Figura 4.5), no presentan una orientación favorable para su reactivación como fallas inversas, de acuerdo al campo de esfuerzos imperante durante el Cenozoico, aunque potencialmente podrían reactivarse como fallas de rumbo (tear faults), conectando fallas inversas (Del Ventisette et al., 2006). Sin embargo, el basamento presenta una profunda deformación de mesoescala (diaclasas y venas; véase Figura 4.8) posibilitada por su condición frágil (adquirida por el metamorfismo) y por los sucesivos episodios de deformación. Esta fracturación, que presenta diversas orientaciones y evidencias de movimiento (véase Figura 4.8d), es la que se propone como debilidad estructural para el deslizamiento de bloques y 
generación de la Falla Tin Tin. Tal como ha sido descripto (véanse páginas 54-55), esta falla se observó como una zona de brechamiento, característica de deformación frágil de baja temperatura (Sibson, 1977; Groshong Jr, 1988). No hay evidencias concretas sobre el ángulo de la falla, pero se puede inferir que, si la fracturación afecta el basamento (o algún sector del mismo) en forma homogénea, este puede actuar como un material homogéneo (a grandes rasgos) ante los esfuerzos regionales compresivos y generar fallas inversas con ángulos medianos a bajos, como predicen los ensayos mecánicos (Price y Cosgrove, 1990; Twiss y Moores, 2007). Esta característica de fracturación en el basamento, asociada a la generación de nuevas estructuras, se ha mencionado para otros sistemas estructurales contraccionales de piel gruesa, como es el caso de los Larámides en Norteamérica (Chase et al., 1993; Schmidt et al., 1993).

A otra escala de observación, se concluye que las superficies axiales de pliegues con rumbo E-W en la Formación Puncoviscana (basamento de la zona) constituyen planos de debilidad que pueden ser reactivados efectivamente, con el consecuente movimiento de bloques menores dentro del basamento. Estas superficies de debilidad pueden alojar diques (véase Figura 4.6e) y generar fallas inversas de alto ángulo que afectan al mismo basamento y/o que se propagan hacia la cobertura sedimentaria (véase Sección "Pliegues en el basamento del núcleo del anticlinal Tin Tin", pág. 47), formando estructuras oblicuas al rumbo general del anticlinal principal (véase Figura 4.18e). A partir de esto se puede concluir que el basamento ejerce una influencia importante en la estructuración de la cobertura sedimentaria.

Con respecto a la falla con rumbo NW-SE que atraviesa el anticlinal Tin Tin y lo desplaza sinestralmente, esta estructura produce un arrastre y estructuración de la cobertura sedimentaria sobre el flanco dorsal en las inmediaciones de la falla. Sobre la vertiente occidental del cerro se observó un desplazamiento sintético en los afloramientos de la Formación Yacoraite (véase Figura 4.11h). Estos datos y observaciones indican que el anticlinal ya se encontraba relativamente formado y estructurado al momento en que la falla sinestral actúo. Otra característica importante es la foliación que presenta la zona de falla (véase Figura 4.9), a diferencia del brechamiento que presenta la Falla Tin Tin. Estos diferentes "productos" indican 
condiciones de deformación diferentes o diferentes condiciones previas de la roca al momento de la deformación. Por último, se piensa que esta falla podría actuar como límite Sur del bloque de basamento que se encuentra al Este del cerro Tin Tin (véase Figura 4.1), dada la coincidencia entre la estructura y la terminación del bloque.

\subsubsection{Pliegues y Fallas de la cobertura sedimentaria del anticlinal Tin Tin}

Los flancos del anticlinal Tin Tin (principalmente el dorsal) presentan numerosos pliegues y fallas de escala media con geometrías y orientaciones consistentes con el rumbo NNE-SSW del anticlinal principal, como así también con estructuras perpendiculares al rumbo mencionado, tanto contraccionales como extensionales, sugiriendo la acción de esfuerzos no coaxiales (locales) en diferentes etapas, resultando en una evolución estructural compleja.

En el capítulo 4 se describieron las estructuras de mesoescala que afectan a la cobertura sedimentaria en ambos flancos del anticlinal Tin Tin y como el anticlinal está altamente estructurado en todas sus posiciones estructurales.

Estructuras paralelas al rumbo del anticlinal Tin Tin (o al rumbo de la secuencia sedimentaria local)

La relación de paralelismo entre los pliegues y fallas con transporte hacia el Oeste y el anticlinal Tin Tin de vergencia occidental sugiere que las estructuras se formaron bajo el mismo campo de esfuerzos y dentro del mismo evento general de deformación, correspondiente a la contracción andina cenozoica. Los pliegues y fallas de escala media con orientación aproximada NNE-SSW se distribuyen a lo largo de todo el anticlinal Tin Tin y afectan a toda la secuencia sedimentaria (véase capítulo 4). La gran mayoría de estas estructuras se asocian genéticamente. Solamente en algunos casos los pliegues se producen desde un despegue de material fino y no se asocian a una falla en particular.

En base a la observación, descripción y mapeo de pliegues y fallas sobre los flancos del anticlinal Tin Tin se concluye que la zona Norte del cerro está estructurada con fallas inversas de bajo ángulo y pliegues asociados de vergencia/transporte 
occidental y gran extensión en la dirección de rumbo, que afectan principalmente a los subgrupos Balbuena y Santa Bárbara (Figura 6.1; véase Figura 4.12), aumentando su espesor. Los niveles de despegue se encontrarían en la sección superior de la Formación Yacoraite y en la transición con el Subgrupo Balbuena (Figura 6.1), en coincidencia con partes de la secuencia sedimentaria con mayor contenido de material fino, como la transición entre ambos subgrupos. Para el nivel de despegue dentro de la Formación Yacoraite no hay evidencias concretas que lo corroboren, pero se infiere un proceso similar al nivel de despegue de la transición entre los subgrupos.

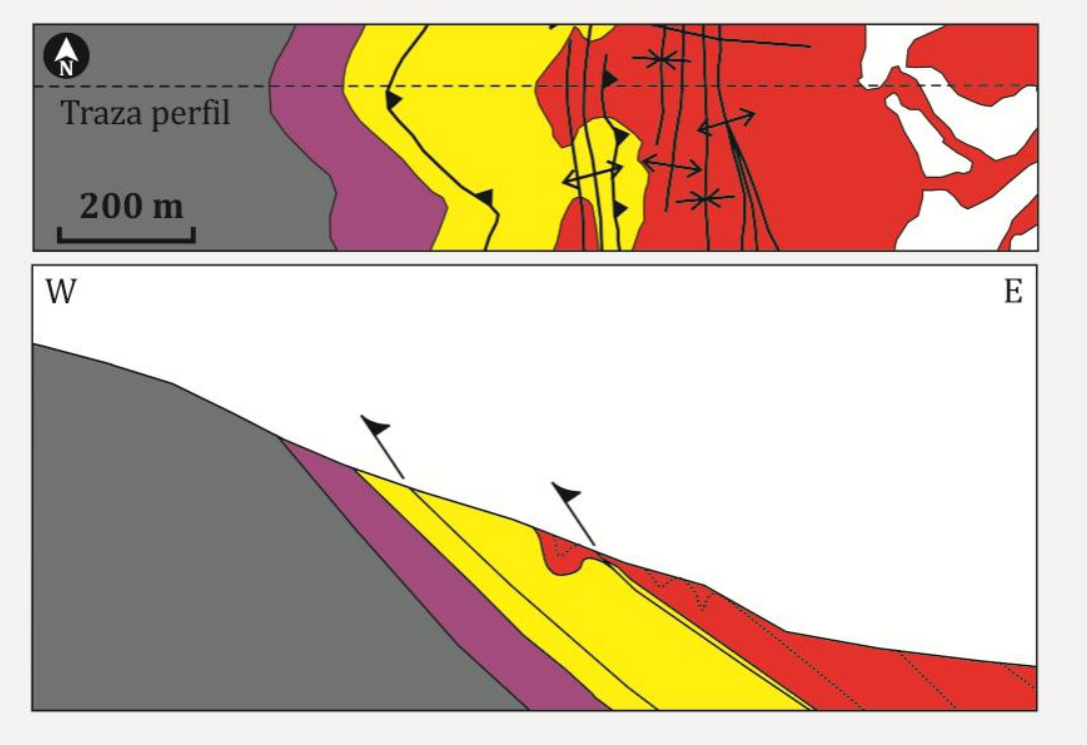

FIGURA 6.1. Perfil geológico en el flanco dorsal del sector Norte del Cerro Tin Tin. Fallas inversas en la secuencia sedimentaria. Véanse referencias estratigráficas en la figura $4.3 \mathrm{y}$ referencias estructurales en la figura 4.12.

Los pliegues mapeados en este sector en el Subgrupo Santa Bárbara presentan buen desarrollo y continuidad y no se observan estructuras similares en el sector medio del cerro, es decir, al Sur de la falla sinestral de rumbo NW-SE que atraviesa el anticlinal. El buen desarrollo de estos pliegues se asocia al empuje generado por el levantamiento posterior del bloque de basamento que se encuentra al Este del anticlinal Tin Tín (levantado por una falla inversa; véase Figura 4.1). La evidencia del levantamiento posterior del bloque (o actividad posterior de la falla inversa con respecto a la Falla Tin Tin) es que la falla corta la secuencia sedimentaria del flanco dorsal del anticlinal Tin Tin en forma oblicua, poniendo en contacto al basamento con el Subgrupo Santa Bárbara a la altura de la falla NW-SE, y con el Grupo Payogastilla en una posición más al Norte (véase Figura 4.3). 
Se constató que el sector central del anticlinal Tin Tin presenta la mayor estructuración y contracción, un rasgo común con muchos anticlinales relacionados a fallas inversas, donde el máximo desplazamiento de la falla se presenta en su parte central (Twiss y Moores, 2007). Este sector también se encuentra engrosado por fallas inversas de bajo ángulo que repite parte de la secuencia sedimentaria (véase Figura 4.13). Los niveles de despegue se encuentran en el Subgrupo Pirgua y en el Subgrupo Balbuena. La evidencia de dominios de inclinación verticales a volcados en la cobertura sedimentaria, con el nivel de despegue en el Subgrupo Pirgua, sugiere que este arreglo estructural se encuentra rotado (con aumento de inclinación; Figura 6.2) por apilamiento de rampas de basamento y el levantamiento de la cuña de basamento principal, lo que indica una cronología en la estructuración donde las deformación de la cobertura sedimentaria es relativamente anterior al levantamiento principal del anticlinal, es decir, del bloque de basamento. La relación entre la deformación de piel fina y piel gruesa ha sido estudiada en muchas fajas plegadas del país, a diferentes escalas, con resultados que indican la que la deformación de piel final precede a la deformación de piel gruesa (Cristallini y Ramos, 2000). Esto se aplica también a las fallas inversas del sector Norte del cerro. 

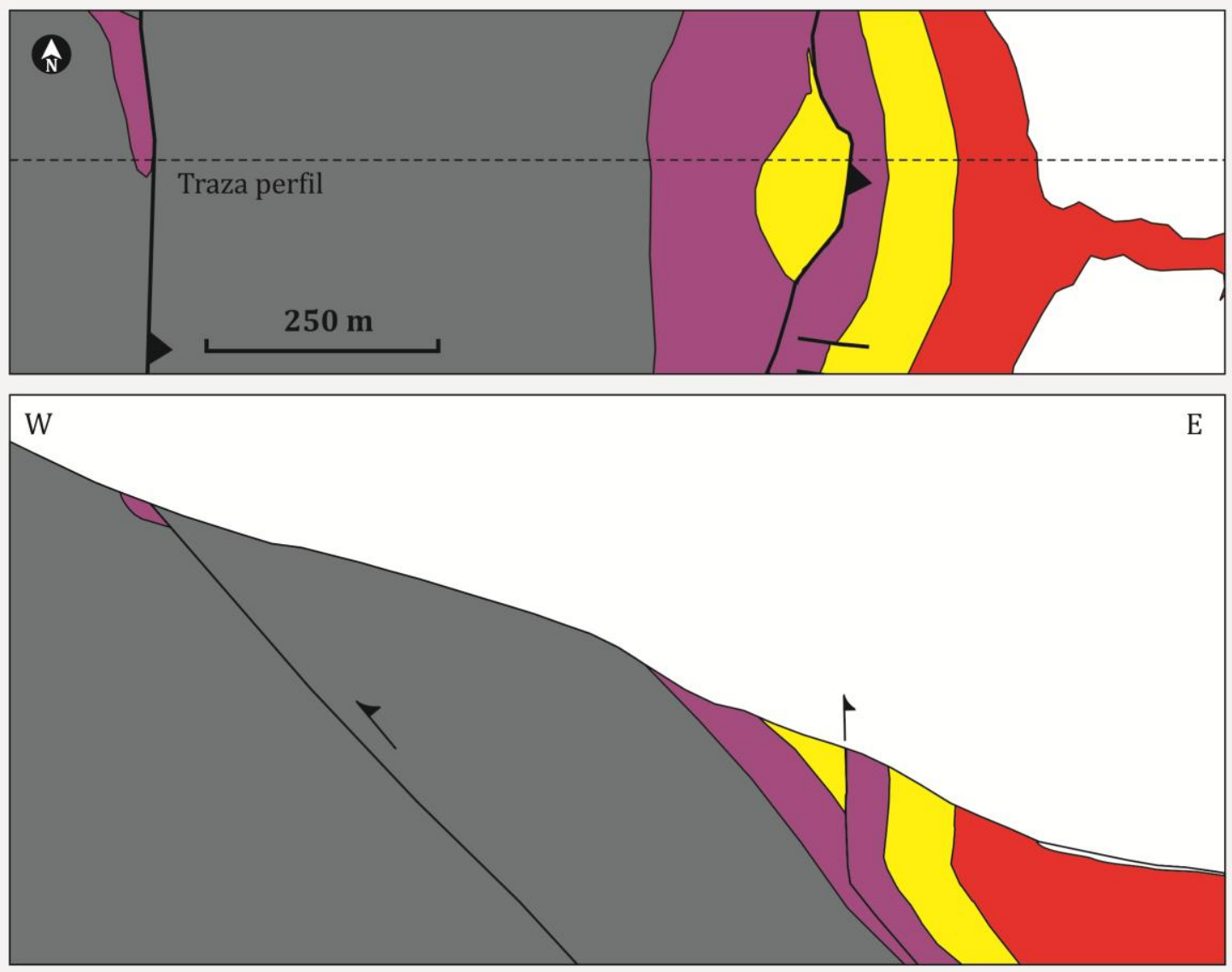

FIGURA 6.2. Perfil geológico en el flanco dorsal del sector central del Cerro Tin Tin. Fallas inversas en el basamento y en la cubierta sedimentaria condicionan los dominios de inclinación subverticales a volcados. Véase referencias estratigráficas en la figura 4.3 y referencias estructurales en la figura 4.12.

Las fallas y pliegues en el sector Sur del cerro (flanco dorsal y frontal en la inmersión Sur del anticlinal) desvían su rumbo conforme la falla Tin Tin pierde rechazo y el basamento su hunde por debajo de la cobertura sedimentaria (véase Figura 4.17). Las estructuras indican una leve convergencia del transporte estructural hacia el núcleo de basamento. Esta desviación se interpreta como la perturbación local de la trayectoria de esfuerzos generada por la terminación de la falla (que podría actuar como una rampa oblicua para ese sector (Apotria, 1995; Apotria y Wilkerson, 2002; Dixon y Spratt, 2004) y la consecuente inmersión del anticlinal. La falla inversa más evidente de este sector (véanse Figuras 4.17 y 4.19) muestra, en el bloque basal, 
diferentes angularidades con respecto al bloque colgante que indican que se activó cuando las capas ya se encontraban plegadas. Esta evidencia sugiere que este proceso de fallamiento ocurrió en un estadio avanzado del anticlinal Tin Tin.

Estructuras oblicuas y subpendiculares al rumbo del anticlinal Tin Tin.

Los pliegues y fallas con estas orientaciones se presentan en menor medida y representan la reactivación de estructuras previamente formadas, como ocurre comúnmente durante la evolución de sistemas estructurales ante la imposibilidad de generar de nuevas estructuras para la acomodación del acortamiento o extensión (Sibson, 1985, 1995; Letouzey et al., 1990; Holdsworth et al., 1997; Wilkins et al., 2001; Fischer y Christensen, 2004; Sanz et al., 2008; entre otros).

Las fallas con desplazamiento de rumbo dextral y sinestral que se encuentran principalmente en el sector Norte y central del flanco dorsal (véanse Figuras 4.12, 4.13, 4.15 y 4.16), se interpretan como diaclasas o conjunto de diaclasas (coalescentes) de un mismo set que se reactivaron como estructuras de rumbo desplazando a la secuencia sedimentaria. Esta interpretación se basa en la ausencia de brechamiento y/o reducción de grano (que indican el desgarre de la roca) y en la orientación preferencial de diaclasas con rumbo favorable, condición importante en la reactivación de estructuras (Del Ventisette et al., 2006), entre otros factores (Sibson, 1985, 1995; Holdsworth et al., 1997). Estas estructuras se formarían cuando los mecanismos de fallamiento inverso y plegamiento dejan de actuar, ya que desplazan a pliegues y a secuencias sedimentarias en diferentes dominios de inclinación. Es por esto que se infiere que su activación se inicia en un estadio intermedio a final de formación del anticlinal Tin Tin.

Otra estructura importante es un pliegue de gran magnitud en el Subgrupo Pirgua (véase Sección 4.1.1.4. Inmersión Sur: Pliegues en el sector de inmersión Sur del anticlinal Tin Tin; véase Figura 4.18). Esta estructura se infiere asociada a una falla inversa de alto ángulo con origen en el basamento, debido a una reactivación de planos de debilidad dentro del mismo. Esta interpretación esta soportada por la condición del basamento para este comportamiento, como se describió previamente, 
además de ser consistente con la orientación de estructuras de basamento cercanas. Se descarta la posibilidad de un episodio contraccional con dirección N-S debido a que esta estructura es aislada, y un episodio de esta dimensión y orientación debería haber generado fallas de piel fina en la cobertura.

Por último, se encuentran discontinuidades con desplazamiento normal o directo, en general con descenso del bloque Sur (véase Figura 4.19i-j-k). Estas estructuras son interpretadas, en forma parecida a las fallas de rumbo, como reactivación de diaclasas o conjunto de diaclasas preferencialmente orientadas. Los fundamentos de la interpretación son, como en el caso de la reactivación de rumbo, la ausencia de evidencia de desgarre y su posición estructural (inmersión Sur) que posibilita la extensión producida por la curvatura periclinal del anticlinal (Mandl, 2005). Esto sugiere que estas estructuras se formaron durante un estadio final de conformación del anticlinal Tin Tin.

\subsubsection{Fracturas de escala de afloramiento en el anticlinal Tin Tin}

En el anticlinal Tin Tin las fracturas de mesoescala son las estructuras de deformación frágil más abundantes y se encuentran distribuidas a lo largo del anticlinal afectando en mayor o menor medida a toda la secuencia sedimentaria.

Las fracturas del anticlinal Tin Tin son mayormente diaclasas y se agrupan en sets relativamente planares y subperpendiculares a las capas que las contienen (Figura 6.3). En menor medida y acompañando a las diaclasas se encuentran venas (individuales o agrupadas con disposición en echelon (Figura 6.3-6), mayormente en capas carbonáticas) y fracturas de cizalla de bajo ángulo (Figura 6.3-5). Localmente se encuentran fracturas de cizalla subperpendiculares a la capa que las contiene, aunque no son muy frecuentes. Muchas diaclasas reutilizan los planos de venas previas. 


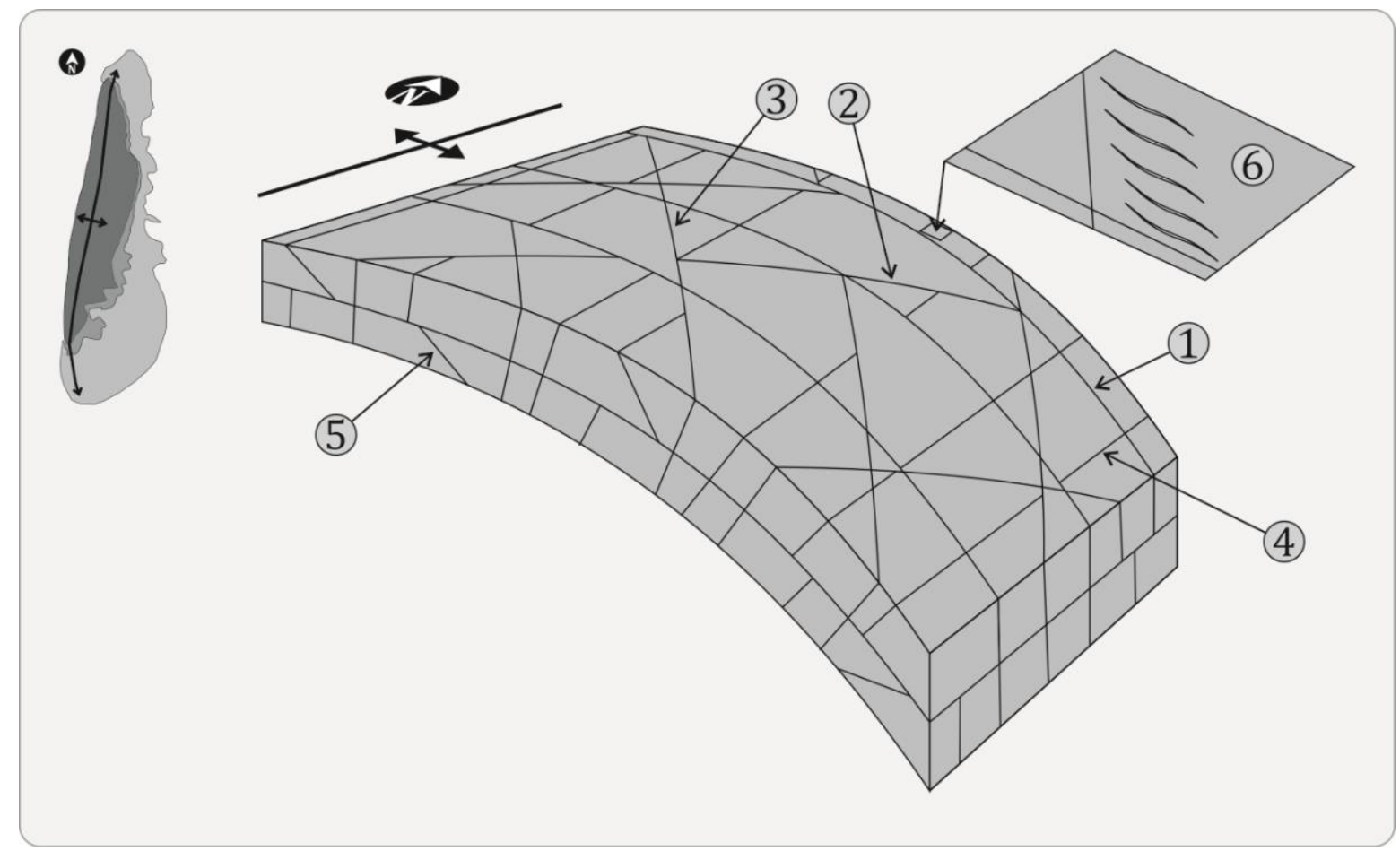

FIGURA 6.3. Esquema de la fracturación de escala de afloramiento. 1) Diaclasas perpendiculares al eje de pliegue. 2-3) Diaclasas oblicuas al eje de pliegue. 4) Diaclasas paralelas al eje de pliegue. 5) Fracturas de cizalla (bajo ángulo). 6) Venas en echelon (ejemplo sinestral).

En general las fracturas más antiguas se presentan con un arreglo sistemático mientras que los sets posteriores pueden o no presentarlo por estar ubicadas entre las primeras e influenciadas por éstas. A medida que los sets son más modernos su arreglo es más irregular. Se registran como mínimo dos sets de diaclasas por afloramiento, llegando hasta cinco. Las dimensiones de las fracturas del anticlinal Tin Tin se mantienen en el rango de metros de longitud de traza, hasta decenas de metros (excepcionalmente), mientras que su altura queda condicionada muchas veces por el espesor de la capa que las contiene. En general la orientación de los sets se mantiene en capas adyacentes, no así su frecuencia. En otros casos se encuentran diferencias en la orientación de los sets en capas adyacentes, tal como es observado en otros sistemas de fracturas relacionadas a pliegues (Belayneh y Cosgrove, 2004).

Las claras relaciones de corte e interacción entre fracturas de diferentes sets indican que las fracturas del anticlinal Tin Tin se formaron secuencialmente, es decir, 
durante episodios individuales de deformación (véase: Hancock, 1985; Rives et al., 1994; Mandl, 2005;). En este contexto, las fracturas más modernas van ocupando los espacios no deformados (cuerpo de roca entre dos fracturas adyacentes) dejados por las fracturas más antiguas, y su formación estará influenciada por éstas (Hancock, 1985; Gross, 1993; Becker y Gross, 1996). Aunque es muy raro establecer que un set de fracturas es unívocamente más antiguo que otros para toda una región o zona (Engelder y Geiser, 1980; Hancock, 1985), es posible establecer la secuencia de formación en cada afloramiento y compararlos entre ellos para determinar un orden cronológico de formación. Las diaclasas del anticlinal Tin Tin se agruparon en base a su disposición espacial con respecto a la orientación de la estructura principal, dada la recurrencia de ciertas orientaciones de fracturas en los anticlinales (Friedman y Stearns, 1971; Zhao y Jacobi, 1997; Fischer y Wilkerson, 2000; Silliphant et al., 2002; Tavani et al., 2006, 2011a; entre otros).

Fracturas perpendiculares al eje de pliegue del anticlinal Tin Tin

Esta categoría corresponde a las fracturas de los sets E-W y ESE-WNW en relación a la orientación N-S a NNE-SSW del anticlinal Tin Tin (Figura 6.3-1).

En base a las relaciones de corte y terminación que presentan los diferentes sets de fracturas en el anticlinal Tin Tin se puede concluir que las fracturas más antiguas son las correspondientes al set E-W como se pudo determinar en muchas de las estaciones de medición. Las evidencias para esta conclusión son las trazas relativamente continuas y de mayor longitud relativa que presentan las diaclasas, y que los demás sets generalmente terminan contra este set E-W (véase: Hancock, 1985; Eyal et al., 2001). En muchos casos, este set de diaclasas se encontraba abierto al momento de la formación de los sets posteriores, evidenciado por la curvatura perpendicular de las fracturas en su terminación, un proceso común en los sistemas de fracturas secuenciales (Dyer, 1988; Hancock, 1985; Engelder y Peacock, 2001). Estas fracturas son interpretadas como diaclasas paralelas al esfuerzo máximo principal $\sigma_{1}$ formadas durante el periodo de compresión horizontal Cenozoico que actuó sobre capas horizontales o subhorizontales, antes del crecimiento y 
amplificación del anticlinal Tin Tin, siguiendo a Guiton et al., 2003, Mandl, 2005 e Ismat, 2008. Las evidencias para esta interpretación son: a) su relación geométrica con respecto al anticlinal $\mathrm{y}, \mathrm{b}$ ) el hecho de que este set se encuentra en diferentes posiciones estructurales (flancos, inmersión Sur) con características similares; esto es indicativo de que se formaron en el estadio contraccional inicial del plegamiento. Este tipo de fracturas y su orientación concuerdan con un régimen contraccional inicial de antepaís (en este caso con dirección de contracción andina E-W), donde los esfuerzos compresivos generan una sobrepresión en los fluidos de la roca con la posible generación de un esfuerzo principal mínimo $\sigma_{3}$ tensional (Mandl, 2005). Otro mecanismo para explicar fracturas con esta orientación es la acción de un estiramiento paralelo a la charnela del pliegue debido a la curvatura periclinal (convexa hacia arriba) del anticlinal (Mandl, 2005). Este mecanismo podría explicar la formación de fracturas cronológicamente posteriores con orientación E-W durante un estado evolutivo avanzado (en curvatura) del anticlinal Tin Tin. Por último, no es considerada la posibilidad de que las fracturas del set E-W no estén relacionadas a la formación del anticlinal Tin Tin. Una evidencia fuerte para determinar fracturas no relacionadas a un pliegue en particular (en las fracturas más antiguas) es la de no presentar relaciones geométricas con el mismo (Silliphant et al., 2002), aunque hay que considerar que el anticlinal es perpendicular a la dirección de contracción actual y eso dificulta la interpretación y discriminación entre fracturas previas (no relacionadas al anticlinal) y fracturas relacionadas al plegamiento (Tavani et al., 2011). Estudios de detalle sobre este set en particular, a escala local y regional, podrían arrojar resultados esclarecedores sobre su origen.

Fracturas paralelas al eje de pliegue del anticlinal Tin Tin

Las fracturas correspondientes a los sets con dirección aproximadamente paralela al eje de plegamiento (sets NNW-SSE, N-S y NNE-SSW) son en general las fracturas relativamente más modernas, es decir, las últimas en formarse, según indican las relaciones geométricas observadas en muchos afloramientos estudiados. Estas fracturas presentan trazas cortas y se ubican entre los demás sets de diaclasas (Figura 6.3-4). 
Estos sets son interpretados como diaclasas formadas por extensión en el arco externo de una capa individual o un conjunto de capas que se pliega (ver: Hancock, 1985). Considerando una escala kilométrica para el anticlinal principal, se esperaría que este mecanismo esté bien desarrollado en la charnela del pliegue, disminuyendo notablemente hacia los flancos (Price y Cosgrove, 1990), situación que no ocurre en el anticlinal Tin Tin ya que las fracturas con orientaciones aproximadas N-S se observan por igual en todas las posiciones estructurales. Si bien este es un mecanismo razonable para la formación de fracturas en la zona charnelar, los flancos del anticlinal requieren de otros mecanismos. Una explicación para esto es considerar la extensión de arco externo a una escala más local donde actuaría sobre los pliegues menores que afectan y estructuran los flancos. Otro mecanismo posible para la formación de fracturas con esta orientación en los flancos de un pliegue es la cizalla interestratal (mecanismo de deslizamiento flexural), observada en el anticlinal Tin Tin, que produce una reorientación en los esfuerzos y condiciones especiales para la formación de fracturas paralelas al eje de plegamiento (Couples et al., 1998; Engelder y Peacock, 2001; Mandl, 2005). Es posible que varios mecanismos actúen en conjunto para la formación de las diaclasas, siendo dificultosa la posibilidad de discriminar entre ellos. Un último mecanismo teórico que colaboraría con los demás procesos es la liberación de esfuerzos residuales (atrapados en la roca, generalmente relacionada a la litificación) durante la relajación producto de la denudación del terreno (Engelder, 1985; Mandl, 2005), aunque no hay evidencias claras sobre este mecanismo.

Una interpretación adicional para este grupo de fracturas es que los tres sets de diaclasas (NNW-SSE, N-S y NNE-SSW) pueden ser formados en un mismo evento de deformación (fracturación) y por lo tanto, encontrarse en un mismo afloramiento (véase Figura 5.4d-e). Las diferentes orientaciones que adquieren las diaclasas son una consecuencia directa de la influencia que tienen la orientación y espaciado de los sets previamente formados sobre las fracturas en formación, y el mecanismo está basado en la reorientación de los esfuerzos en una fractura abierta y la generación de una terminación curvada, véase: Hancock, 1985). La interpretación se explica en la figura 6.4. Un mayor espaciado de las fracturas previas reduce la influencia sobre la 
fractura en propagación, posibilitando su formación de acuerdo al campo de esfuerzos local. Un espaciado reducido (considerando diaclasas previas con apertura) solo generará fracturas cortas perpendiculares a las diaclasas previas (Figura 6.4).

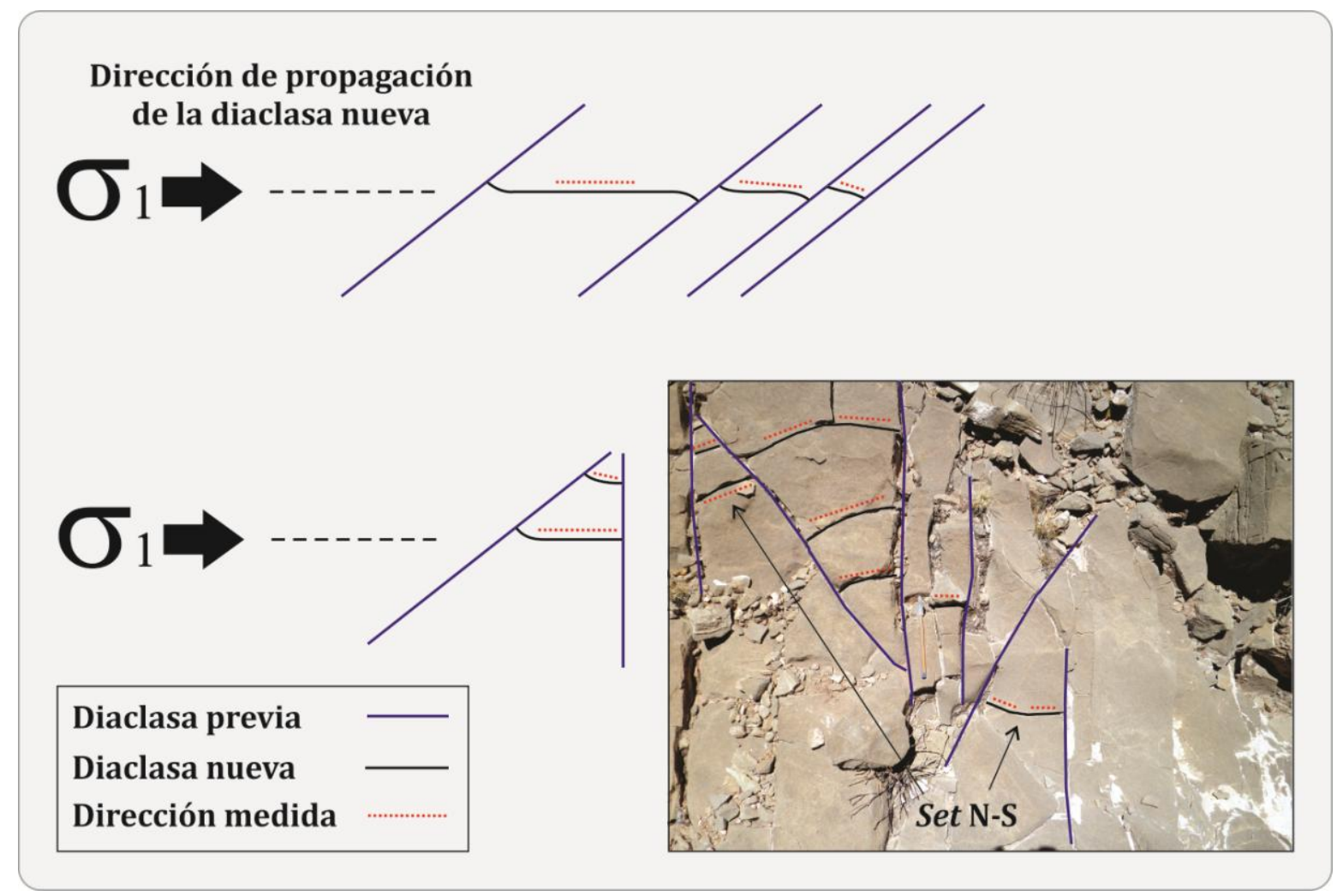

FIGURA 6.4. El esquema muestra cómo la orientación y espaciado de diaclasas previas (superficies libres) condicionan de la orientación de diaclasas nuevas, debido al desvío local de esfuerzos que genera la superficie libre de la diaclasa antigua (véase: Hancock, 1985). Arriba: A medida que el espaciado entre dos fracturas previas adyacentes disminuye, la influencia sobre la fractura en propagación es mayor, y obliga a la nueva fractura a acomodarse en forma subperpendicular a las fracturas antiguas, cambiando su orientación con respecto a las fracturas que pudieron propagarse libremente (sin o con escasa influencia de fracturas previas). Abajo: Fracturas previas de diferentes sets causan el efecto descripto. El efecto producido en las diaclasas nuevas por un espaciado reducido (dos fracturas que convergen) es mayor que el que produce un espaciado mayor (dos fracturas divergentes). Los desvíos en la orientación de las fracturas nuevas pueden conducir erróneamente a separar un set formado en las condiciones descriptas, en dos o más sets diferentes, en el caso de que sólo se traten los datos estadísticamente (diagrama estereográfico) sin considerar las observaciones de campo. La fotografía de un afloramiento muestra el ejemplo del set $\mathrm{N}-\mathrm{S}$, que en general está influenciado por fracturas previas ya que éste es el último en formarse.

Dentro del grupo de fracturas paralelas al rumbo del anticlinal entrarían las fracturas de cizalla de bajo ángulo (fallas pequeñas). Estas son diferentes en origen a 
las diaclasas y en el capítulo 4 se explicaron como fracturas contraccionales formadas cuando las capas se encontraban en posición subhorizontal.

\section{Fracturas oblicuas al eje de pliegue del anticlinal Tin Tin}

Esta categoría corresponde a las fracturas de los sets NE-SE, ENE-WSW y NWSE en relación a la orientación N-S a NNE-SSW del anticlinal Tin Tin (Figura 6.3-2-3). Estas fracturas se formaron entre el primer y último episodio de fracturación, es decir, entre la formación del set E-W y la formación del set N-S.

A pesar de que muchos autores han interpretado a las fracturas oblicuas como fracturas de cizalla en base a su orientación oblicua con respecto al eje de plegamiento y a un ángulo diedro que cuadra en el rango de este tipo de fracturas (véase: Stearns y Friedman, 1972; Pollard and Aydin, 1988), en ocasiones es muy difícil distinguir en el campo entre fracturas de cizalla y diaclasas (Mandl, 2005). Como se mencionó en los capítulos anteriores, estos sets presentan comúnmente movimientos por cizalla, y en ocasiones con estriados sobre sus planos. Aunque ambos sets pueden presentar tanto cizalla dextral como sinestral (véase capítulo 5), comúnmente el set NE-SW presenta cizalla dextral y el set NW-SE cizalla sinestral, en concordancia con un régimen compresivo con dirección E-W. La evidencia más clara para concluir que las fracturas oblicuas del anticlinal Tin Tin son diaclasas y no fracturas de cizalla es que las mismas pertenecen generalmente a sets de fracturas paralelas y relativamente sistemáticas (característica de las diaclasas), en donde algunas presentan estructura plumosa en sus superficies, según se observo en algunos afloramientos (véase: Estaciones de medición 4TT, 5TT, 10TT, 12TT). Esto indica que la cizalla fue posterior (diaclasas reactivadas) y que no está relacionada con su origen (Wilkins et al., 2001).

Un modelo para explicar estas fracturas de extensión oblicuas al eje de plegamiento es mediante la adición de torsión previa al plegamiento de la cobertura sedimentaria (Mandl, 2005: pág. 103). Esta torsión genera localmente "ejes de pliegues" oblicuos en la cobertura sedimentaria, lo que produce fracturas extensionales en el arco externo con una orientación no paralela al eje de pliegue principal. Este mecanismo de torsión de la cobertura sedimentaria podría ser 
posibilitado, a diversas escalas, por ciertas características de la cuña de basamento, como ser la diferencia topográfica entre el centro del anticlinal (máxima contracción) y sus extremos, el levantamiento diferencial de bloques de basamento (dentro del núcleo) durante la contracción, sumado a posibles irregularidades en la topografía original del mismo.

Scan lines: Frecuencia de las fracturas en diferentes posiciones estructurales

Los datos obtenidos a partir de los scan lines realizados en algunas estaciones sugieren que no hay una correlación definida entre la cantidad de fracturas y la posición estructural dentro del anticlinal (Figura 6.5). Esto posiblemente sea causado por la combinación o superposición de procesos de deformación, que generó fracturas en todas las posiciones estructurales, lo que impide, a la escala del anticlinal principal, obtener resultados concretos. Análisis específicos y puntuales sobre los diferentes parámetros de los sistemas de fracturas (espaciado, altura, longitud, etc.) son necesarios para una mayor precisión estadística. En general estos análisis estadísticos corresponden a una etapa posterior de trabajo, una vez determinado la génesis de los sistemas de fracturas y su marco estructural (Nelson, 2001). El análisis expeditivo presentado en este trabajo representa una estimación inicial, la cual puede ser notablemente mejorada con los estudios puntuales mencionados.

\begin{tabular}{|c|c|c|c|c|c|c|c|c|}
\hline \multicolumn{9}{|c|}{ Frecuencia $\left(\mathrm{F}=\mathrm{n}^{\circ}\right.$ fracturas/longitud del scan line $)$} \\
\hline & $\mathrm{N} 350^{\circ}-\mathrm{N} 10^{\circ}$ & $\mathrm{N} 11^{\circ}-\mathrm{N} 34^{\circ}$ & $\mathrm{N} 35^{\circ}-\mathrm{N}^{\circ} 5^{\circ}$ & $\mathrm{N} 56^{\circ}-\mathrm{N}^{\circ} 9^{\circ}$ & ${\mathrm{N} 80^{\circ}-\mathrm{N} 100^{\circ}}^{\circ}$ & $\mathrm{N}_{101^{\circ}-\mathrm{N} 124^{\circ}}$ & $\mathrm{N} 125^{\circ}-\mathrm{N} 145^{\circ}$ & $\mathrm{N} 146^{\circ}-\mathrm{N} 169^{\circ}$ \\
\hline Estación de medición & $\mathrm{N}-\mathrm{S}$ & NNE-SSW & NE-SW & ENE-WSW & E-W & ESE-WNW & NW-SE & NNW-SSE \\
\hline 3TT & & & 2.84 & & 9.11 & 3.74 & 7.51 & \\
\hline 5TT & & 2.27 & & & 4.86 & & 2.13 & \\
\hline 6TT & & & & & 7.19 & & 6.44 & \\
\hline 7TT & & & & 4.26 & & & 6.15 & \\
\hline 8TT & & 5.65 & & 4.74 & 3.93 & 4.51 & & \\
\hline 9TT & & 10.93 & & 5.96 & & 1.53 & & 3.48 \\
\hline 11TT & & & & 5.89 & & 8.64 & & 6 \\
\hline 17TT & & & 4.81 & & 2.65 & 7.31 & & \\
\hline
\end{tabular}

FIGURA 6.5. Tabla que resume los datos de Frecuencia correspondientes a los scan lines realizados. 


\subsection{Anticlinal Cerro Bayo: Diferencias estructurales con el anticlinal Tin Tin}

Las características estructurales del anticlinal Cerro Bayo muestran marcadas diferencias con el anticlinal Tin Tin, partiendo de la poca o nula estructuración que presenta el flanco dorsal del anticlinal Cerro Bayo. Sin embargo, su estudio arroja resultados sobre la deformación del flanco frontal (su característica más importante), casi ausente en el anticlinal Tin Tin, además de que permite mostrar un estilo de deformación en otro ámbito de la cuenca.

\subsubsection{Fallas y pliegues en el anticlinal Cerro Bayo}

El flanco frontal del anticlinal Cerro Bayo presenta la estructuración más importante del cerro. La gran mayoría de las estructuras presentes son subparalelas al rumbo del anticlinal, solo una pocas presentan un rumbo subperpendicular al mismo.

La característica más particular del primer grupo de estructuras (subparalelas al anticlinal) es, como se observó en los sitios mapeados, la presencia de dominios de inclinación verticales o volcados en contacto con capas inclinación en posición normal, sin una continuidad visible o aparente (véase Capítulo 4). La explicación para esta geometría observada se basa en las siguientes interpretaciones.

Se pudieron distinguir pliegues volcados en la Formación Yacoraite (véase Figura 4.23c). Estos pliegues se interpretan como anticlinales volcados de origen gravitacional que pueden ser activados por la remoción de material por erosión de las unidades adyacentes al limbo frontal de alta inclinación (Emami et al., 2010), sumado a un comportamiento mas "dúctil" de la secuencia sedimentaria por la alternancia niveles de material pelítico. Este tipo de estructuras se han observado en valles adyacentes sobre la base del Subgrupo Santa Bárbara (Figura 6.6) y también han sido descriptas para la Formación Yacoraite en otro sector del valle (Figura 6A en Payrola Bosio et al., 2011). 


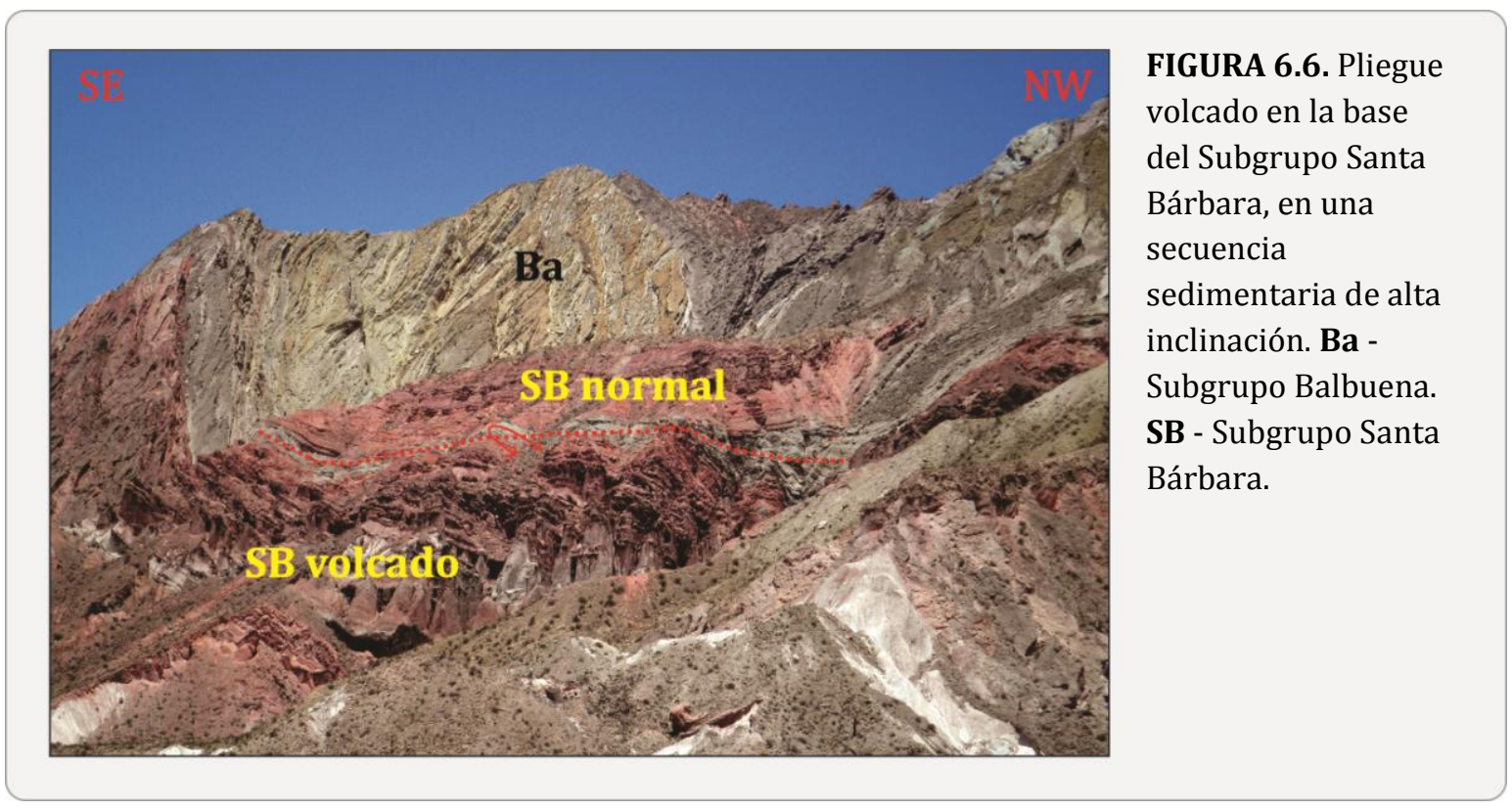

El sector centro-norte del flanco frontal presenta mayor estructuración (véase Figura 4.24), y se observa una falla subhorizontal que despega desde niveles favorables. Esta estructura subhorizontal (y su bloque colgante de similar orientación) muestra una geometría parecida al flanco de posición normal del pliegue gravitacional de la figura 4.23, pero en un estadio más avanzado, donde su superficie axial evoluciona en una falla subhorizontal (véase Figura 4.24). Por lo tanto, un nivel de erosión apropiado mostraría capas volcadas en contacto con capas normales. Por lo expuesto se interpreta que la causa de la disposición estructural de las capas del flanco frontal se debe al deslizamiento/fallamiento por despegue de la secuencia sedimentaria y la consecuente generación de pliegues gravitacionales.

Una interpretación alternativa para estas observaciones, de forma parecida a los dominios de inclinación volcados en el flanco dorsal del anticlinal Tin Tin, es un fallamiento inverso con transporte hacia el Este, que expone mediante erosión el bloque colgante en contacto con el bloque basal, con una geometría plano colganterampa basal (Figura 6.2; Suppe, 1983). En este contexto, la falla se habría formado antes de la inclinación del flanco frontal. En el caso en el que el flanco ya hubiese estado inclinado, la falla correspondería a un corrimiento del tipo out-of-syncline 
thrust (McClay, 1992; Mitra, 2002). En ambos casos, la falla se origina por problemas de espacio de acomodación.

Otros tipos de estructuras presentes son fallas inversas con transporte hacia el Oeste y estructuras de desplazamiento de rumbo subperpendiculares al rumbo del anticlinal (véase Figura 4.26), que forman parte de la deformación general del flanco frontal en respuesta a la evolución contraccional de anticlinal.

\subsubsection{Fracturas de escala de afloramiento en el anticlinal Cerro Bayo}

Las fracturas de mesoescala del anticlinal Cerro Bayo comparten ciertas características con las del anticlinal Tin Tin. Estas fracturas son en su gran mayoría diaclasas, que se agrupan en sets planares y subperpendiculares a las capas que las contienen, y que se formaron de manera secuencial, rasgo que queda en evidencia por sus relaciones de corte y terminación. También se encuentran en todas las posiciones estructurales del anticlinal (véase Figura 5.20).

El estudio de sistemas de fracturas en el anticlinal Cerro Bayo se realizó para compararlos con los sistemas de fracturas del anticlinal Tin Tin. De las mediciones y observaciones realizadas en los afloramientos se puede concluir que los sistemas de fracturación en el anticlinal Cerro Bayo son diferentes al anticlinal Tin Tin, donde las fracturas con rumbo aproximado E-W no representan una fracción importante. En este anticlinal se constató que los sets NW-SE y NNW-SSE, que aparecen en la mayoría de las posiciones estudiadas, son cronológicamente los más antiguos en relación a su formación. Los demás sets, que corresponden a los rumbos N-S, E-W (y sus variantes ESE-WNW y ENE-WSW) y NE-SW, son en general cronológicamente posteriores. En algunos sitios el set E-W aparece como el primero en formarse. Estas observaciones sugieren que las diaclasas subparalelas al eje de plegamiento (set NNW-SSE) adquieren un rol más importante posiblemente debido al estilo de plegamiento, diferente al del anticlinal Tin Tin. Es importante notar que las fracturas del set ENEWSW son comúnmente reactivadas durante la inclinación del flanco frontal (en el sector Noroeste del cerro), dado que es un mecanismo viable para el acortamiento estructural (Gutiérrez-Alonso y Gross, 1999). 
A diferencia del anticlinal Tin Tin, no se puede determinar claramente una cronología general en la deformación del anticlinal Cerro Bayo, principalmente debido a la falta de estructuración del flanco dorsal, donde muchas veces se observaron y constataron (en el caso del anticlinal Tin Tin) las relaciones entre las fracturas de mesoescala y los pliegues y fallas asociados. También se puede inferir, como se concluyo anteriormente, que la estructuración de la cobertura sedimentaria relacionada a la influencia del basamento (ausente en el anticlinal Cerro Bayo) marca una diferencia fundamental entre ambos anticlinales.

\subsection{Evolución estructural del anticlinal Tin Tin: Acortamiento en una zona de alto estructural}

Se proponen tres estadios de formación de estructuras para el anticlinal Tin Tin, relacionados a la contracción horizontal andina instaurada luego del periodo de extensión que originó los depósitos del Grupo Salta. Las únicas estructuras anteriores a la deformación contraccional son las estilolitas paralelas a la estratificación local en capas de alto contenido carbonatico (véase Figura 5.4g), interpretadas en este trabajo como estructuras generadas por la disolución de material por presión de la carga sedimentaria. En base a las descripciones estructurales expuestas en los capítulos anteriores, se proponen los siguientes estadios de deformación:

1- En un primer estadio de deformación (Figura 6.7) se produce un fenómeno de buckling, y más precisamente el proceso de acortamiento paralelo a la capa (layerparallel shortening) donde el esfuerzo horizontal máximo $\sigma_{1}$ con dirección aproximada E-W actúa sobre capas subhorizontales o de muy bajo ángulo de inclinación. Este estadio es considerado como el inicio del plegamiento de la cobertura sedimentaria, como se menciona para muchos sistemas de plegamientos estudiados (Tavarnelli, 1997; Guiton et al., 2003; Ismat, 2008b). En este estadio se forman las diaclasas y venas de rumbo E-W a ESE-WNW y las fracturas de bajo ángulo (fracturas de cizalla, fallas pequeñas) observadas en capas de los subgrupos Balbuena y Santa Bárbara. La mayor cantidad de venas se encuentra en capas con alto contenido carbonático. Las diaclasas se forman limitándose a las diferentes unidades mecánicas 
y su altura depende de la estratigrafía local (alternancia arena-pelita), es decir, pueden confinarse a capas simples o atravesar una secuencia de muchos metros de espesor. Este conjunto de fracturas es el que posibilita la posterior deformación de la cobertura sedimentaria, por lo que son un paso esencial para el plegamiento y deformación de una secuencia sedimentaria. También se podrían formar fracturas de cizalla verticales con ángulo diedro paralelo a $\sigma 1$, aunque no hay un registro importante de éstas estructuras.

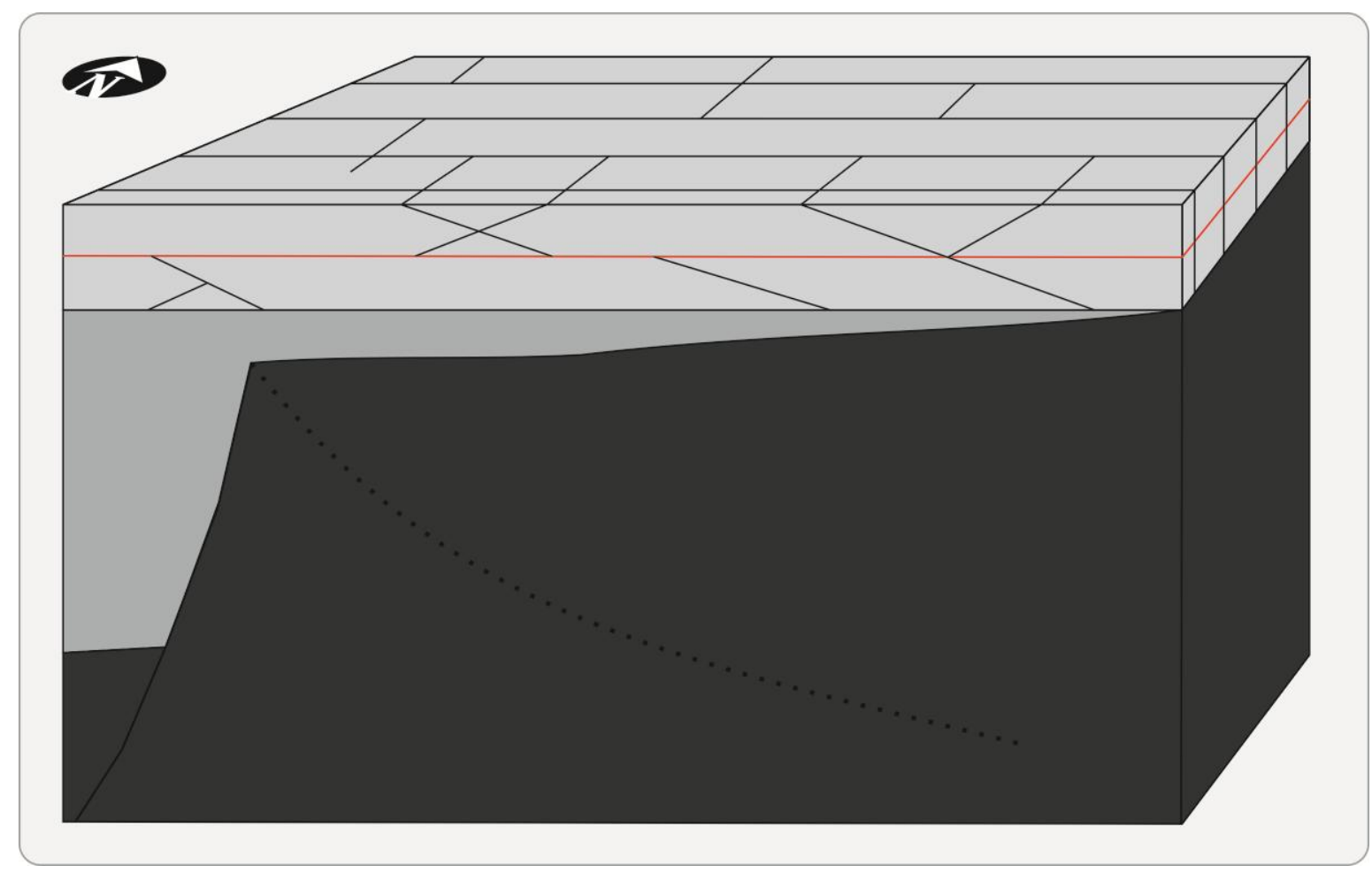

FIGURA 6.7. Primer estadio de deformación en el anticlinal Tin Tin. Se forman diaclasas perpendiculares al futuro eje de pliegue y fracturas de cizalla.

2- El segundo estadio de deformación se divide en un Estado inicial y un Estado avanzado. Al comienzo de este estadio (Estado inicial) se produce el levantamiento inicial del basamento (poco ángulo de pendiente en la topografía del basamento) producto de la actividad de la Falla Tin Tin (Figura 6.8). En este estado inicial, la deformación más significativa es acomodada por fallas inversas de bajo ángulo con transporte occidental que producen el acortamiento y engrosamiento de la secuencia 
sedimentaria mediante la repetición y plegamiento de las unidades del Grupo Salta principalmente (Figura 6.9). Se producen pliegues con geometría de flexión y propagación de falla y pliegues por despegue en capas con pelitas infrayacentes. Estos pliegues podrían considerarse como pliegues de segundo y/o tercer orden, que "parasitan" al pliegue principal de primer orden (Twiss y Moores, 2007) y son comunes en ambientes de inversión tectónica (Cooper et al., 1989; Underhill y Paterson, 1998).

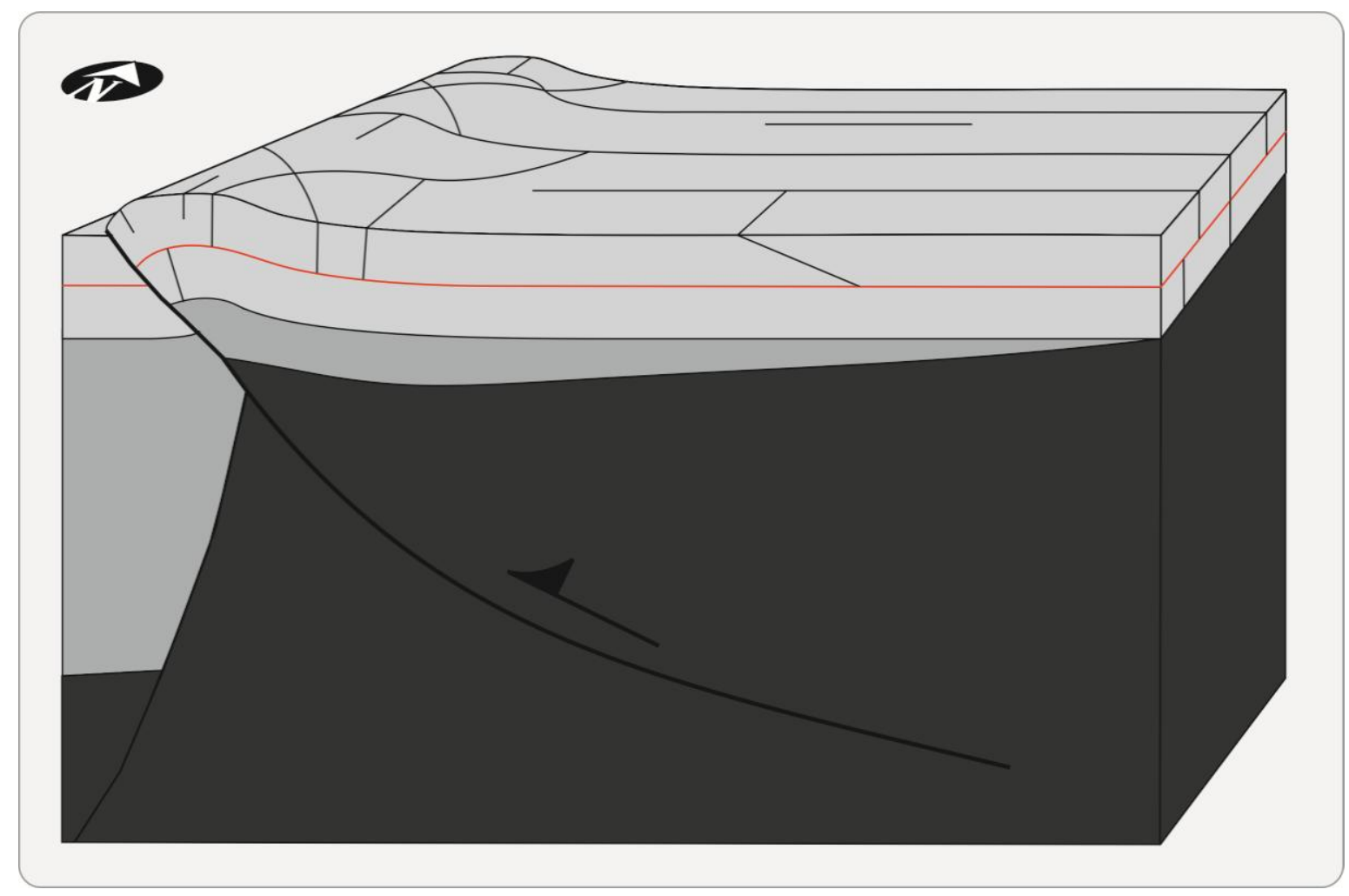

FIGURA 6.8. Segundo estadio de deformación en el anticlinal Tin Tin: Estado inicial. Se forman diaclasas oblicuas al eje de pliegue del anticlinal Tin Tin. Posteriormente se forman diaclasas paralelas al eje de pliegue.

En el estado inicial comenzarían a formarse las diaclasas oblicuas al eje de plegamiento del anticlinal, implicando diferencias topográficas en la superficie del basamento y activación de estructuras dentro del mismo, con posible levantamiento diferencial de bloques en algunos sectores. Conforme el plegamiento, fallamiento y levantamiento del basamento avanza (Estado medio a avanzado), las capas (o 
secuencia de capas) se van acomodando mediante el mecanismo de deslizamiento flexural (flexural slip), indicando una separación de la secuencia sedimentaria en unidades mecánicas que se deslizan en direcciones no necesariamente paralelas, y con estados de esfuerzos locales posiblemente diferentes en cada una (Couples y Lewis, 1999; Shackleton y Cooke, 2007). Aquí comenzarían a formarse las diaclasas paralelas al eje de plegamiento, como respuesta a la extensión producida en el arco externo de las capas debido a su flexión (tangential longitudinal strain, Price y Cosgrove, 1990) y al deslizamiento flexural. También se podrían seguir formando diaclasas paralelas a $\sigma 1$ si se dan las condiciones apropiadas, pero el desarrollo del deslizamiento flexural y las fracturas previamente formadas pueden generar una distorsión del campo de esfuerzos y una divergencia en la orientación del set con respecto a la orientación original E-W (aproximado).

Se constató la influencia de las estructuras de basamento reactivadas (rumbo E-W) en la generación de fallas inversas de alto ángulo (véase Figura 4.18) pero se desconoce la cronología relativa en sus re/activaciones. Estas podrían haberse activado en cualquier momento del levantamiento de la cuña de basamento.

Este estadio de deformación perdura durante gran parte del crecimiento del anticlinal principal, es decir, durante el levantamiento del basamento. A medida que aumenta la inclinación del flanco dorsal (Estado avanzado), los corrimientos adquieren menor capacidad de transportarse, prevaleciendo el plegamiento en el bloque colgante, algo similar a un contrafuerte incipiente. Hacia el final de este estadio, en conjunto con el levantamiento general del cerro, se produciría el fallamiento de rumbo sinestral de la estructura NW-SE al Norte del cerro, y el fallamiento inverso de bajo ángulo dentro del basamento, lo que produce la rotación de un sector del flanco dorsal y el volcamiento de rampas y dominios de inclinación (Figuras 6.2 y 6.9). 


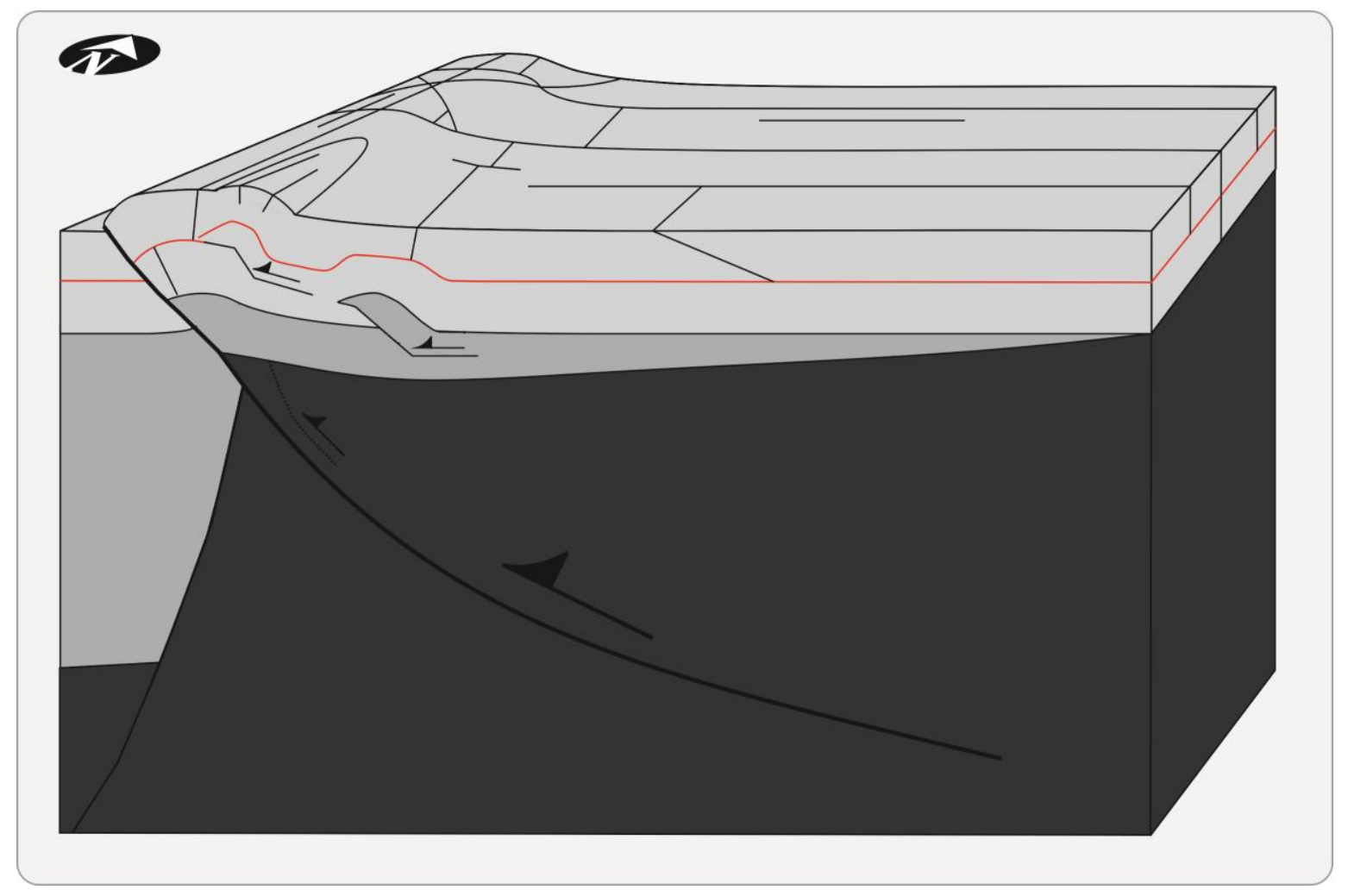

FIGURA 6.9. Segundo estadio de deformación en el anticlinal Tin Tin: Estado medio a avanzado. Fallamiento y plegamiento significativo de la secuencia sedimentaria del flanco dorsal. Fallas en el núcleo de basamento.

3- El tercer estadio de deformación (Figura 6.10) comprende la reactivación de rumbo de grandes fracturas con orientación oblicua a la dirección E-W del esfuerzo principal, mediante la coalescencia y desplazamiento de diaclasas favorablemente orientadas, cuando los pliegues y las fallas no pueden acomodar más deformación (Guiton et al., 2003). Estas fallas de rumbo son tardías y principalmente posteriores a los pliegues (asociadas a fallas inversas durante el crecimiento del pliegue). Cuando el flanco dorsal alcanza cierto ángulo de inclinación (debido al levantamiento principal del núcleo de basamento), las fallas inversas ya no actúan más o ralentizan su actividad, y dejan lugar a las fallas de rumbo dextral y sinestral para seguir acomodando la deformación contraccional. Estas fallas, como se puede observar en las figuras 4.15 y 4.16 , afectan a capas con inclinaciones media a alta, hasta verticales y volcadas, es decir, son independientes de la orientación del dominio. En este estadio 
también se reactivan algunas fracturas con movimiento directo o normal en el sector de inmersión Sur del anticlinal.

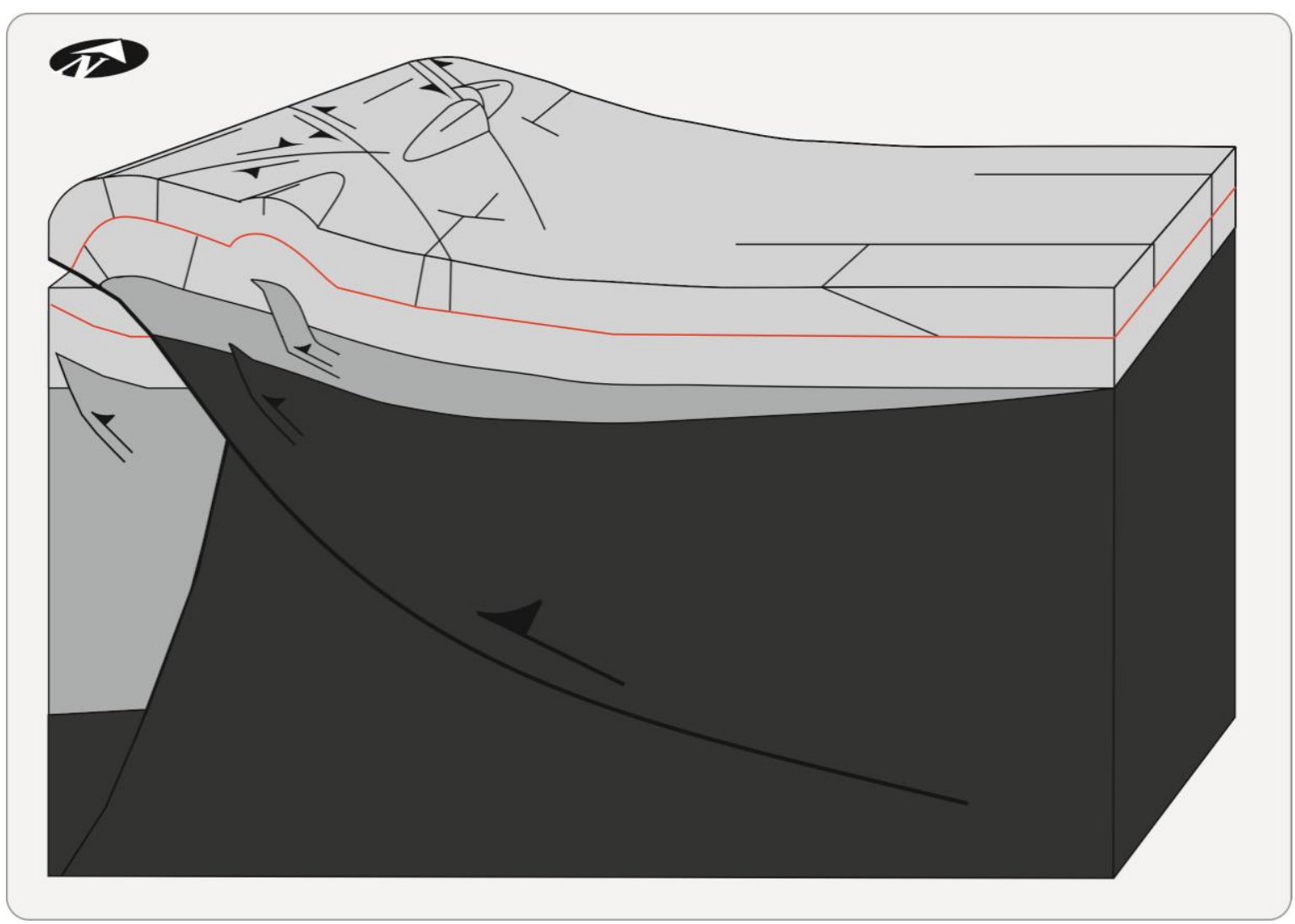

FIGURA 6.10. Tercer estadio de deformación en el anticlinal Tin Tin. Levantamiento principal del núcleo de basamento. Reactivación de rumbo de grandes fracturas que desplazan pliegues.

Con respecto a las edades de la deformación, Hongn et al. (2011) indican que la actividad de la falla Tin Tin comenzó en los primeros estadios de deformación andina para este sector, en el Eoceno Medio aproximadamente. También se sugiere que hubo cierto grado de estructuración en los depósitos del Grupo Salta antes de la depositación de la Formación Quebrada de los Colorados (Grupo Payogastilla, inicio de la cuenca de antepaís) ya que ésta se encuentra apoyando en discordancia con las unidades de postrift infrayacentes, y en ocasiones con una fuerte erosión y eliminación de unidades (Hongn et al., 2008, 2011; del Papa et al., 2013b). Carrapa et al. (2011), a partir muestras del Subgrupo Santa Bárbara tomadas en el Norte del cerro Tin Tin, indican que su exhumación (o la exhumación de esta unidad para el sector medio- 
Norte del Valle Calchaquí) ocurrió entre los 6-12 Ma (Mioceno Medio a Superior). Por último, Galli et al. (2014) describen la presencia de clastos de la Formación Yacoraite y del Subgrupo Pirgua en los conglomerados de la Formación San Felipe (unidad superior del Grupo Payogastilla, de edad Plio-Pleistoceno), y sugieren una importante actividad tectónica durante su depositación. Esto también indicaría la edad aproximada de exhumación de estas unidades del Grupo Salta en el sector medio del Valle Calchaquí. A partir de estos datos se puede pensar que la mayor parte de la fracturación de mesoescala y otras mesoestructuras (como pliegues y fallas) que deforman el flanco dorsal y frontal del anticlinal Tin Tin (primer estadio de deformación y segundo estadio de deformación: Estado inicial), se formaron durante el lapso entre el Eoceno Medio y el Mioceno Inferior a Medio; y que durante el lapso entre el Mioceno Medio y el Plio-Pleistoceno ocurrió la exhumación principal del anticlinal Tin Tin (segundo estadio de deformación: Estado avanzado y tercer estadio de deformación), debido a la actividad de la Falla Tin Tin (Figura 6.11), en concordancia con los pulsos tectónicos neógenos (Quechua y Diaguita) que generaron el relieve estructural actual (Mon y Salfity, 1995). Sin embargo, no hay que dejar de considerar la actividad neotectónica para esta zona (Hongn et al., 2014). 


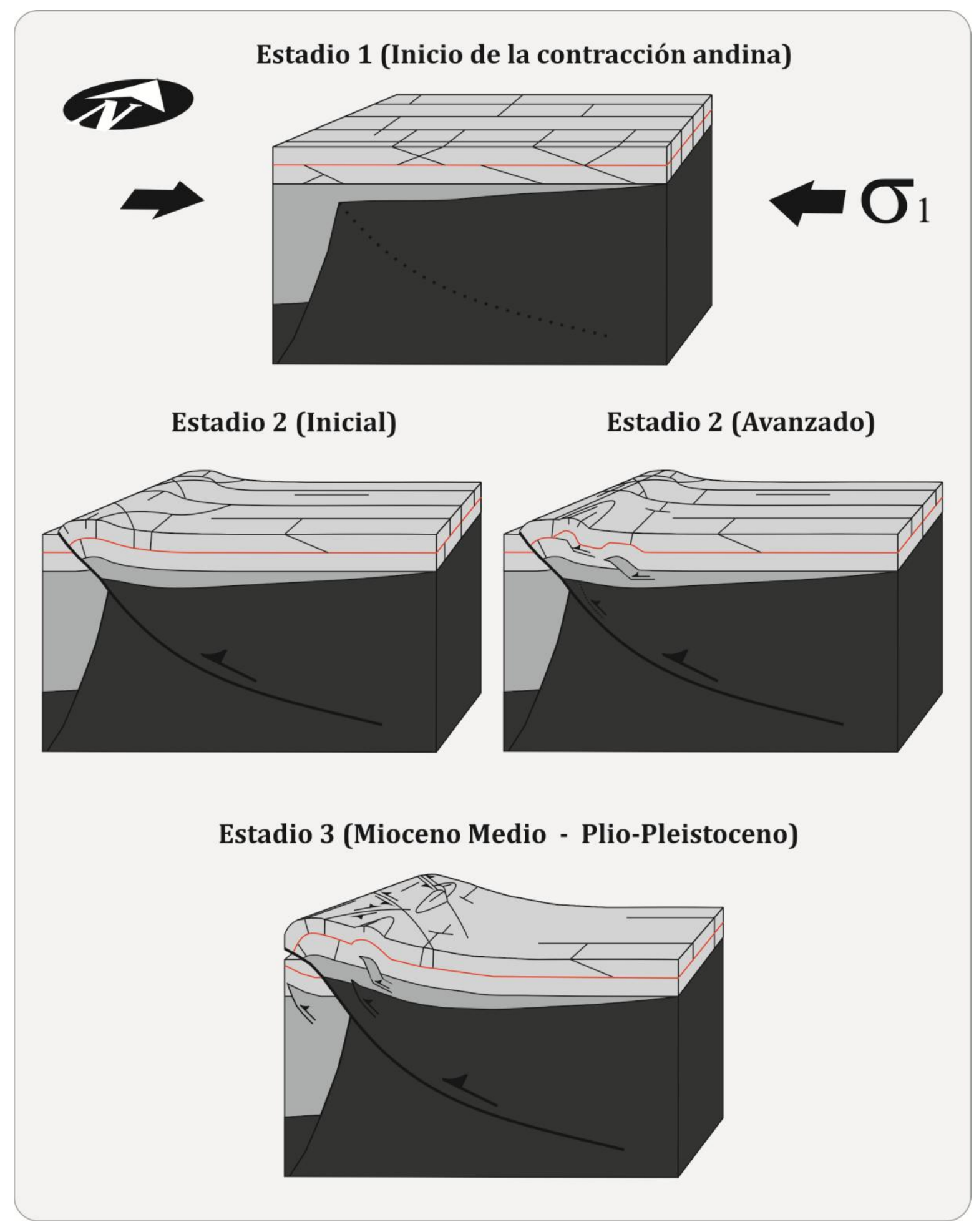

FIGURA 6.11. Evolución estructural del anticlinal Tin Tin. 
Un punto importante sobre los depósitos de antepaís es que han sido estudiados por muchos autores que, mediante trabajos estratigráficos, sedimentológicos y estructurales de gran escala, han podido determinar los episodios de deformación andinos (Hongn et al., 2008; Carrapa et al., 2012; Payrola Bosio et al., 2012; del Papa et al., 2013a, 2013b; Galli et al., 2014). El Grupo Payogastilla en la zona de Valles Calchaquíes registra los diferentes episodios de deformación que ocurrieron durante el Cenozoico, a través de discordancias entre sus unidades constituyentes (Hongn et al., 2008). Un estudio estructural de detalle, como el propuesto en este trabajo, sobre las unidades del antepaís permitiría identificar y caracterizar los eventos de deformación con mayor precisión ya que se cuenta con dataciones de la deformación (edades de discordancias, edades termocronológicas) publicadas por los autores mencionados. Un estudio de tales características aportaría un marco temporal preciso a la evolución estructural y dinámica de cada estructura en particular. En el caso del anticlinal Tin Tin, el estudio de la mesoestructuración de las unidades del Grupo Payogastilla que afloran en el sur del cerro Tin Tin (véase Figura 4.1) podrían potencialmente: a) acotar las edades de deformación del anticlinal y b) ubicar con edades relativamente precisas los diferentes estadios de deformación de mesoescala (plegamiento y fallamiento en los flancos, fracturación de las rocas) dentro del anticlinal, además de poder realizar una comparación entre los procesos de deformación de los Grupos Salta y Payogastilla. Este tipo de estudio realizado sobre diferentes estructuras aportaría mayor precisión en el conocimiento de la dinámica de la cuenca de antepaís y de la inversión tectónica de la región.

Como se puede notar, el segundo estadio de deformación abarca gran parte de la evolución del anticlinal (Figura 6.11). Estudios de detalle sobre otros anticlinales relacionados a basamento podrían arrojar resultados que generen nuevas divisiones en las etapas de deformación propuestas en este trabajo. Por ejemplo, la activación de la falla inversa de bajo ángulo con transporte hacia el Noroeste que afecta al sector Sur del anticlinal (véanse Figuras 4.17 y 4.19). Esta falla (y sus estructuras asociadas) podría haberse formado durante una etapa tardía del segundo estadio de deformación propuesto ya que corta capas oblicuas, indicando que el anticlinal ya presentaba una 
inmersión con algún grado de desarrollo, o podría haberse formado durante el tercer estadio de deformación, mientras que en el sector central del cerro se estaban desarrollando las fallas de rumbo.

Se mencionó al principio del capítulo 4 (véase página 44) que el anticlinal Tin Tin podría ser clasificado como un pliegue forzado debido a su clara relación genética con el basamento (miembro forzante inferior), siguiendo la línea de muchos autores que han tratado con estos tipos de pliegues (Stearns, 1978; Ameen, 1992; Cosgrove y Ameen, 1999). Este tipo de pliegues forzados invocan el proceso de bending, donde el esfuerzo compresivo máximo es aplicado a altos ángulo de la estratificación (Price y Cosgrove, 1990). Basándose en el conjunto total de estructuras que conforman el anticlinal Tin Tin se puede concluir que esta definición es parcialmente correcta, ya que los datos indican que el anticlinal se formó por una combinación de los fenómenos de buckling y bending, como ocurre en la mayoría de los pliegues naturales (Ismat, 2008b). Una característica de los pliegues forzados "puros" es que la deformación se concentra altamente en las cercanías de la falla (Cosgrove y Ameen, 1999; Ismat, 2008b), situación que no se presenta en el anticlinal Tin Tin (Figura 6.5), además de que las características del primer estadio de deformación con el proceso de acortamiento paralelo a la capa, no son compatibles con este tipo de pliegue. Por lo tanto se puede decir, a modo general, que el anticlinal Tin Tin inició su desarrollo dentro del marco del buckling donde se produjo gran parte de la deformación en los flancos (Paleógeno), y adquirió su formal final a través del mecanismo de bending (Neógeno).

En general se puede concluir que durante la conformación y crecimiento del anticlinal en su conjunto (evolución estructural), los mecanismos que ya no pueden acomodar más deformación o cambiar la geometría del pliegue, dejan de actuar y cambian a mecanismos más adecuados para continuar con el evento deformacional. No solo los mecanismos cambian con el tiempo sino que varían con la posición estructural (Gutiérrez-Alonso y Gross, 1999; Guiton et al., 2003). 


\subsection{Estilos de inversión tectónica en el extremo Sur de la Cordillera Oriental}

La inversión tectónica en el extremo Sur de la cordillera oriental plantea básicamente dos hipótesis, la reactivación inversa de las fallas normales de la cuenca del Grupo Salta que se generaron en el basamento pre-cretácico (Grier et al., 1991; Cristallini et al., 1997; Kley et al., 2005; Carrera et al., 2006; Monaldi et al., 2008; Carrera y Muñoz, 2013) y la reactivación inversa de heterogeneidades del basamento, que a su vez facilitaron la nucleación de las fallas normales del rift (Hongn et al., 2007, 2010, 2011). Ambos casos son mecanismos conocidos y aceptados como generadores de fajas plegadas y corridas de piel gruesa (Butler, 1989; Cooper et al., 1989; Hayward y Graham, 1989; Williams et al., 1989; Letouzey et al., 1990; Brown et al., 1999; Butler et al., 2006; Scisciani, 2009).

El área del cerro Tin Tin constituye una parte del extremo Sur del alto o dorsal Salto-Jujeña, donde los depósitos de sinrift del Grupo Salta son escasos a nulos y los depósitos de postrift yacen directamente sobre los extensos afloramientos del basamento (Este del cerro Tin Tin hacia la zona del cerro Malcante, véase Figura 4.2). Mas precisamente, el cerro Tin Tin representa uno de los "hombros" de un depocentro que se encuentra ubicado inmediatamente hacia el Oeste (Carrera y Muñoz, 2013), ya que el anticlinal contiene escasos depósitos de sinrift (en relación al depocentro). Hacia el Oeste del cerro, y principalmente hacia el Sur y Sureste se pueden observar potentes depósitos de sinrift en el área que forma parte de la subcuenca de Alemanía (Monaldi, 2001; Sabino, 2004; Carrera y Muñoz, 2013).

La inversión tectónica (acortamiento) en el área del anticlinal Tin Tin (zona de dorsal o alto estructural) se produjo a través de la generación de fallas inversas de mediano a bajo ángulo en el basamento (cuñas de basamento) con transporte occidental, como preferencia a la reactivación inversa de fallas normales, que en ocasiones fueron truncadas por los mismos corrimientos, tal como ocurre con la Falla directa Pakaskka propuesta por Carrera y Muñoz (2013) y en otros ejemplo mundiales (Butler, 1989; Hayward y Graham, 1989; Butler et al., 2006; Scisciani, 2009). Este comportamiento podría extrapolarse a los bloques de basamento al Este 
del sector (zona del cerro Malcante; véase Figuras 1.3 y 4.2), que también corresponden a la dorsal Salto-Jujeña, donde no hubo depositación del Subgrupo Pirgua. Previamente a la generación de fallas inversas, en el inicio de la contracción de antepaís, el acortamiento habría sido absorbido por la cobertura sedimentaria. Cabe destacar que el bloque colgante de las fallas inversas principales, que pueden o no conformar los núcleos de pliegues anticlinales, puede ser un bloque único o un apilamiento de láminas de basamento.

Hacia el Sur y Sureste del anticlinal Tin Tin, en la zona del centro de la subcuenca, existen evidencias para concluir que el fenómeno de reactivación inversa de antiguas fallas normales fue efectivo (Grier et al., 1991; Carrera y Muñoz, 2008, 2013). Carrera y Muñoz (2013), en la cercanías de la localidad de Alemanía, observaron pliegues y fallas extensionales en el basamento con un rumbo consistente N-S, e interpretaron gran parte de la estructuración como producto de la inversión y reactivación de fallas normales, aunque también sugieren la reactivación de anisotropías del basamento.

Es importante la discusión sobre la posibilidad de generación de fallas inversas nuevas para los casos donde el basamento se encuentra aflorando, como ocurre en la serranía de La Batea, al Oeste del Cerro Bayo (véase Figura 1.3), ya que una reactivación inversa de una falla normal requeriría un grado de inversión muy grande para eliminar su punto nulo (Cooper et al., 1989).

A modo general, toda la región en cuestión presenta características de un sistema corrido y plegado de piel gruesa, con presencia de estructuras (anticlinales y sinclinales) discontinuas relacionadas con el basamento subyacente, que fragmentan y estructuran el antepaís andino del Noroeste argentino (Siks y Horton, 2011; Strecker et al., 2011; del Papa et al., 2013b; Tesón et al., 2013), en contraposición a los sistemas de fajas plegadas y corridas de piel fina donde los pliegues (asociados a rampas) adquieren mayor continuidad y transporte tectónico, como son las Sierras Subandinas (Echavarria et al., 2003; Poblet et al., 2008; Hernández y Echavarria, 2009). Esta característica de antepaís fragmentado resulta ser común en los sistemas de antepaís 
andinos, donde el basamento ejerce una influencia muy importante en su estructuración (Mosquera y Ramos, 2006; Orts et al., 2012; Bilmes et al., 2013; Dávila y Carter, 2013; Sagripanti et al., 2014).

\subsection{Fracturación de la Formación Yacoraite como reservorio de hidrocarburos.}

La permeabilidad de los reservorios naturalmente fracturados depende en gran parte de la geometría de los sistemas de fracturas, los cuales son determinados por los eventos tectónicos que deformaron una región en particular (Stearns y Friedman, 1972; Nelson, 2001). La Formación Yacoraite del Subgrupo Balbuena (Grupo Salta) es una de las unidades más típicas del Noroeste argentino, de amplia distribución regional y fácil reconocimiento en superficie por los característicos colores amarillentos de las rocas calcáreas que la conforman, y en subsuelo por su contraste litológico y su disposición tabular (Disalvo et al., 2002; Starck, 2011; Grosso et al., 2013). La importancia económica que presenta la Formación Yacoraite debido a su carácter de roca madre y reservorio de hidrocarburos (Starck, 2011) ha determinado que sea el intervalo estratigráfico más estudiado del Grupo Salta (Marquillas et al., 2005, 2007; Hernández et al., 1999, 2008; Starck, 2011; entre otros).

Las fracturas que afectan a la Formación Yacoraite son importantes en otros sectores de la cuenca del Grupo Salta ya que se relacionan a la porosidad secundaria de algunos reservorios de hidrocarburos (Disalvo et al., 2002). El yacimiento Caimancito, ubicado en la provincia de Jujuy dentro del ámbito de las Sierras Subandinas, es uno de los reservorios más importantes de la Formación Yacoraite y constituye un reservorio naturalmente fracturado dentro de la subcuenca de Lomas de Olmedo, rama oriental de la cuenca extensional cretácico-paleógena del Grupo Salta (Disalvo et al., 2002; Grosso et al., 2011, 2013). La trampa estructural de este reservorio es un braquianticlinal de rumbo N-S, con fallamiento inverso en los flancos y fallamiento directo en la cresta (Grosso et al., 2011, 2013). El estudio de fracturas de esta zona, tanto en superficie (Serranía de Calilegua, análogo en superficie del

yacimiento Caimancito) como en subsuelo, sugiere tres direcciones principales de fracturación, E-W, NW-SE y N-S, de alta inclinación con respecto a la capa que las 
contiene. Las primeras se encuentran abiertas al orientarse con el campo de esfuerzos actual (constatado por breakout de pozos). El set N-S se encuentra preferencialmente cerrado (Grosso et al., 2011, 2013). No se menciona un estudio sobre la evolución del anticlinal, lo que daría un aspecto importante en la comparación de los sistemas de fracturas asociados a la cinemática del pliegue. Este estudio también menciona estructuras estilolíticas subhorizontales y una mayor cantidad de fracturas con el aumento del contenido carbonático, característica inferida pero no determinada con precisión en el anticlinal Tin Tin.

En otros reservorios de la Formación Yacoraite dentro del ámbito de las Sierras Subandinas (yacimiento Valle Morado) se realizaron estudios de predicción de fracturas usando análisis de curvatura sobre la trampa estructural anticlinal del yacimiento, de orientación NNE-SSW (Masaferro et al., 2003). Sus resultados muestran una buena correlación entre las zonas de máxima curvatura y máxima intensidad de fracturación con el eje del anticlinal. Estos modelos predictivos también tienen buenos resultados en modelos análogos y numéricos en relación a la deformación en las charnelas de superficies plegadas (Likerman y Cristallini, 2012).

Un estudio de fracturas relacionadas a un anticlinal se realizó sobre la Formación Yacoraite en la subcuenca de Tres Cruces, dentro del ámbito de la Cordillera Oriental (Likerman et al., 2011). Los autores mencionan cinco direcciones preferenciales de fracturación: E-W, N-S, NE-SW, NW-SE y ESE-WNW. El set de fracturas E-W es interpretado como fracturas de tensión desarrolladas en forma paralela al esfuerzo principal $\sigma 1$, siendo las más antiguas y primeras en formarse (en base a sus relaciones de corte) durante los primeros estadios de formación del pliegue. El set $\mathrm{N}-\mathrm{S}$ es interpretado como fracturas tensionales posteriores relacionadas al curvamiento de la estructura durante un estado más avanzado del pliegue. Los sets NE-SW, NW-SE y ESE-WNW son interpretados como fracturas de cizalla y se enmarcan dentro del campo de esfuerzos andinos, relacionadas con la evolución del pliegue. 
Los datos de fracturación obtenidos sobre el anticlinal Tin Tin y los datos y descripciones aportadas por otros autores permiten concluir, a modo general, que en diferentes ámbitos de la cuenca del Grupo Salta, la Formación Yacoraite presenta fracturas con orientación E-W formadas paralelamente al esfuerzo principal máximo $\sigma 1$ en los primeros estadios de contracción horizontal andina. Estas fracturas se encuentran abiertas debido a su orientación y serian buenas conductoras de fluidos (en el caso de diaclasas) debido a sus longitudes relativamente mayores y buena continuidad. Este primer set se encuentra conectado por fracturas de orientación perpendicular, de rumbo N-S. Este set se describe como cerrado en base a su orientación, pero sus fracturas podrían encontrarse abiertas si forman parte de una capa arqueada (convexa hacia arriba). Las fracturas oblicuas a las direcciones anteriores requieren de especial atención ya que en general son las que presentan mayores dificultades en su interpretación. A partir de esto surge la necesidad de los estudios geológicos de estructuras en superficie como análogos a los yacimientos en subsuelo (Antonellini y Mollema, 2000; Hennings et al., 2000; Lavenu et al., 2013). Con estos estudios se puede constatar muchas características de los sistemas de fracturas, principalmente las relacionadas a su origen (apertura o cizalla), que en subsuelo en general se infieren a partir de su geometría o estadística (Nelson, 2001). Igual de importarte es la relación entre los sistemas de fracturas y la geometría y cinemática de la estructura que las contiene. Los estudios de superficie aportan elementos para comprender los procesos de deformación que tuvieron lugar en la estructuración de una zona, evidencias que muchas veces presentan escalas subsísmicas e impiden la correcta interpretación de la estructuras en el subsuelo. 


\section{CAPÍTULO 7 CONCLUSIONES}




\section{CAPITULO 7 - CONCLUSIONES}

La fracturación pervasiva del basamento, que presenta diversas orientaciones, es la que posibilita el fallamiento inverso que genera los anticlinales y bloques de basamento principales, y las fallas inversas dentro de estos últimos. La Falla Tin Tin es una falla generada por el deslizamiento de una cuña de basamento sobre un plano de debilidad (zona de fracturación).

La Formación Puncoviscana, núcleo del anticlinal Tin Tin y basamento de esta parte de la cuenca, presenta pliegues con dirección E-W, diferencia fundamental con las descripciones generales (pliegues con dirección N-S) en otros sectores del Noroeste argentino.

Las superficies axiales de pliegues con rumbo E-W en la Formación Puncoviscana constituyen planos de debilidad que pueden ser reactivados efectivamente, con el consecuente movimiento de bloques menores dentro del basamento (movimiento vertical: Fallas inversas de alto ángulo; movimiento horizontal: Fallas de rumbo). De esta forma, el basamento ejerce una influencia importante en la estructuración de la cobertura sedimentaria.

La falla NW-SE sinestral que atraviesa el anticlinal Tin Tin en el sector Norte del cerro, actuó cuando el anticlinal se encontraba relativamente formado. Esta falla presenta condiciones de deformación diferentes a la Falla Tin Tin, caracterizada por foliación con planos sintéticos a la orientación de la falla sinestral, a diferencia del brechamiento de la Falla Tin Tin.

El anticlinal Tin Tin presenta una fuerte deformación de mesoescala en todas sus posiciones estructurales (flanco dorsal principalmente). Esta deformación consta de fracturas de mesoescala, pliegues y fallas, con orientaciones paralelas, oblicuas y subperpendiculaes al eje de pliegue del anticlinal.

Los pliegues y fallas afectan a las tres unidades del Grupo Salta, repitiendo parte de la secuencia sedimentaria y aumentando su espesor. Esta deformación ocurrió relativamente antes del levantamiento y crecimiento principal del anticlinal Tin Tin. 
Los extremos de inmersión del anticlinal Tin Tin (terminación y hundimiento del basamento) constituyen sitios donde los esfuerzos regionales son localmente anómalos, generando su convergencia hacia los extremos laterales de la falla.

Las fracturas de mesoescala de los anticlinales Tin Tin y Cerro Bayo se formaron como consecuencia de los esfuerzos compresivos andinos. Son mayormente diaclasas subverticales y presentan un orden secuencial en su formación. En el anticlinal Tin Tin las diaclasas se dividen en cuatro grandes grupos: Las subperpendiculares (rumbos ENE-WSW, E-W y ESE-WNW) al eje de pliegue del anticlinal se formaron relativamente primero. Los dos grupos de diaclasas oblicuos (NE-SW y NW-SE aproximadamente) se formaron posteriormente. El último grupo en formase son las diaclasas subparalelas (rumbos NNW-SSE, N-S, NNE-SSW) al eje de pliegue del anticlinal. Todas las diaclasas se relacionan a los primeros estadios de plegamiento de anticlinal Tin Tin.

Se propone una evolución estructural de tres estadios de deformación para el anticlinal Tin Tin. 1) Los esfuerzos compresivos de dirección aproximada E-W actúan sobre capas subhorizontales en el inicio de la contracción andina. Se forman diaclasas paralelas a los esfuerzos (subperpendiculares al futuro eje de pliegue) y fracturas de cizalla de bajo ángulo de inclinación. 2) Estado inicial: Levantamiento inicial del basamento. Se forman las diaclasas oblicuas al eje de plegamiento. Con el avance de la deformación se forman los pliegues y fallas inversas que acortan y repiten parte de la cobertura sedimentaria. También se forman las diaclasas paralelas al eje de pliegue del anticlinal Tin Tin. Estado avanzado: Se producen las fallas que afectan el núcleo de basamento (inversa y de rumbo sinestral) y el levantamiento general del cerro, con el volcamiento parcial del flanco dorsal. 3) Se produce la reactivación de fracturas con movimiento de rumbo en algunos sectores del pliegue, para continuar con el acortamiento y acomodar mayor deformación. La generación principal de mesoestructuras (fracturas, pliegues y fallas) que deforman el anticlinal Tin Tin (mayormente su flanco dorsal) ocurre durante el lapso entre el Eoceno Medio y Mioceno Inferior a Medio. Durante el lapso entre el 
Mioceno Medio y el Plio-Pleistoceno ocurre la exhumación principal del anticlinal Tin Tin debido a la actividad de la Falla Tin Tin.

El anticlinal Tin Tin se formó por una combinación de los fenómenos de buckling y bending. El anticlinal inició su desarrollo dentro del marco del buckling donde se produjo gran parte de la deformación en los flancos, y adquirió su formal final a través del mecanismo de bending. Los mecanismos de deformación cambian en el tiempo y también con la posición estructural del anticlinal, en orden de producir una deformación más eficiente.

Las condiciones de plegamiento del anticlinal Cerro Bayo son diferentes a las del anticlinal Tin Tin, principalmente por presentar el basamento a mayor profundidad y no estar influenciado por sus características. Este anticlinal presenta principalmente deformación de flanco frontal, con fallas inversas, pliegues gravitacionales y fracturas reactivadas, como resultado de acomodación de la deformación (problemas de espacio de acomodación de deformación).

La deformación general de la zona de estudio comenzó con una estructuración de piel fina (involucrando sólo cobertura sedimentaria) antes del levantamiento principal de los bloques de basamento (deformación de piel gruesa). El anticlinal Tin Tin se formó dentro de un campo de esfuerzos relativamente homogéneo pero con fluctuaciones locales propias de la evolución particular de la estructura.

La inversión tectónica en el extremo Sur del la provincia geológica Cordillera Oriental constó de la generación de estructuras nuevas (mayormente en la zona de alto o dorsal) y de la reactivación inversa de antiguas fallas normales pertenecientes al rift cretácico (mayormente en la zona de cuenca).

Los sistemas de fracturas en la Formación Yacoraite comparten características similares (geométricas y cronológicas) en diferentes sectores de la cuenca del Grupo Salta. Estos sistemas se formaron bajo un campo de esfuerzos uniforme a escala regional pero fluctuante a escala local. Las fracturas de dirección E-W en general se encuentran abiertas y son importantes como conductores de fluidos en los reservorios naturalmente fracturados. El trabajo estructural de 
campo es imprescindible en la interpretación de procesos y génesis de fracturas, en comparación a los estudios de subsuelo que no aportan datos claros en estos aspectos. 


\section{BIBLIGRAFÍA}

Allmendinger, R.W., Ramos, V.A., Jordan, T.E., Palma, M., Isacks, B.L., 1983. Paleogeography and Andean structural geometry, northwest Argentina. Tectonics 2, 1-16.

Ameen, M.S., 1992. Strain pattern in the Purbeck-Isle of Wight Monocline: A case study of folding due to dip-slip fault in the basement. En: Bartholomew, M., Hyndman, D., Mogk, D., Mason, R. (Editores), Basement Tectonics 8. Springer Netherlands, 559-578.

Ameen, M.S. (Editor), 2003. Fracture and In-Situ Stress Characterization of Hydrocarbon Reservoirs. Geological Society, London, Special Publications 209.

Antonellini, M., Mollema, P.N., 2000. A Natural Analog for a Fractured and Faulted Reservoir in Dolomite: Triassic Sella Group, Northern Italy. AAPG Bulletin 84, 314-344.

Apotria, T.G., 1995. Thrust sheet rotation and out-of-plane strains associated with oblique ramps: An example from the Wyoming salient U.S.A. Journal of Structural Geology 17, 647-662.

Apotria, T., Wilkerson, M.S., 2002. Seismic expression and kinematics of a fault-related fold termination: Rosario structure, Maracaibo Basin, Venezuela. Journal of Structural Geology 24, 671-687.

Aramayo, A., Payrola Bosio, P., del Papa, C.E., Hongn, F.D., 2012. Análisis de proveniencia de la Formación Quebrada de los Colorados (Eoceno medio-Oligoceno?) en el valle de Pucará, Salta: Implicancias en la cuenca de antepaís andina. En: $13^{\circ}$ Reunión Argentina de Sedimentología, 7-8.

Aydin, A., 2000. Fractures, faults, and hydrocarbon entrapment, migration and flow. Marine and Petroleum Geology 17, 797-814.

Bahat, D., Rabinovitch, A., Frid, V., 2005. Tensile Fracturing in Rocks. Tectonofractographic and Electromagnetic Radiation Methods. Springer Berlin/Heidelberg, Germany.

Beaudoin, N., Leprêtre, R., Bellahsen, N., Lacombe, O., Amrouch, K., Callot, J.-P., Emmanuel, L., Daniel, J.-M., 2012. Structural and microstructural evolution of the Rattlesnake Mountain Anticline (Wyoming, USA): New insights into the Sevier and Laramide orogenic stress build-up in the Bighorn Basin. Tectonophysics 576-577, 20-45.

Becker, A., Gross, M.R., 1996. Mechanism for joint saturation in mechanically layered rocks: an example from southern Israel. Tectonophysics 257, 223-237.

Belayneh, M., Cosgrove, J.W., 2004. Fracture-pattern variations around a major fold and their implications regarding fracture prediction using limited data: an example from the Bristol Channel Basin. En: Cosgrove, J. W. y Engelder, T. (Editores), The Initiation, Propagation, and Arrest of Joints and Other Fractures. Geological Society, London, Special Publications 231, 89-102. 
Bellahsen, N., Fiore, P., Pollard, D.D., 2006. The role of fractures in the structural interpretation of Sheep Mountain Anticline, Wyoming. Journal of Structural Geology 28, 850-867.

Bilmes, A., D’Elia, L., Franzese, J.R., Veiga, G.D., Hernández, M., 2013. Miocene block uplift and basin formation in the Patagonian foreland: The Gastre Basin, Argentina. Tectonophysics 601, 98-111.

Brown, D., Alvarez-Marron, J., Perez-Estaun, A., Puchkov, V., Ayala, C., 1999. Basement influence on foreland thrust and fold belt development: an example from the southern Urals. Tectonophysics 308, 459-472.

Butler, R.W.H., 1989. The influence of pre-existing basin structure on thrust system evolution in the Western Alps. En: Cooper, M.A., Williams, G.D. (Editores), Inversion tectonics. Geological Society, London, Special Publications 44, 105-122.

Butler, R.W.H., Tavarnelli, E., Grasso, M., 2006. Structural inheritance in mountain belts: An Alpine-Apennine perspective. Journal of Structural Geology 28, 1893-1908.

Carrapa, B., Trimble, J.D., Stockli, D.F., 2011. Patterns and timing of exhumation and deformation in the Eastern Cordillera of NW Argentina revealed by (U-Th)/He thermochronology. Tectonics 30, TC3003.

Carrapa, B., Bywater-Reyes, S., DeCelles, P.G., Mortimer, E., Gehrels, G.E., 2012. Late EocenePliocene basin evolution in the Eastern Cordillera of northwestern Argentina $\left(25^{\circ}-26^{\circ} \mathrm{S}\right)$ : regional implications for Andean orogenic wedge development. Basin Research 24, 249268.

Carrera, N., Muñoz, J.A., Sàbat, F., Mon, R., Roca, E., 2006. The role of inversion tectonics in the structure of the Cordillera Oriental (NW Argentinean Andes). Journal of Structural Geology 28, 1921-1932.

Carrera, N., Muñoz, J.A., 2008. Thrusting evolution in the southern Cordillera Oriental (northern Argentine Andes): Constraints from growth strata. Tectonophysics 459, 107122.

Carrera, N., Muñoz, J.A., Roca, E., 2009. 3D reconstruction of geological surfaces by the equivalent dip-domain method: An example from field data of the Cerro Bayo Anticline (Cordillera Oriental, NW Argentine Andes). Journal of Structural Geology 31, 1573-1585.

Carrera, N., Muñoz, J.A., 2013. Thick-skinned tectonic style resulting from the inversion of previous structures in the southern Cordillera Oriental (NW Argentine Andes). En: Nemčok, M., Mora, A., Cosgrove, J.W. (Editores), Thick-Skin-Dominated Orogens: From Initial Inversion to Full Accretion. Geological Society, London, Special Publications 377, 77-100.

Casas, J.M., Muñoz, J.A., 1987. Sequences of mesostructures related to the development of Alpine thrusts in the Eastern Pyrenees. Tectonophysics 135, 67-75. 
Chase, R.B., Schmidt, C.J., Genovese, P.W., 1993. Influence of Precambrian rock compositions and fabrics on the development of Rocky Mountain foreland folds. En: Schmidt, J., Chase, R.B., Erslev, E.A. (Editores), Laramide Basement Deformation in the Rocky Mountain Foreland of the Western United States. Geological Society of America Special Papers 280 , 45-72.

Cooper, M.A., Williams, G.D., de Graciansky, P.C., Murphy, R.W., Needham, T., de Paor, D., Stoneley, R., Todd, S.P., Turner, J.P., Ziegler, P.A., 1989. Inversion tectonics - a discussion. En: Cooper, M.A., Williams, G.D. (Editores), Inversion tectonics. Geological Society, London, Special Publications 44, 335-347.

Cooper, S.P., Goodwin, L.B., Lorenz, J.C., 2006. Fracture and fault patterns associated with basement-cored anticlines: The example of Teapot Dome, Wyoming. AAPG Bulletin 90, 1903-1920.

Cooper, M., 2007. Structural style and hydrocarbon prospectivity in fold and thrust belts: a global review. En: Ries, A.C, Butler, R.W.H., Graham, R.H. (Editores), Deformation of the Continental Crust: The Legacy of Mike Coward. Geological Society, London, Special Publications 272, 447-472.

Cosgrove, J.W., Ameen, M.S., 2000. A comparison of the geometry, spatial organization and fracture patterns associated with forced folds and buckle folds. En: Cosgrove, J.W., Ameen, M.S. (Editores), Forced Folds and Fractures. Geological Society, London, Special Publications 169, 7-21.

Couples, G.D., Lewis, H., Geoff Tanner, P.W., 1998. Strain partitioning during flexural-slip folding. En: Coward, M.P., Daltaban, T.S., Johnson, H. (Editores), Structural Geology in Reservoir Characterization. Geological Society, London, Special Publications 127, 149165.

Couples, G.D., Lewis, H., 1999. Effects of interlayer slip in model forced folds. En: Cosgrove, J.W., Ameen, M.S. (Editores), Forced Folds and Fractures. Geological Society, London, Special Publications 169, 129-144.

Cristallini, E., Cominguez, A.H., Ramos, V., 1997. Deep structure of the Metan-Guachipas region: tectonic inversion in Northwestern Argentina. Journal of South American Earth Sciences 10, 403-421.

Cristallini, E., Ramos, V., 2000. Thick-skinned and thin-skinned thrusting in the La Ramada fold and thrust belt: crustal evolution of the High Andes of San Juan, Argentina (32 $\left.{ }^{\circ} \mathrm{SL}\right)$. Tectonophysics 317, 205-235.

Dávila, F.M., Carter, A., 2013. Exhumation history of the Andean broken foreland revisited. Geology 41, 443-446.

DeCelles, P.G., Carrapa, B., Horton, B.K., Gehrels, G.E., 2011. Cenozoic foreland basin system in the central Andes of northwestern Argentina: Implications for Andean geodynamics and modes of deformation. Tectonics 30, TC6013. 
Deeken, A., Sobel, E.R., Coutand, I., Haschke, M., Riller, U., Strecker, M.R., 2006. Development of the southern Eastern Cordillera, NW Argentina, constrained by apatite fission track thermochronology: From early Cretaceous extension to middle Miocene shortening. Tectonics 25, TC6003.

Del Papa, C.E., Hongn, F.D., Petrinovic, I.A., Domínguez, R., 2004. Evidencias de deformación pre-miocena media asociada al antepaís andino en la Cordillera Oriental $\left(24^{\circ} 35^{\prime} \mathrm{S}\right.$ 66²12' 0). Revista de la Asociación Geológica Argentina 59, 506-509.

Del Papa, C.E., Hongn, F.D., Payrola Bosio, P.A., Powell, J., Deraco, V., Herrera, C., 2013a. Relaciones estratigráficas de las formaciones Quebrada de los Colorados y Angastaco (Paleógeno-Neógeno), Valles Calchaquíes, Salta (Argentina): Significado en el análisis de la cuenca del Grupo Payogastilla. Latin American journal of Sedimentology and Basin Analysis 20, 51-64.

Del Papa, C.E., Hongn, F.D., Powell, J., Payrola Bosio, P., Do Campo, M., Strecker, M.R., Petrinovic, I., Schmitt, A.K., Pereyra, R., 2013b. Middle Eocene-Oligocene broken-foreland evolution in the Andean Calchaqui Valley, NW Argentina: insights from stratigraphic, structural and provenance studies. Basin Research 25, 574-593.

Del Ventisette, C., Montanari, D., Sani, F., Bonini, M., 2006. Basin inversion and fault reactivation in laboratory experiments. Journal of Structural Geology 28, 2067-2083.

Dewey, J.F., Lamb, S.H., 1992. Active tectonics of the Andes. Tectonophysics 205, 79-95.

Díaz, J., Malizzia, D., 1983. Estudio Geológico y sedimentológico del Terciario Superior del Valle Calchaquí (departamento de San Carlos, Salta). Boletín Sedimentológico 2, 2-28.

Disalvo, A., Rodriguez Schelotto, M.L., Gomez Omil, R., Hoffman, C., Benitez, J., Hurtado, S., 2002. Los reservorios de la Formación Yacoraite. En: Schiuma, M., Hinterwimmer, G., Vergani, G. (Editores), Rocas Reservorios de Las Cuencas Productivas de La Argentina. $5^{\circ}$ Congreso de Exploración Y Desarrollo de Hidrocarburos. 717-738.

Disalvo, A., 2002. Cuenca del noroeste: Marco geológico y reseña histórica de la actividad petrolera. En: Schiuma, M., Hinterwimmer, G., Vergani, G. (Editores), Rocas Reservorios de Las Cuencas Productivas de La Argentina. $5^{\circ}$ Congreso de Exploración Y Desarrollo de Hidrocarburos, 663-681.

Dixon, J.M., Spratt, D.A., 2004. Deformation at Lateral Ramps and Tear Faults - Centrifuge Models and Examples from the Canadian Rocky Mountain Foothills. En: McClay, K. (Editor), Thrust Tectonics and Hydrocarbon Systems. AAPG Memoir 82, 239-258.

Dyer, R., 1988. Using joint interactions to estimate paleostress ratios. Journal of Structural Geology 10, 685-699.

Echavarria, L., Hernández, R., Allmendinger, R., Reynolds, J., 2003. Subandean thrust and fold belt of northwestern Argentina: Geometry and timing of the Andean evolution. AAPG Bulletin 87, 965-985. 
Emami, H., Vergés, J., Nalpas, T., Gillespie, P., Sharp, I., Karpuz, R., Blanc, E.P., Goodarzi, M.G.H., 2010. Structure of the Mountain Front Flexure along the Anaran anticline in the Pusht-e Kuh Arc (NW Zagros, Iran): insights from sand box models. En: Leturmy, P., Robin, C. (Editores), Tectonic and Stratigraphic Evolution of Zagros and Makran during the Mesozoic-Cenozoic. Geological Society, London, Special Publications 330 , 155-178.

Engelder, T., 1985. Loading paths to joint propagation during a tectonic cycle: an example from the Appalachian Plateau, U.S.A. Journal of Structural Geology 7, 459-476.

Engelder, T., 1987. Joints and shear fractures in rock. En: Atkinson, B.K. (Editor), Fracture Mechanics of Rocks. Academic Press, London, 27-69.

Engelder, T., Geiser, P., 1980. On the Use of Regional Joint Sets as Trajectories of Paleostress Fields During the Development of the Appalachian Plateau, New York. Journal of Geophysical Research 85, 6319-6341.

Engelder, T., Peacock, D.C.P., 2001. Joint development normal to regional compression during flexural-flow folding: the Lilstock buttress anticline, Somerset, England. Journal of Structural Geology 23, 259-277.

Eyal, Y., Gross, M.R., Engelder, T., Becker, A., 2001. Joint development during fluctuation of the regional stress field in southern Israel. Journal of Structural Geology 23, 279-296.

Fischer, M.P., Christensen, R.D., 2004. Insights into the growth of basement uplifts deduced from a study of fracture systems in the San Rafael monocline, east central Utah. Tectonics 23, TC1018.

Fischer, M.P., Wilkerson, M.S., 2000. Predicting the orientation of joints from fold shape: Results of pseudo-three-dimensional modeling and curvature analysis. Geology 28, 1518.

Friedman, M., 1969. Structural Analysis of Fractures in Cores from Saticoy Field, Ventura County, California. AAPG Bulletin 53, 367-389.

Friedman, M., Stearns, D.W., 1971. Relations between Stresses Inferred from Calcite Twin Lamellae and Macrofractures, Teton Anticline, Montana. Geological Society of America Bulletin 82, 3151-3162.

Galli, C.I., Ramírez, A., Reynolds, J., Viramonte, J.G., Idleman, B., Barrientos, C., 2011. Procedencia de los depósitos del Grupo Payogastilla (Cenozoico), río Calchaquí, provincia de Salta. Revista de la Asociación Geológica Argentina 68, 261-276.

Galli, C.I., Coira, B., Alonso, R., Reynolds, J., Matteini, M., Hauser, N., 2014. Tectonic controls on the evolution of the Andean Cenozoic foreland basin: Evidence from fluvial system variations in the Payogastilla Group, in the Calchaquí, Tonco and Amblayo Valleys, NW Argentina. Journal of South American Earth Sciences 52, 234-259.

Galliski, M.A., Viramonte, J.G., 1988. The Cretaceous paleorift in northwestern Argentina: A petrologic approach. Journal of South American Earth Sciences 1, 329-342. 
González, R.E., 2001. Cenozoico Sedimentario de la Cordillera Oriental. En: Hongn, F.D., Seggiaro, R.E. (Editores), Hoja Geológica 2566-III, Cachi. Provincias de Salta y Catamarca. Instituto de Geología y Recursos Minerales, Servicio Geológico Minero Argentino. Boletín 248: 20-23. Buenos Aires.

Grier, M.E., Dallmeyer, R.D., 1990. Age of the Payogastilla Group: Implications for foreland basin development, NW Argentina. Journal of South American Earth Sciences 3, 269-278.

Grier, M.E., Salfity, J.A., Allmendinger, R.W., 1991. Andean reactivation of the Cretaceous Salta rift, northwestern Argentina. Journal of South American Earth Sciences 4, 351-372.

Groshong Jr, R.H., 1988. Low-temperature deformation mechanisms and their interpretation. Geological Society of America Bulletin 100, 1329-1360.

Gross, M.R., 1993. The origin and spacing of cross joints: examples from the Monterey Formation, Santa Barbara Coastline, California. Journal of Structural Geology 15, 737751.

Grosso, S., López, R., Vergani, G., O’leary, S., 2011. Los reservorios carbonáticos naturalmente fracturados de la Formación Yacoraite en el yacimiento Caimancito, cuenca cretácica del noroeste argentino, En: $18^{\circ}$ Congreso Geológico Argentino. Actas CD.

Grosso, S., López, R., Vergani, G., O’leary, S., 2013. Reservorios carbonáticos naturalmente fracturados en el Yacimiento Caimancito (Formación Yacoraite), cuenca cretácica del noroeste Argentino. Revista de la Asociación Geológica Argentina 70, 53-69.

Guiton, M.L.E., Sassi, W., Leroy, Y.M., Gauthier, B.D.M., 2003. Mechanical constraints on the chronology of fracture activation in folded Devonian sandstone of the western Moroccan Anti-Atlas. Journal of Structural Geology 25, 1317-1330.

Gutiérrez-Alonso, G., Gross, M.R., 1999. Structures and mechanisms associated with development of a fold in the Cantabrian Zone thrust belt, NW Spain. Journal of Structural Geology 21, 653-670.

Hain, M.P., Strecker, M.R., Bookhagen, B., Alonso, R.N., Pingel, H., Schmitt, A.K., 2011. Neogene to Quaternary broken foreland formation and sedimentation dynamics in the Andes of NW Argentina $\left(25^{\circ}\right.$ S). Tectonics 30, TC2006.

Hancock, P.L., 1985. Brittle microtectonics: principles and practice. Journal of Structural Geology 7, 437-457.

Hayward, A.B., Graham, R.H., 1989. Some geometrical characteristics of inversion. En: Cooper, M.A., Williams, G.D. (Editores), Inversion tectonics. Geological Society, London, Special Publications 44, 17-39.

Hennings, P.H., Olson, J.E., Thompson, L.B., 2000. Combining Outcrop Data and ThreeDimensional Structural Models to Characterize Fractured Reservoirs: An Example from Wyoming. AAPG Bulletin 84, 830-849. 
Hernández, R., Disalvo, A., Boll, A., Gómez Omil, R., Galli, C.I., 1999. Estratigrafía secuencial del Grupo Salta, con énfasis en las subcuencas de Metán-Alemania, Noroeste Argentino. En: González Bonorino, G., Viramonte, J., Omarini, R. (Editores), Geología Del Noroeste Argentino, Relatorio $14^{\circ}$ Congreso Geológico Argentino I, 264-284.

Hernández, R., Gómez Omil, R., Boll, A., 2008. Estratigrafía, tectónica y potencial petrolero del rift cretácico en la Pcia. de Jujuy. En: Coira, B., Zappettini, E. (Editores), Geología de La Provincia de Jujuy, Relatorio Del $17^{\circ}$ Congreso Geológico Argentino. 207-232.

Hernández, R., Echavarria, L., 2009. Faja plegada y corrida subandina del noroeste argentino: estratigrafía, geometría y cronología de la deformación. Revista de la Asociación Geológica Argentina 65, 68-80.

Holdsworth, R.E., Butler, C.A., Roberts, A.M., 1997. The recognition of reactivation during continental deformation. Journal of the Geological Society 154, 73-78.

Hongn, F.D., Becchio, R., 1999. Las fajas miloníticas de Brealito, basamento del Valle Calchaquí, Salta, Argentina. Revista de la Asociación Geológica Argentina 54, 74-97.

Hongn, F.D., Seggiaro, R., 2001. Hoja Geológica 2566-III, Cachi. Provincias de Salta y Catamarca. Instituto de Geología y Recursos Minerales, Servicio Geológico Minero Argentino. Boletín 248, 87 p. Buenos Aires.

Hongn, F., Papa, C. del, Powell, J., Petrinovic, I., Mon, R., Deraco, V., 2007. Middle Eocene deformation and sedimentation in the Puna-Eastern Cordillera transition $\left(23^{\circ}-26^{\circ} \mathrm{S}\right)$ : Control by preexisting heterogeneities on the pattern of initial Andean shortening. Geology 35, 271-274.

Hongn, F.D., del Papa, C.E., Powell, J., Petrinovic, I.A., Mon, R., 2008. Discordancias en el cerro Tin Tín (Salta): claves para interpretar la evolución tectónica cenozoica en el noroeste argentino. $17^{\circ}$ Congreso Geológico Argentino. Actas 1. Jujuy, 26-27.

Hongn, F., Mon, R., Petrinovic, I., del Papa, C., Powell, J., 2010a. Inversión y reactivación tectónicas cretácico-cenozoicas en el noroeste argentino: influencia de las heterogeneidades del basamento neoproterozoico-paleozoico inferior. Revista de la Asociación Geológica Argentina 66, 38-53.

Hongn, F., Tubía, J., Aranguren, A., Vegas, N., Mon, R., Dunning, G., 2010b. Magmatism coeval with lower Paleozoic shelf basins in NW-Argentina (Tastil batholith): Constraints on current stratigraphic and tectonic interpretations. Journal of South American Earth Sciences 29, 289-305.

Hongn, F.D., del Papa, C.E., Powell, J., Payrola Bosio, P., Petrinovic, I.A., Mon, R., 2011. Fragmented Paleogene foreland basin in the Valles Calchaquíes, NW of Argentina. En: Salfity, J.A., Marquillas, R.A. (Editores), Cenozoic Geology of the Central Andes of Argentina. SCS Publisher, Salta, 189-209.

Hongn, F.D., Amengual, R., García, V., Yamin, M., Casa, A., 2014. Neotectónica del Valle Calchaquí, Salta. $19^{\circ}$ Congreso Geológico Argentino. 
Iaffa, D.N., Sàbat, F., Muñoz, J.A., Carrera, N., 2013. Basin fragmentation controlled by tectonic inversion and basement uplift in Sierras Pampeanas and Santa Bárbara System, northwest Argentina. En: Nemčok, M., Mora, A., Cosgrove, J.W. (Editores), Thick-SkinDominated Orogens: From Initial Inversion to Full Accretion. Geological Society, London, Special Publications 377, 101-117.

Iñigo, J.F., Laubach, S.E., Hooker, J.N., 2012. Fracture abundance and patterns in the Subandean fold and thrust belt, Devonian Huamampampa Formation petroleum reservoirs and outcrops, Argentina and Bolivia. Marine and Petroleum Geology 35, 201-218.

Ismat, Z., 2008a. Folding kinematics expressed in fracture patterns: An example from the AntiAtlas fold belt, Morocco. Journal of Structural Geology 30, 1396-1404.

Ismat, Z., 2008b. Folding kinematics expressed in fracture patterns: An example from the AntiAtlas fold belt, Morocco. Journal of Structural Geology 30, 1396-1404.

Jordan, T.E., Isacks, B.L., Allmendinger, R.W., Brewer, J.A., Ramos, V.A., Ando, C.J., 1983. Andean tectonics related to geometry of subducted Nazca plate. Geological Society of America Bulletin 94, 341-361.

Jordan, T.E., 1998. Retroarc foreland and related basins. En: Busby, C., Ingersoll, R. (Editores), Tectonics of Sedimentary Basins. Wiley-Blackwell, 331-362.

Kley, J., Monaldi, C.R., Salfity, J.A., 1999. Along-strike segmentation of the Andean foreland: causes and consequences. Tectonophysics 301, 75-94.

Kley, J., Rossello, E.A., Monaldi, C.R., Habighorst, B., 2005. Seismic and field evidence for selective inversion of Cretaceous normal faults, Salta rift, northwest Argentina. Tectonophysics 399, 155-172.

Lacombe, O., Lavé, J., Roure, F., Verges, J., 2007. Thrust Belts and Foreland Basins. From Fold Kinematics to Hydrocarbon Systems. Springer-Verlag Berlin/Heidelberg.

Lavenu, A.P.C., Lamarche, J., Gallois, A., Gauthier, B.D.M., 2013. Tectonic versus diagenetic origin of fractures in a naturally fractured carbonate reservoir analog (Nerthe anticline, southeastern France). AAPG Bulletin 97, 2207-2232.

Letouzey, J., Werner, P., Marty, A., 1990. Fault reactivation and structural inversion. Backarc and intraplate compressive deformations. Example of the eastern Sunda shelf (Indonesia). Tectonophysics 183, 341-362.

Likerman, J., Cristallini, E., Selles Martínez, J., 2011. Estudio de fracturas asociado al sistema de plegamiento en la localidad de tres cruces, provincia de Jujuy. En: $18^{\circ}$ Congreso Geológico Argentino. Jujuy. Actas CD.

Likerman, J., Cristallini, E., 2012. Predicción de la probabilidad de fracturamiento utilizando métodos estáticos sobre superficies geológicas irregulares. En: $15^{\circ}$ Reunión de Tectónica. San Juan, 78-79. 
Mandl, G., 2005. RockJoints. The Mechanical Genesis. Springer Berlin/Heidelberg.

Marquillas, R., Del Papa, C., Sabino, I., Heredia, J., 2003. Prospección del límite K/T en la cuenca del Noroeste, Argentina. Revista de la Asociación Geológica Argentina 58, 271-274.

Marquillas, R.A., del Papa, C., Sabino, I.F., 2005. Sedimentary aspects and paleoenvironmental evolution of a rift basin: Salta Group (Cretaceous-Paleogene), northwestern Argentina. International Journal of Earth Sciences 94, 94-113.

Marquillas, R., Sabino, I., Nobrega Sial, A., Papa, C. del, Ferreira, V., Matthews, S., 2007. Carbon and oxygen isotopes of Maastrichtian-Danian shallow marine carbonates: Yacoraite Formation, northwestern Argentina. Journal of South American Earth Sciences 23, 304320.

Marrett, R.A., Allmendinger, R.W., Alonso, R.N., Drake, R.E., 1994. Late Cenozoic tectonic evolution of the Puna Plateau and adjacent foreland, northwestern Argentine Andes. Journal of South American Earth Sciences 7, 179-207.

Marshak, S., Mitra, G., 1988. Basic Methods of Structural Geology. Prentice-Hall, Inc.

Masaferro, J.L., Bulnes, M., Poblet, J., Casson, N., 2003. Kinematic evolution and fracture prediction of the Valle Morado structure inferred from 3-D seismic data, Salta province, northwest Argentina. AAPG Bulletin 87, 1083-1104.

McCaffrey, K., Lonergan, L., Wilkinson, J. (Editores), 1999. Fractures, Fluid Flow and Mineralization. Geological Society Special Publication 155. Geological Society of London.

McClay, K., 1992. Glossary of thrust tectonics terms. En: McClay, K. (Editor), Thrust Tectonics. Springer Netherlands, 419-433.

McGroder, M.F., Lease, R.O., Pearson, D.M., 2014. Along-strike variation in structural styles and hydrocarbon occurrences, Subandean fold-and-thrust belt and inner foreland, Colombia to Argentina. En: DeCelles, P.G., Ducea, M.N., Carrapa, B., Kapp, P.A. (Editores), Geodynamics of a Cordilleran Orogenic System: The Central Andes of Argentina and Northern Chile. Geological Society of America Memoirs 212, first published on September 23, 2014, doi: 10.1130/2015.1212(05)

Mitra, S., 2002. Fold-Accommodation Faults. AAPG Bulletin 86, 671-693.

Mon, R., 1979. Esquema tectónico de los Andes del norte argentino. Revista de la Asociación Geológica Argentina 34, 53-60.

Mon, R., Hongn, F., 1991. The structure of the Precambrian and Lower Paleozoic basement of the Central Andes between $22^{\circ}$ and $32^{\circ} \mathrm{S}$. Lat. Geologische Rundschau 80, 745-758.

Mon, R., Hongn, F.D., 1996. Estructura del basamento proterozoico y paleozoico inferior del norte argentino. Revista de la Asociación Geológica Argentina 51, 3-14. 
Mon, R., Salfity, J.A., 1995. Tectonic Evolution of the Andes of Northern Argentina. En: Tankard, A.J., Suarez Soruco, R., Welsin, H.J. (Editores), Petroleum Basins of South America. AAPG Memoir 62, 269-283.

Mon, R., Gutiérrez, A.A., Sabat, F., Iaffa, D., 2012. A Miocene Continental Basin associated with the back thrusting of the Eastern Sierras Pampeanas in the Santa Maria Valley, Northwestern Argentina. Italian Journal of Geosciences 131, 123-135.

Monaldi, C.R., 2001. Cratácico - Paleógeno. En: Hongn, F.D., Seggiaro, R.E. (Editores), Hoja Geológica 2566-III, Cachi. Provincias de Salta y Catamarca. Instituto de Geología y Recursos Minerales, Servicio Geológico Minero Argentino. Boletín 248: 20-23. Buenos Aires.

Monaldi, C.R., Salfity, J.A., Kley, J., 2008. Preserved extensional structures in an inverted Cretaceous rift basin, northwestern Argentina: Outcrop examples and implications for fault reactivation. Tectonics 27, TC1011.

Moreno, J.A., 1970. Estratigrafía y Paleogeografía del Cretácico Superior en la cuenca del Noroeste argentino, con especial mención de los Subgrupos Balbuena y Santa Bárbara. Revista de la Asociación Geológica Argentina 25, 9-44.

Mortimer, E., Carrapa, B., Coutand, I., Schoenbohm, L., Sobel, E.R., Sosa Gomez, J., Strecker, M.R., 2007. Fragmentation of a foreland basin in response to out-of-sequence basement uplifts and structural reactivation: El Cajón-Campo del Arenal basin, NW Argentina. Geological Society of America Bulletin 119, 637-653.

Mosquera, A., Ramos, V.A., 2006. Intraplate deformation in the Neuquén Embayment. En: Kay S.M., Ramos, V.A. (Editores), Evolution of an Andean Margin: A Tectonic and Magmatic

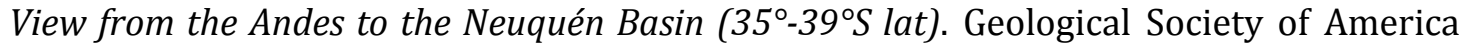
Special Papers 407, 97-123.

Nelson, R.A., 2001. Geologic Analysis of Naturally Fractured Reservoirs. $2^{\circ}$ ed. Gulf Professional Publishing.

Orts, D.L., Folguera, A., Encinas, A., Ramos, M., Tobal, J., Ramos, V.A., 2012. Tectonic development of the North Patagonian Andes and their related Miocene foreland basin $\left(41^{\circ} 30^{\prime}-43^{\circ} \mathrm{S}\right)$. Tectonics $31, \mathrm{TC} 3012$.

Payrola Bosio, P.A., Powell, J., Papa, C. del, Hongn, F., 2009. Middle Eocene deformationsedimentation in the Luracatao Valley: Tracking the beginning of the foreland basin of northwestern Argentina. Journal of South American Earth Sciences 28, 142-154.

Payrola Bosio, P.A., Hongn, F.D., del Papa, C.E., Aramayo, A., Gorustovic, S., 2011. Inversión tectónica cenozoica y variaciones estructurales a lo largo del Valle del Tonco, Valles Calchaquíes - Noroeste de la Argentina. Acta Geológica Lilloana 23, 27-45.

Payrola Bosio, P.A., del Papa, C.E., Hongn, F.D., Aramayo, A., 2012. La discordancia eocena en el valle del Tonco-valles Calchaquíes: Configuración de las cuencas del Antepaís andino. En: $13^{\circ}$ Reunión Argentina de Sedimentología, 161-162. 
Poblet, J., Seggiaro, R., Aguilera, N., Rodríguez-Fernández, R., Heredia, N., Alonso, J.L., Bulnes, M., 2008. Structural styles in the Eastern Cordillera, Subandean Ranges - Santa Barbara System transition, and Lomas de Olmedo Trough (northern Argentine Andes). 7th International Symposium on Andean Geodynamics (ISAG 2008, Nice), 401-404.

Pollard, D.D., Aydin, A., 1988. Progress in understanding jointing over the past century. Geological Society of America Bulletin 100, 1181-1204.

Price, N.J., Cosgrove, J.W., 1990. Analysis of Geological Structures. Cambridge University Press.

Quintà, A., Tavani, S., 2012. The foreland deformation in the south-western BasqueCantabrian Belt (Spain). Tectonophysics 576-577, 4-19.

Ramos, V.A., 1999. Las provincias geológicas del territorio argentino. En: Caminos, R. (Editor), Geologia Argentina. Instituto de Geología y Recursos Minerales, Anales 29 (3), 41-96, Buenos Aires.

Ramsay, J.G., Huber, M.I., 1987. The Techniques of Modern Structural Geology. Volume 2: Folds and Fractures. Academic Press, London.

Riller, U., Oncken, 0., 2003. Growth of the Central Andean Plateau by tectonic segmentation is controlled by the gradient in crustal shortening. The Journal of Geology 111, 367-384.

Rives, T., Rawnsley, K.D., Petit, J.-P., 1994. Analogue simulation of natural orthogonal joint set formation in brittle varnish. Journal of Structural Geology 16, 419-429.

Ruiz Huidobro, 0.J., 1955. Tectónica de las hojas Chicoana y Salta. Revista de la Asociación Geológica Argentina 10, 7-43.

Sagripanti, L., Aguirre-Urreta, B., Folguera, A., Ramos, V.A., 2014. The Neocomian of Chachahuén (Mendoza, Argentina): evidence of a broken foreland associated with the Payenia flat-slab. En: Sepúlveda, S.A., Giambiagi, L.B., Moreiras, S.M., Pinto, L., Tunik, M., Hoke, G.D., Farías, M. (Editores), Geodynamic Processes in the Andes of Central Chile and Argentina. Geological Society, London, Special Publications, 399, first published on February 5, 2014, doi:10.1144/SP399.9

Salfity, J.A., 2004. Geología regional del Valle Calchaquí, Argentina. Anales de la Academia Nacional de Ciencias Exactas, Físicas y Naturales 56, 133-150. Buenos Aires.

Salfity, J.A., Marquillas, R.A., 1981. Las unidades estratigráficas cretácicas del norte de la Argentina. En: Volkheimer, W., Musacchio, E. (Editores), Cuencas Sedimentarias del Jurásico y Cretácico de América del Sur, 1, 303-317.

Salfity, J.A., Marquillas, R.A., 1994. Tectonic and sedimentary evolution of the CretaceousEocene Salta Group basin, Argentina. En: Salfity, A. (Editor), Cretaceous Tectonics of the Andes. Earth Evolution Sciences, Friedr. Vieweg and Sohn, 266-315. 
Santimano, T., Riller, U., 2012. Kinematics of Tertiary to Quaternary intracontinental deformation of upper crust in the Eastern Cordillera, southern Central Andes, NW Argentina. Tectonics 31, TC4002.

Sanz, P.F., Pollard, D.D., Allwardt, P.F., Borja, R.I., 2008. Mechanical models of fracture reactivation and slip on bedding surfaces during folding of the asymmetric anticline at Sheep Mountain, Wyoming. Journal of Structural Geology 30, 1177-1191.

Savage, H.M., Ryan Shackleton, J., Cooke, M.L., Riedel, J.J., 2010. Insights into fold growth using fold-related joint patterns and mechanical stratigraphy. Journal of Structural Geology 32, 1466-1475.

Schmidt, C.J., Genovese, P.W., Chase, R.B., 1993. Role of basement fabric and cover-rock lithology on the geometry and kinematics of twelve folds in the Rocky Mountain foreland. En: Schmidt, J., Chase, R.B., Erslev, E.A. (Editores), Laramide Basement Deformation in the Rocky Mountain Foreland of the Western United States. Geological Society of America Special Papers 280, 1-44.

Scisciani, V., 2009. Styles of positive inversion tectonics in the Central Apennines and in the Adriatic foreland: Implications for the evolution of the Apennine chain (Italy). Journal of Structural Geology 31, 1276-1294.

Shackleton, J.R., Cooke, M.L., 2007. Is plane strain a valid assumption in non-cylindrical faultcored folds? Journal of Structural Geology 29, 1229-1240.

Sibson, R.H., 1977. Fault rocks and fault mechanisms. Journal of the Geological Society 133, 191-213.

Sibson, R.H., 1985. A note on fault reactivation. Journal of Structural Geology 7, 751-754.

Sibson, R.H., 1995. Selective fault reactivation during basin inversion: potential for fluid redistribution through fault-valve action. En: Buchanan, J. G., Buchanan, P. G. (Editores), Basin inversion. Geological Society, London, Special Publications 88, 3-19.

Siks, B.C., Horton, B.K., 2011. Growth and fragmentation of the Andean foreland basin during eastward advance of fold-thrust deformation, Puna plateau and Eastern Cordillera, northern Argentina. Tectonics 30, TC6017.

Silliphant, L.J., Engelder, T., Gross, M.R., 2002. The state of stress in the limb of the Split Mountain anticline, Utah: constraints placed by transected joints. Journal of Structural Geology 24, 155-172.

Starck, D., 2011. Cuenca cretácica-paleógena del noroeste argentino. En: Simposio Cuencas Argentinas: Visión Actual. $8^{\circ}$ Congreso de Exploración Y Desarrollo de Hidrocarburos, Mar del Plata, 407-453.

Stearns, D.W., 1964. Macrofracture Patterns on Teton Anticline, Northwest Montana. American Geophysical Union Transactions 45, 107-108. 
Stearns, D.W., 1978. Faulting and forced folding in the Rocky Mountains foreland. En: Matthews III, V. (Editor), Laramide Folding Associated with Basement Block Faulting in the Western United States. Geological Society of America Memoirs 151, 1-38.

Stearns, D.W., Friedman, M., 1972. Reservoirs in Fractured Rock. En: King, R. (Editor), Stratigraphic Oil and Gas Fields - Classification, Exploration Methods, and Case Histories. AAPG Memoir 16, 82-106.

Strecker, M.R., Hilley, G.E., Bookhagen, B., Sobel, E.R., 2012. Structural, Geomorphic, and Depositional Characteristics of Contiguous and Broken Foreland Basins: Examples from the Eastern Flanks of the Central Andes in Bolivia and NW Argentina. En: Busby, C., Azor, A. (Editores), Tectonics of Sedimentary Basins - Recent Advances. Blackwell Publishing Ltd, 508-521.

Suppe, J., 1983. Geometry and kinematics of fault-bend folding. American Journal of Science $283,684-721$.

Suppe, J., Medwedeff, D.A., 1990. Geometry and kinematics of fault-propagation folding. Eclogae Geologicae Helvetiae 83, 409-454.

Tavani, S., Storti, F., Fernández, O., Muñoz, J.A., Salvini, F., 2006. 3-D deformation pattern analysis and evolution of the Añisclo anticline, southern Pyrenees. Journal of Structural Geology 28, 695-712.

Tavani, S., Storti, F., Salvini, F., Toscano, C., 2008. Stratigraphic versus structural control on the deformation pattern associated with the evolution of the Mt. Catria anticline, Italy. Journal of Structural Geology 30, 664-681.

Tavani, S., Mencos, J., Bausà, J., Muñoz, J.A., 2011a. The fracture pattern of the Sant Corneli Bóixols oblique inversion anticline (Spanish Pyrenees). Journal of Structural Geology 33, 1662-1680.

Tavani, S., Storti, F., Soleimany, B., Fallah, M., Muñoz, J.A., Gambini, R., 2011b. Geometry, kinematics and fracture pattern of the Bangestan anticline, Zagros, SW Iran. Geological Magazine 148, 964-979.

Tavani, S., Fernandez, O., Muñoz, J.A., 2012. Stress fluctuation during thrust-related folding: Boltaña anticline (Pyrenees, Spain). En: Healy, D., Butler, R.W.H., Shipton, Z.K., Sibson, R.H. (Editores), Faulting, Fracturing and Igneous Intrusion in the Earth's Crust. Geological Society, London, Special Publications, 367, 131-140

Tavarnelli, E., 1997. Structural evolution of a foreland fold-and-thrust belt: the UmbriaMarche Apennines, Italy. Journal of Structural Geology 19, 523-534.

Tesón, E., Mora, A., Silva, A., Namson, J., Teixell, A., Castellanos, J., Casallas, W., Julivert, M., Taylor, M., Ibáñez-Mejía, M., Valencia, V.A., 2013. Relationship of Mesozoic graben development, stress, shortening magnitude, and structural style in the Eastern Cordillera of the Colombian Andes. En: Nemčok, M., Mora, A., Cosgrove, J.W. (Editores), Thick-Skin- 
Dominated Orogens: From Initial Inversion to Full Accretion. Geological Society, London, Special Publications 377, 257-283.

Turienzo, M., Dimieri, L., Frisicale, C., Araujo, V., Sánchez, N., 2012. Cenozoic structural evolution of the Argentinean Andes at 34.40'S: A close relationship between thick and thin-skinned deformation. Andean geology 39, 317-357.

Twiss, R.J., Moores, E.M., 2007. Structural Geology. W. H. Freeman, 2nd ed. New York.

Underhill, J.R., Paterson, S., 1998. Genesis of tectonic inversion structures: seismic evidence for the development of key structures along the Purbeck-Isle of Wight Disturbance. Journal of the Geological Society 155, 975-992.

Urien, C.M., Zambrano, J.J., Yrigoyen, M.R., 1995. Petroleum Basins of Southern South America: An Overview. En: Tankard, A.J., Suarez Soruco, R., Welsin, H.J. (Editores), Petroleum Basins of South America. AAPG Memoir 62, 63-77.

Viramonte, J.G., Kay, S.M., Becchio, R., Escayola, M., Novitski, I., 1999. Cretaceous rift related magmatism in central-western South America. Journal of South American Earth Sciences $12,109-121$.

Whitaker, A.E., Engelder, T., 2005. Characterizing stress fields in the upper crust using joint orientation distributions. Journal of Structural Geology 27, 1778-1787.

Whitaker, A.E., Engelder, T., 2006. Plate-scale stress fields driving the tectonic evolution of the central Ouachita salient, Oklahoma and Arkansas. Geological Society of America Bulletin $118,710-723$.

Wilkins, S.J., Gross, M.R., Wacker, M., Eyal, Y., Engelder, T., 2001. Faulted joints: kinematics, displacement-length scaling relations and criteria for their identification. Journal of Structural Geology 23, 315-327.

Williams, G.D., Powell, C.M., Cooper, M.A., 1989. Geometry and kinematics of inversion tectonics. En: Cooper, M.A., Williams, G.D. (Editores), Inversion tectonics. Geological Society, London, Special Publications $44,3-15$.

Zhao, M., Jacobi, R.D., 1997. Formation of regional cross-fold joints in the northern Appalachian Plateau. Journal of Structural Geology 19, 817-834. 


\begin{tabular}{|l|c|}
\hline Estación & 3TT \\
\hline Rbz capa & $93^{\circ} / 35^{\circ}$ \\
\hline Dirección scan line & $\mathrm{N} 0^{\circ}$ \\
\hline Longitud scan line & $321 \mathrm{~cm}$ \\
\hline $\mathbf{N}^{\circ}$ de fracturas & 39 \\
\hline
\end{tabular}

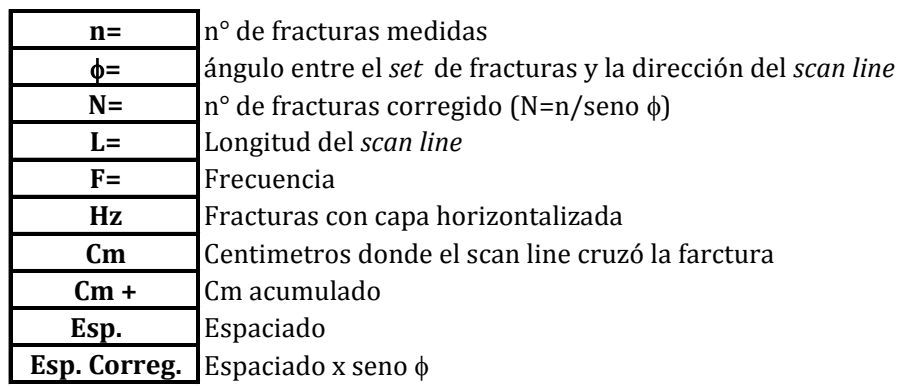

\begin{tabular}{|c|c|c|c|c|c|c|}
\hline & & & & & & \\
\hline$\#$ & $\mathrm{Cm}$ & $\mathrm{Cm}+$ & Rbz & Inclin & $\mathbf{R b z}$ & Inclin \\
\hline 0 & 0 & 0 & 167 & 85 & 173 & 77 \\
\hline 1 & 16 & 16 & 28 & 74 & 14 & 63 \\
\hline 2 & 7 & 23 & 311 & 62 & 126 & 89 \\
\hline 3 & 7 & 30 & 2 & 60 & 344 & 66 \\
\hline 4 & 19 & 49 & 5 & 70 & 353 & 73 \\
\hline & & 49 & 235 & 60 & 241 & 89 \\
\hline & & 49 & 191 & 48 & 215 & 61 \\
\hline 5 & 18 & 67 & 195 & 75 & 201 & 84 \\
\hline & & 67 & 320 & 80 & 141 & 76 \\
\hline & & 67 & 252 & 66 & 74 & 81 \\
\hline 6 & 15 & 82 & 235 & 65 & 59 & 86 \\
\hline 7 & 18 & 100 & 330 & 64 & 322 & 86 \\
\hline 8 & 5 & 105 & 32 & 80 & 22 & 65 \\
\hline & & 105 & 1 & 77 & 354 & 81 \\
\hline & & 105 & 289 & 51 & 285 & 85 \\
\hline 9 & 11 & 116 & 32 & 80 & 22 & 65 \\
\hline 10 & 3 & 119 & 234 & 65 & 58 & 87 \\
\hline 11 & 20 & 139 & 172 & 85 & 177 & 80 \\
\hline & & 139 & 47 & 37 & 348 & 27 \\
\hline 12 & 6 & 145 & 172 & 85 & 177 & 80 \\
\hline 13 & 9 & 154 & 202 & 77 & 206 & 90 \\
\hline 14 & 4 & 158 & 170 & 71 & 184 & 67 \\
\hline 15 & 8 & 166 & 170 & 71 & 184 & 67 \\
\hline 16 & 9 & 175 & 170 & 71 & 184 & 67 \\
\hline 17 & 20 & 195 & 209 & 62 & 219 & 81 \\
\hline 18 & 7 & 202 & 225 & 76 & 46 & 80 \\
\hline 19 & 4 & 206 & 1 & 80 & 356 & 83 \\
\hline 20 & 15 & 221 & 1 & 80 & 356 & 83 \\
\hline 21 & 8 & 229 & 9 & 90 & 8 & 87 \\
\hline 22 & 4 & 233 & 228 & 58 & 236 & 85 \\
\hline 23 & 6 & 239 & 355 & 80 & 351 & 86 \\
\hline 24 & 5 & 244 & 355 & 80 & 351 & 86 \\
\hline 25 & 17 & 261 & 355 & 80 & 351 & 86 \\
\hline 26 & 11 & 272 & 222 & 63 & 229 & 87 \\
\hline 27 & 3 & 275 & 222 & 63 & 229 & 87 \\
\hline 28 & 26 & 301 & 341 & 79 & 159 & 87 \\
\hline 29 & 3 & 304 & 195 & 75 & 201 & 84 \\
\hline 30 & 7 & 311 & 3 & 88 & 2 & 88 \\
\hline 31 & 10 & 321 & 3 & 88 & 2 & 88 \\
\hline
\end{tabular}

\begin{tabular}{|c|c|c|}
\hline Cm + & Rbz & Inclin \\
\hline 0 & 173 & 77 \\
\hline 16 & 14 & 63 \\
\hline 23 & 126 & 89 \\
\hline 30 & 344 & 66 \\
\hline 49 & 353 & 73 \\
\hline 49 & 241 & 89 \\
\hline 49 & 215 & 61 \\
\hline 67 & 201 & 84 \\
\hline 67 & 141 & 76 \\
\hline 67 & 74 & 81 \\
\hline 82 & 59 & 86 \\
\hline 100 & 322 & 86 \\
\hline 105 & 22 & 65 \\
\hline 105 & 354 & 81 \\
\hline 105 & 285 & 85 \\
\hline 116 & 22 & 65 \\
\hline 119 & 58 & 87 \\
\hline 139 & 177 & 80 \\
\hline 139 & 348 & 27 \\
\hline 145 & 177 & 80 \\
\hline 154 & 206 & 90 \\
\hline 158 & 184 & 67 \\
\hline 166 & 184 & 67 \\
\hline 175 & 184 & 67 \\
\hline 195 & 219 & 81 \\
\hline 202 & 46 & 80 \\
\hline 206 & 356 & 83 \\
\hline 221 & 356 & 83 \\
\hline 229 & 8 & 87 \\
\hline 233 & 236 & 85 \\
\hline 239 & 351 & 86 \\
\hline 244 & 351 & 86 \\
\hline 261 & 351 & 86 \\
\hline 272 & 229 & 87 \\
\hline 275 & 229 & 87 \\
\hline 301 & 159 & 87 \\
\hline 304 & 201 & 84 \\
\hline 311 & 2 & 88 \\
\hline 321 & 2 & 88 \\
\hline
\end{tabular}

Inclinación prom. 78.718 \begin{tabular}{c|c} 
Inclin. Máx. & 90 \\
Inclin. Min. & 27 \\
\hline
\end{tabular} 


\begin{tabular}{|c|c|c|}
\hline Set ESE-WNW & \multicolumn{2}{|c|}{ Hz } \\
\hline $\mathbf{C m}+$ & $\mathbf{R b z}$ & Inclin \\
\hline 16 & 14 & 63 \\
\hline 49 & 215 & 61 \\
\hline 67 & 201 & 84 \\
\hline 105 & 22 & 65 \\
\hline 116 & 22 & 65 \\
\hline 154 & 206 & 90 \\
\hline 304 & 201 & 84 \\
\hline
\end{tabular}

\begin{tabular}{|c|c|c|c|}
\hline Esp. & Esp. Correg. & n & 7 \\
\hline 33 & 31.01 & $\phi$ & 70 \\
\hline 18 & 16.91 & $\operatorname{sen} \phi$ & 0.94 \\
\hline 38 & 35.71 & $\mathbf{N}$ & 7.45 \\
\hline 11 & 10.34 & $F=N / L$ & 3.74 \\
\hline 38 & 35.71 & & \\
\hline 150 & 140.95 & & \\
\hline
\end{tabular}

\begin{tabular}{|r|c|}
\hline Moda & 35.71 \\
\hline Promedio & 45.11 \\
\hline Máx. & 140.95 \\
\hline Min. & 10.34 \\
\hline
\end{tabular}

\begin{tabular}{|c|c|c|}
\hline Set E-W & \multicolumn{2}{|c|}{ Hz } \\
\hline Cm + & Rbz & Inclin \\
\hline 0 & 173 & 77 \\
\hline 30 & 344 & 66 \\
\hline 49 & 353 & 73 \\
\hline 105 & 354 & 81 \\
\hline 139 & 177 & 80 \\
\hline 145 & 177 & 80 \\
\hline 158 & 184 & 67 \\
\hline 166 & 184 & 67 \\
\hline 175 & 184 & 67 \\
\hline 206 & 356 & 83 \\
\hline 221 & 356 & 83 \\
\hline 229 & 8 & 87 \\
\hline 239 & 351 & 86 \\
\hline 244 & 351 & 86 \\
\hline 261 & 351 & 86 \\
\hline 301 & 159 & 87 \\
\hline 311 & 2 & 88 \\
\hline 321 & 2 & 88 \\
\hline & & \\
\hline & & \\
\hline
\end{tabular}

\begin{tabular}{|c|c|c|c|}
\hline Esp. & Esp. Correg. & $\mathbf{n}$ & 18 \\
\hline 30 & 29.78 & $\phi$ & 83 \\
\hline 19 & 18.86 & $\operatorname{sen} \phi$ & 0.99 \\
\hline 56 & 55.58 & $\mathbf{N}$ & 18.14 \\
\hline 34 & 33.75 & $F=N / L$ & 9.11 \\
\hline 6 & 5.96 & & \\
\hline 13 & 12.90 & & \\
\hline 8 & 7.94 & & \\
\hline 9 & 8.93 & & \\
\hline 31 & 30.77 & & \\
\hline 15 & 14.89 & & \\
\hline 8 & 7.94 & & \\
\hline 10 & 9.93 & & \\
\hline 5 & 4.96 & & \\
\hline 17 & 16.87 & & \\
\hline 40 & 39.70 & & \\
\hline 10 & 9.93 & & \\
\hline 10 & 9.93 & & \\
\hline
\end{tabular}

\begin{tabular}{|r|c|}
\hline Moda & 9.93 \\
\hline Promedio & 18.74 \\
\hline Máx. & 55.58 \\
\hline Min. & 4.96 \\
\hline
\end{tabular}

\begin{tabular}{|c|c|c|}
\hline Set NE-SW & \multicolumn{2}{|c|}{ Hz } \\
\hline $\mathbf{C m}+$ & Rbz & Inclin \\
\hline 23 & 126 & 89 \\
\hline 67 & 141 & 76 \\
\hline 100 & 322 & 86 \\
\hline 105 & 285 & 85 \\
\hline
\end{tabular}

\begin{tabular}{|c|c|c|c|}
\hline Esp. & Esp. Correg. & $\mathbf{n}$ & 4 \\
\hline 44 & 31.11 & $\bar{\phi}$ & 45 \\
\hline 33 & 23.33 & $\operatorname{sen} \phi$ & 0.71 \\
\hline 5 & 3.54 & $\mathbf{N}$ & 5.66 \\
\hline & & $F=N / L$ & 2.84 \\
\hline Moda & $\# \mathrm{~N} / \mathrm{A}$ & & \\
\hline Promedio & 19.33 & & \\
\hline Máx. & 31.11 & & \\
\hline Min. & 3.54 & & \\
\hline
\end{tabular}

\begin{tabular}{|c|c|c|}
\hline Set NW-SE & \multicolumn{2}{|c|}{ Hz } \\
\hline $\mathbf{C m}+$ & Rbz & Inclin \\
\hline 49 & 241 & 89 \\
\hline 67 & 74 & 81 \\
\hline 82 & 59 & 86 \\
\hline 119 & 58 & 87 \\
\hline 195 & 219 & 81 \\
\hline 202 & 46 & 80 \\
\hline 233 & 236 & 85 \\
\hline 272 & 229 & 87 \\
\hline 275 & 229 & 87 \\
\hline
\end{tabular}

\begin{tabular}{|c|c|c|c|}
\hline Esp. & Esp. Correg. & $\mathbf{n}$ & 9 \\
\hline 18 & 10.83 & $\boldsymbol{\phi}$ & 37 \\
\hline 15 & 9.03 & sen $\boldsymbol{\phi}$ & 0.60 \\
\hline 37 & 22.27 & $\mathbf{N}$ & 14.95 \\
\hline 76 & 45.74 & F=N/L & $\mathbf{7 . 5 1}$ \\
\hline 7 & 4.21 & \multicolumn{3}{|c}{} \\
\cline { 1 - 2 } 31 & 18.66 & & \\
\cline { 1 - 2 } 39 & 23.47 & & \\
\cline { 1 - 2 } 3 & 1.81 & &
\end{tabular}

\begin{tabular}{|r|c|}
\hline Moda & \#N/A \\
\hline Promedio & 17.00 \\
\hline Máx. & 45.74 \\
\hline Min. & 1.81 \\
\hline
\end{tabular}




\begin{tabular}{|l|c|}
\hline Estación & 5TT \\
\hline Rbz capa & $155^{\circ} / 62^{\circ}$ \\
\hline Dirección scan line & $\mathrm{N} 35^{\circ}$ \\
\hline Longitud scan line & $340 \mathrm{~cm}$ \\
\hline $\mathbf{N}^{\circ}$ de fracturas & 24 \\
\hline
\end{tabular}

\begin{tabular}{|c|c|}
\hline $\mathbf{n}=$ & $\mathrm{n}^{\circ}$ de fracturas medidas \\
\hline$\phi=$ & ángulo entre el set de fracturas y la dirección del scan line \\
\hline $\mathrm{N}=$ & $\mathrm{n}^{\circ}$ de fracturas corregido $(\mathrm{N}=\mathrm{n} / \mathrm{seno} \phi)$ \\
\hline $\mathbf{L}=$ & Longitud del scan line \\
\hline$F=$ & Frecuencia \\
\hline $\mathrm{Hz}$ & Fracturas con capa horizontalizada \\
\hline $\mathbf{C m}$ & Centimetros donde el scan line cruzó la fractura \\
\hline $\mathrm{Cm}+$ & $\mathrm{Cm}$ acumulado \\
\hline Esp. & Espaciado \\
\hline
\end{tabular}

Esp. Correg. Espaciado x seno $\phi$

\begin{tabular}{|c|c|c|c|c|c|c|}
\cline { 5 - 6 } & \multicolumn{2}{c}{ Hz } & \multicolumn{1}{l}{} \\
\hline$\#$ & $\mathbf{C m}$ & $\mathbf{C m}+$ & $\mathbf{R b z}$ & Inclin & $\mathbf{R b z}$ & Inclin \\
\hline 0 & 0 & 0 & 224 & 70 & 52 & 84 \\
\hline 1 & 17 & 17 & 35 & 76 & 17 & 75 \\
\hline 2 & & 17 & 287 & 27 & 291 & 89 \\
\hline 3 & 16 & 33 & 30 & 80 & 18 & 81 \\
\hline 4 & 10 & 43 & 21 & 75 & 10 & 86 \\
\hline 5 & 12 & 55 & 21 & 75 & 10 & 86 \\
\hline 6 & 14 & 69 & 21 & 75 & 10 & 86 \\
\hline 7 & 20 & 89 & 21 & 77 & 12 & 87 \\
\hline 8 & 8 & 97 & 221 & 72 & 48 & 85 \\
\hline 9 & 16 & 113 & 17 & 71 & 5 & 88 \\
\hline 10 & 8 & 121 & 31 & 85 & 23 & 82 \\
\hline 11 & 12 & 133 & 225 & 78 & 45 & 79 \\
\hline 12 & 17 & 150 & 23 & 72 & 8 & 83 \\
\hline 13 & 7 & 157 & 23 & 72 & 8 & 83 \\
\hline 14 & 45 & 202 & 27 & 70 & 8 & 79 \\
\hline & 28 & 230 & 20 & 64 & 0 & 82 \\
\hline 15 & & 230 & 235 & 77 & 52 & 71 \\
\hline & 20 & 250 & 34 & 90 & 29 & 82 \\
\hline 16 & & 250 & 232 & 78 & 49 & 81 \\
\hline 17 & 20 & 270 & 233 & 69 & 57 & 77 \\
\hline & 18 & 288 & 26 & 60 & 358 & 76 \\
\hline 18 & & 288 & 275 & 24 & 287 & 85 \\
\hline 19 & 12 & 300 & 225 & 74 & 49 & 73 \\
\hline & 40 & 340 & 28 & 68 & 7 & 77 \\
\hline
\end{tabular}

\begin{tabular}{|c|c|c|}
\hline $\mathbf{C m}+$ & Rbz & Inclin \\
\hline 0 & 52 & 84 \\
\hline 17 & 17 & 75 \\
\hline 17 & 291 & 89 \\
\hline 33 & 18 & 81 \\
\hline 43 & 10 & 86 \\
\hline 55 & 10 & 86 \\
\hline 69 & 10 & 86 \\
\hline 89 & 12 & 87 \\
\hline 97 & 48 & 85 \\
\hline 113 & 5 & 88 \\
\hline 121 & 23 & 82 \\
\hline 133 & 45 & 79 \\
\hline 150 & 8 & 83 \\
\hline 157 & 8 & 83 \\
\hline 202 & 8 & 79 \\
\hline 230 & 0 & 82 \\
\hline 230 & 52 & 71 \\
\hline 250 & 29 & 82 \\
\hline 250 & 49 & 81 \\
\hline 270 & 57 & 77 \\
\hline 288 & 358 & 76 \\
\hline 288 & 287 & 85 \\
\hline 300 & 49 & 73 \\
\hline 340 & 7 & 77 \\
\hline
\end{tabular}

Inclinación prom. 81.542 \begin{tabular}{l|c|}
\hline Inclin. Máx. & 89 \\
\hline
\end{tabular} Inclin. Min. 71

\begin{tabular}{|c|c|c|}
\hline Set NW-SE & \multicolumn{2}{|c|}{ Hz } \\
\hline $\mathbf{C m}+$ & $\mathbf{R b z}$ & Inclin \\
\hline 0 & 52 & 84 \\
\hline 97 & 48 & 85 \\
\hline 133 & 45 & 79 \\
\hline 230 & 52 & 71 \\
\hline 250 & 49 & 81 \\
\hline 270 & 57 & 77 \\
\hline 300 & 49 & 73 \\
\hline
\end{tabular}

\begin{tabular}{|c|c|c|}
\hline Set NNE-SSW & \multicolumn{2}{|c|}{ Hz } \\
\hline $\mathbf{C m}+$ & Rbz & Inclin \\
\hline 17 & 291 & 89 \\
\hline 288 & 287 & 85 \\
\hline
\end{tabular}

\begin{tabular}{|c|c|c|c|}
\hline Esp. & Esp. Correg. & $\mathrm{n}$ & 7 \\
\hline 97 & 93.69 & $\phi$ & 75 \\
\hline 36 & 34.77 & $\operatorname{sen} \phi$ & 0.97 \\
\hline 97 & 93.69 & $\mathbf{N}$ & 7.25 \\
\hline 20 & 19.32 & $F=N / L$ & 2.13 \\
\hline 20 & 19.32 & & \\
\hline 30 & 28.98 & & \\
\hline Moda & 93.69 & & \\
\hline Promedio & 48.30 & & \\
\hline Máx. & 93.69 & & \\
\hline Min. & 19.32 & & \\
\hline
\end{tabular}

\begin{tabular}{|c|c|c|c|}
\hline Esp. & Esp. Correg. & $\mathbf{n}$ & 2 \\
\hline 271 & 70.14 & $\phi$ & 15 \\
\hline \multirow{4}{*}{} & sen $\phi$ & 0.26 \\
\cline { 3 - 4 } & $\mathbf{N}$ & 7.73 \\
\cline { 2 - 4 } & F=N/L & $\mathbf{2 . 2 7}$ \\
\cline { 3 - 4 }
\end{tabular}




\begin{tabular}{|c|c|c|}
\hline Set E-W & \multicolumn{2}{|c|}{ Hz } \\
\hline $\mathbf{C m}+$ & Rbz & Inclin \\
\hline 17 & 17 & 75 \\
\hline 33 & 18 & 81 \\
\hline 43 & 10 & 86 \\
\hline 55 & 10 & 86 \\
\hline 69 & 10 & 86 \\
\hline 89 & 12 & 87 \\
\hline 113 & 5 & 88 \\
\hline 121 & 23 & 82 \\
\hline 150 & 8 & 83 \\
\hline 157 & 8 & 83 \\
\hline 202 & 8 & 79 \\
\hline 230 & 0 & 82 \\
\hline 250 & 29 & 82 \\
\hline 288 & 358 & 76 \\
\hline 340 & 7 & 77 \\
\hline
\end{tabular}

\begin{tabular}{|c|c|c|c|}
\hline Esp. & Esp. Correg. & $\mathbf{n}$ & 15 \\
\hline 16 & 14.50 & $\phi$ & 65 \\
\hline 10 & 9.06 & $\operatorname{sen} \phi$ & 0.91 \\
\hline 12 & 10.88 & $\mathbf{N}$ & 16.55 \\
\hline 14 & 12.69 & $F=N / L$ & 4.868 \\
\hline 20 & 18.13 & & \\
\hline 24 & 21.75 & & \\
\hline 8 & 7.25 & & \\
\hline 29 & 26.28 & & \\
\hline 7 & 6.34 & & \\
\hline 45 & 40.78 & & \\
\hline 28 & 25.38 & & \\
\hline 20 & 18.13 & & \\
\hline 38 & 34.44 & & \\
\hline 52 & 47.13 & & \\
\hline Moda & 18.13 & & \\
\hline Promedio & 20.91 & & \\
\hline Máx. & 47.13 & & \\
\hline Min. & 6.34 & & \\
\hline
\end{tabular}




\begin{tabular}{|l|c|}
\hline Estación & 6TT \\
\hline Rbz capa & $108^{\circ} / 55^{\circ}$ \\
\hline Dirección scan line & $\mathrm{N} 22^{\circ}$ \\
\hline Longitud scan line & $246 \mathrm{~cm}$ \\
\hline $\mathbf{N}^{\circ}$ de fracturas & 29 \\
\hline
\end{tabular}

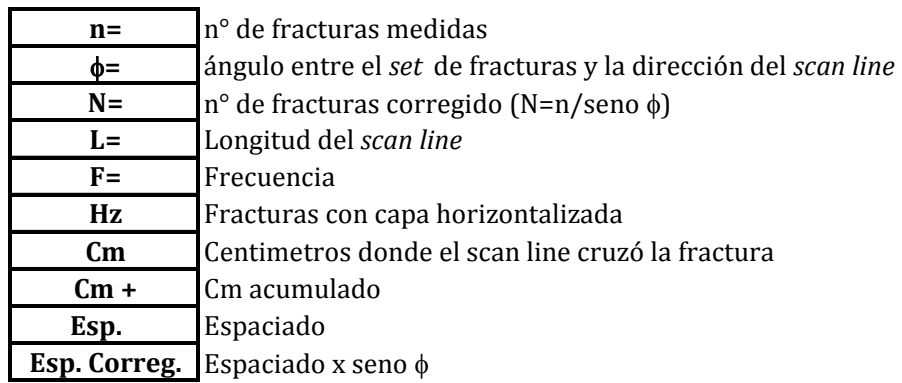

\begin{tabular}{|c|c|c|c|c|c|c|}
\cline { 4 - 5 } & \multicolumn{2}{c}{ Hz } & \multicolumn{2}{c|}{} \\
\hline$\#$ & $\mathbf{C m}$ & $\mathbf{C m}+$ & $\mathbf{R b z}$ & Inclin & Rbz & Inclin \\
\hline 0 & 0 & 0 & 10 & 74 & 0 & 88 \\
\hline & & 0 & 195 & 77 & 207 & 80 \\
\hline 1 & 22 & 22 & 215 & 68 & 46 & 89 \\
\hline 3 & 18 & 40 & 9 & 64 & 351 & 83 \\
\hline 4 & 3 & 43 & 237 & 66 & 61 & 75 \\
\hline 5 & 4 & 47 & 237 & 66 & 61 & 75 \\
\hline 6 & 2 & 49 & 3 & 66 & 350 & 89 \\
\hline 7 & 5 & 54 & 219 & 81 & 37 & 78 \\
\hline 8 & 3 & 57 & 219 & 81 & 37 & 78 \\
\hline & 13 & 70 & 5 & 63 & 349 & 85 \\
\hline 9 & & 70 & 238 & 49 & 73 & 87 \\
\hline 10 & 5 & 75 & 207 & 81 & 30 & 87 \\
\hline 11 & 18 & 93 & 1 & 79 & 179 & 82 \\
\hline 12 & 7 & 100 & 1 & 79 & 179 & 82 \\
\hline & 7 & 107 & 3 & 61 & 346 & 86 \\
\hline 13 & & 107 & 222 & 74 & 45 & 80 \\
\hline 14 & 8 & 115 & 1 & 79 & 179 & 82 \\
\hline 15 & 17 & 132 & 1 & 79 & 179 & 82 \\
\hline & 8 & 140 & 3 & 59 & 344 & 85 \\
\hline 16 & & 140 & 229 & 68 & 54 & 79 \\
\hline 17 & 5 & 145 & 3 & 59 & 344 & 85 \\
\hline 18 & 14 & 159 & 225 & 73 & 47 & 78 \\
\hline 19 & 4 & 163 & 225 & 73 & 47 & 78 \\
\hline 20 & 10 & 173 & 350 & 59 & 157 & 87 \\
\hline 21 & 25 & 198 & 350 & 59 & 157 & 87 \\
\hline 22 & 4 & 202 & 230 & 60 & 60 & 84 \\
\hline 23 & 7 & 209 & 350 & 59 & 157 & 87 \\
\hline 24 & 20 & 229 & 224 & 72 & 48 & 80 \\
\hline & 17 & 246 & 350 & 59 & 157 & 87 \\
\hline
\end{tabular}

\begin{tabular}{|c|c|c|}
\hline $\mathbf{C m}+$ & $\mathbf{R b z}$ & Inclin \\
\hline 0 & 0 & 88 \\
\hline 0 & 207 & 80 \\
\hline 22 & 46 & 89 \\
\hline 40 & 351 & 83 \\
\hline 43 & 61 & 75 \\
\hline 47 & 61 & 75 \\
\hline 49 & 350 & 89 \\
\hline 54 & 37 & 78 \\
\hline 57 & 37 & 78 \\
\hline 70 & 349 & 85 \\
\hline 70 & 73 & 87 \\
\hline 75 & 30 & 87 \\
\hline 93 & 179 & 82 \\
\hline 100 & 179 & 82 \\
\hline 107 & 346 & 86 \\
\hline 107 & 45 & 80 \\
\hline 115 & 179 & 82 \\
\hline 132 & 179 & 82 \\
\hline 140 & 344 & 85 \\
\hline 140 & 54 & 79 \\
\hline 145 & 344 & 85 \\
\hline 159 & 47 & 78 \\
\hline 163 & 47 & 78 \\
\hline 173 & 157 & 87 \\
\hline 198 & 157 & 87 \\
\hline 202 & 60 & 84 \\
\hline 209 & 157 & 87 \\
\hline 229 & 48 & 80 \\
\hline 246 & 157 & 87 \\
\hline & & \\
\hline
\end{tabular}

Inclinación prom. 82.9 \begin{tabular}{l|l} 
Inclin. Máx. & 89 \\
\hline
\end{tabular} \begin{tabular}{ll} 
Inclin. Min. 75 \\
\cline { 2 - 2 }
\end{tabular} 


\begin{tabular}{|c|c|c|}
\hline Set E-W & \multicolumn{2}{|c|}{ Hz } \\
\hline $\mathbf{C m}+$ & Rbz & Inclin \\
\hline 0 & 0 & 88 \\
\hline 40 & 351 & 83 \\
\hline 49 & 350 & 89 \\
\hline 70 & 349 & 85 \\
\hline 93 & 179 & 82 \\
\hline 100 & 179 & 82 \\
\hline 107 & 346 & 86 \\
\hline 115 & 179 & 82 \\
\hline 132 & 179 & 82 \\
\hline 140 & 344 & 85 \\
\hline 145 & 344 & 85 \\
\hline 173 & 157 & 87 \\
\hline 198 & 157 & 87 \\
\hline 209 & 157 & 87 \\
\hline 246 & 157 & 87 \\
\hline
\end{tabular}

\begin{tabular}{|c|c|c|c|}
\hline Esp. & Esp. Correg. & $\mathbf{n}$ & 15 \\
\hline 40 & 33.92 & $\phi$ & 58 \\
\hline 9 & 7.63 & $\operatorname{sen} \phi$ & 0.85 \\
\hline 21 & 17.81 & $\mathbf{N}$ & 17.69 \\
\hline 23 & 19.51 & $F=N / L$ & 7.19 \\
\hline 7 & 5.94 & & \\
\hline 7 & 5.94 & & \\
\hline 8 & 6.78 & & \\
\hline 17 & 14.42 & & \\
\hline 8 & 6.78 & & \\
\hline 5 & 4.24 & & \\
\hline 28 & 23.75 & & \\
\hline 25 & 21.20 & & \\
\hline 11 & 9.33 & & \\
\hline 37 & 31.38 & & \\
\hline Moda & 5.94 & & \\
\hline Promedio & 14.90 & & \\
\hline Máx. & 33.92 & & \\
\hline Min. & 4.24 & & \\
\hline
\end{tabular}

\begin{tabular}{|c|c|c|}
\hline Set NW-SE & \multicolumn{2}{|c|}{ Hz } \\
\hline $\mathbf{C m}+$ & Rbz & Inclin \\
\hline 0 & 207 & 80 \\
\hline 22 & 46 & 89 \\
\hline 43 & 61 & 75 \\
\hline 47 & 61 & 75 \\
\hline 54 & 37 & 78 \\
\hline 57 & 37 & 78 \\
\hline 70 & 73 & 87 \\
\hline 75 & 30 & 87 \\
\hline 107 & 45 & 80 \\
\hline 140 & 54 & 79 \\
\hline 159 & 47 & 78 \\
\hline 163 & 47 & 78 \\
\hline 202 & 60 & 84 \\
\hline 229 & 48 & 80 \\
\hline
\end{tabular}

\begin{tabular}{|c|c|c|c|}
\hline Esp. & Esp. Correg. & n & 14 \\
\hline 22 & 19.42 & $\phi$ & 62 \\
\hline 21 & 18.54 & $\operatorname{sen} \phi$ & 0.88 \\
\hline 4 & 3.53 & $\mathbf{N}$ & 15.86 \\
\hline 7 & 6.18 & $F=N / L$ & 6.446 \\
\hline 3 & 2.65 & & \\
\hline 13 & 11.48 & & \\
\hline 5 & 4.41 & & \\
\hline 32 & 28.25 & & \\
\hline 33 & 29.14 & & \\
\hline 19 & 16.78 & & \\
\hline 4 & 3.53 & & \\
\hline 39 & 34.43 & & \\
\hline 27 & 23.84 & & \\
\hline
\end{tabular}

\begin{tabular}{|r|c|}
\hline Moda & 3.53 \\
\hline Promedio & 15.55 \\
\hline Máx. & 34.43 \\
\hline Min. & 2.65 \\
\hline
\end{tabular}




\begin{tabular}{|l|c|}
\hline Estación & 7TT \\
\hline Rbz capa & $112^{\circ} / 49^{\circ}$ \\
\hline Dirección scan line & $\mathrm{N} 15^{\circ}$ \\
\hline Longitud scan line & $244 \mathrm{~cm}$ \\
\hline $\mathbf{N}^{\circ}$ de fracturas & 25 \\
\hline
\end{tabular}

\begin{tabular}{|c|c|}
\hline $\mathbf{n}=$ & $\mathrm{n}^{\circ}$ de fracturas medidas \\
\hline$\phi=$ & ángulo entre el set de fracturas y la dirección del scan line \\
\hline $\mathrm{N}=$ & $\mathrm{n}^{\circ}$ de fracturas corregido $(\mathrm{N}=\mathrm{n} /$ seno $\phi)$ \\
\hline $\mathbf{L}=$ & Longitud del scan line \\
\hline $\mathbf{F}=$ & Frecuencia \\
\hline $\mathrm{Hz}$ & Fracturas con capa horizontalizada \\
\hline $\mathbf{C m}$ & Centimetros donde el scan line cruzó la fractura \\
\hline $\mathrm{Cm}+$ & $\mathrm{Cm}$ acumulado \\
\hline Esp. & Espaciado \\
\hline Esp. Correg. & Espaciado x seno $\phi$ \\
\hline
\end{tabular}

\begin{tabular}{|c|c|c|c|c|c|c|}
\hline \multirow[b]{2}{*}{$\#$} & \multirow[b]{2}{*}{$\mathbf{C m}$} & \multirow[b]{2}{*}{$\mathrm{Cm}+$} & \multirow[b]{2}{*}{ Rbz } & \multicolumn{2}{|c|}{$\mathrm{Hz}$} & \multirow[b]{2}{*}{ Inclin } \\
\hline & & & & Inclin & Rbz & \\
\hline 0 & 0 & 0 & 226 & 70 & 53 & 86 \\
\hline 1 & 9 & 9 & 358 & 74 & 174 & 83 \\
\hline 2 & 3 & 12 & 226 & 70 & 53 & 86 \\
\hline 3 & 14 & 26 & 257 & 71 & 76 & 67 \\
\hline 4 & 23 & 49 & 231 & 70 & 56 & 83 \\
\hline \multirow[t]{2}{*}{5} & 20 & 69 & 25 & 52 & 353 & 65 \\
\hline & & 69 & 203 & 82 & 209 & 86 \\
\hline \multirow[t]{2}{*}{6} & 28 & 97 & 25 & 52 & 353 & 65 \\
\hline & & 97 & 203 & 82 & 209 & 86 \\
\hline 7 & 30 & 127 & 4 & 54 & 344 & 79 \\
\hline \multirow[t]{2}{*}{8} & 12 & 139 & 4 & 54 & 344 & 79 \\
\hline & & 139 & 203 & 82 & 209 & 86 \\
\hline 9 & 20 & 159 & 203 & 82 & 209 & 86 \\
\hline \multirow[t]{3}{*}{10} & 25 & 184 & 227 & 73 & 51 & 83 \\
\hline & & 184 & 334 & 68 & 152 & 73 \\
\hline & & 184 & 283 & 39 & 286 & 89 \\
\hline 11 & 10 & 194 & 214 & 72 & 223 & 87 \\
\hline \multirow[t]{2}{*}{12} & 10 & 204 & 206 & 86 & 28 & 90 \\
\hline & & 204 & 1 & 63 & 348 & 87 \\
\hline 13 & 6 & 210 & 1 & 63 & 348 & 87 \\
\hline 14 & 4 & 214 & 214 & 72 & 223 & 87 \\
\hline \multirow[t]{2}{*}{15} & 20 & 234 & 6 & 57 & 347 & 80 \\
\hline & & 234 & 214 & 72 & 223 & 87 \\
\hline \multirow[t]{2}{*}{16} & 10 & 244 & 224 & 71 & 51 & 86 \\
\hline & & & 16 & 79 & 10 & 87 \\
\hline
\end{tabular}

\begin{tabular}{|c|c|c|}
\hline $\mathbf{C m}+$ & Rbz & Inclin \\
\hline 0 & 53 & 86 \\
\hline 9 & 174 & 83 \\
\hline 12 & 53 & 86 \\
\hline 26 & 76 & 67 \\
\hline 49 & 56 & 83 \\
\hline 69 & 353 & 65 \\
\hline 69 & 209 & 86 \\
\hline 97 & 353 & 65 \\
\hline 97 & 209 & 86 \\
\hline 127 & 344 & 79 \\
\hline 139 & 344 & 79 \\
\hline 139 & 209 & 86 \\
\hline 159 & 209 & 86 \\
\hline 184 & 51 & 83 \\
\hline 184 & 152 & 73 \\
\hline 184 & 286 & 89 \\
\hline 194 & 223 & 87 \\
\hline 204 & 28 & 90 \\
\hline 204 & 348 & 87 \\
\hline 210 & 348 & 87 \\
\hline 214 & 223 & 87 \\
\hline 234 & 347 & 80 \\
\hline 234 & 223 & 87 \\
\hline 244 & 51 & 86 \\
\hline 244 & 10 & 87 \\
\hline
\end{tabular}

Inclinación prom. 82.4 \begin{tabular}{l|c|} 
Inclin. Máx. & 90 \\
\cline { 2 - 2 } & \\
\hline
\end{tabular} \begin{tabular}{ll} 
Inclin. Min. 65 \\
\hline
\end{tabular} 


\begin{tabular}{|c|c|c|}
\hline Set NW-SE & \multicolumn{2}{|c|}{ Hz } \\
\hline $\mathbf{C m}+$ & Rbz & Inclin \\
\hline 0 & 53 & 86 \\
\hline 12 & 53 & 86 \\
\hline 49 & 56 & 83 \\
\hline 69 & 209 & 86 \\
\hline 97 & 209 & 86 \\
\hline 139 & 209 & 86 \\
\hline 159 & 209 & 86 \\
\hline 184 & 51 & 83 \\
\hline 194 & 223 & 87 \\
\hline 204 & 28 & 90 \\
\hline 214 & 223 & 87 \\
\hline 234 & 223 & 87 \\
\hline 244 & 51 & 86 \\
\hline
\end{tabular}

\begin{tabular}{|c|c|c|c|}
\hline Esp. & Esp. Correg. & $\mathbf{n}$ & 13 \\
\hline 12 & 10.39 & $\phi$ & 60 \\
\hline 37 & 32.04 & $\operatorname{sen} \phi$ & 0.87 \\
\hline 20 & 17.32 & $\mathbf{N}$ & 15.01 \\
\hline 28 & 24.25 & $F=N / L$ & 6.15 \\
\hline 42 & 36.37 & & \\
\hline 20 & 17.32 & & \\
\hline 25 & 21.65 & & \\
\hline 10 & 8.66 & & \\
\hline 10 & 8.66 & & \\
\hline 10 & 8.66 & & \\
\hline 20 & 17.32 & & \\
\hline 10 & 8.66 & & \\
\hline
\end{tabular}

\begin{tabular}{|r|c|}
\hline Moda & 8.66 \\
\hline Promedio & 17.61 \\
\hline Máx. & 36.37 \\
\hline Min. & 8.66 \\
\hline
\end{tabular}

\begin{tabular}{|c|c|c|}
\hline Set ENE-WSW & \multicolumn{2}{|c|}{ Hz } \\
\hline $\mathbf{C m}+$ & Rbz & Inclin \\
\hline 9 & 174 & 83 \\
\hline 69 & 353 & 65 \\
\hline 97 & 353 & 65 \\
\hline 127 & 344 & 79 \\
\hline 139 & 344 & 79 \\
\hline 184 & 152 & 73 \\
\hline 204 & 348 & 87 \\
\hline 210 & 348 & 87 \\
\hline 234 & 347 & 80 \\
\hline
\end{tabular}

\begin{tabular}{|c|c|c|c|}
\hline Esp. & Esp. Correg. & $\mathbf{n}$ & 9 \\
\hline 60 & 51.96 & $\phi$ & 60 \\
\hline 28 & 24.25 & $\operatorname{sen} \phi$ & 0.87 \\
\hline 30 & 25.98 & $\mathbf{N}$ & 10.39 \\
\hline 12 & 10.39 & $\mathbf{F = N} / \mathbf{L}$ & $\mathbf{4 . 2 6}$ \\
\hline 45 & 38.97 & \multicolumn{2}{|}{} \\
\hline 20 & 17.32 & & \\
\hline 6 & 5.20 & & \\
\hline 24 & 20.78 & &
\end{tabular}

\begin{tabular}{|r|c|}
\hline Moda & \#N/A \\
\hline Promedio & 24.36 \\
\hline Máx. & 51.96 \\
\hline Min. & 5.20 \\
\hline
\end{tabular}




\begin{tabular}{|l|c|}
\hline Estación & 8TT \\
\hline Rbz capa & $106^{\circ} / 49^{\circ}$ \\
\hline Dirección scan line & $\mathrm{N} 12^{\circ}$ \\
\hline Longitud scan line & $261 \mathrm{~cm}$ \\
\hline $\mathbf{N}^{\circ}$ de fracturas & 37 \\
\hline
\end{tabular}

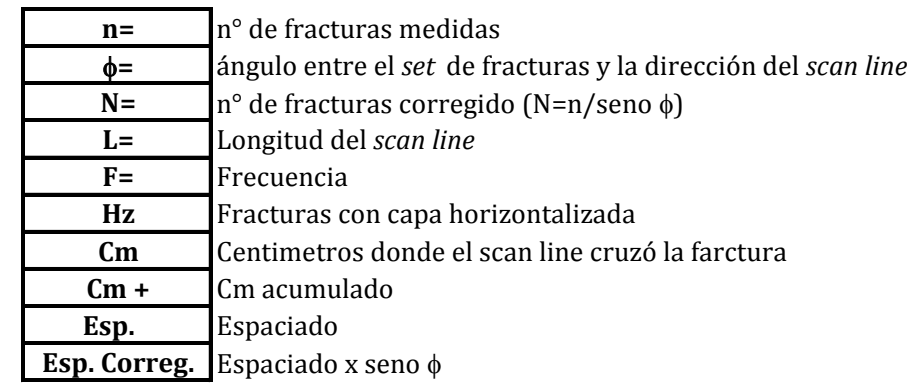

\begin{tabular}{|c|c|c|c|c|c|c|}
\hline \multirow[b]{2}{*}{$\#$} & \multirow[b]{2}{*}{$\mathrm{Cm}$} & \multirow[b]{2}{*}{$\mathrm{Cm}+$} & \multirow[b]{2}{*}{ Rbz } & \multicolumn{2}{|c|}{$\mathrm{Hz}$} & \multirow[b]{2}{*}{ Inclin } \\
\hline & & & & Inclin & Rbz & \\
\hline 0 & 0 & 0 & 342 & 55 & 328 & 89 \\
\hline \multirow[t]{2}{*}{1} & 27 & 27 & 220 & 84 & 35 & 73 \\
\hline & & 27 & 342 & 55 & 328 & 89 \\
\hline \multirow[t]{2}{*}{2} & 3 & 30 & 345 & 62 & 154 & 88 \\
\hline & & 30 & 240 & 52 & 70 & 86 \\
\hline 3 & 5 & 35 & 5 & 68 & 351 & 83 \\
\hline 4 & 6 & 41 & 209 & 72 & 37 & 89 \\
\hline 5 & 2 & 43 & 209 & 72 & 37 & 89 \\
\hline 6 & 7 & 50 & 355 & 42 & 325 & 73 \\
\hline 7 & 9 & 59 & 17 & 80 & 8 & 81 \\
\hline \multirow[t]{2}{*}{8} & 5 & 64 & 351 & 66 & 161 & 89 \\
\hline & & 64 & 262 & 35 & 271 & 85 \\
\hline \multirow[t]{2}{*}{9} & 10 & 74 & 12 & 71 & 357 & 79 \\
\hline & & 74 & 239 & 45 & 254 & 88 \\
\hline \multirow[t]{2}{*}{10} & 23 & 97 & 6 & 71 & 354 & 84 \\
\hline & & 97 & 204 & 74 & 212 & 89 \\
\hline 11 & 3 & 100 & 204 & 74 & 212 & 89 \\
\hline 12 & 6 & 106 & 204 & 74 & 212 & 89 \\
\hline 13 & 1 & 107 & 223 & 62 & 53 & 87 \\
\hline 14 & 9 & 116 & 8 & 78 & 0 & 87 \\
\hline 15 & 1 & 117 & 8 & 78 & 0 & 87 \\
\hline 16 & 2 & 119 & 204 & 74 & 212 & 89 \\
\hline 17 & 13 & 132 & 10 & 70 & 355 & 80 \\
\hline \multirow[t]{2}{*}{18} & 7 & 139 & 245 & 61 & 69 & 76 \\
\hline & & 139 & 210 & 50 & 234 & 77 \\
\hline 19 & 6 & 145 & 345 & 61 & 154 & 89 \\
\hline 20 & 10 & 155 & 11 & 72 & 357 & 81 \\
\hline \multirow[t]{2}{*}{21} & 8 & 163 & 28 & 45 & 340 & 55 \\
\hline & & 163 & 246 & 37 & 262 & 84 \\
\hline 22 & 8 & 171 & 210 & 79 & 32 & 84 \\
\hline 23 & 8 & 179 & 354 & 58 & 337 & 84 \\
\hline 24 & 8 & 187 & 354 & 58 & 337 & 84 \\
\hline \multirow[t]{2}{*}{25} & 13 & 200 & 210 & 79 & 32 & 84 \\
\hline & & 200 & 245 & 39 & 260 & 85 \\
\hline 26 & 11 & 211 & 16 & 75 & 3 & 79 \\
\hline 27 & 30 & 241 & 14 & 88 & 12 & 88 \\
\hline 28 & 20 & 261 & 359 & 65 & 345 & 85 \\
\hline
\end{tabular}

\begin{tabular}{|c|c|c|}
\hline Cm + & Rbz & Inclin \\
\hline 0 & 328 & 89 \\
\hline 27 & 35 & 73 \\
\hline 27 & 328 & 89 \\
\hline 30 & 154 & 88 \\
\hline 30 & 70 & 86 \\
\hline 35 & 351 & 83 \\
\hline 41 & 37 & 89 \\
\hline 43 & 37 & 89 \\
\hline 50 & 325 & 73 \\
\hline 59 & 8 & 81 \\
\hline 64 & 161 & 89 \\
\hline 64 & 271 & 85 \\
\hline 74 & 357 & 79 \\
\hline 74 & 254 & 88 \\
\hline 97 & 354 & 84 \\
\hline 97 & 212 & 89 \\
\hline 100 & 212 & 89 \\
\hline 106 & 212 & 89 \\
\hline 107 & 53 & 87 \\
\hline 116 & 0 & 87 \\
\hline 117 & 0 & 87 \\
\hline 119 & 212 & 89 \\
\hline 132 & 355 & 80 \\
\hline 139 & 69 & 76 \\
\hline 139 & 234 & 77 \\
\hline 145 & 154 & 89 \\
\hline 155 & 357 & 81 \\
\hline 163 & 340 & 55 \\
\hline 163 & 262 & 84 \\
\hline 171 & 32 & 84 \\
\hline 179 & 337 & 84 \\
\hline 187 & 337 & 84 \\
\hline 200 & 32 & 84 \\
\hline 200 & 260 & 85 \\
\hline 211 & 3 & 79 \\
\hline 241 & 12 & 88 \\
\hline 261 & 345 & 85 \\
\hline & & \\
\cline { 3 - 3 } Inclinación prom. & 83.703 \\
\cline { 3 - 3 } Inclin. Máx. & 89 \\
\cline { 3 - 3 } Inclin. Min. & 55 \\
\hline
\end{tabular}




\begin{tabular}{|c|c|c|}
\hline Set ENE-WSW & \multicolumn{2}{|c|}{ Hz } \\
\hline $\mathbf{C m}+$ & $\mathbf{R b z}$ & Inclin \\
\hline 0 & 328 & 89 \\
\hline 27 & 328 & 89 \\
\hline 30 & 154 & 88 \\
\hline 50 & 325 & 73 \\
\hline 64 & 161 & 89 \\
\hline 145 & 154 & 89 \\
\hline 163 & 340 & 55 \\
\hline 179 & 337 & 84 \\
\hline 187 & 337 & 84 \\
\hline 261 & 345 & 85 \\
\hline
\end{tabular}

\begin{tabular}{|c|c|c|c|}
\hline Esp. & Esp. Correg. & $\mathrm{n}$ & 10 \\
\hline 27 & 21.84 & $\phi$ & 54 \\
\hline 3 & 2.43 & $\operatorname{sen} \phi$ & 0.81 \\
\hline 20 & 16.18 & $\mathbf{N}$ & 12.36 \\
\hline 14 & 11.33 & $F=N / L$ & 4.74 \\
\hline 81 & 65.53 & & \\
\hline 18 & 14.56 & & \\
\hline 16 & 12.94 & & \\
\hline 8 & 6.47 & & \\
\hline 74 & 59.87 & & \\
\hline
\end{tabular}

\begin{tabular}{|r|c|}
\hline Moda & \#N/A \\
\hline Promedio & 23.46 \\
\hline Máx. & 65.53 \\
\hline Min. & 2.43 \\
\hline
\end{tabular}

\begin{tabular}{|c|c|c|}
\hline Set ESE-WNW & \multicolumn{2}{|c|}{ Hz } \\
\hline $\mathbf{C m}+$ & $\mathbf{R b z}$ & Inclin \\
\hline 27 & 35 & 73 \\
\hline 41 & 37 & 89 \\
\hline 43 & 37 & 89 \\
\hline 97 & 212 & 89 \\
\hline 100 & 212 & 89 \\
\hline 106 & 212 & 89 \\
\hline 107 & 53 & 87 \\
\hline 119 & 212 & 89 \\
\hline 139 & 234 & 77 \\
\hline 171 & 32 & 84 \\
\hline 200 & 32 & 84 \\
\hline
\end{tabular}

\begin{tabular}{|c|c|c|c|}
\hline Esp. & Esp. Correg. & $\bar{n}$ & 11 \\
\hline 14 & 13.07 & $\phi$ & 69 \\
\hline 2 & 1.87 & $\operatorname{sen} \phi$ & 0.93 \\
\hline 54 & 50.41 & $\mathbf{N}$ & 11.78 \\
\hline 3 & 2.80 & $F=N / L$ & 4.51 \\
\hline 6 & 5.60 & & \\
\hline 1 & 0.93 & & \\
\hline 12 & 11.20 & & \\
\hline 20 & 18.67 & & \\
\hline 32 & 29.87 & & \\
\hline 29 & 27.07 & & \\
\hline
\end{tabular}

\begin{tabular}{|r|c|}
\hline Moda & \#N/A \\
\hline Promedio & 16.15 \\
\hline Máx. & 50.41 \\
\hline Min. & 0.93 \\
\hline
\end{tabular}

\begin{tabular}{|c|c|c|}
\hline Set E-W & \multicolumn{2}{|c|}{ Hz } \\
\hline $\mathbf{C m}+$ & Rbz & Inclin \\
\hline 35 & 351 & 83 \\
\hline 59 & 8 & 81 \\
\hline 74 & 357 & 79 \\
\hline 97 & 354 & 84 \\
\hline 116 & 0 & 87 \\
\hline 117 & 0 & 87 \\
\hline 132 & 355 & 80 \\
\hline 155 & 357 & 81 \\
\hline 211 & 3 & 79 \\
\hline 241 & 12 & 88 \\
\hline
\end{tabular}

\begin{tabular}{|c|c|c|c|}
\hline Esp. & Esp. Correg. & $\mathbf{n}$ & 10 \\
\hline 24 & 23.38 & $\phi$ & 77 \\
\hline 15 & 14.62 & $\operatorname{sen} \phi$ & 0.97 \\
\hline 23 & 22.41 & $\mathbf{N}$ & 10.26 \\
\hline 19 & 18.51 & $F=N / L$ & 3.93 \\
\hline 1 & 0.97 & & \\
\hline 15 & 14.62 & & \\
\hline 23 & 22.41 & & \\
\hline 56 & 54.56 & & \\
\hline 30 & 29.23 & & \\
\hline
\end{tabular}

\begin{tabular}{|r|c|}
\hline Moda & 14.62 \\
\hline Promedio & 14.66 \\
\hline Máx. & 23.38 \\
\hline Min. & 0.97 \\
\hline
\end{tabular}

\begin{tabular}{|c|c|c|}
\hline Set NNW-SSE & \multicolumn{2}{|c|}{ Hz } \\
\hline Cm + & Rbz & Inclin \\
\hline 30 & 70 & 86 \\
\hline 64 & 271 & 85 \\
\hline 74 & 254 & 88 \\
\hline 139 & 69 & 76 \\
\hline 163 & 262 & 84 \\
\hline 200 & 260 & 85 \\
\hline
\end{tabular}

\begin{tabular}{|c|c|c|c|}
\hline Esp. & Esp. Correg. & $\mathbf{n}$ & 6 \\
\hline 34 & 13.83 & $\phi$ & 24 \\
\hline 10 & 4.07 & $\operatorname{sen} \phi$ & 0.41 \\
\hline 65 & 26.44 & $\mathbf{N}$ & 14.75 \\
\hline 24 & 9.76 & $\mathbf{F}=\mathbf{N} / \mathbf{L}$ & $\mathbf{5 . 6 5}$ \\
\hline 37 & 15.05 & \multicolumn{2}{|c}{} \\
\cline { 2 - 3 } & \multicolumn{3}{|c}{}
\end{tabular}

\begin{tabular}{|r|c|}
\hline Moda & \#N/A \\
\hline Promedio & 13.83 \\
\hline Máx. & 26.44 \\
\hline Min. & 4.07 \\
\hline
\end{tabular}




\begin{tabular}{|l|c|}
\hline Estación & 9TT \\
\hline Rbz capa & $125^{\circ} / 64^{\circ}$ \\
\hline Dirección scan line & $\mathrm{N} 26^{\circ}$ \\
\hline Longitud scan line & $263 \mathrm{~cm}$ \\
\hline $\mathbf{N}^{\circ}$ de fracturas & 26 \\
\hline
\end{tabular}

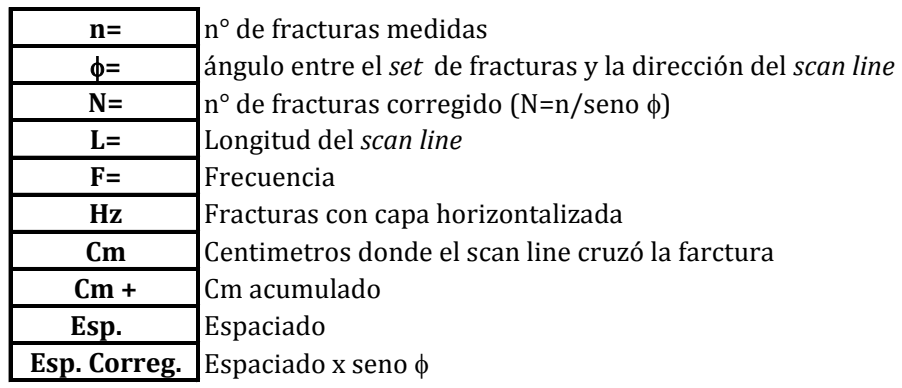

\begin{tabular}{|c|c|c|c|c|c|c|}
\hline \multirow[b]{2}{*}{ \# } & \multirow[b]{2}{*}{$\mathrm{Cm}$} & \multirow[b]{2}{*}{$\mathrm{Cm}+$} & \multirow[b]{2}{*}{ Rbz } & \multicolumn{2}{|c|}{$\mathrm{Hz}$} & \multirow[b]{2}{*}{ Inclin } \\
\hline & & & & Inclin & Rbz & \\
\hline 0 & 0 & 0 & 224 & 54 & 253 & 80 \\
\hline 1 & 13 & 13 & 18 & 39 & 345 & 82 \\
\hline 2 & 7 & 20 & 224 & 54 & 253 & 80 \\
\hline 3 & 4 & 24 & 35 & 80 & 28 & 88 \\
\hline 4 & 1 & 25 & 18 & 39 & 345 & 82 \\
\hline 5 & 3 & 28 & 224 & 54 & 253 & 80 \\
\hline 6 & 4 & 32 & 35 & 80 & 28 & 88 \\
\hline \multirow[t]{2}{*}{7} & 25 & 57 & 18 & 39 & 345 & 82 \\
\hline & & 57 & 224 & 54 & 253 & 80 \\
\hline 8 & 10 & 67 & 18 & 39 & 345 & 82 \\
\hline \multirow[t]{2}{*}{9} & 15 & 82 & 224 & 54 & 253 & 80 \\
\hline & & 82 & 290 & 17 & 303 & 80 \\
\hline 10 & 20 & 102 & 22 & 45 & 351 & 82 \\
\hline 11 & 4 & 106 & 22 & 45 & 351 & 82 \\
\hline 12 & 8 & 114 & 22 & 45 & 351 & 82 \\
\hline \multirow[t]{2}{*}{13} & 26 & 140 & 279 & 41 & 109 & 79 \\
\hline & & 140 & 236 & 69 & 65 & 84 \\
\hline 14 & 18 & 158 & 19 & 44 & 349 & 84 \\
\hline 15 & 12 & 170 & 269 & 31 & 289 & 89 \\
\hline 16 & 10 & 180 & 19 & 44 & 349 & 84 \\
\hline 17 & 11 & 191 & 69 & 31 & 342 & 52 \\
\hline 18 & 17 & 208 & 19 & 44 & 349 & 84 \\
\hline 19 & 5 & 213 & 19 & 44 & 349 & 84 \\
\hline 20 & 34 & 247 & 46 & 80 & 32 & 79 \\
\hline \multirow[t]{2}{*}{21} & 16 & 263 & 46 & 80 & 32 & 79 \\
\hline & & 263 & 251 & 24 & 288 & 78 \\
\hline
\end{tabular}

\begin{tabular}{|c|c|c|}
\hline $\mathbf{C m}+$ & $\mathbf{R b z}$ & Inclin \\
\hline 0 & 253 & 80 \\
\hline 13 & 345 & 82 \\
\hline 20 & 253 & 80 \\
\hline 24 & 28 & 88 \\
\hline 25 & 345 & 82 \\
\hline 28 & 253 & 80 \\
\hline 32 & 28 & 88 \\
\hline 57 & 345 & 82 \\
\hline 57 & 253 & 80 \\
\hline 67 & 345 & 82 \\
\hline 82 & 253 & 80 \\
\hline 82 & 303 & 80 \\
\hline 102 & 351 & 82 \\
\hline 106 & 351 & 82 \\
\hline 114 & 351 & 82 \\
\hline 140 & 109 & 79 \\
\hline 140 & 65 & 84 \\
\hline 158 & 349 & 84 \\
\hline 170 & 289 & 89 \\
\hline 180 & 349 & 84 \\
\hline 191 & 342 & 52 \\
\hline 208 & 349 & 84 \\
\hline 213 & 349 & 84 \\
\hline 247 & 32 & 79 \\
\hline 263 & 32 & 79 \\
\hline 263 & 288 & 78 \\
\hline & & \\
\hline
\end{tabular}

Inclinación prom. 81

\begin{tabular}{l|c|} 
Inclin. Máx. & 89 \\
\cline { 2 - 2 } Inclin. Min. & 52 \\
\hline
\end{tabular}




\begin{tabular}{|c|c|c|}
\hline Set NNW-SSE & \multicolumn{2}{|c|}{ Hz } \\
\hline $\mathbf{C m}+$ & Rbz & Inclin \\
\hline 0 & 253 & 80 \\
\hline 20 & 253 & 80 \\
\hline 28 & 253 & 80 \\
\hline 57 & 253 & 80 \\
\hline 82 & 253 & 80 \\
\hline 140 & 65 & 84 \\
\hline
\end{tabular}

\begin{tabular}{|c|c|c|c|}
\hline Esp. & Esp. Correg. & $\mathbf{n}$ & 6 \\
\hline 20 & 13.12 & $\boldsymbol{\phi}$ & 41 \\
\hline 8 & 5.25 & $\operatorname{sen} \boldsymbol{\phi}$ & 0.66 \\
\hline 29 & 19.03 & $\mathbf{N}$ & 9.15 \\
\hline 25 & 16.40 & $\mathbf{F}=\mathbf{N} / \mathbf{L}$ & $\mathbf{3 . 4 8}$ \\
\hline 58 & 38.05 & \multicolumn{3}{|l}{} \\
\cline { 2 - 4 } & \multicolumn{3}{|l}{}
\end{tabular}

\begin{tabular}{|r|c|}
\hline Moda & \#N/A \\
\hline Promedio & 18.37 \\
\hline Máx. & 38.05 \\
\hline Min. & 5.25 \\
\hline
\end{tabular}

\begin{tabular}{|c|c|c|}
\hline Set ENE-WSW & \multicolumn{2}{|c|}{ Hz } \\
\hline $\mathbf{C m}+$ & $\mathbf{R b z}$ & Inclin \\
\hline 13 & 345 & 82 \\
\hline 25 & 345 & 82 \\
\hline 57 & 345 & 82 \\
\hline 67 & 345 & 82 \\
\hline 102 & 351 & 82 \\
\hline 106 & 351 & 82 \\
\hline 114 & 351 & 82 \\
\hline 158 & 349 & 84 \\
\hline 180 & 349 & 84 \\
\hline 191 & 342 & 52 \\
\hline 208 & 349 & 84 \\
\hline 213 & 349 & 84 \\
\hline
\end{tabular}

\begin{tabular}{|c|c|c|c|}
\hline Esp. & Esp. Correg. & $\mathbf{n}$ & 12 \\
\hline 12 & 9.19 & $\phi$ & 50 \\
\hline 32 & 24.51 & $\operatorname{sen} \phi$ & 0.77 \\
\hline 10 & 7.66 & $\mathbf{N}$ & 15.66 \\
\hline 35 & 26.81 & $\mathbf{F}=\mathbf{N} / \mathrm{L}$ & 5.96 \\
\hline 4 & 3.06 & & \\
\hline 8 & 6.13 & & \\
\hline 44 & 33.71 & & \\
\hline 22 & 16.85 & & \\
\hline 11 & 8.43 & & \\
\hline 17 & 13.02 & & \\
\hline 5 & 3.83 & & \\
\hline
\end{tabular}

\begin{tabular}{|r|c|}
\hline Moda & \#N/A \\
\hline Promedio & 13.93 \\
\hline Máx. & 33.71 \\
\hline Min. & 3.06 \\
\hline
\end{tabular}

\begin{tabular}{|c|c|c|}
\hline Set ESE-WNW & \multicolumn{2}{|c|}{ Hz } \\
\hline $\mathbf{C m}+$ & Rbz & Inclin \\
\hline 24 & 28 & 88 \\
\hline 32 & 28 & 88 \\
\hline 247 & 32 & 79 \\
\hline 263 & 32 & 79 \\
\hline
\end{tabular}

\begin{tabular}{|c|c|c|c|}
\hline Esp. & Esp. Correg. & $\mathbf{n}$ & 4 \\
\hline 8 & 7.96 & $\bar{\phi}$ & 84 \\
\hline 215 & 213.82 & $\operatorname{sen} \phi$ & 0.99 \\
\hline 16 & 15.91 & $\mathbf{N}$ & 4.02 \\
\hline & & $F=N / L$ & 1.53 \\
\hline Moda & $\# \mathrm{~N} / \mathrm{A}$ & & \\
\hline Promedio & 79.23 & & \\
\hline Máx. & 213.82 & & \\
\hline Min. & 7.96 & & \\
\hline
\end{tabular}

\begin{tabular}{|c|c|c|}
\hline Set NNE-SSW & \multicolumn{2}{|c|}{ Hz } \\
\hline $\mathbf{C m}+$ & $\mathbf{R b z}$ & Inclin \\
\hline 82 & 303 & 80 \\
\hline 140 & 109 & 79 \\
\hline 170 & 289 & 89 \\
\hline 263 & 288 & 78 \\
\hline
\end{tabular}

\begin{tabular}{|c|c|c|c|}
\hline Esp. & Esp. Correg. & $\bar{n}$ & 4 \\
\hline 58 & 8.07 & $\phi$ & 8 \\
\hline 30 & 4.18 & $\operatorname{sen} \phi$ & 0.14 \\
\hline 93 & 12.94 & $\mathbf{N}$ & 28.74 \\
\hline & & $F=N / L$ & 10.93 \\
\hline Moda & $\# \mathrm{~N} / \mathrm{A}$ & & \\
\hline Promedio & 8.40 & & \\
\hline Máx. & 12.94 & & \\
\hline Min. & 4.18 & & \\
\hline
\end{tabular}




\begin{tabular}{|l|c|}
\hline Estación & 11TT \\
\hline Rbz capa & $111^{\circ} / 27$ \\
\hline Dirección scan line & $\mathrm{N} 27^{\circ}$ \\
\hline Longitud scan line & $199 \mathrm{~cm}$ \\
\hline $\mathbf{N}^{\circ}$ de fracturas & 33 \\
\hline
\end{tabular}

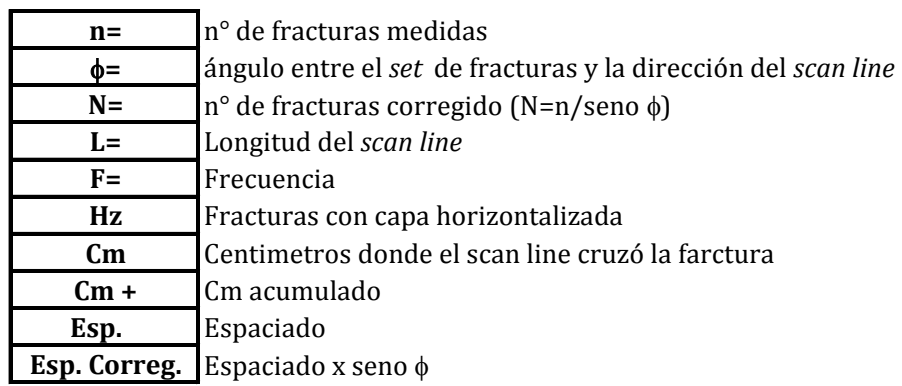

\begin{tabular}{|c|c|c|c|c|c|c|}
\hline \multirow[b]{2}{*}{$\#$} & \multirow[b]{2}{*}{$\mathrm{Cm}$} & \multirow[b]{2}{*}{$\mathrm{Cm}+$} & \multirow[b]{2}{*}{ Rbz } & \multicolumn{2}{|c|}{$\mathrm{Hz}$} & \multirow[b]{2}{*}{ Inclin } \\
\hline & & & & Inclin & Rbz & \\
\hline \multirow[t]{2}{*}{0} & 0 & 0 & 350 & 69 & 344 & 84 \\
\hline & & 0 & 245 & 70 & 248 & 90 \\
\hline \multirow[t]{2}{*}{1} & 6 & 6 & 344 & 65 & 338 & 82 \\
\hline & & 6 & 245 & 70 & 248 & 90 \\
\hline 2 & 12 & 18 & 15 & 84 & 13 & 87 \\
\hline 3 & 17 & 35 & 346 & 71 & 342 & 87 \\
\hline 4 & 6 & 41 & 14 & 82 & 11 & 86 \\
\hline \multirow{2}{*}{5} & 9 & 50 & 15 & 84 & 13 & 87 \\
\hline & & 50 & 262 & 66 & 85 & 90 \\
\hline 6 & 5 & 55 & 15 & 84 & 13 & 87 \\
\hline \multirow[t]{2}{*}{7} & 4 & 59 & 356 & 73 & 351 & 85 \\
\hline & & 59 & 262 & 66 & 85 & 90 \\
\hline 8 & 5 & 64 & 15 & 84 & 13 & 87 \\
\hline 9 & 8 & 72 & 15 & 84 & 13 & 87 \\
\hline 10 & 7 & 79 & 254 & 69 & 77 & 89 \\
\hline 11 & 7 & 86 & 25 & 90 & 24 & 88 \\
\hline \multirow[t]{2}{*}{12} & 20 & 106 & 22 & 87 & 20 & 86 \\
\hline & & 106 & 254 & 69 & 77 & 89 \\
\hline 13 & 11 & 117 & 22 & 87 & 20 & 86 \\
\hline 14 & 9 & 126 & 22 & 87 & 20 & 86 \\
\hline \multirow[t]{2}{*}{15} & 8 & 134 & 22 & 87 & 20 & 86 \\
\hline & & 134 & 90 & 57 & 78 & 33 \\
\hline \multirow[t]{2}{*}{16} & 9 & 143 & 197 & 88 & 198 & 87 \\
\hline & & 143 & 344 & 75 & 161 & 88 \\
\hline 17 & 13 & 156 & 23 & 82 & 19 & 82 \\
\hline 18 & 10 & 166 & 344 & 75 & 161 & 88 \\
\hline 19 & 10 & 176 & 19 & 82 & 15 & 83 \\
\hline \multirow[t]{2}{*}{20} & 10 & 186 & 19 & 82 & 15 & 83 \\
\hline & & 186 & 336 & 86 & 158 & 75 \\
\hline \multirow[t]{3}{*}{21} & 3 & 189 & 19 & 82 & 15 & 83 \\
\hline & & 189 & 336 & 86 & 158 & 75 \\
\hline & & 189 & 245 & 59 & 252 & 79 \\
\hline 22 & 10 & 199 & 19 & 82 & 15 & 83 \\
\hline
\end{tabular}

\begin{tabular}{|c|c|c|}
\hline $\mathbf{C m}+$ & Rbz & Inclin \\
\hline 0 & 344 & 84 \\
\hline 0 & 248 & 90 \\
\hline 6 & 338 & 82 \\
\hline 6 & 248 & 90 \\
\hline 18 & 13 & 87 \\
\hline 35 & 342 & 87 \\
\hline 41 & 11 & 86 \\
\hline 50 & 13 & 87 \\
\hline 50 & 85 & 90 \\
\hline 55 & 13 & 87 \\
\hline 59 & 351 & 85 \\
\hline 59 & 85 & 90 \\
\hline 64 & 13 & 87 \\
\hline 72 & 13 & 87 \\
\hline 79 & 77 & 89 \\
\hline 86 & 24 & 88 \\
\hline 106 & 20 & 86 \\
\hline 106 & 77 & 89 \\
\hline 117 & 20 & 86 \\
\hline 126 & 20 & 86 \\
\hline 134 & 20 & 86 \\
\hline 134 & 78 & 33 \\
\hline 143 & 198 & 87 \\
\hline 143 & 161 & 88 \\
\hline 156 & 19 & 82 \\
\hline 166 & 161 & 88 \\
\hline 176 & 15 & 83 \\
\hline 186 & 15 & 83 \\
\hline 186 & 158 & 75 \\
\hline 189 & 15 & 83 \\
\hline 189 & 158 & 75 \\
\hline 189 & 252 & 79 \\
\hline 199 & 15 & 83 \\
\hline & & \\
\hline
\end{tabular}

Inclinación prom. 83.879 \begin{tabular}{l|c|} 
Inclin. Máx. & 90 \\
\hline
\end{tabular} Inclin. Min. 33 


\begin{tabular}{|c|c|c|}
\hline Set ENE-WSW & \multicolumn{2}{|c|}{ Hz } \\
\hline $\mathbf{C m}+$ & $\mathbf{R b z}$ & Inclin \\
\hline 0 & 344 & 84 \\
\hline 6 & 338 & 82 \\
\hline 35 & 342 & 87 \\
\hline 59 & 351 & 85 \\
\hline 143 & 161 & 88 \\
\hline 166 & 161 & 88 \\
\hline 186 & 158 & 75 \\
\hline 189 & 158 & 75 \\
\hline
\end{tabular}

\begin{tabular}{|c|c|c|c|}
\hline Esp. & Esp. Correg. & $\mathbf{n}$ & 8 \\
\hline 6 & 4.09 & $\phi$ & 43 \\
\hline 29 & 19.78 & $\operatorname{sen} \phi$ & 0.68 \\
\hline 24 & 16.37 & $\mathbf{N}$ & 11.73 \\
\hline 84 & 57.29 & $F=N / L$ & 5.89 \\
\hline 23 & 15.69 & & \\
\hline 20 & 13.64 & & \\
\hline 3 & 2.05 & & \\
\hline
\end{tabular}

\begin{tabular}{|r|c|}
\hline Moda & \#N/A \\
\hline Promedio & 18.41 \\
\hline Máx. & 57.29 \\
\hline Min. & 2.05 \\
\hline
\end{tabular}

\begin{tabular}{|c|c|c|}
\hline Set ESE-WNW & \multicolumn{2}{|c|}{ Hz } \\
\hline $\mathbf{C m}+$ & Rbz & Inclin \\
\hline 18 & 13 & 87 \\
\hline 41 & 11 & 86 \\
\hline 50 & 13 & 87 \\
\hline 55 & 13 & 87 \\
\hline 64 & 13 & 87 \\
\hline 72 & 13 & 87 \\
\hline 86 & 24 & 88 \\
\hline 106 & 20 & 86 \\
\hline 117 & 20 & 86 \\
\hline 126 & 20 & 86 \\
\hline 134 & 20 & 86 \\
\hline 143 & 198 & 87 \\
\hline 156 & 19 & 82 \\
\hline 176 & 15 & 83 \\
\hline 186 & 15 & 83 \\
\hline 189 & 15 & 83 \\
\hline 199 & 15 & 83 \\
\hline & & \\
\hline & & \\
\hline
\end{tabular}

\begin{tabular}{|c|c|c|c|}
\hline Esp. & Esp. Correg. & $\bar{n}$ & 17 \\
\hline 23 & 22.72 & $\phi$ & 81 \\
\hline 9 & 8.89 & $\operatorname{sen} \phi$ & 0.99 \\
\hline 5 & 4.94 & $\mathbf{N}$ & 17.21 \\
\hline 9 & 8.89 & $F=N / L$ & 8.649 \\
\hline 8 & 7.90 & & \\
\hline 14 & 13.83 & & \\
\hline 20 & 19.75 & & \\
\hline 11 & 10.86 & & \\
\hline 9 & 8.89 & & \\
\hline 8 & 7.90 & & \\
\hline 9 & 8.89 & & \\
\hline 13 & 12.84 & & \\
\hline 20 & 19.75 & & \\
\hline 10 & 9.88 & & \\
\hline 3 & 2.96 & & \\
\hline 10 & 9.88 & & \\
\hline
\end{tabular}

\begin{tabular}{|r|c|}
\hline Moda & 8.89 \\
\hline Promedio & 11.17 \\
\hline Máx. & 22.72 \\
\hline Min. & 2.96 \\
\hline
\end{tabular}

\begin{tabular}{|c|c|c|}
\hline Set NNW-SSE & \multicolumn{2}{|c|}{ Hz } \\
\hline Cm + & Rbz & Inclin \\
\hline 0 & 248 & 90 \\
\hline 6 & 248 & 90 \\
\hline 50 & 85 & 90 \\
\hline 59 & 85 & 90 \\
\hline 79 & 77 & 89 \\
\hline 106 & 77 & 89 \\
\hline 134 & 78 & 33 \\
\hline 189 & 252 & 79 \\
\hline
\end{tabular}

\begin{tabular}{|c|c|c|c|}
\hline Esp. & Esp. Correg. & n & 8 \\
\hline 6 & 4.01 & $\phi$ & 42 \\
\hline 44 & 29.44 & $\operatorname{sen} \phi$ & 0.67 \\
\hline 9 & 6.02 & $\mathbf{N}$ & 11.96 \\
\hline 20 & 13.38 & $F=N / L$ & 6.0 \\
\hline 27 & 18.07 & & \\
\hline 28 & 18.74 & & \\
\hline 55 & 36.80 & & \\
\hline
\end{tabular}

\begin{tabular}{|r|c|}
\hline Moda & \#N/A \\
\hline Promedio & 18.07 \\
\hline Máx. & 36.80 \\
\hline Min. & 4.01 \\
\hline
\end{tabular}




\begin{tabular}{|l|c|}
\hline Estación & 17TT \\
\hline Rbz capa & $180^{\circ} / 30^{\circ}$ \\
\hline Dirección scan line & $\mathrm{N} 60^{\circ}$ \\
\hline Longitud scan line & $460^{\circ}$ \\
\hline $\mathbf{N}^{\circ}$ de fracturas & 41 \\
\hline
\end{tabular}

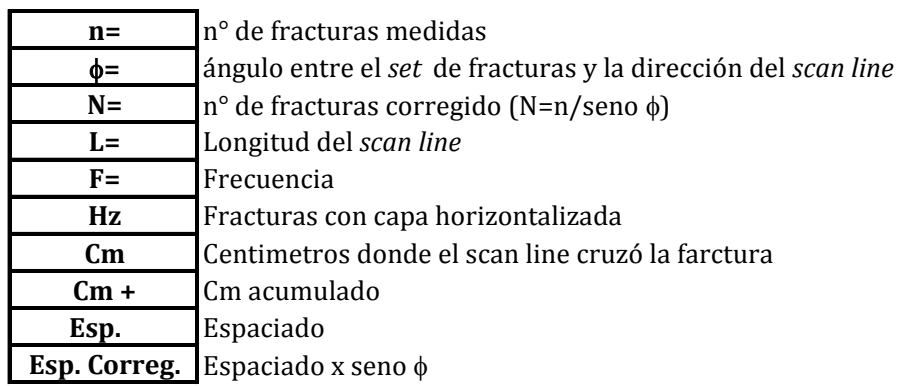

\begin{tabular}{|c|c|c|c|c|c|c|}
\hline \multirow[b]{2}{*}{$\#$} & \multirow[b]{2}{*}{$\mathrm{Cm}$} & \multirow[b]{2}{*}{$\mathrm{Cm}+$} & \multirow[b]{2}{*}{ Rbz } & \multicolumn{2}{|c|}{$\mathrm{Hz}$} & \multirow[b]{2}{*}{ Inclin } \\
\hline & & & & Inclin & Rbz & \\
\hline \multirow[t]{2}{*}{0} & 0 & 0 & 7 & 63 & 190 & 87 \\
\hline & & 0 & 90 & 84 & 91 & 84 \\
\hline 1 & 26 & 26 & 1 & 59 & 5 & 89 \\
\hline \multirow[t]{2}{*}{2} & 2 & 28 & 1 & 59 & 5 & 89 \\
\hline & & 28 & 266 & 80 & 276 & 80 \\
\hline 3 & 17 & 45 & 1 & 59 & 5 & 89 \\
\hline 4 & 3 & 48 & 14 & 68 & 197 & 83 \\
\hline \multirow[t]{2}{*}{5} & 9 & 57 & 14 & 68 & 197 & 83 \\
\hline & & 57 & 297 & 68 & 308 & 84 \\
\hline \multirow[t]{2}{*}{6} & 7 & 64 & 14 & 68 & 197 & 83 \\
\hline & & 64 & 297 & 68 & 308 & 84 \\
\hline \multirow[t]{2}{*}{7} & 12 & 76 & 14 & 68 & 197 & 83 \\
\hline & & 76 & 297 & 68 & 308 & 84 \\
\hline \multirow[t]{2}{*}{8} & 13 & 89 & 14 & 68 & 197 & 83 \\
\hline & & 89 & 297 & 68 & 308 & 84 \\
\hline \multirow[t]{2}{*}{9} & 5 & 94 & 14 & 68 & 197 & 83 \\
\hline & & 94 & 297 & 68 & 308 & 84 \\
\hline 10 & 8 & 102 & 17 & 65 & 200 & 86 \\
\hline 11 & 6 & 108 & 17 & 65 & 200 & 86 \\
\hline 12 & 4 & 112 & 17 & 65 & 200 & 86 \\
\hline 13 & 8 & 120 & 17 & 65 & 200 & 86 \\
\hline 14 & 2 & 122 & 17 & 65 & 200 & 86 \\
\hline 15 & 8 & 130 & 17 & 65 & 200 & 86 \\
\hline 16 & 5 & 135 & 17 & 65 & 200 & 86 \\
\hline 17 & 13 & 148 & 2 & 54 & 6 & 84 \\
\hline 18 & 4 & 152 & 19 & 54 & 20 & 83 \\
\hline 19 & 40 & 192 & 357 & 55 & 2 & 85 \\
\hline 20 & 6 & 198 & 24 & 64 & 206 & 88 \\
\hline 21 & 13 & 211 & 270 & 69 & 285 & 72 \\
\hline 22 & 20 & 231 & 9 & 61 & 192 & 89 \\
\hline 23 & 15 & 246 & 9 & 61 & 192 & 89 \\
\hline 24 & 19 & 265 & 9 & 61 & 192 & 89 \\
\hline 25 & 44 & 309 & 9 & 61 & 192 & 89 \\
\hline 26 & 8 & 317 & 277 & 72 & 289 & 78 \\
\hline 27 & 30 & 347 & 20 & 66 & 202 & 86 \\
\hline 28 & 8 & 355 & 20 & 66 & 202 & 86 \\
\hline 29 & 16 & 371 & 20 & 66 & 202 & 86 \\
\hline 30 & 28 & 399 & 17 & 54 & 18 & 83 \\
\hline 31 & 13 & 412 & 17 & 54 & 18 & 83 \\
\hline 32 & 34 & 446 & 353 & 61 & 178 & 89 \\
\hline 33 & 14 & 460 & 353 & 61 & 178 & 89 \\
\hline
\end{tabular}

\begin{tabular}{|c|c|c|}
\hline $\mathbf{C m}+$ & Rbz & Inclin \\
\hline 0 & 190 & 87 \\
\hline 0 & 91 & 84 \\
\hline 26 & 5 & 89 \\
\hline 28 & 5 & 89 \\
\hline 28 & 276 & 80 \\
\hline 45 & 5 & 89 \\
\hline 48 & 197 & 83 \\
\hline 57 & 197 & 83 \\
\hline 57 & 308 & 84 \\
\hline 64 & 197 & 83 \\
\hline 64 & 308 & 84 \\
\hline 76 & 197 & 83 \\
\hline 76 & 308 & 84 \\
\hline 89 & 197 & 83 \\
\hline 89 & 308 & 84 \\
\hline 94 & 197 & 83 \\
\hline 94 & 308 & 84 \\
\hline 102 & 200 & 86 \\
\hline 108 & 200 & 86 \\
\hline 112 & 200 & 86 \\
\hline 120 & 200 & 86 \\
\hline 122 & 200 & 86 \\
\hline 130 & 200 & 86 \\
\hline 135 & 200 & 86 \\
\hline 148 & 6 & 84 \\
\hline 152 & 20 & 83 \\
\hline 192 & 2 & 85 \\
\hline 198 & 206 & 88 \\
\hline 211 & 285 & 72 \\
\hline 231 & 192 & 89 \\
\hline 246 & 192 & 89 \\
\hline 265 & 192 & 89 \\
\hline 309 & 192 & 89 \\
\hline 317 & 289 & 78 \\
\hline 347 & 202 & 86 \\
\hline 355 & 202 & 86 \\
\hline 371 & 202 & 86 \\
\hline 399 & 18 & 83 \\
\hline 412 & 18 & 83 \\
\hline 446 & 178 & 89 \\
\hline 460 & 178 & 89 \\
\hline & & \\
\hline
\end{tabular}

Inclinación prom. 85.024 \begin{tabular}{l|l|}
\hline Inclin. Máx. & 89 \\
\hline
\end{tabular} Inclin. Min. 72 


\begin{tabular}{|c|c|c|}
\hline Set NE-SW & \multicolumn{2}{|c|}{ Hz } \\
\hline $\mathbf{C m}+$ & Rbz & Inclin \\
\hline 0 & 91 & 84 \\
\hline 28 & 276 & 80 \\
\hline 57 & 308 & 84 \\
\hline 64 & 308 & 84 \\
\hline 76 & 308 & 84 \\
\hline 89 & 308 & 84 \\
\hline 94 & 308 & 84 \\
\hline 211 & 285 & 72 \\
\hline 317 & 289 & 78 \\
\hline
\end{tabular}

\begin{tabular}{|c|c|c|c|}
\hline Esp. & Esp. Correg. & $\mathbf{n}$ & 9 \\
\hline 28 & 11.39 & $\phi$ & 24 \\
\hline 29 & 11.80 & $\operatorname{sen} \phi$ & 0.41 \\
\hline 7 & 2.85 & $\mathbf{N}$ & 22.13 \\
\hline 12 & 4.88 & $F=N / L$ & 4.81 \\
\hline 13 & 5.29 & & \\
\hline 5 & 2.03 & & \\
\hline 117 & 47.59 & & \\
\hline 106 & 43.11 & & \\
\hline
\end{tabular}

\begin{tabular}{|r|c|}
\hline Moda & \#N/A \\
\hline Promedio & 16.12 \\
\hline Máx. & 47.59 \\
\hline Min. & 2.03 \\
\hline
\end{tabular}

\begin{tabular}{|c|c|c|}
\hline Set E-W & \multicolumn{2}{|c|}{ Hz } \\
\hline $\mathbf{C m}+$ & Rbz & Inclin \\
\hline 26 & 5 & 89 \\
\hline 28 & 5 & 89 \\
\hline 45 & 5 & 89 \\
\hline 148 & 6 & 84 \\
\hline 192 & 2 & 85 \\
\hline 446 & 178 & 89 \\
\hline 460 & 178 & 89 \\
\hline
\end{tabular}

\begin{tabular}{|c|c|c|c|}
\hline Esp. & Esp. Correg. & $\mathbf{n}$ & 7 \\
\hline 2 & 1.15 & $\phi$ & 35 \\
\hline 17 & 9.75 & $\operatorname{sen} \phi$ & 0.57 \\
\hline 103 & 59.08 & $\mathbf{N}$ & 12.20 \\
\hline 44 & 25.24 & $F=N / L$ & 2.65 \\
\hline 254 & 145.69 & & \\
\hline 14 & 8.03 & & \\
\hline
\end{tabular}

\begin{tabular}{|r|c|}
\hline Moda & \#N/A \\
\hline Promedio & 41.49 \\
\hline Máx. & 145.69 \\
\hline Min. & 1.15 \\
\hline
\end{tabular}

\begin{tabular}{|c|c|c|}
\hline Set ESE-WNW & \multicolumn{2}{|c|}{$\mathrm{Hz}$} \\
\hline $\mathrm{Cm}+$ & Rbz & Inclin \\
\hline 0 & 190 & 87 \\
\hline 48 & 197 & 83 \\
\hline 57 & 197 & 83 \\
\hline 64 & 197 & 83 \\
\hline 76 & 197 & 83 \\
\hline 89 & 197 & 83 \\
\hline 94 & 197 & 83 \\
\hline 102 & 200 & 86 \\
\hline 108 & 200 & 86 \\
\hline 112 & 200 & 86 \\
\hline 120 & 200 & 86 \\
\hline 122 & 200 & 86 \\
\hline 130 & 200 & 86 \\
\hline 135 & 200 & 86 \\
\hline 152 & 20 & 83 \\
\hline 198 & 206 & 88 \\
\hline 231 & 192 & 89 \\
\hline 246 & 192 & 89 \\
\hline 265 & 192 & 89 \\
\hline 309 & 192 & 89 \\
\hline 347 & 202 & 86 \\
\hline 355 & 202 & 86 \\
\hline 371 & 202 & 86 \\
\hline 399 & 18 & 83 \\
\hline 412 & 18 & 83 \\
\hline
\end{tabular}

\begin{tabular}{|c|c|c|c|}
\hline Esp. & Esp. Correg. & $\bar{n}$ & 25 \\
\hline 48 & 35.67 & $\phi$ & 48 \\
\hline 9 & 6.69 & $\operatorname{sen} \phi$ & 0.74 \\
\hline 7 & 5.20 & $\mathbf{N}$ & 33.64 \\
\hline 12 & 8.92 & $F=N / L$ & 7.31 \\
\hline 13 & 9.66 & & \\
\hline 5 & 3.72 & & \\
\hline 8 & 5.95 & & \\
\hline 6 & 4.46 & & \\
\hline 4 & 2.97 & & \\
\hline 8 & 5.95 & & \\
\hline 2 & 1.49 & & \\
\hline 8 & 5.95 & & \\
\hline 5 & 3.72 & & \\
\hline 17 & 12.63 & & \\
\hline 46 & 34.18 & & \\
\hline 33 & 24.52 & & \\
\hline 15 & 11.15 & & \\
\hline 19 & 14.12 & & \\
\hline 44 & 32.70 & & \\
\hline 38 & 28.24 & & \\
\hline 8 & 5.95 & & \\
\hline 16 & 11.89 & & \\
\hline 28 & 20.81 & & \\
\hline 13 & 9.66 & & \\
\hline
\end{tabular}

\begin{tabular}{|r|c|}
\hline Moda & 5.95 \\
\hline Promedio & 12.76 \\
\hline Máx. & 35.67 \\
\hline Min. & 1.49 \\
\hline
\end{tabular}

